Cochrane Database of Systematic Reviews

\title{
Electromechanical-assisted training for walking after stroke
} (Review)

Mehrholz J, Thomas S, Werner C, Kugler J, Pohl M, Elsner B

Mehrholz J, Thomas S, Werner C, Kugler J, Pohl M, Elsner B.

Electromechanical-assisted training for walking after stroke.

Cochrane Database of Systematic Reviews 2017, Issue 5. Art. No.: CD006185.

DOI: 10.1002/14651858.CD006185.pub4.

www.cochranelibrary.com 
TABLE OF CONTENTS

HEADER

ABSTRACT

PLAIN LANGUAGE SUMMARY

SUMMARY OF FINDINGS

BACKGROUND

OBJECTIVES

METHODS

RESULTS

Figure 1.

Figure 2.

DISCUSSION

Figure 3.

Figure 4.

AUTHORS' CONCLUSIONS

ACKNOWLEDGEMENTS

REFERENCES

CHARACTERISTICS OF STUDIES

DATA AND ANALYSES

Analysis 1.1. Comparison 1 Electromechanical- and robotic-assisted gait training plus physiotherapy versus physiotherapy (or usual care), Outcome 1 Independent walking at the end of intervention phase, all electromechanical devices used.

Analysis 1.2. Comparison 1 Electromechanical- and robotic-assisted gait training plus physiotherapy versus physiotherapy (or usual care), Outcome 2 Recovery of independent walking at follow-up after study end.

Analysis 1.3. Comparison 1 Electromechanical- and robotic-assisted gait training plus physiotherapy versus physiotherapy (or usual care), Outcome 3 Walking velocity (metres per second) at the end of intervention phase.

Analysis 1.4. Comparison 1 Electromechanical- and robotic-assisted gait training plus physiotherapy versus physiotherapy (or usual care), Outcome 4 Walking velocity (metres per second) at follow-up.

Analysis 1.5. Comparison 1 Electromechanical- and robotic-assisted gait training plus physiotherapy versus physiotherapy (or usual care), Outcome 5 Walking capacity (metres walked in 6 minutes) at the end of intervention phase.

Analysis 1.6. Comparison 1 Electromechanical- and robotic-assisted gait training plus physiotherapy versus physiotherapy (or usual care), Outcome 6 Walking capacity (metres walked in 6 minutes) at follow-up.

Analysis 1.7. Comparison 1 Electromechanical- and robotic-assisted gait training plus physiotherapy versus physiotherapy (or usual care), Outcome 7 Acceptability of electromechanical-assisted gait training devices during intervention phase: dropouts.

Analysis 1.8. Comparison 1 Electromechanical- and robotic-assisted gait training plus physiotherapy versus physiotherapy (or usual care), Outcome 8 Death from all causes until the end of intervention phase.

Analysis 2.1. Comparison 2 Planned sensitivity analysis by trial methodology, Outcome 1 Regaining independent walking ability.

Analysis 3.1. Comparison 3 Subgroup analysis comparing participants in acute and chronic phases of stroke, Outcome 1 Independent walking at the end of intervention phase, all electromechanical devices used.

Analysis 4.1. Comparison 4 Post hoc sensitivity analysis: ambulatory status at study onset, Outcome 1 Recovery of independent walking: ambulatory status at study onset.

Analysis 4.2. Comparison 4 Post hoc sensitivity analysis: ambulatory status at study onset, Outcome 2 Walking velocity: ambulatory status at study onset.

Analysis 5.1. Comparison 5 Post hoc sensitivity analysis: type of device, Outcome 1 Different devices for regaining walking ability.

Analysis 5.2. Comparison 5 Post hoc sensitivity analysis: type of device, Outcome 2 Different devices for regaining walking speed.

Analysis 5.3. Comparison 5 Post hoc sensitivity analysis: type of device, Outcome 3 Different devices for regaining walking capacity.

ADDITIONAL TABLES

APPENDICES

FEEDBACK

WHAT'S NEW

HISTORY 
[Intervention Review]

\title{
Electromechanical-assisted training for walking after stroke
}

\author{
Jan Mehrholz ${ }^{1}$, Simone Thomas ${ }^{2}$, Cordula Werner ${ }^{3}$, Joachim Kugler ${ }^{1}$, Marcus Pohl' ${ }^{4}$, Bernhard Elsner 5
}

1Department of Public Health, Dresden Medical School, Technical University Dresden, Dresden, Germany. ${ }^{2}$ Wissenschaftliches Institut, Klinik Bavaria Kreischa, Kreischa, Germany. ${ }^{3}$ Medicalpark, Schlaganfallzentrum Berlin, 13507 Berlin - Tegel, Germany. ${ }^{4} \mathrm{Neurological}$ Rehabilitation, Helios Klinik Schloss Pulsnitz, Pulsnitz, Germany. ${ }^{5}$ Department of Public Health, Dresden Medical School, Technical University Dresden, Dresden, Germany

Contact address: Jan Mehrholz, Department of Public Health, Dresden Medical School, Technical University Dresden, Fetscherstr. 74, Dresden, 01307, Germany.jan.mehrholz@tu-dresden.de, jan.mehrholz@srh.de.

Editorial group: Cochrane Stroke Group

Publication status and date: New search for studies and content updated (conclusions changed), published in Issue 5, 2017.

Citation: Mehrholz J, Thomas S, Werner C, Kugler J, Pohl M, Elsner B. Electromechanical-assisted training for walking after stroke. Cochrane Database of Systematic Reviews 2017, Issue 5. Art. No.: CD006185. DOI: 10.1002/14651858.CD006185.pub4.

Copyright ( 2017 The Cochrane Collaboration. Published by John Wiley \& Sons, Ltd.

\begin{abstract}
A B S T R A C T

\section{Background}

Electromechanical- and robotic-assisted gait-training devices are used in rehabilitation and might help to improve walking after stroke. This is an update of a Cochrane Review first published in 2007.

\section{Objectives}

To investigate the effects of automated electromechanical- and robotic-assisted gait-training devices for improving walking after stroke.

\section{Search methods}

We searched the Cochrane Stroke Group Trials Register (last searched 9 August 2016), the Cochrane Central Register of Controlled Trials (CENTRAL) (the Cochrane Library 2016, Issue 8), MEDLINE in Ovid (1950 to 15 August 2016), Embase (1980 to 15 August 2016), CINAHL (1982 to 15 August 2016), AMED (1985 to 15 August 2016), Web of Science (1899 to 16 August 2016), SPORTDiscus (1949 to 15 September 2012), the Physiotherapy Evidence Database (PEDro) (searched 16 August 2016), and the engineering databases COMPENDEX (1972 to 16 November 2012) and Inspec (1969 to 26 August 2016). We handsearched relevant conference proceedings, searched trials and research registers, checked reference lists, and contacted authors in an effort to identify further published, unpublished, and ongoing trials.
\end{abstract}

\section{Selection criteria}

We included all randomised controlled trials and randomised controlled cross-over trials in people over the age of 18 years diagnosed with stroke of any severity, at any stage, in any setting, evaluating electromechanical- and robotic-assisted gait training versus normal care.

\section{Data collection and analysis}

Two review authors independently selected trials for inclusion, assessed methodological quality and risk of bias, and extracted the data. The primary outcome was the proportion of participants walking independently at follow-up.

\section{Main results}

We included 36 trials involving 1472 participants in this review update. Electromechanical-assisted gait training in combination with physiotherapy increased the odds of participants becoming independent in walking (odds ratio (random effects) 1.94, 95\% confidence interval $(\mathrm{Cl}) 1.39$ to $2.71 ; \mathrm{P}<0.001 ; \mathrm{I}^{2}=8 \%$; moderate-quality evidence) but did not significantly increase walking velocity (mean difference (MD) $0.04 \mathrm{~m} / \mathrm{s}, 95 \% \mathrm{Cl} 0.00$ to $0.09 ; \mathrm{P}=0.08 ; \mathrm{I}^{2}=65 \%$; low-quality evidence) or walking capacity (MD 5.84 metres walked in 6 minutes, $95 \% \mathrm{Cl}-16.73$ to $28.40 ; \mathrm{P}=0.61 ;\left.\right|^{2}=53 \%$; very low-quality evidence). The results must be interpreted with caution because 1 ) some trials investigated people who were independent in walking at the start of the study, 2) we found variations between the trials with respect 
to devices used and duration and frequency of treatment, and 3) some trials included devices with functional electrical stimulation. Our planned subgroup analysis suggested that people in the acute phase may benefit, but people in the chronic phase may not benefit from electromechanical-assisted gait training. Post hoc analysis showed that people who are non-ambulatory at intervention onset may benefit, but ambulatory people may not benefit from this type of training. Post hoc analysis showed no differences between the types of devices used in studies regarding ability to walk, but significant differences were found between devices in terms of walking velocity.

\section{Authors' conclusions}

People who receive electromechanical-assisted gait training in combination with physiotherapy after stroke are more likely to achieve independent walking than people who receive gait training without these devices. We concluded that seven patients need to be treated to prevent one dependency in walking. Specifically, people in the first three months after stroke and those who are not able to walk seem to benefit most from this type of intervention. The role of the type of device is still not clear. Further research should consist of large definitive pragmatic phase III trials undertaken to address specific questions about the most effective frequency and duration of electromechanicalassisted gait training as well as how long any benefit may last.

\section{PLAIN LANGUAGE SUMMARY}

\section{Automated training devices for improving walking after stroke}

\section{Review question}

Do machine- and robot-assisted walking training devices improve walking after stroke?

\section{Background}

Many people who have had a stroke have difficulties walking, and improving walking is one of the main goals of rehabilitation. Automated training devices assist walking practice.

\section{Search date}

The review is current to August 2016

\section{Study characteristics}

We included 36 studies involving a total of 1472 participants over the age of 18 years with acute, postacute, or chronic ischaemic or haemorrhagic stroke. The mean age in the included studies ranged from 48 years to 76 years. The majority of studies were conducted in an inpatient setting.

\section{Key results}

We found moderate-quality evidence that electromechanical-assisted gait training combined with physiotherapy when compared with physiotherapy alone may improve recovery of independent walking in people after stroke.

We determined that for every seven patients treated with electromechanical-and robotic-assisted gait training devices, just one prevention of dependency in walking occurs.

Specifically, people in the first three months after stroke and those who are not able to walk appear to benefit most from this type of intervention. The importance of the type of device is still not clear. Further research should address what frequency or duration of walking training might be most effective and how long the benefit lasts. It also remains unclear how such devices should be used in routine rehabilitation.

\section{Quality of the evidence}

The quality of the evidence for automated electromechanical- and robotic-assisted gait-training devices for improving walking after stroke was moderate. The quality of evidence was low for walking speed, very low for walking capacity, and low for adverse events and people discontinuing treatment. 


\begin{tabular}{|c|c|c|c|c|c|c|}
\hline \multicolumn{7}{|c|}{$\begin{array}{l}\text { Summary of findings for the main comparison. Electromech } \\
\text { (or usual care) for walking after stroke }\end{array}$} \\
\hline \multicolumn{7}{|c|}{ Electromechanical- and robotic-assisted gait training plus physiotherapy compared to physiotherapy (or usual care) for walking after stroke } \\
\hline \multicolumn{7}{|c|}{$\begin{array}{l}\text { Patient or population: walking after stroke } \\
\text { Setting: inpatient and outpatient setting } \\
\text { Intervention: electromechanical- and robotic-assisted gait training plus physiotherapy } \\
\text { Comparison: physiotherapy (or usual care) }\end{array}$} \\
\hline \multirow[t]{2}{*}{ Outcomes } & \multicolumn{2}{|c|}{ Anticipated absolute effects* $(95 \% \mathrm{Cl})$} & \multirow{2}{*}{$\begin{array}{l}\text { Relative ef- } \\
\text { fect } \\
(95 \% \mathrm{CI})\end{array}$} & \multirow{2}{*}{$\begin{array}{l}\text { № of partici- } \\
\text { pants } \\
\text { (studies) }\end{array}$} & \multirow{2}{*}{$\begin{array}{l}\text { Quality of the } \\
\text { evidence } \\
\text { (GRADE) }\end{array}$} & \multirow[t]{2}{*}{ Comments } \\
\hline & $\begin{array}{l}\text { Risk with physiotherapy (or usual } \\
\text { care) }\end{array}$ & $\begin{array}{l}\text { Risk with electromechan- } \\
\text { ical- and robotic-assisted } \\
\text { gait training plus physio- } \\
\text { therapy }\end{array}$ & & & & \\
\hline \multirow{2}{*}{$\begin{array}{l}\text { Independent walking at the } \\
\text { end of intervention phase, } \\
\text { all electromechanical de- } \\
\text { vices used } \\
\text { Assessed with FAC }\end{array}$} & \multicolumn{2}{|l|}{ Study population } & \multirow{2}{*}{$\begin{array}{l}\text { OR } 1.94 \\
(1.39 \text { to } 2.71)\end{array}$} & \multirow{2}{*}{$\begin{array}{l}1472 \\
(36 \mathrm{RCTs})\end{array}$} & \multirow{2}{*}{\multicolumn{2}{|c|}{$\begin{array}{l}\oplus \oplus \oplus \odot \\
\text { MODERATE } 1\end{array}$}} \\
\hline & 457 per 1000 & $\begin{array}{l}615 \text { per } 1000 \\
(530 \text { to } 693)\end{array}$ & & & & \\
\hline \multirow{2}{*}{$\begin{array}{l}\text { Recovery of independent } \\
\text { walking at follow-up after } \\
\text { study end } \\
\text { Assessed with FAC }\end{array}$} & \multicolumn{2}{|l|}{ Study population } & \multirow{2}{*}{$\begin{array}{l}\text { OR } 1.93 \\
(0.72 \text { to } 5.13)\end{array}$} & \multirow{2}{*}{$\begin{array}{l}496 \\
(6 \mathrm{RCTs})\end{array}$} & \multirow{2}{*}{\multicolumn{2}{|c|}{$\begin{array}{l}\oplus \oplus \oplus \odot \\
\text { MODERATE } 1\end{array}$}} \\
\hline & 551 per 1000 & $\begin{array}{l}703 \text { per } 1000 \\
\text { ( } 469 \text { to } 863 \text { ) }\end{array}$ & & & & \\
\hline $\begin{array}{l}\text { Walking velocity (metres per } \\
\text { second) at the end of inter- } \\
\text { vention phase } \\
\text { Assessed with timed mea- } \\
\text { sures of gait } \\
\text { Scale: } 0 \text { to infinity }\end{array}$ & $\begin{array}{l}\text { The mean walking velocity (metres } \\
\text { per second) at the end of interven- } \\
\text { tion phase was } 0 .\end{array}$ & $\begin{array}{l}\text { MD } 0.04 \text { higher } \\
\text { ( } 0 \text { to } 0.09 \text { higher) }\end{array}$ & - & $\begin{array}{l}985 \\
(24 \mathrm{RCTs})\end{array}$ & $\begin{array}{l}\oplus \oplus \Theta \Theta \\
\text { LOW } 12\end{array}$ & \\
\hline $\begin{array}{l}\text { Walking velocity (metres per } \\
\text { second) at follow-up } \\
\text { Assessed with timed mea- } \\
\text { sures of gait } \\
\text { Scale: } 0 \text { to infinity }\end{array}$ & $\begin{array}{l}\text { The mean walking velocity (metres } \\
\text { per second) at follow-up was } 0 \text {. }\end{array}$ & $\begin{array}{l}\text { MD } 0.07 \text { higher } \\
\text { ( } 0.05 \text { lower to } 0.19 \text { higher) }\end{array}$ & - & $\begin{array}{l}578 \\
(9 \text { RCTs) }\end{array}$ & $\begin{array}{l}\oplus \oplus \oplus \ominus \\
\text { MODERATE } 1\end{array}$ & \\
\hline
\end{tabular}




\begin{tabular}{|c|c|c|c|c|c|c|}
\hline 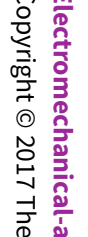 & $\begin{array}{l}\text { Walking capacity (metres } \\
\text { walked in } 6 \text { minutes) at the } \\
\text { end of intervention phase } \\
\text { Assessed with timed mea- } \\
\text { sures of gait } \\
\text { Scale: } 0 \text { to infinity }\end{array}$ & $\begin{array}{l}\text { The mean walking capacity (metres } \\
\text { walked in } 6 \text { minutes) at the end of in- } \\
\text { tervention phase was } 0 .\end{array}$ & $\begin{array}{l}\text { MD } 5.84 \text { higher } \\
\text { (16.73 lower to } 28.40 \text { higher) }\end{array}$ & - & $\begin{array}{l}594 \\
\text { (12 RCTs) }\end{array}$ & $\begin{array}{l}\oplus \ominus \ominus \ominus \\
\text { VERY LOW } 134\end{array}$ \\
\hline 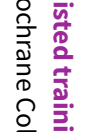 & $\begin{array}{l}\text { Walking capacity (metres } \\
\text { walked in } 6 \text { minutes) at fol- } \\
\text { low-up }\end{array}$ & $\begin{array}{l}\text { The mean walking capacity (metres } \\
\text { walked in } 6 \text { minutes) at follow-up } \\
\text { was } 0 .\end{array}$ & $\begin{array}{l}\text { MD } 0.82 \text { lower } \\
\text { (32.17 lower to } 30.53 \text { higher) }\end{array}$ & - & $\begin{array}{l}463 \\
\text { (7 RCTs) }\end{array}$ & $\begin{array}{l}\oplus \ominus \ominus \ominus \\
\text { VERY LOW } 124\end{array}$ \\
\hline$\frac{1}{2}$ & \multirow{2}{*}{$\begin{array}{l}\text { Acceptability of electro- } \\
\text { mechanical-assisted gait- } \\
\text { training devices during in- } \\
\text { tervention phase } \\
\text { Assessed with number of } \\
\text { dropouts }\end{array}$} & Study population & & \multirow{2}{*}{$\begin{array}{l}\text { OR } 0.67 \\
\text { (0.43 to } 1.05)\end{array}$} & \multirow{2}{*}{$\begin{array}{l}1472 \\
\text { (36 RCTs) }\end{array}$} & \multirow{2}{*}{$\begin{array}{l}\oplus \oplus \oplus \ominus \\
\text { LOW } 15\end{array}$} \\
\hline 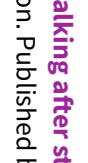 & & 131 per 1000 & $\begin{array}{l}92 \text { per } 1000 \\
(61 \text { to } 136)\end{array}$ & & & \\
\hline
\end{tabular}

${ }^{\star}$ The risk in the intervention group (and its $95 \%$ confidence interval) is based on the assumed risk in the comparison group and the relative effect of the intervention (and its $95 \% \mathrm{Cl}$ ).

Cl: confidence interval; FAC: Functional Ambulation Category; MD: mean difference; OR: odds ratio; RCT: randomised controlled trial; RR: risk ratio

\section{GRADE Working Group grades of evidence}

High quality: We are very confident that the true effect lies close to that of the estimate of the effect.

Moderate quality: We are moderately confident in the effect estimate: The true effect is likely to be close to the estimate of the effect, but there is a possibility that it is substantially different.

Low quality: Our confidence in the effect estimate is limited: The true effect may be substantially different from the estimate of the effect.

Very low quality: We have very little confidence in the effect estimate: The true effect is likely to be substantially different from the estimate of effect.

1Downgraded due to several ratings of 'unclear' and 'high' risk of bias.

2Downgraded due to statistical heterogeneity and no overlap of several confidence intervals.

3 3 owngraded because the $95 \%$ confidence interval includes no effect and the upper confidence limit crosses the minimal important difference.

${ }^{4}$ Downgraded due to funnel plot asymmetry.

${ }^{5}$ Downgraded because the total number of events (157) is less than 300 (a threshold rule-of-thumb value). 


\section{B A C K G R O U N D}

\section{Description of the condition}

A stroke is a sudden, non-convulsive loss of neurological function due to an ischaemic or haemorrhagic intracranial vascular event (WHO 2006). In general, cerebrovascular accidents are classified by anatomic location in the brain, vascular distribution, aetiology, age of the affected individual, and haemorrhagic versus non-haemorrhagic nature (Adams 1993). Stroke is a leading cause of death and serious long-term disability in adults. Three months after stroke, $20 \%$ of people remain wheelchair bound, and approximately $70 \%$ walk at a reduced velocity and capacity (Jorgensen 1995). Restoration of walking ability and gait rehabilitation are therefore highly relevant for people who are unable to walk independently after stroke (Bohannon 1991), as well as for their relatives. To restore gait, modern concepts of rehabilitation favour a repetitive task-specific approach (Carr 2003; French 2007). In recent years it has also been shown that higher intensities of walking practice (resulting in more repetitions trained) resulted in better outcomes for people after stroke (Kwakkel 1999; Van Peppen 2004).

\section{Description of the intervention}

As an adjunct to overground gait training (States 2009), in recent years treadmill training has been introduced for the rehabilitation of people after stroke (Mehrholz 2014). Treadmill training with and without partial body weight support enables the repetitive practice of complex gait cycles for these people. However, one disadvantage of treadmill training might be the effort required by therapists to set the paretic limbs and to control weight shift, thereby possibly limiting the intensity of therapy, especially in more severely disabled people. Automated electromechanical gait machines were developed to reduce dependence on therapists. They consist of either a robot-driven exoskeleton orthosis or an electromechanical solution, with two driven foot plates simulating the phases of gait (Colombo 2000; Hesse 1999).

One example of automated electromechanical gait rehabilitation is the Lokomat (Colombo 2000). A robotic gait orthosis combined with a harness-supported body weight system is used together with a treadmill. The main difference from treadmill training is that the patient's legs are guided by the robotic device according to a preprogrammed gait pattern. A computer-controlled robotic gait orthosis guides the patient, and the process of gait training is automated.

A second example is the Gait Trainer GT I, which is based on a double crank and rocker gear system (Hesse 1999). In contrast to a treadmill, the electromechanical Gait Trainer GT I consists of two foot plates positioned on two bars, two rockers, and two cranks, which provide the propulsion. The harness-secured patient is positioned on the foot plates, which symmetrically simulate the stance and swing phases of walking (Hesse 1999). A servo-controlled motor guides the patient during walking exercise. Vertical and horizontal movements of the trunk are controlled in a phase-dependent manner. Again, the main difference from treadmill training is that the process of gait training is automated and is supported by an electromechanical solution.

Other similar electromechanical devices that have been developed in recent years include the Haptic Walker (Schmidt 2005), the Anklebot (MIT 2005), and the LOPES (Lower Extremity Powered Exoskeleton) (Veneman 2005). More recently, new socalled powered mobile solutions, Buesing 2015, Stein 2014, Watanabe 2014, and ankle robots, Forrester 2014, Waldman 2013, to improve walking have been described in the literature.

\section{How the intervention might work}

Electromechanical devices (such as those previously described) can be used to give non-ambulatory patients intensive practice (in terms of high repetitions) of complex gait cycles. The advantage of these electromechanical devices compared with treadmill training with partial body weight support may be the reduced effort required of therapists, as they no longer need to set the paretic limbs or assist trunk movements (Hesse 2003).

\section{Why it is important to do this review}

Scientific evidence for the benefits of the above-mentioned technologies may have changed since our Cochrane Review was first published in 2007 (Mehrholz 2007), and so an update of the review was required to justify the large equipment and human resource costs needed to implement electromechanical-assisted gait devices, as well as to confirm the safety and acceptance of this method of training. The aim of this review was therefore to provide an update of the best available evidence about the abovementioned approach.

\section{O B J E C T IVES}

To investigate the effects of automated electromechanical- and robotic-assisted gait-training devices for improving walking after stroke.

\section{METHODS}

\section{Criteria for considering studies for this review}

\section{Types of studies}

We searched for all randomised controlled trials and randomised controlled cross-over trials for inclusion in this review. If we included randomised controlled cross-over trials, we planned to analyse only the first period as a parallel-group trial.

\section{Types of participants}

We included studies with participants of any gender over 18 years of age after stroke, using the World Health Organization (WHO) definition of stroke or a clinical definition of stroke if the WHO definition was not specifically stated (WHO 2006).

\section{Types of interventions}

We included all trials that evaluated electromechanicaland robotic-assisted gait training plus physiotherapy versus physiotherapy (or usual care) for regaining and improving walking after stroke. We also included automated electromechanical devices that were used in combination with therapies such as functional electrical stimulation applied to the legs during gait training (compared with therapies not using electromechanical devices). We defined an automated electromechanical device as any device with an electromechanical solution designed to assist stepping cycles by supporting body weight and automating the walking therapy process in people after stroke. This category included any mechanical or computerised device designed to 
improve walking function. We also searched for electromechanical devices such as robots for gait training after stroke (MIT 2005; Schmidt 2005; Veneman 2005).

Electromechanical devices can principally be differentiated into end-effector and exoskeleton devices. Examples of end-effector devices are the LokoHelp (Freivogel 2009), the Haptic Walker (Schmidt 2005), and the Gait Trainer GT I (Hesse 1999). The definition of an end-effector principle is that a patient's feet are placed on foot plates, whose trajectories simulate the stance and swing phases during gait training (Hesse 2010). An example of exoskeleton devices is the Lokomat (Colombo 2000). Such exoskeletons are outfitted with programmable drives or passive elements, which move the knees and hips during the phases of gait (Hesse 2010).

We did not include non-weight-bearing interventions such as noninteractive devices that deliver continuous passive motion only (Nuyens 2002). We excluded trials testing the effectiveness of treadmill training or other approaches such as repetitive task training in physiotherapy or electrical stimulation alone (French 2016; Pollock 2014), to prevent duplication with other Cochrane Reviews and protocols (e.g. Mehrholz 2014).

\section{Types of outcome measures}

\section{Primary outcomes}

Regaining the ability to walk is a very important goal for people after stroke (Bohannon 1988). We therefore defined the primary outcome as the ability to walk independently. We measured the ability to walk with the Functional Ambulation Category (FAC) (Holden 1984). A FAC score of 4 or 5 indicated independent walking over a 15-metre surface, irrespective of aids used such as a cane. A FAC score of less than 4 indicates dependency in walking (supervision or assistance, or both must be given in performing walking).

If the included studies did not report FAC scores, we used alternative indicators of independent walking, such as:

- a score of 3 on the ambulation item of the Barthel Index (Wade 1988); or

- a score of 6 or 7 for the walking item of the Functional Independence Measure (Hamilton 1994); or

- a 'yes' response to the item 'walking inside, with an aid if necessary (but with no standby help)' or 'yes' to 'walking on uneven ground' in the Rivermead Mobility Index (Collen 1991).

\section{Secondary outcomes}

We defined secondary outcomes as measures of activity limitations. We used walking speed (in metres per second), walking capacity (metres walked in 6 minutes), and the Rivermead Mobility Index score as relevant measures of activity limitations, if stated by the trialists. Additionally, we used death from all causes as a secondary outcome.

\section{Adverse outcomes}

We investigated the safety of electromechanical-assisted gaittraining devices with the incidence of adverse outcomes such as thrombosis, major cardiovascular events, injuries, pain, and any other reported adverse events. To measure the acceptance of electromechanical-assisted gait-training devices in walking therapies, we used visual analogue scales or withdrawal from the study for any reason (dropout rates), or both during the study period, depending on data provided by the study authors.

Depending on the above-stated categories and the availability of variables used in the included trials, we discussed and reached consensus on which outcome measures should be included in the analysis.

\section{Search methods for identification of studies}

See the 'Specialized register' section in the Cochrane Stroke Group module. We searched for trials in all languages and arranged for translation of relevant papers published in languages other than English.

\section{Electronic searches}

We searched the Cochrane Stroke Group Trials Register (last searched August 2016) and the following electronic bibliographic databases:

- The Cochrane Central Register of Controlled Trials (CENTRAL) (the Cochrane Library, Issue 8, 2016) (Appendix 1);

- MEDLINE in Ovid (1950 to 15 August 2016) (Appendix 2);

- Embase (1980 to 15 August 2016) (Appendix 3);

- CINAHL (Cumulative Index to Nursing and Allied Health Literature) in EBSCO (1982 to 15 August 2016) (Appendix 4);

- AMED (Allied and Complementary Medicine Database) (1985 to 15 August 2016) (Appendix 5);

- Web of Science (Science Citation Index Expanded, Social Sciences Citation Index, Arts and Humanities Citation Index) (1899 to 16 August 2016) (Appendix 6);

- PEDro (Physiotherapy Evidence Database) (searched 16 August 2016) (Appendix 7);

- COMPENDEX (1972 to 16 November 2012) (Appendix 8);

- SPORTDiscus (1949 to 15 September 2012) (Appendix 9); and

- Inspec (1969 to 26 August 2016) (Appendix 10).

We developed the search strategies with the help of the Cochrane Stroke Group Information Specialist and adapted the MEDLINE search strategy for the other databases.

We identified and searched the following ongoing trials and research registers:

- International Standard Randomised Controlled Trial Number Register at www.isrctn.com/ (searched August 2016);

- ClinicalTrials.gov at www.clinicaltrials.gov (searched 27 August 2016);

- Stroke Trials Register at www.strokecenter.org (searched 27 August 2016); and

- World Health Organization International Clinical Trials Registry Platform (WHO ICTRP) at apps.who.int/trialsearch/ (searched 27 August 2016) (Appendix 11).

\section{Searching other resources}

We also: 
- handsearched the following relevant conference proceedings:

* World Congress of NeuroRehabilitation (2002, 2006, 2008, 2010, 2012, 2014, and 2016);

* World Congress of Physical Medicine and Rehabilitation (2001, 2003, 2005, 2007, 2009, 2011, 2013, and 2015);

* World Congress of Physical Therapy (2003, 2007, 2011, and 2015);

* Deutsche Gesellschaft für Neurotraumatologie und Klinische Neurorehabilitation (2001 to 2015);

* Deutsche Gesellschaft für Neurologie (2000 to 2016);

* Deutsche Gesellschaft für Neurorehabilitation (1999 to 2016); and

* Asia-Oceanian Conference of Physical \& Rehabilitation Medicine (2008 to 2016).

- screened reference lists of all relevant articles; and

- contacted trialists, experts, and researchers in our field of study.

\section{Data collection and analysis}

\section{Selection of studies}

Two review authors (JM, BE) independently read the titles and abstracts of the identified references and eliminated obviously irrelevant studies. We obtained the full text for the remaining studies. Based on our inclusion criteria (types of studies, participants, aims of interventions, outcome measures), the same two review authors independently ranked these studies as relevant, irrelevant, or possibly relevant. We excluded all trials ranked initially as irrelevant but included all other trials at this stage. We excluded all trials of specific treatment components, such as electrical stimulation as stand-alone treatment, treadmill training, and continuous passive motion treatment, because these have been the subject of other Cochrane Reviews (e.g. Mehrholz 2014). We resolved any disagreements through discussion between all four review authors. If we required further information to reach consensus, we contacted trialists in an attempt to obtain the missing information. We recorded the selection process in sufficient detail to complete a PRISMA flow diagram, and listed all studies that did not match our inclusion criteria regarding types of studies, participants, and aims of interventions in the Characteristics of excluded studies table.

\section{Data extraction and management}

Two review authors (JM, BE) independently extracted trial and outcome data from the selected trials. We established the characteristics of unpublished trials through correspondence with the trial co-ordinator or principal investigator. If any review author was involved in any of the selected studies, another review author not involved in the study extracted the study information. If there was any doubt as to whether a study should be excluded, we retrieved the full text of the article. In cases of disagreement between the two review authors, a third review author (JK) reviewed the information to decide on inclusion or exclusion of a study. We used checklists to independently record the following details.

- Methods of generating the randomisation schedule.

- Method of concealment of allocation.

- Blinding of assessors.
- Use of an intention-to-treat analysis (all participants initially randomly assigned were included in the analyses as allocated to groups).

- Adverse events and dropouts for all reasons.

- Important imbalance in prognostic factors.

- Participants (country, number of participants, age, gender, type of stroke, time from stroke onset to entry to the study, inclusion and exclusion criteria)

- Comparison (details of the intervention in treatment and control groups, details of co-intervention(s) in both groups, duration of treatment).

- Outcomes and time points of measures (number of participants in each group and outcome, regardless of compliance).

The two review authors checked all of the extracted data for agreement, with a third review author (JK) arbitrating any items for which consensus could not be reached. If necessary, we contacted trialists to request more information, clarification, and missing data.

\section{Assessment of risk of bias in included studies}

Two review authors (JM, MP) independently evaluated the methodological quality of the included trials using the Cochrane 'Risk of bias' tool, as described in Chapter 8 of the Cochrane Handbook for Systematic Reviews of Interventions (Higgins 2011a).

We checked all methodological quality assessments for agreement between review authors. We resolved disagreements by discussion. If one of the review authors was a co-author of an included trial, another review author (BE or JK) conducted the methodological quality assessment for this trial in this case.

\section{Measures of treatment effect}

We planned to compare electromechanical- and robotic-assisted gait training plus physiotherapy versus physiotherapy (or usual care) for primary and secondary outcome parameters. We used the effect measures odds ratio (OR) or mean difference (MD) in the meta-analyses.

\section{Unit of analysis issues}

We analysed binary (dichotomous) outcomes with an OR, randomeffects model with 95\% confidence intervals (Cls). We analysed continuous outcomes with MDs, using the same outcome scale. We used a random-effects model for all analyses. We used Cochrane Review Manager 5 software for all statistical comparisons, (RevMan 2014).

\section{Dealing with missing data}

In the case of missing outcome data, we attempted to analyse data according to the intention-to-treat approach. We contacted the trial co-ordinator or principal investigator if data were missing.

\section{Assessment of heterogeneity}

We used the $I^{2}$ statistic to assess heterogeneity. We used a randomeffects model, regardless of the level of heterogeneity.

\section{Assessment of reporting biases}

We inspected funnel plots to assess the risk of publication bias. 


\section{Data synthesis}

\section{GRADE and 'Summary of findings' table}

We created two 'Summary of findings' tables using the following outcomes.

- Primary outcome measure: Independent walking at the end of intervention phase, all electromechanical devices used. Scale from 0 to infinity.

- Primary outcome measure: Recovery of independent walking at follow-up after study end. Scale from 0 to infinity.

- Primary outcome measure: Walking velocity (metres per second) at the end of intervention phase. Scale from 0 to infinity.

- Secondary outcome measure: Walking velocity (metres per second) at follow-up. Scale from 0 to infinity.

- Secondary outcome measure: Walking capacity (metres walked in 6 minutes) at the end of intervention phase. Scale from 0 to infinity.

- Secondary outcome measure: Walking capacity (metres walked in 6 minutes) at follow-up. Scale from 0 to infinity.

- Secondary outcome measure: Acceptability of electromechanical-assisted gait-training devices during intervention phase: number of dropouts.

We used the five GRADE considerations (study limitations, consistency of effect, imprecision, indirectness, and publication bias) to assess the quality of a body of evidence as it relates to the studies that contribute data to the meta-analyses for the prespecified outcomes (Atkins 2004). We used methods and recommendations described in Section 8.5 and Chapter 12 of the Cochrane Handbook for Systematic Reviews of Interventions (Higgins 2011b), employing GRADEpro GDT software (GRADEpro GDT). We justified all decisions to down- or upgrade the quality of studies using footnotes, and made comments to aid the reader's understanding of the review where necessary.

\section{Subgroup analysis and investigation of heterogeneity}

As planned in our protocol (Mehrholz 2006), we performed a formal subgroup analysis following the guidance in the Cochrane Handbook for Systematic Reviews of Interventions (Deeks 2011), comparing participants treated in the acute and subacute phases of their stroke (within three months) with participants treated in the chronic phase (longer than three months).

\section{Sensitivity analysis}

As planned in our protocol, we performed a sensitivity analysis of methodological quality for each included study.

We carried out the following sensitivity analyses by including only those studies:

- with an adequate sequence generation process;

- with adequate concealed allocation;

- with blinded assessors for the primary outcome; and

- without incomplete outcome data.

We considered it necessary to do a further sensitivity analysis by removing the largest study, Pohl 2007, because some of the review authors (JM, MP, and CW) were investigators in this large trial. We carried out this sensitivity analysis by including all studies without the largest study (Pohl 2007).

We performed two further (post hoc) sensitivity analyses.

- Ambulatory status at start of study (including only studies that included an independent walker; including only studies that included dependent and independent walkers; and including only studies that included a dependent walker).

- Type of device used in trials (including only studies that used end-effector devices and including only studies that used exoskeleton devices).

\section{RES U L T S}

\section{Description of studies}

See the Characteristics of included studies, Characteristics of excluded studies, and Characteristics of ongoing studies tables.

\section{Results of the search}

Figure 1 shows the flow diagram of the selection of studies for this update. 
Figure 1. Study flow diagram.

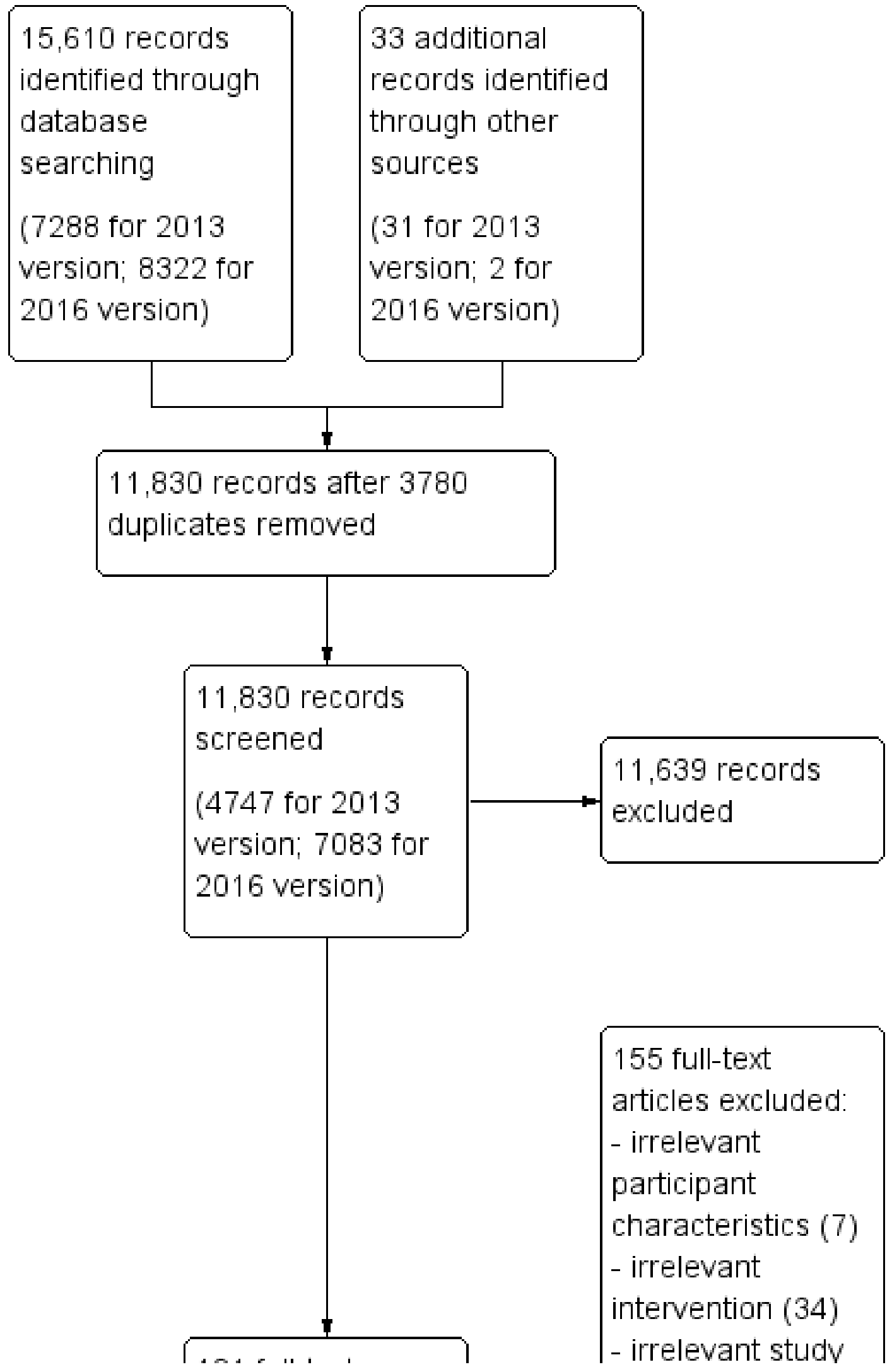


Figure 1. (Continued)

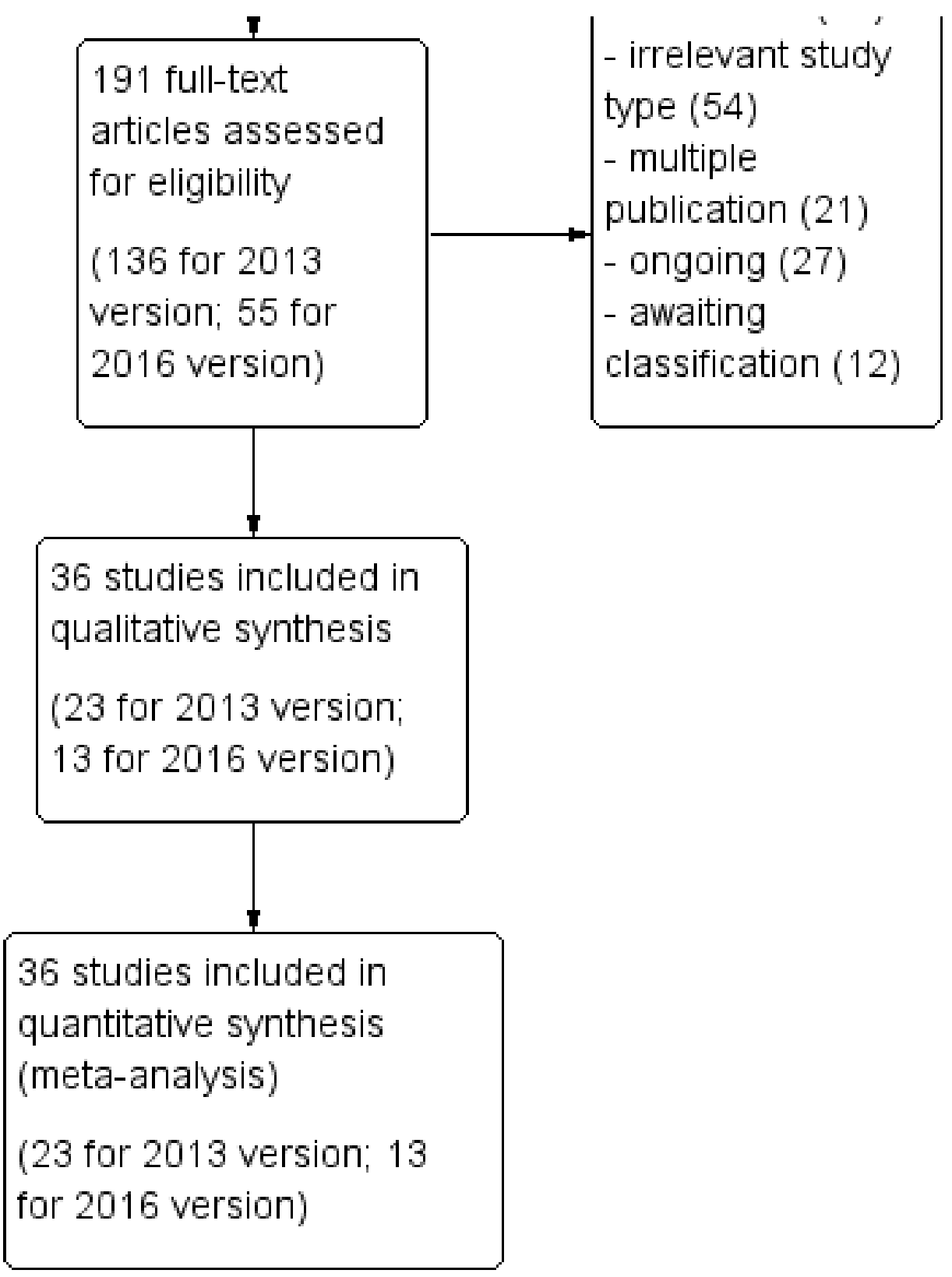

Searches of the electronic databases and trials registers generated 7083 new unique references for screening. After excluding nonrelevant citations, we obtained the full text of 55 new papers, and from these identified and included 13 new trials in the review.

\section{Included studies}

We included 36 trials involving a total of 1472 participants (see the Characteristics of included studies, Figure 1, Table 1, and Table 2). All included studies investigated the effects of electromechanicalor robotic-assisted gait-training devices in improving walking after stroke.

For one of the included studies published only as an abstract we obtained at least some results through correspondence with the trial co-ordinator or principal investigator (Mayr 2008). Another study was not yet published, but the results of the trial were presented orally, and we were able to obtain a handout with information about the study from the principal investigator (Aschbacher 2006).

A detailed description of all participant characteristics can be found in Table 1 and Table 2 (see also the Characteristics of included studies). The mean age in the included studies ranged from 48 years, in Kyung 2008, to 76 years, in Watanabe 2014 (Table 1). More males than females were included the studies (approximately 60\% males). More participants with ischaemic stroke than haemorrhagic stroke lesions (approximately 70\% ischaemic stroke) were included, and almost as many participants with left-sided hemiparesis compared with participants with rightsided hemiparesis (approximately 50\% left-sided) were included in the studies (see Table 1 and Table 2). 
Twelve studies provided information about baseline stroke severity (Table 2), of which seven used the Barthel Index score, ranging from 20 Barthel Index points, in Kim 2015, to 75 of 100 Barthel Index points, in Dias 2006 (Table 2). Details of all inclusion and exclusion criteria used in the studies can be found in the Characteristics of included studies table.

The duration of study intervention (time frame during which experimental interventions were applied) was heterogeneous, ranging from 10 days, in Chang 2012, to eight weeks, in Mayr 2008. The study intervention period for most studies was three or four weeks (Table 2). Fifteen of the 36 studies included participants who could walk independently at the start of the study; a further nine studies included participants who were dependent and independent walkers (Analysis 4.1); and 12 studies included only non-ambulatory participants (Analysis 4.1). The experimental intervention in 17 studies was the robotic-assisted device Lokomat, and the experimental intervention in nine studies was the electromechanical-assisted device Gait Trainer; a detailed description of devices used in studies can be found in Table 2 .

Frequency (in terms of therapy provided per week) of treatment ranged from two or three times a week, in Tanaka 2012, to five times a week (Table 2). Intensity (in terms of duration of experimental therapy provided) of treatment ranged from 20 minutes, in Werner 2002, to 60 minutes, in Forrester 2014. In many studies, details of the interventions were unclear or incomplete, for example details about the intensity of the experimental treatment were unclear in some studies (Table 2). Except for Tanaka 2012 and Picelli 2016, the gait training time did not differ between control and experimental groups in the included studies. Eleven included studies used a follow-up assessment after the study ended (Buesing 2015; Chua 2016; Dias 2006; Hidler 2009; Hornby 2008; Peurala 2005; Peurala 2009; Pohl 2007; Schwartz 2006; Stein 2014; Waldman 2013). Most studies investigated improvement in walking function as a primary outcome for analysis and used the Functional Ambulation Category (FAC) or comparable scales to assess independent walking. Furthermore, frequently investigated outcomes included assessment of walking function using gait velocity in metres per second. A more detailed description of the primary and secondary outcomes for each trial can be found in the Characteristics of included studies table.

We found the highest dropout rates for all reasons at the end of the treatment phase to be $23 \%$, in Hornby 2008 , and $29 \%$, in Kyung 2008. Seventeen trialists reported no dropouts at scheduled followup (Analysis 1.7; Table 2).

\section{Excluded studies}

We excluded 24 studies (see Characteristics of excluded studies and Figure 1 for further information).

\section{Ongoing studies and studies awaiting assessment}

We identified 16 ongoing studies (see Characteristics of ongoing studies). Thirteen studies for which we were unable to make contact with the trialists are still awaiting assessment (see Characteristics of studies awaiting classification).

\section{Risk of bias in included studies}

The risk of bias in included studies is described in greater detail in Characteristics of included studies and Figure 2. 
Figure 2. Risk of bias summary: review authors' judgements about each risk of bias item for each included study.

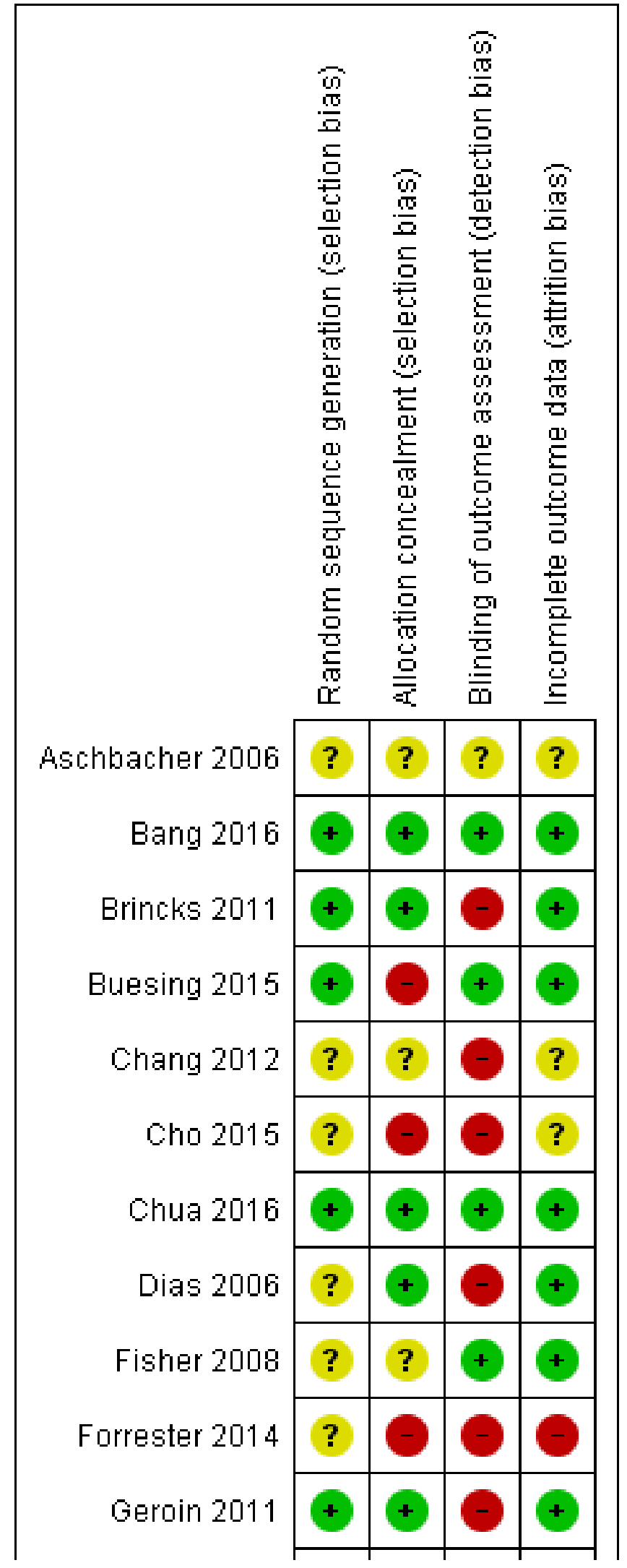


Figure 2. (Continued)

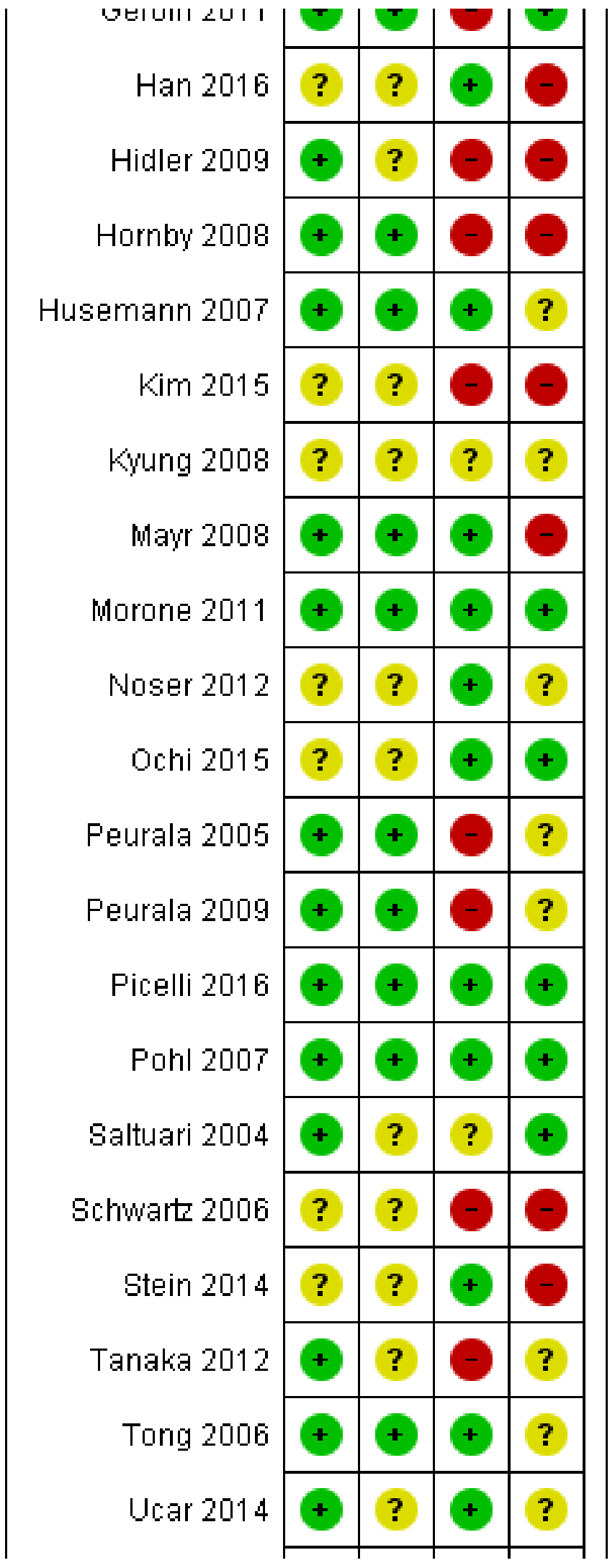


Figure 2. (Continued)

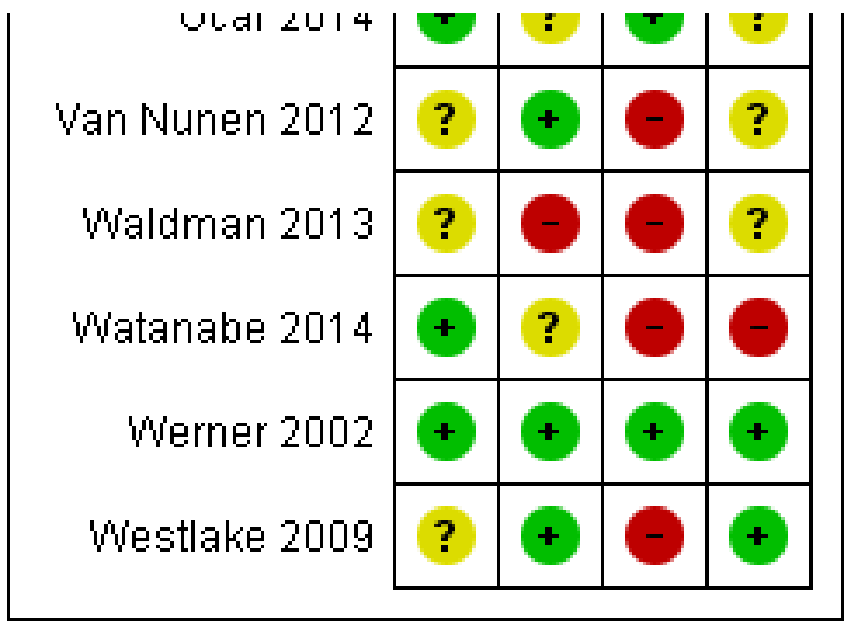

We wrote to the trialists of all included studies and studies awaiting assessment to request clarification of design features or for missing information to complete the quality ratings. We sent the correspondence via email or letter, followed by reminders every month if we received no response. Most trialists provided at least some of the requested data, but we were not able to obtain all of the required data.

Two review authors (JM, MP) used the 'Risk of bias' assessment tool to independently assess the methodological quality of the studies for the domains random sequence generation, allocation concealment, blinding of outcome assessment, and incomplete outcome data for all of the included trials except two (Pohl 2007; Werner 2002), which two other review authors (BE, JK) rated in an interview with the trialists. The review authors discussed all disagreements and sought arbitration by another review author (JK or BE) if necessary.

\section{Allocation}

Of the 36 included studies, 20 described adequate random sequence generation, and 17 described adequate allocation concealment.

\section{Blinding}

Of the 36 included studies, 6 reported blinding of the primary outcome assessment.

\section{Incomplete outcome data}

Of the 36 included studies, 14 reported incomplete outcome data (attrition bias).

\section{Selective reporting}

For the majority of studies, particularly the older trials, we did not find study protocols. Where study protocols were available, there was no evidence of selective reporting of outcomes relevant to this review.

\section{Other potential sources of bias}

Five out of 36 included trials used a cross-over design with random allocation to the order of treatment sequences (Brincks 2011; Cho 2015; Saltuari 2004; Tanaka 2012; Werner 2002). We analysed only the first intervention period as a parallel-group trial in this review. All other included studies used a parallel-group design with true randomisation to group allocation.

Three studies used two experimental groups and one control group (Geroin 2011; Peurala 2005; Tong 2006), and one study used one experimental group and two control groups (Peurala 2009). In the former three studies (Geroin 2011; Peurala 2005; Tong 2006), additional functional electrical stimulation of leg muscles (or transcranial stimulation of the brain in Geroin 2011) during gait training was applied in one of the treatment groups. Because functional electrical stimulation or transcranial stimulation of the brain was done as an adjunct during electromechanical-assisted gait training, and because the results in these experimental groups did not differ significantly, we combined the results of both experimental groups into one (collapsed) group and compared this with the results from the control group. In one study, an electromechanical-assisted device was used in the experimental group and was compared with two control groups that did not use a device (Peurala 2009). Because we were interested in the effects of electromechanical- and robotic-assisted gait-training devices for improving walking after stroke, we combined the results of both control groups without devices into one (collapsed control) group and compared this with results of the one experimental group.

\section{Effects of interventions}

See: Summary of findings for the main comparison Electromechanical- and robotic-assisted gait training plus physiotherapy compared to physiotherapy (or usual care) for walking after stroke

Independent walking at the end of the intervention phase, all electromechanical devices used

Thrity-six trials with a total of 1472 participants measured independent walking at study end, but for 21 included trials, no effect estimate (odds ratio (OR)) was feasible because no events (e.g. no participant reached the ability to walk) or only events (e.g. all participants regained walking) were reported (Analysis 1.1) (Deeks 2011).

The use of electromechanical devices in gait rehabilitation for people after stroke increased the chance of walking independently 
(OR 1.94, 95\% confidence interval (CI) 1.39 to 2.71; $\mathrm{P}<0.001$; level of heterogeneity $\mathrm{I}^{2}=8 \%$; moderate-quality evidence; Summary of findings for the main comparison). However, 15 out of 36 studies investigated at least some participants who were already independent in walking at the start of the study. A further nine studies included participants who were dependent and independent walkers, and 12 studies included only nonambulatory participants (Analysis 4.1). Of the total population of 1472 participants, approximately 39\% were independent and approximately $59 \%$ were dependent walkers at the start of the study.

\section{Recovery of independent walking at follow-up after study end}

Six trials with a total of 496 participants measured recovery of independent walking with follow-up after the study end (Chua 2016; Hidler 2009; Hornby 2008; Peurala 2009; Pohl 2007; Tong 2006), but for two included trials (with 125 participants), no effect estimate (OR) was feasible because no events (e.g. no participant reached ability to walk) or only events (e.g. all participants regained walking) were reported (Analysis 1.2). The use of electromechanical devices for gait rehabilitation of people after stroke did not increase the chance of walking independently at follow-up after study end (OR $1.93,95 \% \mathrm{Cl} 0.72$ to $5.13 ; \mathrm{P}=0.19$; level of heterogeneity $\mathrm{I}^{2}=$ $79 \%$; moderate-quality evidence). However, some included trials investigated participants who were already independent in walking at the start of the study. We could draw no definitive conclusion regarding a longer-lasting effect of the use of electromechanical devices.

\section{Walking velocity (metres per second) at the end of the intervention phase}

Twenty-four trials with a total of 985 participants provided data for walking velocity $(\mathrm{m} / \mathrm{s})$ at study end (Analysis 1.3). The use of electromechanical devices for gait rehabilitation did not significantly increase walking velocity. The pooled mean difference (MD) (random-effects model) for walking velocity was $0.04 \mathrm{~m} / \mathrm{s}$ $\left(95 \% \mathrm{Cl} 0.00\right.$ to $0.09 ; \mathrm{P}=0.08$; level of heterogeneity $\mathrm{I}^{2}=65 \%$; low-quality evidence). Participants who were unable to walk were regarded as having a walking velocity of zero metres per second.

\section{Walking velocity (metres per second) at follow-up}

Nine trials with a total of 578 participants provided data for walking velocity (m/s) at follow-up after study end (Buesing 2015; Chua 2016; Hidler 2009; Hornby 2008; Kyung 2008; Noser 2012; Pohl 2007; Stein 2014; Tong 2006). The use of electromechanical devices for gait rehabilitation did not significantly increase the walking velocity at follow-up after study end. The pooled MD (randomeffects model) for walking velocity was $0.07 \mathrm{~m} / \mathrm{s}(95 \% \mathrm{Cl}-0.05$ to $0.19 ; \mathrm{P}=0.26$; level of heterogeneity $\mathrm{I}^{2}=80 \%$; moderate-quality evidence; Analysis 1.4). Participants who were unable to walk were regarded as having a walking velocity of zero metres per second. We could draw no definitive conclusion regarding a longer-lasting effect of the use of electromechanical devices for walking velocity.

\section{Walking capacity (metres walked in 6 minutes) at the end of} the intervention phase

Twelve trials with a total of 594 participants provided data for walking capacity (metres walked in 6 minutes) at study end (Chua 2016; Hidler 2009; Hornby 2008; Noser 2012; Peurala 2005; Picelli 2016; Pohl 2007; Saltuari 2004; Stein 2014; Waldman 2013;
Watanabe 2014; Westlake 2009). The use of electromechanical devices in gait rehabilitation did not increase the walking capacity of people after stroke. The pooled MD (random-effects model) for walking capacity was 5.84 metres walked in 6 minutes $(95 \% \mathrm{Cl}$ -16.73 to $28.40 ; P=0.61$; level of heterogeneity $I^{2}=53 \%$; very lowquality evidence; Analysis 1.5).

\section{Walking capacity (metres walked in 6 minutes) at follow-up}

Seven trials with a total of 463 participants provided data for walking capacity (metres walked in 6 minutes) at follow-up after study end (Chua 2016; Hidler 2009; Hornby 2008; Noser 2012; Pohl 2007; Stein 2014; Waldman 2013). The use of electromechanical devices for gait rehabilitation did not increase walking capacity at follow-up after study end. The pooled MD (random-effects model) for walking capacity was -0.82 metres walked in 6 minutes $(95 \% \mathrm{Cl}$ -32.17 to 30.53 ; $P=0.96$; level of heterogeneity $\mathrm{I}^{2}=58 \%$; very lowquality evidence; Analysis 1.6).

\section{Death from all causes until the end of the intervention phase}

Only three larger trials reported any deaths during the intervention period (Chua 2016; Hidler 2009; Pohl 2007). In Pohl 2007 one participant in the control group died as the result of aspiration pneumonia, and one participant in the treatment group died due to recurrent stroke. In Hidler 2009, the group in which the death occurred was not stated. We therefore used a worstcase (conservative) scenario and counted the one death for the experimental group. In the study of Chua 2016 the deaths occurred after the treatment period. The use of electromechanical devices for gait rehabilitation of non-ambulatory people after stroke did not increase the risk of participants dying during the intervention period (risk difference (random-effects model) $0.00,95 \% \mathrm{Cl}-0.01$ to 0.02 ; $\mathrm{P}=0.77$; level of heterogeneity $\mathrm{I}^{2}=0 \%$; moderate-quality evidence; Analysis 1.8).

\section{Adverse outcomes: acceptability of electromechanical-assisted gait-training devices during the intervention phase in terms of dropouts}

All trialists provided information about participants who dropped out from all causes during the trial period, but for 17 of the 36 included trials, no events/dropouts were reported (Analysis 1.7). The use of electromechanical devices for gait rehabilitation of non-ambulatory people after stroke did not increase the risk of participants dropping out (OR (random-effects model) $0.67,95 \% \mathrm{Cl}$ 0.43 to $1.05 ; P=0.08$; level of heterogeneity $\mathrm{I}^{2}=24 \%$; low-quality evidence). The reasons for dropouts and all adverse events are described in detail for each trial in Table 2.

\section{Regaining independent walking ability: planned sensitivity analysis by trial methodology}

To examine the robustness of the results, we specified variables in a sensitivity analysis that we believed could influence the size of the observed effect (adequate sequence generation process, adequate concealed allocation, blinded assessors for the primary outcome, incomplete outcome data, and excluding the largest study). As stated above, for some of the included trials, no effect estimate (OR) was feasible (Analysis 2.1).

\section{Studies with adequate sequence generation process}

We included 20 trials with a total of 949 participants with an adequate sequence generation process (Figure 2). The use 
of electromechanical devices for gait rehabilitation of people after stroke increased the chance of walking independently (OR (random-effects model) $1.80,95 \% \mathrm{Cl} 1.06$ to $3.08 ; \mathrm{P}=0.03$; level of heterogeneity $\mathrm{I}^{2}=38 \%$ ).

\section{Studies with adequate concealed allocation}

We included 17 trials with a total of 831 participants with adequate concealed allocation (Figure 2). The use of electromechanical devices for gait rehabilitation of people after stroke increased the chance of walking independently (OR (random-effects model) 1.87 , $95 \% \mathrm{Cl} 1.12$ to $3.12 ; \mathrm{P}=0.02$; level of heterogeneity $\mathrm{I}^{2}=37 \%$ ).

\section{Studies with blinded assessors for the primary outcome}

Sixteen trials with a total of 762 participants had blinded assessors for the primary outcome (Figure 2). The use of electromechanical devices for gait rehabilitation of people after stroke increased the chance of walking independently (OR (random-effects model) 1.81 , $95 \% \mathrm{Cl} 1.10$ to $2.98 ; \mathrm{P}=0.02$; level of heterogeneity $\mathrm{I}^{2}=31 \%$ ).

\section{Studies with complete outcome data}

Fourteen trials with a total of 590 participants adequately described complete outcome data (Figure 2). The use of electromechanical devices for gait rehabilitation of people after stroke increased the chance of walking independently (OR (random-effects model) 2.23, $95 \% \mathrm{Cl} 1.16$ to $4.29 ; \mathrm{P}=0.02$; level of heterogeneity $\mathrm{I}^{2}=29 \%$ ).

\section{Excluding the largest study (Pohl 2007)}

After excluding the largest study (Pohl 2007), 35 trials with a total of 1317 participants remained in this analysis. The use of electromechanical devices for gait rehabilitation of people after stroke increased the chance of walking independently (OR (random-effects model) $1.65,95 \% \mathrm{Cl} 1.17$ to $2.34 ; \mathrm{P}=0.005$; level of heterogeneity $\left.\right|^{2}=0 \%$ )

\section{Subgroup analysis comparing participants in the acute and chronic phases of stroke}

\section{Independent walking at the end of the intervention phase, all electromechanical devices used}

In our planned subgroup analysis comparing independent walking at the end of the intervention phase in people in the acute and chronic phases of stroke, we attempted to assign all included studies to one of two subgroups (acute and chronic phases).

Twenty trials with a total of 1143 participants investigated people in the acute or subacute phase, defined as less than or equal to three months after stroke (Analysis 3.1). As stated in the comparisons above, for some of the included trials no effect estimate (OR) was feasible (Analysis 3.1). The use of electromechanical devices for gait rehabilitation of people after stroke increased the chance of walking independently (OR (random-effects model) $1.90,95 \% \mathrm{Cl}$ 1.38 to $2.63 ; \mathrm{P}<0.001$; level of heterogeneity $\left.\right|^{2}=5 \%$ ).

Sixteen trials with a total of 461 participants investigated people in the chronic phase, defined as more than three months after stroke (Analysis 3.1). The use of electromechanical devices for gait rehabilitation of people after stroke did not increase the chance of walking independently (OR (random-effects model) $1.20,95 \% \mathrm{Cl}$ 0.40 to $3.65 ; P=0.74$; level of heterogeneity $\mathrm{I}^{2}=29 \%$ ).
In a formal subgroup analysis, we did not find statistically significant differences in regaining independent walking between participants treated in the acute/subacute phase compared with participants treated in the chronic phase after stroke $\left(\mathrm{Chi}^{2}=0.61\right.$, $\mathrm{df}=1 ; \mathrm{P}=0.44)$.

\section{Post hoc sensitivity analysis by ambulatory status at study onset}

\section{Independent walking at the end of the intervention phase}

To examine the robustness of the results and to explore the relationship between the main effect and walking status at the start of the study, we compared independent walking rates at the end of the intervention phase by ambulatory status at start of study.

\section{Ambulatory participants at start of study}

Fifteen trials with a total of 500 participants investigated independent walkers (Analysis 4.1). As stated in the comparisons above, for some of the included trials, no effect estimate (OR) was feasible; the conclusions are therefore based on one trial. The use of electromechanical devices for gait rehabilitation of people after stroke did not increase the chance of walking independently (OR (random-effects model) $1.38,95 \% \mathrm{Cl} 0.45$ to $4.20 ; \mathrm{P}=0.57$; level of heterogeneity $\mathrm{I}^{2}=$ not applicable).

\section{Ambulatory and non-ambulatory participants at start of study}

Nine trials with a total of 340 participants investigated a mixed population of dependent and independent walkers (Analysis 4.1). The use of electromechanical devices for gait rehabilitation of people after stroke increased the chance of walking independently (OR (random-effects model) $1.90,95 \% \mathrm{Cl} 1.11$ to $3.25 ; \mathrm{P}=0.02$; level of heterogeneity $\mathrm{I}^{2}=0 \%$ ).

\section{Non-ambulatory participants at start of study}

Twelve trials with a total of 632 participants investigated dependent walkers (Analysis 4.1). The use of electromechanical devices for gait rehabilitation of people after stroke increased the chance of walking independently (OR (random-effects model) $1.90,95 \% \mathrm{Cl}$ 1.04 to $3.48 ; P=0.04$; level of heterogeneity $I^{2}=45 \%$ ).

In a subgroup analysis, we did not find statistically significant differences between people who were dependent or independent walkers at the start of the study in regaining independent walking $\left(\mathrm{Chi}^{2}=0.28, \mathrm{df}=2 ; \mathrm{P}=0.87\right)$.

\section{Walking speed at the end of the intervention phase}

To examine the robustness of the results and to explore the relationship between walking velocity and ambulatory status at the start of the study, we compared achieved walking velocity at the end of the intervention phase by ambulatory status at the start of the study.

\section{Ambulatory participants at start of study}

Ten trials with a total of 317 participants investigated independent walkers at the start of the study and provided data for walking velocity $(\mathrm{m} / \mathrm{s})$ at study end (Analysis 4.2). The use of electromechanical devices for gait rehabilitation did not significantly increase walking velocity. The pooled MD (randomeffects model) for walking velocity was $-0.02 \mathrm{~m} / \mathrm{s}(95 \% \mathrm{Cl}-0.10$ to 0.06; $P=0.66$; level of heterogeneity $\mathrm{I}^{2}=59 \%$ ). 


\section{Ambulatory and non-ambulatory participants at start of study}

Five trials with a total of 146 participants investigated dependent and independent walkers at the start of the study and provided data for walking velocity $(\mathrm{m} / \mathrm{s})$ at study end (Analysis 4.2). The use of electromechanical devices for gait rehabilitation did not significantly increase walking velocity. The pooled MD (randomeffects model) for walking velocity was $0.03 \mathrm{~m} / \mathrm{s}(95 \% \mathrm{Cl}-0.05$ to $0.11 ; \mathrm{P}=0.44$; level of heterogeneity $\mathrm{I}^{2}=0 \%$ ).

\section{Non-ambulatory participants at start of study}

Nine trials with a total of 522 participants investigated dependent walkers at the start of the study and provided data for walking velocity $(\mathrm{m} / \mathrm{s})$ at study end (Analysis 4.2 ). The use of electromechanical devices for gait rehabilitation significantly increased walking velocity. The pooled MD (random-effects model) for walking velocity was $0.10 \mathrm{~m} / \mathrm{s}(95 \% \mathrm{Cl} 0.03$ to $0.17 ; \mathrm{P}=0.006$; level of heterogeneity $\mathrm{I}^{2}=73 \%$ ).

In a subgroup analysis, we did not find statistically significant differences in regaining independent walking between participants who were dependent or independent walkers at the start of the study $\left(\mathrm{Chi}^{2}=4.55, \mathrm{df}=2 ; \mathrm{P}=0.10\right)$.

\section{Post hoc sensitivity analysis by type of electromechanical device}

\section{Independent walking at the end of the intervention phase}

To examine the robustness of the results and to explore the relationship between independent walking and type of electromechanical device, we compared achieved independent walking rates at the end of the intervention phase by type of electromechanical device.

\section{End-effector devices}

Eleven trials with a total of 598 participants used an endeffector device as the experimental intervention (Table 2). As stated in the comparisons above, for some of the included trials, no effect estimate (OR) was feasible (Analysis 5.1). The use of electromechanical devices for gait rehabilitation of people after stroke did not increase the chance of walking independently (OR (random-effects model) $1.90,95 \% \mathrm{Cl} 0.99$ to $3.63 ; \mathrm{P}=0.05$; level of heterogeneity $\left.\right|^{2}=50 \%$ ).

\section{Exoskeleton devices}

Sixteen trials with a total of 585 participants used an exoskeleton device as the experimental intervention (Table 2). The use of electromechanical devices for gait rehabilitation of people after stroke increased the chance of walking independently (OR (random-effects model) $2.05,95 \% \mathrm{Cl} 1.21$ to $3.50 ; \mathrm{P}=0.008$; level of heterogeneity $\mathrm{I}^{2}=0 \%$ ).

We did not find statistically significant differences in regaining independent walking between participants treated with endeffector or exoskeleton devices $\left(\mathrm{Chi}^{2}=0.04, \mathrm{df}=1 ; \mathrm{P}=0.85\right)$.

\section{Mobile devices}

Three trials with a total of 106 participants used powered mobile devices as the experimental intervention (Table 2), but the effects on walking ability were not estimable.

\section{Ankle devices}

Two trials with a total of 63 participants used ankle devices while sitting as the experimental intervention (Table 2), but the effects on walking ability were not estimable.

We did not find statistically significant differences in regaining independent walking by type of electromechanical device (endeffector, exoskeleton, mobile or ankle device $)\left(\mathrm{Chi}^{2}=0.04, \mathrm{df}=1 ; \mathrm{P}\right.$ $=0.85$ ).

\section{Walking speed at the end of the intervention phase}

To examine the robustness of the results and to explore the relationship between independent walking and type of electromechanical device, we compared the walking speed at the end of the intervention phase by type of electromechanical device.

\section{End-effector devices}

Nine trials with a total of 519 participants used an end-effector device as the experimental intervention and provided data for walking velocity $(\mathrm{m} / \mathrm{s})$ at study end (Analysis 5.2). The use of electromechanical devices for gait rehabilitation significantly increased walking velocity. The pooled MD (random-effects model) for walking velocity was $0.11 \mathrm{~m} / \mathrm{s}(95 \% \mathrm{Cl} 0.04$ to $0.18 ; \mathrm{P}=0.003$; level of heterogeneity $\left.\right|^{2}=73 \%$ ).

\section{Exoskeleton devices}

Twelve trials with a total of 360 participants used an exoskeleton device as the experimental intervention and provided data for walking velocity $(\mathrm{m} / \mathrm{s})$ at study end (Analysis 5.2). The use of electromechanical devices for gait rehabilitation did not increase walking velocity. The pooled MD (random-effects model) for walking velocity was $-0.02 \mathrm{~m} / \mathrm{s}(95 \% \mathrm{Cl}-0.08$ to $0.04 ; \mathrm{P}=0.60$; level of heterogeneity $I^{2}=44 \%$ ).

In a formal subgroup analysis, we found statistically significant differences in improvement in walking velocity between participants treated with an end-effector device or an exoskeleton device $\left(\mathrm{Chi}^{2}=6.79, \mathrm{df}=1 ; \mathrm{P}=0.009 ; \mathrm{I}^{2}=85.3 \%\right)$.

\section{Mobile devices}

Three trials with a total of 106 participants used powered mobile devices as the experimental intervention and provided data for walking velocity $(\mathrm{m} / \mathrm{s})$ at study end (Analysis 5.2). The use of electromechanical devices for gait rehabilitation did not increase walking velocity. The pooled MD (random-effects model) for walking velocity was $0.02 \mathrm{~m} / \mathrm{s}(95 \% \mathrm{Cl}-0.11$ to $0.15 ; \mathrm{P}=0.78$; level of heterogeneity $\mathrm{I}^{2}=0 \%$ ).

\section{Ankle devices}

One trial with 39 participants used an ankle mobile device as the experimental intervention and provided data for walking velocity $(\mathrm{m} / \mathrm{s})$ at study end (Analysis 5.2). The use of electromechanical devices for gait rehabilitation increased walking velocity. The MD (random-effects model) for walking velocity was $0.04 \mathrm{~m} / \mathrm{s}(95 \% \mathrm{Cl}$ 0.01 to $0.07 ; \mathrm{P}=0.02$; level of heterogeneity not applicable).

In a subgroup analysis, we did not find statistically significant differences in improvement in walking velocity by type of electromechanical device (end-effector, exoskeleton, mobile or ankle device $)\left(\mathrm{Chi}^{2}=6.56, \mathrm{df}=3 ; \mathrm{P}=0.09 ; \mathrm{I}^{2}=54.3 \%\right)$. 


\section{Walking capacity at the end of the intervention phase}

To examine the robustness of the results and to explore the relationship between independent walking and type of electromechanical device, we compared the walking capacity at the end of the intervention phase by type of electromechanical device.

\section{End-effector devices}

Four trials with a total of 328 participants used an end-effector device as the experimental intervention and provided data for walking capacity (metres) at study end (Analysis 5.3). The use of electromechanical devices for gait rehabilitation significantly increased walking capacity. The pooled MD (random-effects model) for walking capacity was $27.5 \mathrm{~m}(95 \% \mathrm{Cl} 3.63$ to 51.36 ; $\mathrm{P}=0.02$; level of heterogeneity $I^{2}=4 \%$ ).

\section{Exoskeleton devices}

Five trials with a total of 186 participants used an exoskeleton device as the experimental intervention and provided data for walking capacity (metres) at study end (Analysis 5.3). The use of electromechanical devices for gait rehabilitation did not increase walking capacity. The pooled MD (random-effects model) for walking capacity was $-15.64 \mathrm{~m}(95 \% \mathrm{Cl}-46.34$ to $15.05 ; \mathrm{P}=0.32$; level of heterogeneity $\mathrm{I}^{2}=51 \%$ ).

In a formal subgroup analysis, we found statistically significant differences in improvement in walking capacity between participants treated with an end-effector device or an exoskeleton device $\left(\mathrm{Chi}^{2}=4.73, \mathrm{df}=1 ; \mathrm{P}=0.03 ; \mathrm{I}^{2}=78.9 \%\right)$.

\section{Mobile devices}

Two trials with a total of 56 participants used powered mobile devices as the experimental intervention and provided data for walking capacity (metres) at study end (Analysis 5.3). The use of electromechanical devices for gait rehabilitation did not increase walking capacity. The pooled MD (random-effects model) for walking capacity was $20.06 \mathrm{~m}(95 \% \mathrm{Cl}-39.52$ to $79.63 ; \mathrm{P}=0.51$; level of heterogeneity $\left.\right|^{2}=0 \%$ ).

\section{Ankle devices}

One trial with 24 participants used an ankle mobile device as the experimental intervention and provided data for walking capacity (metres) at study end (Analysis 5.3). The use of electromechanical devices for gait rehabilitation did not increase walking capacity. The MD (random-effects model) for walking capacity was $8.0 \mathrm{~m}(95 \% \mathrm{Cl}$ -83.03 to $99.03 ; P=0.86$; level of heterogeneity not applicable).

In a subgroup analysis, we did not find statistically significant differences in improvement in walking capacity between participants treated by type of electromechanical device (endeffector, exoskeleton, mobile or ankle device) $\left(\mathrm{Chi}^{2}=4.81, \mathrm{df}=3 ; \mathrm{P}\right.$ $=0.19 ;\left.\right|^{2}=37.7 \%$ ).

\section{DISCUSSION}

\section{Summary of main results}

The aim of this review was to evaluate the effects of electromechanical- and robotic-assisted gait-training devices (with body weight support) for improving walking after stroke. We sought to estimate the likelihood or chance of becoming independent in walking as a result of these interventions, which is a main rehabilitation goal for people who have had a stroke (Bohannon 1988; Bohannon 1991).

We included 36 trials with a total of 1472 participants and found evidence that the use of electromechanical-assisted devices in combination with physiotherapy in rehabilitation settings may improve walking function after stroke.

Furthermore, adverse events, dropouts, and deaths do not appear to be more frequent in participants who received electromechanical- or robotic-assisted gait training, which indicates that the use of electromechanical-assisted gait-training devices was safe and acceptable to most participants included in the trials analysed by this review.

The exclusion of certain patient groups, such as people over 80 years of age, people with unstable cardiovascular conditions, people with cognitive and communication deficits, and people with a limited range of motion in the lower limb joints at the start of the intervention, may limit the general applicability of the findings. However, using the results from the primary outcomes, it is possible to explore the apparent effectiveness of electromechanical-assisted devices for regaining walking ability. Of 761 participants in the treatment group, 412 (54\%) were walking independently at the end of the intervention phase. We used the primary outcome of independently walking at the end of the intervention phase for all included participants (OR 1.94) to calculate the number needed to treat for an additional beneficial outcome (NNTB). Together with our control event rate of 45\% (325 out of 711 control participants were independently walking), we calculated an NNTB of 7 (95\% Cl 6 to 8) (Sackett 1996). This means that every seventh dependency in walking ability after stroke could be avoided with the use of electromechanical-assisted devices. However, the optimum amount of electromechanical-assisted gait training (optimal frequency, optimal duration in the use of assistive technologies and timing of application) remains unclear.

It appears that people in the acute and subacute phases after stroke profit more than people treated more than three months poststroke from this type of therapy (Analysis 3.1). This means that people may benefit more from electromechanical- and roboticassisted gait training in the first three months after stroke than after three months poststroke.

We argue that $582(39 \%)$ of the 1472 included participants were independently walking at baseline (see Description of studies and the Characteristics of included studies table). Because people who are already ambulatory cannot regain or recover independent walking, our effect estimate could have been influenced by performance bias. We therefore performed two further sensitivity analyses by ambulatory status at the start of the study (Analysis 4.1 and Analysis 4.2).

We found that studies that included mainly dependent walkers (i.e. participants who were non-ambulatory at the start of the study) were more likely to report that these participants were able to walk at study end and to reach greater walking velocities at the end of the intervention phase compared with participants who were already ambulatory at the start of the study (Analysis 4.1; Analysis 4.2). This means that ambulatory people do not benefit from electromechanical- and robotic-assisted gait training. 
We found that the ability to walk at study end was not dependent on the type of device used in the studies (Analysis 5.1). However, walking velocities at the end of the intervention phase were higher when end-effector devices were used compared with participants who received training by an exoskeleton device (Analysis 5.2), meaning that the type of device used could play a role in improving walking function after stroke. This is in line with the former version of this review from 2013, Mehrholz 2013, and another review that compared the effects of different types of devices on walking ability after stroke (Mehrholz 2012a). However, in the absence of a direct

Figure 3. Funnel plot of comparison: 1 Electromechanical- and robotic-assisted gait training plus physiotherapy versus physiotherapy (or usual care), outcome: 1.1 Independent walking at the end of intervention phase, all electromechanical devices used.

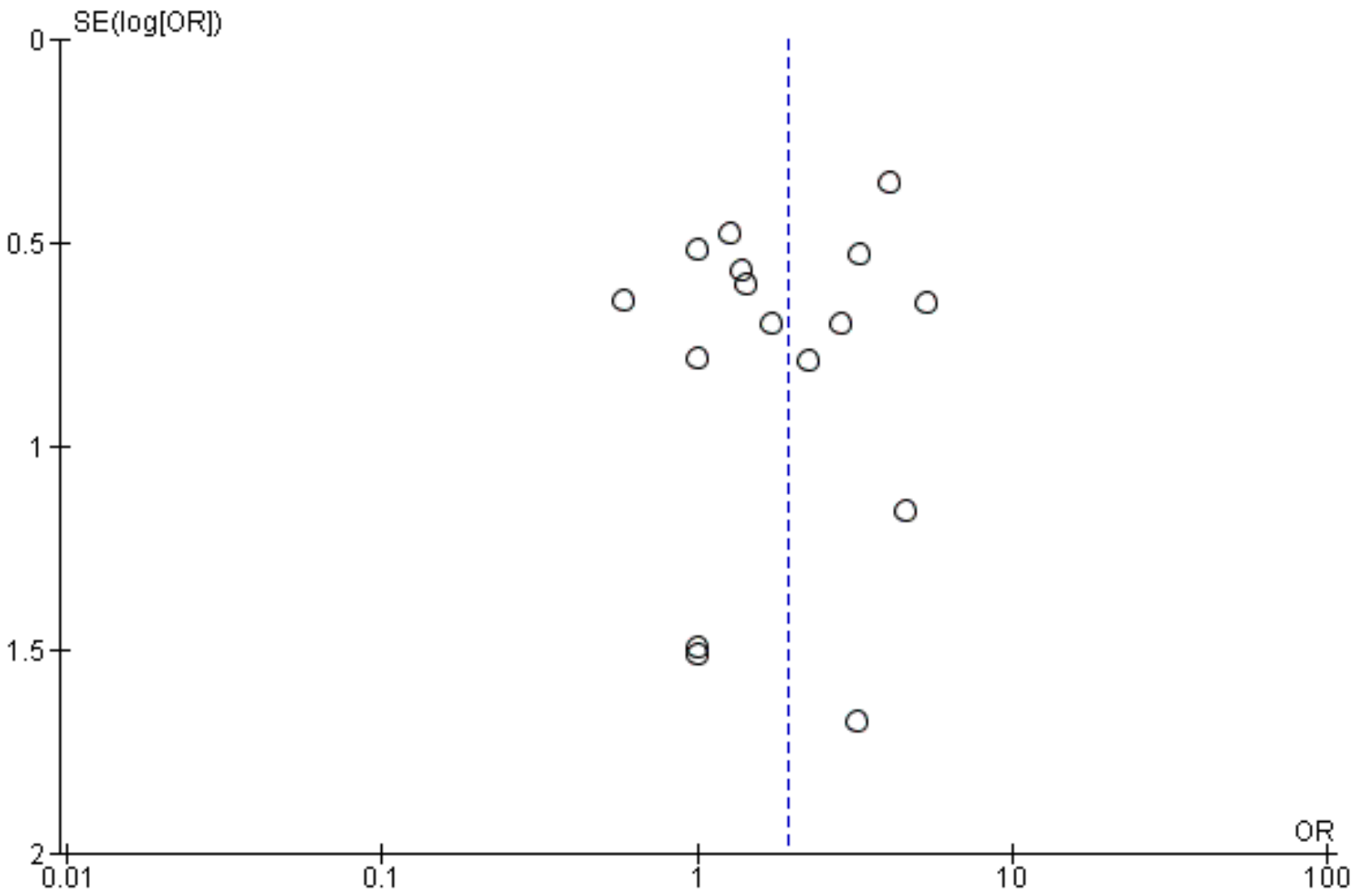

empirical comparison between electromechanical-assisted gaittraining devices, this point warrants further investigation.

\section{Overall completeness and applicability of evidence}

In all systematic reviews the risk of publication bias is present. However, we performed an extensive search for relevant literature in electronic databases and handsearched conference abstracts. Additionally, we contacted and asked authors, trialists, and experts in the field for other unpublished and ongoing trials.

Upon visual inspection, we did not detect graphical evidence of publication bias (see Figure 3 and Figure 4). 
Figure 4. Funnel plot of comparison: 1 Electromechanical- and robotic-assisted gait training plus physiotherapy versus physiotherapy (or usual care), outcome: 1.3 Walking velocity (metres per second) at the end of intervention phase.

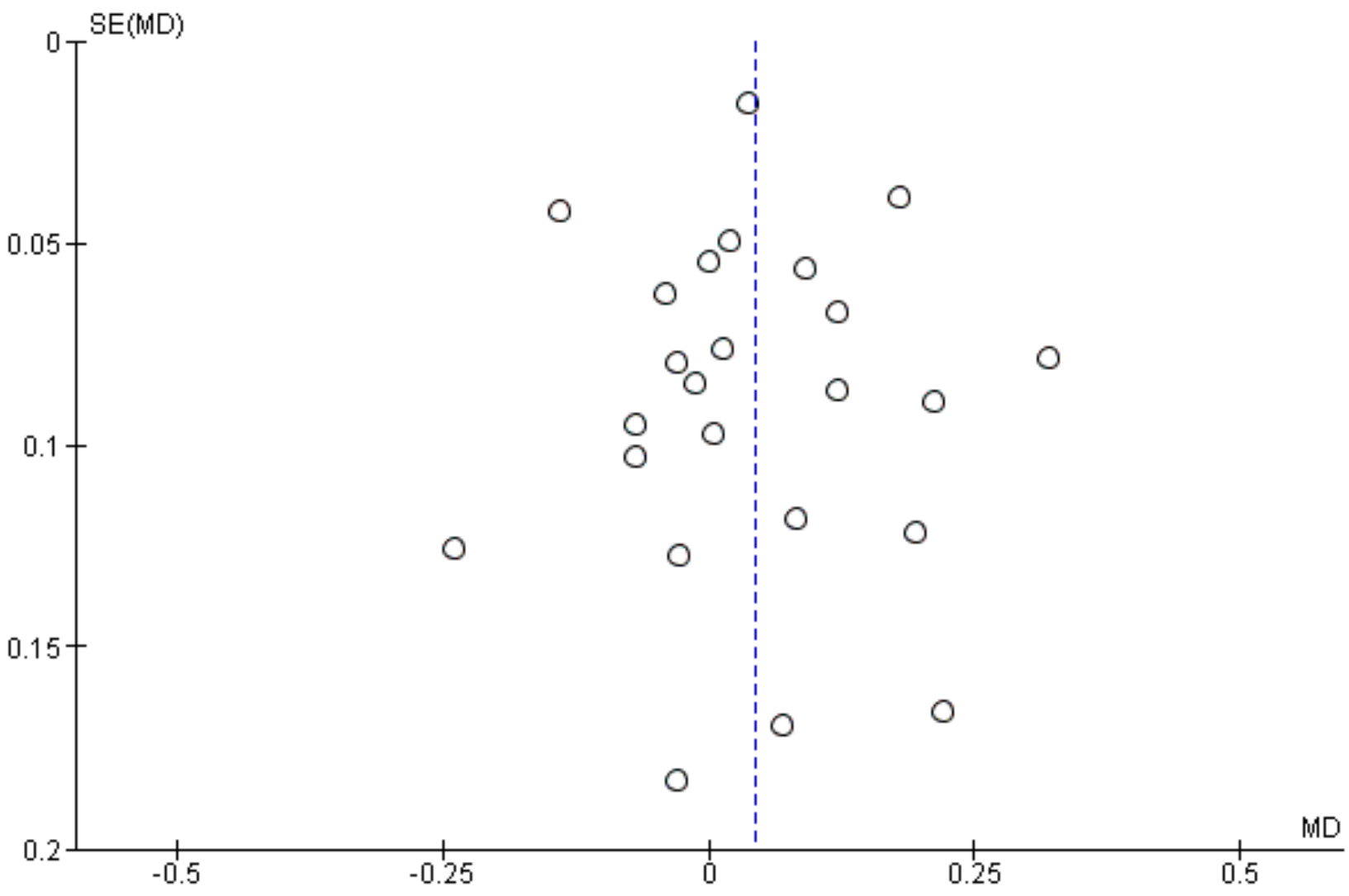

Given that we found several ongoing studies of substantial size, it is possible that these ongoing studies could potentially impact our overall conclusion when they are included in the review (see Characteristics of ongoing studies).

It is not clear whether the observed differences between experimental and control groups depend on the intensity of therapy, in terms of repetitions of gait practice. Time devoted to therapy is a crude measure of intensity. A 30-minute therapy session could include no walking practice or high-intensity walking practice with many steps taken. Reviews of the effectiveness of arm robotic therapy suggest that the positive benefit of robotic therapy may be lost when the intensity of practice is matched between experimental and control groups (Mehrholz 2012b). However, the numbers of repetitions in the experimental and control groups were not exactly counted in any of the included studies. Further studies should therefore ascertain whether the benefits described here are still apparent when the intensity of gait practice (e.g. step repetitions) is exactly matched between groups.

It should be mentioned that we do not know yet whether these devices provide any cost benefit. Further studies should investigate, under the premise that gait practice is matched in terms of objective measures of intensity, the long-term costs of regaining walking ability and the cost-effectiveness of these devices.

\section{Quality of the evidence}

There was heterogeneity between the trials in terms of trial design (two arms, three arms, parallel-group or cross-over trial, duration of follow-up, and selection criteria for participants), characteristics of the therapy interventions (especially duration of the intervention), and participant characteristics (length of time since stroke onset and stroke severity at baseline). We noted methodological differences in the mechanisms of randomisation and in the allocation concealment methods used, as well as in the blinding of primary outcomes and the presence or use of intentionto-treat analysis.

After examining the effects of methodological quality on the odds of independence in walking, we found that the benefits were relatively robust when we removed trials with an inadequate sequence generation process, inadequate concealed allocation, no blinded assessors for the primary outcome, and incomplete outcome data (Analysis 2.1). However, we found that the odds of independence in walking were slightly lower after the largest included study (Pohl 2007, $N=155$ ) was removed, but a statistically significant and clinically relevant benefit for participants is still observed.

Although the methodological quality of the included trials seemed generally good to moderate (Figure 2), trials investigating electromechanical- and robotic-assisted gait-training devices are subject to potential methodological limitations. These include inability to blind the therapist and participants, so-called 
contamination (provision of the intervention to the control group), and co-intervention (when the same therapist unintentionally provides additional care to either treatment or comparison group). All these potential methodological limitations introduce the possibility of performance bias. However, as discussed previously, this was not supported in our sensitivity analyses by methodological quality.

The quality of the evidence for automated electromechanical- and robotic-assisted gait-training devices for improving walking after stroke was moderate. The quality of the evidence was low for walking speed, very low for walking capacity, and low for adverse events and people discontinuing treatment.

\section{Potential biases in the review process}

In all systematic reviews the risk of publication bias is present. However, we performed an extensive search for relevant literature in electronic databases and handsearched conference abstracts. Additionally, we contacted and asked authors, trialists, and experts in the field for other unpublished and ongoing trials.

Upon visual inspection, we did not detect graphical evidence of publication bias (see Figure 3 and Figure 4).

Given that we found several ongoing studies of substantial size, it is possible that these ongoing studies could potentially impact our overall conclusion (see Characteristics of ongoing studies).

\section{Agreements and disagreements with other studies or reviews}

The most recent and relevant review describes the effects of new so-called powered mobile solutions (Louie 2016). We included three studies of mobile devices in this update. When pooling these results, we did not find significant improvements in walking speed and walking capacity; this result is in agreement with the recent review of Louie 2016. Additionally, there are two new studies describing the effects of ankle robots (Forrester 2014; Waldman 2013) to improve walking were described. When pooling these studies, we did not find significant improvements in walking speed and walking capacity. We are not aware of any systematic review about this type of devices so far.

\section{AUTHORS' CONCLUSIONS}

\section{Implications for practice}

This systematic review provides moderate-quality evidence that the use of electromechanical-assisted gait-training devices in combination with physiotherapy increases the chance of regaining independent walking ability in people after stroke. These results could be interpreted as preventing one participant from remaining dependent in walking after stroke for every seven treated. However, this apparent benefit for patients is not supported by our secondary outcomes. Gait-training devices were associated with neither improvements in walking velocity nor walking capacity (low- to very low-quality evidence). It appears that the greatest benefits with regard to independence in walking and walking speed were achieved in participants who were non-ambulatory at the start of the study and in those for whom the intervention was applied early poststroke.

\section{Implications for research}

There is still a need for well-designed, large-scale, multicentre studies to evaluate the benefits and harms of electromechanicalassisted gait training for walking after stroke, including only non-ambulatory people in the very early stages after stroke. Comparisons between different devices are also currently lacking. Future research should include estimates of the costs (or savings) associated with electromechanical gait training. Further analyses should investigate whether non-ambulatory or ambulatory people benefit most, and trials should include outcome measures in the activities of daily living and quality of life domains. In future updates of this review we will consider investigating the effects of different control interventions using subgroup analysis. Additionally, in the next update we will compare the effects of different duration and intensity of treatment (e.g. less than versus more than four weeks; five days per week versus less than five days).

\section{ACKNOWLEDGEMENTS}

We thank Brenda Thomas for help with developing the search strategy and for providing us with relevant trials and systematic reviews from CINAHL, AMED, SPORTDiscus, and Inspec; Hazel Fraser for providing us with relevant information about trials and systematic reviews from the Cochrane Stroke Group Trials Register; and Gabi Voigt for conducting research and for providing us with many helpful studies. We thank Stanley Fisher, Carmen Krewer, Jorge Lians, Andreas Mayer, Stefan Hesse, Joseph Hidler, George Hornby, Yun-Hee Kim, Zeev Meiner, Sinnika Peurala, Leopold Saltuari, Isabella Schwartz, Raymond Tong, John Brincks, Michael van Nunen, and Naoki Tanaka for providing additional information or unpublished data for their trials. 


\section{R E F E R E N C E S}

\section{References to studies included in this review}

Aschbacher 2006 \{unpublished data only\}

Aschbacher B. Comparing gait training in patients after stroke with task oriented physiotherapy or robot-assisted treadmill training: a feasibility study. Unpublished 2006.

\section{Bang 2016 \{published data only\}}

Bang DH, Shin WS. Effects of robot-assisted gait training on spatiotemporal gait parameters and balance in patients with chronic stroke: a randomized controlled pilot trial. NeuroRehabilitation 2016;38:343-9.

\section{Brincks 2011 \{published data only\}}

Brincks J. The order of gait training, including Lokomat ${ }^{\circledR}$ and Physiotherapy, does not influence gait symmetry in subacute ambulatory persons with stroke. Physiotherapy, Supplement S1, 16th World Congress of Physical Therapy, 2011 June 20-23 , Amsterdam. World Confederation of Physical Therapy, 2011; Vol. 97. [Number: RR-PO-208-17-Tue]

\section{Buesing 2015 \{published data only\}}

Buesing C, Fisch G, O'Donnell M, Shahidi I, Thomas L, Mummidisetty CK, et al. Effects of a wearable exoskeleton stride management assist system (SMA) on spatiotemporal gait characteristics in individuals after stroke: a randomized controlled trial. Journal of NeuroEngineering and Rehabilitation 2015; Vol. 12, issue 69.

\section{Chang 2012 \{published data only\}}

* Chang WH, Kim MS, Huh JP, Lee PK, Kim YH. Effects of robot-assisted gait training on cardiopulmonary fitness in subacute stroke patients: a randomized controlled study. Neurorehabilitation and Neural Repair 2012;26(4):318-24.

Kim M, Kim YH, Lee PKW, Hyong MK, Jung PH. Effect of robot-assisted gait therapy on cardiopulmonary fitness in subacute stroke patients. Neurorehabilitation and Neural Repair 2008;22:594.

\section{Cho 2015 \{published data only\}}

Cho DY, Park SW, Lee MJ, Park DS, Kim EJ. Effects of robotassisted gait training on the balance and gait of chronic stroke patients: focus on dependent ambulators. Journal of Physical Therapy Science 2015;27(10):3053-7. [0915-5287]

\section{Chua 2016 \{published data only\}}

Chua J, Culpan J, Menon E. Efficacy of an electromechanical gait trainer poststroke in Singapore: a randomized controlled trial. Archives of Physical Medicine and Rehabilitation 2016;97:683-90.

\section{Dias 2006 \{published data only\}}

* Dias D, Laíns J, Pereira A, Nunes R, Caldas J, Amaral C, et al. Partial body weight support in chronic hemiplegics: a randomized control trial. Europa Medicophysica 2007;43(4):499-504.
Fisher 2008 \{published and unpublished data\}

* Fisher S. Use of autoambulator for mobility improvement in patients with central nervous system (CNS) injury or disease. Neurorehabilitation and Neural Repair 2008;22:556.

Fisher S, Lucas L, Thrasher TA. Robot-assisted gait training for patients with hemiparesis due to stroke. Topics in Stroke Rehabilitation 2011;18(3):269-76.

\section{Forrester 2014 \{published data only\}}

Forrester LW, Roy A, Krywonis A, Kehs G, Krebs HI, Macko RF. Modular ankle robotics training in early subacute stroke: a randomized controlled pilot study. Neurorehabilitation and Neural Repair 2014; Vol. 28, issue 7:678-87. [1552-6844]

\section{Geroin 2011 \{published data only\}}

Geroin C, Picelli A, Munari D, Waldner A, Tomelleri C, Smania N. Combined transcranial direct current stimulation and robot-assisted gait training in patients with chronic stroke: a preliminary comparison. Clinical Rehabilitation 2011;25(6):537-48

\section{Han 2016 \{published data only\}}

Han EY, Im SH, Kim BR, Seo MJ, Kim MO. Robot-assisted gait training improves brachial-ankle pulse wave velocity and peak aerobic capacity in subacute stroke patients with totally dependent ambulation: Randomized controlled trial. Medicine 2016;95:e5078.

Hidler 2009 \{published data only (unpublished sought but not used)\}

Hidler J, Nichols D, Pelliccio M, Brady K, Campbell DD, Kahn JH, et al. Multicenter randomized clinical trial evaluating the effectiveness of the Lokomat in subacute stroke. Neurorehabilitation and Neural Repair 2009;23(1):5-13.

\section{Hornby 2008 \{published data only\}}

Hornby TG, Campbell DD, Kahn JH, Demott T, Moore JL, Roth HR. Enhanced gait-related improvements after therapistversus robotic-assisted locomotor training in subjects with chronic stroke: a randomized controlled study. Stroke 2008;39(6):1786-92.

\section{Husemann 2007 \{published data only\}}

Husemann B, Müller F, Krewer C, Laß A, Gille C, Heller S, et al. Effects of locomotion training with assistance of a driven gait orthosis in hemiparetic patients after stroke. Neurologie \& Rehabilitation 2004;10(4):25.

* Husemann B, Müller F, Krewer C, Laß A, Gille C, Heller S, et al. Effects of locomotion training with assistance of a robot-driven gait orthosis in hemiparetic patients after stroke: a randomized controlled pilot study. Stroke 2007;38(2):349-54.

Kim 2015 \{published data only\}

Kim S-Y, Yang L, Park IJ, Kim EJ, Park MS, You SH, et al. Effects of innovative WALKBOT robotic-assisted locomotor training on balance and gait recovery in hemiparetic stroke: a prospective, randomized, experimenter blinded case control study with a 
four-week follow-up. IEEE Transactions on Neural Systems \& Rehabilitation Engineering 2015;23(4):636-42. [1558-0210]

Kyung 2008 \{published and unpublished data\}

Jung KH, Ha HG, Shin HJ, Ohn SH, Sung DH, Lee PKW, et al. Effects of robot-assisted gait therapy on locomotor recovery in stroke patients. Journal of Korean Academy of Rehabilitation Medicine 2008;32:258-66.

* Kyung HJ, Kim YH. Effects of robot-assisted gait therapy on locomotor recovery in stroke patients. Asia-Oceanian Conference of Physical \& Rehabilitation Medicine; 2008 May 16-19; Nanjing, China. 2008.

\section{Mayr 2008 \{published and unpublished data\}}

Mayr A, Quirbach E, Picelli A, Kofler M, Smania N, Saltuari L. Effect of early robot-assisted gait retraining in nonambulatory patients with stroke: a single-blind randomized controlled trial. Unpublished 2016.

Mayr A, Saltuari L, Quirbach E. Impact of Lokomat training on gait rehabilitation. Neurorehabilitation and Neural Repair 2008;22(5):596.

\section{Morone 2011 \{published and unpublished data\}}

Morone G, Bragoni M, losa M, De Angelis D, Venturiero V, Coiro P, et al. Who may benefit from robotic-assisted gait training? A randomized clinical trial in patients with subacute stroke. Neurorehabilitation and Neural Repair 2011;25(7):636-44.

Noser 2012 \{published data only (unpublished sought but not used)\}

* NCT00975156. NCT00975156 [Improving ambulation post stroke with robotic training]. clinicaltrials.gov/show/ NCT00975156 (first received: 10 September 2009).

\section{Ochi 2015 \{published data only\}}

Ochi M, Wada F, Saeki S, Hachisuka K. Gait training in subacute non-ambulatory stroke patients using a full weight-bearing gaitassistance robot: a prospective, randomized, open, blindedendpoint trial. Journal of the Neurological Sciences 2015; Vol. 353 , issue 1-2:130-6. [1878-5883]

\section{Peurala 2005 \{published data only\}}

* Peurala S, Tarkka I, Pitkänen K, Sivenius J. The effectiveness of body weight-supported gait training and floor walking in patients with chronic stroke. Archives of Physical Medicine and Rehabilitation 2005;86:1557-64.

Peurala SH, Pitkanen K, Sivenius J, Tarkka I. Body-weight supported gait exercise compared with floor walking in chronic stroke patients. Archives of Physical Medicine and Rehabilitation 2004;85:E7.

Peurala SH, Pitkanen K, Sivenius J, Tarkka IM. Body-weight supported gait trainer exercises with or without functional electrical stimulation improves gait in patients with chronic stroke. Neurorehabilitation and Neural Repair 2006;20(1):98.

\section{Peurala 2009 \{published and unpublished data\}}

Peurala SH, Airaksinen O, Huuskonen P, Jäkälä P, Juhakoski M, Sandell K, et al. Effects of intensive therapy using Gait
Trainer or floorwalking exercises early after stroke. Journal of Rehabilitation Medicine 2009;41(3):166-73.

Picelli 2016 \{published data only\}

* Picelli A, Bacciga M, Melotti C, Marchina E, Verzini E, Ferrari F, et al. Combined effects of robot-assisted gait training and botulinum toxin type A effect on spastic equinus foot in patients with chronic stroke: a pilot, single blind, randomized controlled trial. European Journal of Physical and Rehabilitation Medicine 2016; Vol. 52, issue 6:759-766. [PUBMED: 27098300]

\section{Pohl 2007 \{published data only\}}

Pohl M, Werner C, Holzgraefe M, Kroczek G, Mehrholz J, Wingendorf I, et al. Repetitive locomotor training and physiotherapy improve walking and basic activities of daily living in subacute, non-ambulatory stroke patients: a single-blind, randomised multi-centre trial (DEutsche GAngtrainerStudie, DEGAS). Clinical Rehabilitation 2007;21(1):17-27.

\section{Saltuari 2004 \{published data only\}}

Saltuari L. Efficiency of Lokomat training in stroke patients. Neurologie \& Rehabilitation 2004;10(4):S4.

\section{Schwartz 2006 \{unpublished data only\}}

Schwartz I, Katz-Leurer M, Fisher I, Sajin A, Shochina M, Meiner Z . The effectiveness of early locomotor therapy in patients with first CVA. Collaborative Evaluation of Rehabilitation in Stroke Across Europe (CERISE) Congress; 2006 February 10-11; Leuven, Belgium. 2006.

\section{Stein 2014 \{published data only\}}

Stein J, Bishop L, Stein DJ, Wong CK. Gait training with a robotic leg brace after stroke. American Journal of Physical Medicine \& Rehabilitation 2014;93(11):987-94. [0894-9115]

\section{Tanaka 2012 \{published data only\}}

Tanaka N, Saitou H, Takao T, lizuka N, Okuno J, Yano H, et al. Effects of gait rehabilitation with a footpad-type locomotion interface in patients with chronic post-stroke hemiparesis: a pilot study. Clinical Rehabiilation 2012;26(8):686-95.

Tong 2006 \{published and unpublished data\}

Li LSW, Tong RYU, Ng MFW, So EFM. Effectiveness of gait trainer in stroke rehabilitation. Journal of the Neurological Sciences 2005;238(Suppl 1):S81.

Ng MFW, Tong RKY, Li LSW. A pilot study of randomized clinical controlled trial of gait training in subacute stroke patients with partial body-weight support electromechanical gait trainer and functional electrical stimulation: six-month follow-up. Stroke 2008;39:154-60.

Ng MFW, Tong RKY, So EFM, Li LSW. The therapeutic effect of electromechanical gait trainer and functional electrical stimulation for patients with acute stroke. Neurorehabilitation and Neural Repair 2006;20(1):97 (Abstract F1D-7).

* Tong RKY, Ng MF, Li LS. Effectiveness of gait training using an electromechanical gait trainer, with and without functional electric stimulation, in subacute stroke: a randomized 
controlled trial. Archives of Physical Medicine and Rehabilitation 2006;87(10):1298-304.

\section{Ucar 2014 \{published data only\}}

Uçar DE, Paker N, Buğdaycı D. Lokomat: a therapeutic chance for patients with chronic hemiplegia. NeuroRehabilitation 2014;34(3):447-53. [1053: 8135]

Van Nunen 2012 \{published data only\}

* Van Nunen M. RCT evaluating the effectiveness of robotassisted treadmill training in restoring walking ability of stroke patients. 7th World Congress of Neurological Rehabilitation; 2012 May 16-19; Melbourne, Australia. Melbourne: World Federation for Neurorehabilittaion, 2012:210. [Abstract ID: 537, Poster No. 296]

Van Nunen MPM, Gerrits KHL, Konijnenbelt M, Janssen TWJ, de Haan $A$. Recovery of walking ability using a robotic device in subacute stroke patients: a randomized controlled study. Disability \& Rehabilitation: Assistive Technology 2015;10(2):141-8. [1748-3107]

\section{Waldman 2013 \{published data only\}}

Waldman G, Yang C-Y, Ren Y, Liu L, Guo X, Harvey RL, et al. Effects of robot-guided passive stretching and active movement training of ankle and mobility impairments in stroke. NeuroRehabilitation. IOS Press, 2013; Vol. 32, issue 3:625-34. [1053-8135]

\section{Watanabe 2014 \{published data only\}}

Watanabe H, Tanaka N, Inuta T, Saitou H, Yanagi H. Locomotion improvement using a hybrid assistive limb in recovery phase stroke patients: a randomized controlled pilot study. Archives of Physical Medicine and Rehabilitation 2014;95(11):2006-12. [0003: 9993]

\section{Werner 2002 \{published data only\}}

Werner C, Von Frankenberg S, Treig T, Konrad M, Hesse S. Treadmill training with partial body weight support and an electromechanical gait trainer for restoration of gait in subacute stroke patients: a randomized crossover study. Stroke 2002;33(12):2895-901.

\section{Westlake 2009 \{published data only\}}

Westlake K, Patten C. Pilot study of Lokomat versus manualassisted treadmill training for locomotor recovery post-stroke. Journal of NeuroEngineering and Rehabilitation 2009;6:18. [DOI: 10.1186/1743-0003-6-18]

\section{References to studies excluded from this review}

\section{Bae 2014 \{published data only\}}

Bae Y, Ko Y, Chang W, Lee J, Lee K, Park Y, et al. Effects of robotassisted gait training combined with functional electrical stimulation on recovery of locomotor mobility in chronic stroke patients: a randomized controlled trial. Journal of Physical Therapy Science 2014; Vol. 26, issue 12:1949-53. [0915: 5287]

Byun 2011 \{published data only\}

Byun SD, Jung TD, Kim CH, Lee YS. Effects of the sliding rehabilitation machine on balance and gait in chronic stroke patients - a controlled clinical trial. Clinical Rehabilitation 2011;25(5):408-15. [1477-0873: (Electronic)]

Caldwell 2000 \{published data only\}

Caldwell C, Medley A. Effects of bicycling, treadmill, and variable surfaces on gait in people following a CVA. Neurology Report 2000;24(5):203.

Danzl 2013 \{published data only\}

Danzl MM, Chelette KC, Lee K, Lykins D, Sawaki L. Brain stimulation paired with novel locomotor training with robotic gait orthosis in chronic stroke: a feasibility study. NeuroRehabilitation 2013;33(1):67-76. [1053-8135]

David 2006 \{published data only\}

David D, Regnaux JP, Lejaille M, Louis A, Bussel B, Lofasso F. Oxygen consumption during machine-assisted and unassisted walking: a pilot study in hemiplegic and healthy humans. Archives of Physical Medicine and Rehabilitation 2006;87:482-9.

\section{Forrester 2016 \{published data only\}}

Forrester LW, Roy A, Hafer-Macko C, Krebs HI, Macko RF. Taskspecific ankle robotics gait training after stroke: a randomized pilot study. Journal of NeuroEngineering and Rehabilitation 2016; Vol. 13, issue 51.

\section{Gong 2003 \{published data only\}}

Gong S, Zhang J. Effect of early rehabilitation training on daily life activity of patients with hemiplegia after stroke. Chinese Journal of Clinical Rehabilitation 2003;7(5):848-9.

\section{Goodman 2014 \{published data only\}}

Goodman R, Rietsehel J, Roy A, Jung B, Diaz J, Macko R, et al. Increased reward in ankle robotics training enhances motor control and cortical efficiency in stroke. Journal of Rehabilitation Research and Development 2014; Vol. 51, issue 2:213-7. [0748: 7711]

\section{Hesse 2001 \{published data only\}}

Hesse S, Werner C, Uhlenbrock D, von Frankenberg S, Bardeleben A, Brandl-Hesse B. An electromechanical gait trainer for restoration of gait in hemiparetic stroke patients: preliminary results. Neurorehabilitation and Neural Repair 2001;15:37-48.

\section{Hsieh 2014 \{published data only\}}

Hsieh YW, Lin KC, Horng YS, Wu CY, Wu TC, Ku FL. Sequential combination of robot-assisted therapy and constraint-induced therapy in stroke rehabilitation: a randomized controlled trial. Journal of Neurology 2014, (5):1037-45.

\section{Mirelman 2009 \{published data only\}}

Mirelman A, Bonato P, Deutsch JE. Effects of training with a robot-virtual reality system compared with a robot alone on the gait of individuals after stroke. Stroke 2009;40(1):169-74.

\section{Morone 2016 \{published data only\}}

Morone G, Annicchiarico R, losa M, Federici A, Paolucci S, Cortes $\mathrm{U}$, et al. Overground walking training with the i-Walker, a robotic servo-assistive device, enhances balance in patients 
with subacute stroke: a randomized controlled trial. Journal of NeuroEngineering and Rehabilitation 2016;13(47).

NCT01337960 \{published data only\}

NCT01337960. Ankle robotics training after stroke. clinicaltrials.gov/show/NCT01337960 (first received 15 April 2011).

\section{Page 2008 \{published data only\}}

Page SJ, Levine P, Teepen J, Hartman EC. Resistance-based, reciprocal upper and lower limb locomotor training in chronic stroke: a randomized, controlled crossover study. Clinical Rehabilitation 2008;22(7):610-7.

Park 2015 \{published data only\} Park BS, Kim MY, Lee LK, Yang SM, Lee WD, Kim J. Effects of conventional overground gait training and a gait trainer with partial body weight support on spatiotemporal gait parameters of patients after stroke. Journal of Physical Therapy Science 2015;27:1603-7.

\section{Patten 2006 \{published data only\}}

* Westlake KP, Patten C. Pilot study of Lokomat versus manualassisted treadmill training for locomotor recovery post-stroke. Journal of NeuroEngineering and Rehabilitation 2009;6:18.

\section{Pennati 2015 \{published data only\}}

Pennati GV, Da Re C, Messineo I, Bonaiuti D. How could robotic training and botulinum toxin be combined in chronic post stroke upper limb spasticity? A pilot study. European Journal of Physical \& Rehabilitation Medicine 2015;51(4):381-7. [1973-9095]

\section{Picelli 2015 \{published data only\}}

Picelli A, Chemello E, Castellazzi P, Roncari L, Waldner A, Saltuari $\mathrm{L}$, et al. Combined effects of transcranial direct current stimulation (tDCS) and transcutaneous spinal direct current stimulation (tsDCS) on robot-assisted gait training in patients with chronic stroke: a pilot, double blind, randomized controlled trial. Restorative Neurology \& Neuroscience 2015;33(3):357-68. [1878-3627]

\section{Pitkanen 2002 \{published data only\}}

* Pitkanen K, Tarkka I, Sivenius J. Walking training with partial body weight support versus conventional walking training of chronic stroke patients: preliminary findings. Neurorehabilitation and Neural Repair 2001;15(4; SupplementAbstracts 3rd World Conference On Neurorehabilitation; April 2-6, 2002 Venice, Italy):312. [http:// journals.sagepub.com/doi/pdf/10.1177/154596830101500402]

\section{Richards 1993 \{published data only\}}

Richards CL, Malouin F, Wood-Dauphinee S, Williams JI, Bouchard JP, Brunet D. Task-specific physical therapy for optimization of gait recovery in acute stroke patients. Archives of Physical Medicine and Rehabilitation 1993;74:612-20.

\section{Richards 2004 \{published data only\}}

Richards CL, Malouin F, Bravo G, Dumas F, Wood-Dauphinee S. The role of technology in task-oriented training in persons with subacute stroke: a randomized controlled trial. Neurorehabilitation and Neural Repair 2004;18(4):199-211.

\section{Shirakawa 2001 \{published data only\}}

Shirakawa R, Uchida SU, Okajima YO, Sakaki TS, Shutou HS. Therapeutic effects of power-assist training combined with biofeedback on hemiplegia by Therapeutic Exercise Machine (TEM). 1st International Congress of International Society of Physical and Rehabilitation Medicine (ISPRM); 2001 July 7-13; Amsterdam. 2001.

Skvortsova 2008 \{published data only (unpublished sought but not used)\}

Skvortsova VI, Ivanova GE, Kovrazhkina EA, Rumiantseva NA, Staritsyn AN, Suvorov Alu, et al. The use of a robot-assisted Gait Trainer GT1 in patients in the acute period of cerebral stroke: a pilot study. Zhurnal nevrologii i psikhiatrii imeni S.S. Korsakova 2008;Suppl 23:28-34.

* Skvortsova VI, Ivanova GE, Kovrazhkina EA, Rumyantseva NA, Staritsin AN, Sogomonyan EK. The efficacy of gait rehabilitation after stroke training with assistance of a robotic device gait trainer: a pilot study. International Journal of Stroke 2008;3(Suppl 3):355.

\section{Stoller 2015 \{published data only\}}

Stoller O, De Bruin ED, Schindelholz M, Schuster-Amft C, De Bie RA, Hunt KJ. Feedback-controlled robotics-assisted treadmill exercise for cardiovascular training and assessment early after severe stroke. Cerebrovascular Diseases 2015;39:107. [1015-9770]

Stoller O, de Bruin E, Schindelholz M, Schuster-Amft C, de Bie R, Hunt KJ. Efficacy of feedback-controlled robotics-assisted treadmill exercise to improve cardiovascular fitness early after stroke. Journal of Neurologic Physical Therapy 2015;39(3):156.

\section{Wu 2014 \{published data only\}}

Wu M, Landry J, Kim J, Schmit B, Yen S, MacDonald J. Robotic resistance/assistance training improves locomotor function in individuals poststroke: A randomized controlled study. Archives of Physical Medicine and Rehabilitation 2014; Vol. 95, issue 5:799-806. [0003: 9993]

\section{References to studies awaiting assessment}

\section{Chernikova 2014 \{published data only\}}

Chernikova LA, Klochkov AS. The influence of physical training with the use of a Lokomat robotic system on the walking ability of the patients with post-stroke hemiparesis. Voprosy Kurortologii, Fizioterapii i Lechebnoi Fizicheskoi Kultury 2014, issue 3:13-7. [0042-8787]

\section{Globokar 2005 \{published data only\}}

Globokar D. Gait trainer in neurorehabilitation of patients after stroke. 3rd World Congress of the International Society of Physical and Rehabilitation Medicine ISPRM; 2005 April 10-15; Sao Paulo, Brazil. Sao Paulo, Brazil, 2005:987-1.

Golyk 2006 \{published data only (unpublished sought but not used)\}

Golyk VA, Pivnyk AP, Ipatov AV. Constraint-induced movement therapy for walking improvement (comparison of two walking 
training machine modifications' efficacy) for stroke patients. European Journal of Neurology 2006;13(Suppl 2):263.

Jang 2005 \{published data only\}

Jang SJ, Park SW, Kim ES, Wee HM, Kim YH. Electromechanical gait trainer for restoring gait in hemiparetic stroke patients. 3rd World Congress of the International Society of Physical and Rehabilitation Medicine ISPRM; 2005 April 10-15; Sao Paulo, Brazil. Sao Paulo, Brazil, 2005:909-1.

Kim 2001 \{published data only\}

Kim BO, Lee JJ, Cho KH, Kim SH. Gait training robot (gaiTrainer) in rehabilitation. 1st International Congress of International Society of Physical and Rehabilitation Medicine (ISPRM); 2001 July 7-13; Amsterdam. 2001. [Abstract Th.139.P]

\section{Kim 2014 \{published data only\}}

Kim JH, Park HI, Jang CH, Lim YH. Effects of robot-assisted therapy on lower limb in geriatric patients with subacute stroke. European Geriatric Medicine 2014; Vol. 5, issue Supplement 1:S174. [DOI: 10.1016/S1878-7649(14)70458-9]

Koeneman 2004 \{published data only (unpublished sought but not used)\}

Koeneman JB. Air muscle device for ankle stroke rehabilitation. www.sbir.gov/sbirsearch/detail/210093 (accessed May 2017).

Mehrberg 2001 \{published data only (unpublished sought but not used)\}

Mehrberg RD, Flick C, Dervay J, Carmody J, Carrington C, Jermer M. Clinical evaluation of a new over ground partial body weight support assistive device in hemiparetic stroke patients. Archives of Physical Medicine and Rehabilitation 2001;82:1293 (Abstract 10).

\section{Ohata 2015 \{published data only\}}

Ohata K, Tsuboyama T, Watanabe A, Takahashi H. Gait training using new robotics device for patients with hemiplegia after stroke: a randomized cross-over trial. Physiotherapy 2015;101:eS1123-4. [0031-9406]

\section{Sale 2012 \{published data only\}}

NCT01678547. Robot Walking Rehabilitation in Stroke Patients. clinicaltrials.gov/show/NCT01678547 (date first received 31 August 2012. [NCT01678547]

\section{Wu 2012 \{published data only\}}

Wu H, Gu XD, Fu JM, Yao YH, Li JH, Xu ZS. Effects of rehabilitation robot for lower-limb on motor function in hemiplegic patients after stroke. National Medical Journal of China 2012, issue 37:2628-31.

Yoon 2015 \{published data only\}

Yoon Y, Seok TY, Yu K, Lee KJ, Kang SK, Yun SB. Gait training with the newly developed active-assistive system for gait is feasible for hemiplegic patients after stroke. PM\&R 2015; Vol. 1:S115-6. [193-4148]

\section{Zhu 2016 \{published data only\}}

Zhu L, Song W, Liu L, Zhang R, Zhang Y. Rehabilitation effect of lower limb rehabilitation training robot combined with task-oriented training on walking ability after stroke. Chinese Journal of Cerebrovascular Diseases 2016; Vol. 13, issue 5:240-4 and 248. [1672-5921]

\section{References to ongoing studies}

Louie 2015 \{published data only\}

* Louie DR, Eng JJ, Mortenson WB, Yao J. Use of a powered robotic exoskeleton to promote walking recovery after stroke: study protocol for a randomized controlled trial. International Journal of Stroke. 2015; Vol. 10, Supplement 4:89. [http:// onlinelibrary.wiley.com/doi/10.1111/ijs.12633_2/pdf]

\section{NCT00284115 \{unpublished data only\}}

Brissot R, Laviolle B. Efficacy of a mechanical gait repetitive training technique in hemiparetic stroke patients. www.clinicaltrials.gov (last accessed September 2016).

\section{NCT00530543 \{published data only\}}

NCT00530543. Effects of gait training with assistance of a robot-driven gait orthosis in hemiparetic patients after stroke. clinicaltrials.gov 2007.

\section{NCT01146587 \{published data only\}}

Waldner A. Robot assisted therapy for acute stroke patients: a comparative study of GangTrainer GT I, Lokomat system and conventional physiotherapy. www.clinicaltrials.gov (last accessed September 2016).

\section{NCT01187277 \{published data only\}}

Chanubol R. Robotic versus conventional training on hemiplegic gait. www.clinicaltrials.gov (last accessed September 2016).

* Chanubol R, Wongphaet P, Werner C, Chavanich N, Panichareon L. Gait rehabilitation in subacute hemiparetic stroke: robot-assisted gait training versus conventional physical therapy. Journal of the Neurological Sciences 2013; Vol. 333, issue Suppl 1:e574.

\section{NCT01678547 \{published data only\}}

Sale P. Effect of robot assisted treatment on gait performance in stroke patients. www.clinicaltrials.gov (last accessed December 2012).

\section{NCT01726998 \{published data only\}}

NCT01726998. Effects of locomotion training with assistance of a robot-driven gait orthosis in hemiparetic patients after subacute stroke. www.clinicaltrials.gov 2014.

\section{NCT02114450 \{published data only\}}

NCT02114450. Human-machine system for the H2 lower limb exoskeleton. www.clinicaltrials.gov 2016.

\section{NCT02471248 \{published data only\}}

NCT02471248. Interactive exoskeleton robot for walking - ankle joint. www.clinicaltrials.gov 2016.

\section{NCT02483676 \{published data only\}}

NCT02483676. Ankle robot to reduce foot-drop in stroke. www.clinicaltrials.gov 2016. 


\section{NCT02545088 \{published data only\}}

NCT02545088. New technology for individualised, intensive training of gait after stroke - study II (HAL-RCT-II). www.clinicaltrials.gov 2015.

\section{NCT02680691 \{published data only\}}

NCT02680691. Robot assisted gait training in patients with infratentorial stroke. www.clinicaltrials.gov 2016.

\section{NCT02694302 \{published data only\}}

NCT02694302. Clinical trial of robot-assisted-gait-training (RAGT) in stroke patients. www.clinicaltrials.gov 2016.

\section{NCT02755415 \{published data only\}}

NCT02755415. Clinical applicability of robot-assisted gait training system in acute stroke patients. www.clinicaltrials.gov 2016.

\section{NCT02781831 \{published data only\}}

NCT02781831. Robot-assisted gait training for patients with stroke. www.clinicaltrials.gov 2016.

\section{NCT02843828 \{published data only\}}

NCT02843828. Gait pattern analysis and feasibility of gait training with a walking assist robot in stroke patients and elderly adults. www.clinicaltrials.gov 2016.

\section{Additional references}

\section{Adams 1993}

Adams HP Jr, Bendixen BH, Kappelle LJ, Biller J, Love BB, Gordon DL, et al. Classification of subtype of acute ischemic stroke: definitions for use in a multicenter clinical trial (TOAST: Trial of Org 10172 in Acute Stroke Treatment). Stroke 1993;24(1):35-41.

\section{Atkins 2004}

Atkins D, Best D, Briss PA, Eccles M, Falck-Ytter Y, Flottorp S, et al. Grading quality of evidence and strength of recommendations. BMJ 2004;328:1490.

\section{Bohannon 1988}

Bohannon R. Rehabilitation goals of patients with hemiplegia. International Journal of Rehabilitation Research 1988;11(2):181-3.

\section{Bohannon 1991}

Bohannon RW, Horton MG, Wikholm JB. Importance of four variables of walking to patients with stroke. International Journal of Rehabilitation Research 1991;14:246-50.

\section{Carr 2003}

Carr J, Shepherd R. Stroke Rehabilitation: Guidelines for Exercises and Training. London: Butterworth Heinemann, 2003.

\section{Collen 1991}

Collen FM, Wade DT, Robb GF, Bradshaw CM. The Rivermead Mobility Index: a further development of the Rivermead Motor Assessment. International Disability Studies 1991;13(2):50-4.

\section{Colombo 2000}

Colombo G, Joerg M, Schreier R, Dietz V. Treadmill training of paraplegic patients using a robotic orthosis. Journal of Rehabilitation Research and Development 2000;37(6):693-700.

\section{Deeks 2011}

Deeks JJ, Higgins JPT, Altman DG. Chapter 9: Analysing data and undertaking meta-analyses. In: Higgins JPT, Green S (editors). Cochrane Handbook for Systematic Reviews of Interventions Version 5.1.0 [updated March 2011]. The Cochrane Collaboration, 2011. Available from handbook.cochrane.org.

\section{Freivogel 2009}

Freivogel S, Schmalohr D, Mehrholz J. Improved walking ability and reduced therapeutic stress with an electromechanical gait device. Journal of Rehabilitation Medicine 2009;41:734-9.

\section{French 2007}

French B, Thomas LH, Leathley MJ, Sutton CJ, McAdam J, Forster A. Repetitive task training for improving functional ability after stroke. Cochrane Database of Systematic Reviews 2007, Issue 4. [DOI: 10.1002/14651858.CD006073.pub2]

\section{French 2016}

French B, Thomas LH, Coupe J, McMahon NE, Connell L, Harrison J, et al. Repetitive task training for improving functional ability after stroke. Cochrane Database of Systematic Reviews 2016, Issue 11. [DOI: 10.1002/14651858.CD006073.pub3]

\section{GRADEpro GDT [Computer program]}

McMaster University (developed by Evidence Prime, Inc.). Available from gradepro.org. GRADEpro GDT: GRADEpro Guideline Development Tool. McMaster University (developed by Evidence Prime, Inc.). Available from gradepro.org, 2015.

\section{Hamilton 1994}

Hamilton BB, Laughlin JA, Fiedler RC, Granger CV. Interrater reliability of the 7-level functional independence measure (FIM). Scandinavian Journal of Rehabilitation Medicine 1994;26(3):115-9.

\section{Hesse 1999}

Hesse S, Sarkodie-Gyan T, Uhlenbrock D. Development of an advanced mechanised gait trainer, controlling movement of the centre of mass, for restoring gait in non-ambulant subjects. Biomedizinische Technik [Biomedical Engineering] 1999;44(7-8):194-201.

\section{Hesse 2003}

Hesse S, Schmidt H, Werner C, Bardeleben A. Upper and lower extremity robotic devices for rehabilitation and for studying motor control. Current Opinion in Neurology 2003;16(6):705-10.

\section{Hesse 2010}

Hesse S, Waldner A, Tomelleri C. Innovative gait robot for the repetitive practice of floor walking and stair climbing up and down in stroke patients. Journal of NeuroEngineering and Rehabilitation 2010;7:30. 


\section{Higgins 2011a}

Higgins JPT, Altman DG, Sterne JAC (editors). Chapter 8: Assessing risk of bias in included studies. In: Higgins JPT, Green $S$ (editors). Cochrane Handbook for Systematic Reviews of Interventions Version 5.1.0 [updated March 2011]. The Cochrane Collaboration, 2011. Available from handbook.cochrane.org.

\section{Higgins 2011b}

Schünemann HJ, Oxman AD, Vist GE, Higgins JPT, Deeks JJ, Glasziou P, et al. Chapter 12: Interpreting results and drawing conclusions. In: Higgins JPT, Green S (editors). Cochrane Handbook for Systematic Reviews of Interventions Version 5.1.0 [updated March 2011]. The Cochrane Collaboration, 2011. Available from handbook.cochrane.org.

\section{Holden 1984}

Holden MK, Gill KM, Magliozzi MR, Nathan J, PiehlBaker L. Clinical gait assessment in the neurologically impaired: reliability and meaningfulness. Physical Therapy 1984;64(1):35-40.

\section{Jorgensen 1995}

Jorgensen H, Nakayama H, Raaschou H, Olsen T. Recovery of walking function in stroke patients: the Copenhagen stroke study. Archives of Physical Medicine and Rehabilitation 1995;76:27-32.

\section{Kelley 2013}

Kelley CP, Childress J, Boake C, Noser EA. Over-ground and robotic-assisted locomotor training in adults with chronic stroke: a blinded randomized clinical trial. Disability \& Rehabilitation: Assistive Technology. Philadelphia, Pennsylvania: Taylor \& Francis Ltd, 2013; Vol. 8, issue 2:161-8. [1748-3107]

\section{Kim 2008}

Kim M, Kim YH, Lee PKWY, Hyong MK, Jung PH. Effect of robot-assisted gait therapy on cardiopulmonary fitness in subacute stroke patients. Neurorehabilitation and Neural Repair 2008;22:594

\section{Kwakkel 1999}

Kwakkel G, Wagenaar RC, Twisk JW, Lankhorst GJ, Koetsier JC. Intensity of leg and arm training after primary middle-cerebralartery stroke: a randomised trial. Lancet 1999;354(9174):191-6.

\section{Louie 2016}

Louie DR, Eng JJ. Powered robotic exoskeletons in poststroke rehabilitation of gait: a scoping review. Journal of NeuroEngineering and Rehabilitation 2016; Vol. 13, issue 1:1-10. [MEDLINE: Louie2016; 1743-0003]

\section{Mehrholz 2012a}

Mehrholz J, Pohl M. Electromechanical-assisted gait training after stroke: a systematic review comparing end-effector and exoskeleton devices. Journal of Rehabilitation Medicine 2012;44(3):193-9.

\section{Mehrholz 2012b}

Mehrholz J, Hädrich A, Platz T, Kugler J, Pohl M. Electromechanical and robot-assisted arm training for improving generic activities of daily living, arm function, and arm muscle strength after stroke. Cochrane Database of Systematic Reviews 2012, Issue 6. [DOI: 10.1002/14651858.CD006876.pub3]

\section{Mehrholz 2014}

Mehrholz J, Pohl M, Elsner B. Treadmill training and body weight support for walking after stroke. Cochrane Database of Systematic Reviews 2014, Issue 1. [DOI: 10.1002/14651858.CD002840.pub3]

\section{MIT 2005}

Massachusetts Institute of Technology. MIT develops Anklebot for stroke patients. web.mit.edu/newsoffice/2005/strokerobot.html (accessed 20 December 2005).

\section{Nuyens 2002}

Nuyens GE, De Weerdt WJ, Spaepen AJ Jr, Kiekens C, Feys HM. Reduction of spastic hypertonia during repeated passive knee movements in stroke patients. Archives of Physical Medicine and Rehabilitation 2002;83(7):930-5.

\section{Pollock 2014}

Pollock A, Farmer SE, Brady MC, Langhorne P, Mead GE, Mehrholz J. Interventions for improving upper limb function after stroke. Cochrane Database of Systematic Reviews 2014, Issue 11. [DOI: 10.1002/14651858.CD010820.pub2]

\section{RevMan 2014 [Computer program]}

The Nordic Cochrane Centre, The Cochrane Collaboration. Review Manager (RevMan). Version 5.3. Copenhagen: The Nordic Cochrane Centre, The Cochrane Collaboration, 2014.

\section{Sackett 1996}

Sackett DL, Deeks JJ, Altman DG. Down with odds ratios!. Evidence-based Medicine 1996;1:164-6.

\section{Schmidt 2005}

Schmidt $\mathrm{H}$, Hesse S, Bernhardt R, Krüger J. HapticWalker - a novel haptic foot device. ACM Transactions on Applied Perception 2005;2(2):166-80.

\section{States 2009}

States RA, Pappas E, Salem Y. Overground physical therapy gait training for chronic stroke patients with mobility deficits. Cochrane Database of Systematic Reviews 2009, Issue 3. [DOI: 10.1002/14651858.CD006075.pub2]

\section{Van Peppen 2004}

Van Peppen RP, Kwakkel G, Wood-Dauphinee S, Hendriks HJ, Van der Wees PJ, Dekker J. The impact of physical therapy on functional outcomes after stroke: what's the evidence?. Clinical Rehabilitation 2004;18(8):833-62.

\section{Veneman 2005}

Veneman J, Kruidhof R, van der Helm FCT, van der Kooy H. Design of a Series Elastic- and Bowdencable-based actuation system for use as torque-actuator in exoskeleton-type training robots. International Conference on Rehabilitation Robotics; 2005 June 28-July 1; Chicago (IL). 2005. 


\section{Wade 1988}

Wade DT, Collin C. The Barthel ADL Index: a standard measure of physical disability?. International Disability Studies 1988;10(2):64-7.

\section{WHO 2006}

World Health Organization. Cerebrovascular accident, stroke. www.who.int/topics/cerebrovascular_accident/en/ (accessed 1 February 2006).

\section{References to other published versions of this review \\ Mehrholz 2006}

Mehrholz J, Werner C, Kugler J, Pohl M. Electromechanicalassisted training for walking after stroke [Protocol].

\section{CHARACTERISTICS OF STUDIES}

Characteristics of included studies [ordered by study ID]
Cochrane Database of Systematic Reviews 2006, Issue 4. [DOI: 10.1002/14651858.CD006185]

\section{Mehrholz 2007}

Mehrholz J, Werner C, Kugler J, Pohl M. Electromechanicalassisted training for walking after stroke. Cochrane Database of Systematic Reviews 2007, Issue 4. [DOI: 10.1002/14651858.CD006185.pub2]

\section{Mehrholz 2013}

Mehrholz J, Elsner B, Werner C, Kugler J, Pohl M.

Electromechanical-assisted training for walking after stroke. Cochrane Database of Systematic Reviews 2013, Issue 7. [DOI: 10.1002/14651858.CD006185.pub3]

* Indicates the major publication for the study

\section{Aschbacher 2006}

$\begin{array}{ll}\text { Methods } & \text { RCT } \\ \text { Method of randomisation: not stated } \\ \text { Blinding of outcome assessors: stated as 'yes' by the investigator } \\ \text { Adverse events: not stated } \\ \text { Deaths: not stated } \\ \text { Dropouts: } 4 \text { ( } 1 \text { in treatment group, } 3 \text { in control group) } \\ \text { ITT: unclear }\end{array}$

Country: Switzerland
23 participants (12 in treatment group, 11 in control group)
Not ambulatory at start of study
Mean age: 57 to 67 years (control and treatment groups, respectively)
Inclusion criteria: $\leq 3$ months after stroke, ability to stand or walk 5 metres
Exclusion criteria: orthopaedic problems, contractures, NYHA III-IV

\begin{tabular}{ll}
\hline Interventions & $\begin{array}{l}\text { arms: } \\
\text { - Control group used task-oriented physiotherapy, } 5 \text { times a week for } 3 \text { weeks (2.5 hours a week) } \\
\text { - Experimental group used robotic-assisted treadmill training (Lokomat) for the same time and fre- } \\
\text { quency }\end{array}$ \\
\hline Outcomes & $\begin{array}{l}\text { Outcomes were recorded at baseline and after } 3 \text { weeks and } 6 \text { months } \\
\text { Primary outcomes: walking velocity, step length, endurance, walking ability (FAC) } \\
\text { Secondary outcomes: isometric knee extension strength, patient acceptance and satisfaction (visual } \\
\text { analogue scale) }\end{array}$ \\
\hline Notes & Unpublished data \\
\hline
\end{tabular}

\section{Risk of bias}

\begin{tabular}{lll}
\hline Bias & Authors' judgement & Support for judgement \\
\hline $\begin{array}{l}\text { Random sequence genera- } \\
\text { tion (selection bias) }\end{array}$ & Unclear risk & Method of randomisation not described \\
\hline
\end{tabular}


Aschbacher 2006 (Continued)

$\begin{aligned} & \text { Allocation concealment } \\ & \text { (selection bias) }\end{aligned}$
Unclear risk Not described

\begin{tabular}{lll}
\hline $\begin{array}{l}\text { Blinding of outcome as- } \\
\text { sessment (detection bias) } \\
\text { All outcomes }\end{array}$ & Unclear risk & Unclear \\
\hline $\begin{array}{l}\text { Incomplete outcome data } \\
\text { (attrition bias) }\end{array}$ & Unclear risk & Unclear \\
All outcomes & & \\
\hline
\end{tabular}

Bang 2016

\begin{tabular}{ll}
\hline Methods & RCT \\
Method of randomisation: opaque, closed envelopes & Blinding of outcome assessors: stated as 'yes' by the investigator \\
Adverse events: not stated \\
Deaths: not stated \\
Dropouts: no
\end{tabular}

Outcomes

Outcomes were recorded at baseline and after 2 weeks.

Outcome measures: gait speed, cadence, step length, double support period (GAITRite system), balance, level of balance confidence (ABC scale)

Notes

\section{Risk of bias}

Bias Authors' judgement Support for judgement

Random sequence genera- Low risk tion (selection bias)

The randomisation was performed by selection of an opaque, closed envelope in which the group assignment was written, which was given to the physical therapist.

\begin{tabular}{lll}
\hline $\begin{array}{l}\text { Allocation concealment } \\
\text { (selection bias) }\end{array}$ & Low risk sealed envelopes
\end{tabular}


Bang 2016 (Continued)

Blinding of outcome as- Low risk Described as blinded by an assessor not participating in study sessment (detection bias)

All outcomes

Incomplete outcome data Low risk No dropouts
(attrition bias)

All outcomes

\section{Brincks 2011}

\begin{tabular}{|c|c|}
\hline Methods & $\begin{array}{l}\text { Randomised cross-over trial } \\
\text { Method of randomisation: shuffled envelopes } \\
\text { Blinding of outcome assessors: no } \\
\text { Adverse events: none } \\
\text { Deaths: none } \\
\text { Dropouts: none } \\
\text { ITT: yes }\end{array}$ \\
\hline Participants & $\begin{array}{l}\text { Country: Denmark } \\
13 \text { participants ( } 7 \text { in treatment group, } 6 \text { in control group) } \\
\text { All participants were ambulatory at start of study } \\
\text { Mean age: } 59 \text { to } 61 \text { years (control and treatment groups, respectively) } \\
\text { Inclusion criteria: unknown } \\
\text { Exclusion criteria: unknown }\end{array}$ \\
\hline
\end{tabular}

$\begin{array}{ll}\text { Outcomes } & \text { Outcomes were recorded at baseline, after } 3 \text { and } 6 \text { weeks } \\ & \text { Primary outcomes: single support stance time in impaired extremity and gait asymmetry and swing } \\ & \text { time ratio } \\ & \text { Secondary outcomes: walking speed }\end{array}$

Notes

\section{Risk of bias}

\begin{tabular}{|c|c|c|}
\hline Bias & Authors' judgement & Support for judgement \\
\hline $\begin{array}{l}\text { Random sequence genera- } \\
\text { tion (selection bias) }\end{array}$ & Low risk & Shuffling envelopes \\
\hline $\begin{array}{l}\text { Allocation concealment } \\
\text { (selection bias) }\end{array}$ & Low risk & Using sealed, shuffled envelopes \\
\hline $\begin{array}{l}\text { Blinding of outcome as- } \\
\text { sessment (detection bias) } \\
\text { All outcomes }\end{array}$ & High risk & No blinding was done. \\
\hline $\begin{array}{l}\text { Incomplete outcome data } \\
\text { (attrition bias) } \\
\text { All outcomes }\end{array}$ & Low risk & ITT \\
\hline
\end{tabular}




$\begin{array}{ll}\text { Methods } & \text { RCT } \\ & \text { Method of randomisation: random number generator } \\ & \text { Blinding of outcome assessors: stated as 'yes' by the investigator } \\ \text { Adverse events: no adverse events } \\ \text { Deaths: not stated } \\ \text { Dropouts: none }\end{array}$

$\begin{array}{ll}\text { Outcomes } & \text { Outcomes were recorded at baseline and after visit } 10 \text { and 18, 3-month follow-up } \\ \text { Outcome measures: gait velocity, cadence, step time, step length, stride length, swing time, stance } \\ \text { time, double support time (GAITRite) }\end{array}$

Notes NCT01994395

\section{Risk of bias}

Bias Authors' judgement Support for judgement

Random sequence genera- Low risk Method of randomisation described as "random number generator". tion (selection bias)

Allocation concealment $\quad$ High risk $\quad$ Allocation concealment not described.
(selection bias)

\begin{tabular}{|c|c|c|}
\hline $\begin{array}{l}\text { Blinding of outcome as- } \\
\text { sessment (detection bias) }\end{array}$ & Low risk & $\begin{array}{l}\text { Evaluated by a research physical therapist, who was blinded to the partici- } \\
\text { pant's training group }\end{array}$ \\
\hline
\end{tabular}

All outcomes pant's training group

Incomplete outcome data Low risk No dropouts
(attrition bias)

All outcomes

\section{Chang 2012}

$\begin{array}{ll}\text { Methods } & \text { RCT } \\ \text { Method of randomisation: not stated } \\ \text { Blinding of outcome assessors: not stated } \\ \text { Adverse events: not stated } \\ \text { Deaths: not stated } \\ \text { Dropouts: } 3 \text { (2 in experimental group, } 1 \text { in control group) }\end{array}$


Chang 2012 (Continued)

ITT analysis: not described

\begin{tabular}{l} 
Participants \\
$\begin{array}{l}\text { Country: Republic of Korea } \\
38 \text { participants were non-ambulatory at start of study } \\
\text { Mean age: } 58 \text { years } \\
\text { Inclusion criteria: first-ever stroke, stroke onset within } 1 \text { month, supratentorial lesion, age }>20 \text { years } \\
\text { and }<65 \text { years, not an independent ambulator (FAC }<2 \text { ), and ability to co-operate during exercise test- } \\
\text { ing } \\
\text { Exclusion criteria: people who met criteria for absolute and relative contraindications to exercise test- } \\
\text { ing established by the American College of Sports Medicine (ACSM) were excluded. Also, people who } \\
\text { met contraindications for Lokomat therapy or musculoskeletal disease involving the lower limbs, such } \\
\text { as severe painful arthritis, osteoporosis, or joint contracture and other neurological diseases, were also } \\
\text { excluded } \\
\text { 2 arms: } \\
\text { - Robotic gait trainer (Lokomat) } 40 \text { minutes per day, and } 60 \text { minutes conventional physiotherapy for } \\
10 \text { days } \\
\text { Conventional physiotherapy, same sessions of conventional gait training by physical therapist }\end{array}$ \\
\hline Interventions
\end{tabular}

\begin{tabular}{ll} 
Outcomes & Outcomes were recorded at baseline and after training: \\
- FAC \\
- Exercise and gas exchange capacity \\
- Cardiopulmonary function \\
- Fugl-Meyer Assessment \\
- Motricity Index \\
\hline This study describes the same study protocol and participants as described in the study Kim 2008, but \\
provides further explanation of participant characteristics; the ID Chang 2012 therefore replaces the \\
formerly review used ID Kim 2008.
\end{tabular}

\section{Risk of bias}

\begin{tabular}{lll}
\hline Bias & Authors' judgement & Support for judgement \\
\hline $\begin{array}{l}\text { Random sequence genera- } \\
\text { tion (selection bias) }\end{array}$ & Unclear risk & Method of randomisation is unclear. \\
\hline $\begin{array}{l}\text { Allocation concealment } \\
\text { (selection bias) }\end{array}$ & Unclear risk & Method of concealment is unclear. \\
\hline $\begin{array}{l}\text { Blinding of outcome as- } \\
\text { sessment (detection bias) } \\
\text { All outcomes }\end{array}$ & High risk & No \\
\hline $\begin{array}{l}\text { Incomplete outcome data } \\
\text { (attrition bias) } \\
\text { All outcomes }\end{array}$ & Unclear risk & Unclear \\
\hline
\end{tabular}

\section{Cho 2015}

$\begin{array}{ll}\text { Methods } & \text { RCT, cross-over } \\ & \text { Method of randomisation: not stated } \\ & \text { Blinding of outcome assessors: not stated }\end{array}$


Cho 2015 (Continued)

Adverse events: not stated

Deaths: not stated

Dropouts: not stated

ITT: not stated

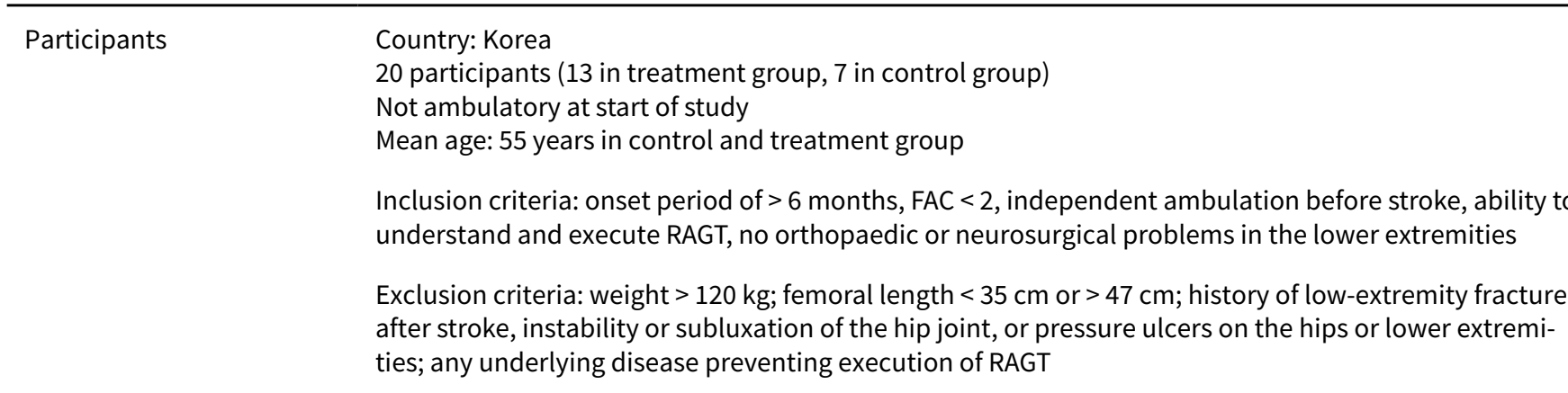

\begin{tabular}{l}
\hline Interventions \\
$\begin{array}{l}\text { - Exps: } \\
\text { utes/day) and conventional physical therapy } 5 \text { times per week, } 8 \text { weeks (30 minutes/day) } \\
\text { - Control group: conventional physical therapy } 5 \text { times per week, } 8 \text { weeks (30 minutes/day) }\end{array}$
\end{tabular}

Outcomes

Outcomes were recorded at baseline and after 4 and 8 weeks:

- Primary outcome measures: balance (Berg Balance Scale, Modified Functional Reach Test)

- Secondary outcome measures: walking ability (FAC), motor function (Modified Ashworth Scale, FuglMeyer Assessment of Lower Extremity, Motricity Index), activities of daily living (Modified Barthel Index)

$\begin{array}{ll}\text { Notes } & \text { Higher dose of intervention in experimental group compared to control group; group differences at } \\ \text { baseline (modified forward reach) }\end{array}$

\section{Risk of bias}

\begin{tabular}{lll}
\hline Bias & Authors' judgement & Support for judgement \\
\hline $\begin{array}{l}\text { Random sequence genera- } \\
\text { tion (selection bias) }\end{array}$ & Unclear risk & Method of randomisation not described. \\
\hline $\begin{array}{l}\text { Allocation concealment } \\
\text { (selection bias) }\end{array}$ & High risk & Allocation not described. \\
\hline $\begin{array}{l}\text { Blinding of outcome as- } \\
\text { sessment (detection bias) } \\
\text { All outcomes }\end{array}$ & High risk & Not mentioned \\
\hline $\begin{array}{l}\text { Incomplete outcome data } \\
\text { (attrition bias) }\end{array}$ & Unclear risk & Unclear \\
\begin{tabular}{l} 
All outcomes \\
\hline
\end{tabular} & & \\
\hline
\end{tabular}

Chua 2016

$\begin{array}{ll}\text { Methods } & \text { RCT } \\ & \text { Method of randomisation: computer-generated sequence } \\ & \text { Blinding of outcome assessors: stated as 'yes' by the investigator } \\ & \text { Adverse events: no }\end{array}$


Chua 2016 (Continued)

Deaths: yes

Dropouts: yes (7 in treatment group, 13 in control group)

ITT: yes

\begin{tabular}{ll}
\hline Participants & Country: Singapore \\
& 108 participants ( 53 in treatment group, 53 in control group) \\
& Not ambulatory at start of study \\
& Mean age: 62 years experimental and 61 years control group \\
Inclusion criteria: unilateral haemorrhagic/ischaemic stroke, age between 18 and 80 years, indepen- \\
dent ambulation pre-stroke \\
Exclusion criteria: $>8$ weeks poststroke, FAC $\geq 4$, cardiovascular instability, MMSE $<16$, communication \\
deficits, lower limb joint contractures
\end{tabular}

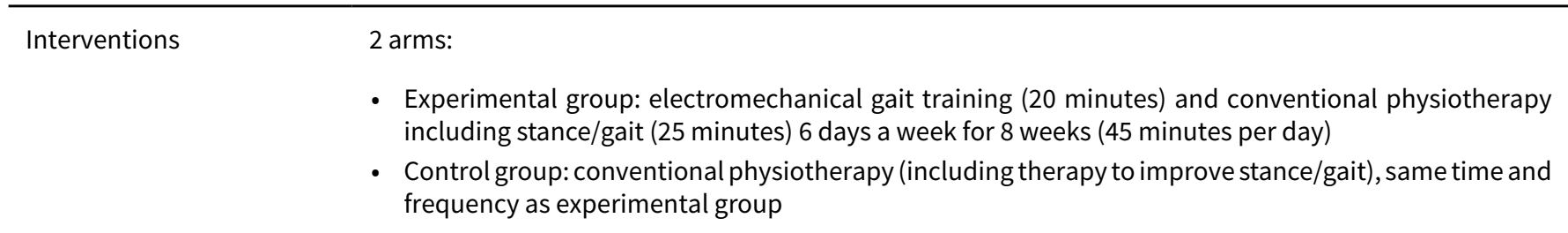

Outcomes Outcomes were recorded at baseline and 4, 8, 12, 24, and 48 weeks after baseline

Outcome measures: walking ability (FAC), Barthel Index, gait velocity (10-metre walk test), gait endurance (6-minute walk test), health status (Stroke Impact Scale)

Notes

\section{Risk of bias}

\begin{tabular}{lll}
\hline Bias & Authors' judgement & Support for judgement \\
\hline $\begin{array}{l}\text { Random sequence genera- } \\
\text { tion (selection bias) }\end{array}$ & Low risk & $\begin{array}{l}\text { Authors state: "Randomization was performed using a computer-generated } \\
\text { sequence of random numbers." }\end{array}$ \\
\hline $\begin{array}{l}\text { Allocation concealment } \\
\text { (selection bias) }\end{array}$ & Low risk & $\begin{array}{l}\text { Authors state: "An independent department generated the random group al- } \\
\text { location sequence and transferred the sequence to a series of serially num- } \\
\text { bered opaque envelopes, which were not opened and revealed until after ac- } \\
\text { ceptance into the study and the baseline tests, therefore ensuring allocation } \\
\text { concealment." }\end{array}$ \\
\hline $\begin{array}{l}\text { Blinding of outcome as- } \\
\text { sessment (detection bias) } \\
\text { All outcomes }\end{array}$ & Low risk & $\begin{array}{l}\text { Authors state: "The data assessors were blinded to group allocation, but it was } \\
\text { not possible to blind participants or the health care professionals providing in- } \\
\text { terventions." }\end{array}$ \\
\hline $\begin{array}{l}\text { Incomplete outcome data } \\
\text { (attrition bias) }\end{array}$ & Low risk & $\begin{array}{l}\text { All data for all participants provided and analysed. Authors state: "An inten- } \\
\text { tion-to-treat approach was used. Data from subjects were analysed according } \\
\text { to the group to which they were randomised, regardless of whether they com- } \\
\text { pleted the intervention. Participants failing to complete either intervention } \\
\text { were asked to return for follow-up." }\end{array}$ \\
\hline
\end{tabular}

Dias 2006

\begin{tabular}{ll}
\hline Methods & RCT \\
& Method of randomisation: permuted block randomisation \\
& Blinding of outcome assessors: stated as blinded
\end{tabular}


Dias 2006 (Continued)

Adverse events: none stated

Deaths: none

Dropouts: none

ITT: not stated but probably done because there were no dropouts

\begin{tabular}{ll}
\hline Participants & Country: Portugal \\
& 40 participants ( 20 in treatment group, 20 in control group) \\
Ambulatory at start of study & Mean age: 69 years \\
Inclusion criteria: first-ever stroke patients $>12$ months after stroke; age $>18$ and $<80$ years; cognitive \\
(MMSE > 19) and communication capacities to understand the treatment; absence of cardiac, psycho- \\
logical, and orthopaedic contraindications \\
Exclusion criteria: not stated
\end{tabular}

\begin{tabular}{ll}
\hline Interventions & arms: \\
& - Control group used the Bobath method, 5 times a week for 5 weeks \\
- Experimental group used the Gait Trainer for the same time and frequency
\end{tabular}

Outcomes Outcomes were recorded at baseline and after 4 weeks and 3 months:

- Motricity Index

- Toulouse Motor Scale

- Modified Ashworth Scale

- Berg Balance Scale

- Rivermead Motor Score

- Fugl-Meyer Stroke Scale (lower limb and balance)

- FAC

- Barthel Index

- 10-metre walking test and gait cycle parameters

- Timed Up and Go test

- 6-minute walking distance test

- Step test

After study end and at follow-up, participants rated satisfaction with and efficiency of treatment in a self questionnaire (Likert scale).

\begin{tabular}{|c|c|c|}
\hline Notes & \multicolumn{2}{|c|}{ Published and unpublished data provided by the authors. } \\
\hline \multicolumn{3}{|l|}{ Risk of bias } \\
\hline Bias & Authors' judgement & Support for judgement \\
\hline $\begin{array}{l}\text { Random sequence genera- } \\
\text { tion (selection bias) }\end{array}$ & Unclear risk & Unclear \\
\hline $\begin{array}{l}\text { Allocation concealment } \\
\text { (selection bias) }\end{array}$ & Low risk & Central allocation \\
\hline $\begin{array}{l}\text { Blinding of outcome as- } \\
\text { sessment (detection bias) } \\
\text { All outcomes }\end{array}$ & High risk & Not done \\
\hline $\begin{array}{l}\text { Incomplete outcome data } \\
\text { (attrition bias) } \\
\text { All outcomes }\end{array}$ & Low risk & No missing outcome data \\
\hline
\end{tabular}


Fisher 2008

\begin{tabular}{|c|c|}
\hline Methods & $\begin{array}{l}\text { RCT } \\
\text { Method of randomisation: blocked randomisation } \\
\text { Blinding of outcome assessors: stated as 'yes' } \\
\text { Adverse events: control group 14, experimental group } 11 \\
\text { Deaths: none } \\
\text { Dropouts: none } \\
\text { ITT: stated as 'yes' }\end{array}$ \\
\hline Participants & $\begin{array}{l}\text { Country: USA } \\
20 \text { participants ( } 10 \text { in treatment group, } 10 \text { in control group) } \\
5 \text { in treatment group and } 7 \text { in control group were ambulatory at start of study } \\
\text { Mean age: not stated } \\
\text { Inclusion criteria: subacute, }<2 \text { months after stroke } \\
\text { Exclusion criteria: not stated }\end{array}$ \\
\hline Interventions & $\begin{array}{l}2 \text { arms: } \\
\text { - Control group received standard physical therapy, } 3 \text { to } 5 \text { times a week for } 24 \text { consecutive sessions } \\
\text { - Experimental group used the AutoAmbulator for the same time and frequency }\end{array}$ \\
\hline Outcomes & $\begin{array}{l}\text { Outcomes were recorded at baseline and after } 24 \text { sessions: } \\
\text { - Gait test portion of Tinetti's balance and mobility assessment } \\
\text { - 3-minute walk } \\
\text { - } 25 \text {-foot walk }\end{array}$ \\
\hline
\end{tabular}

\section{Risk of bias}

Bias Authors' judgement Support for judgement

Random sequence genera- Unclear risk Unclear

tion (selection bias)

$\begin{aligned} & \text { Allocation concealment } \\ & \text { (selection bias) }\end{aligned}$ Unclear risk Stated as concealed, but method not described.

\begin{tabular}{ll}
\hline Blinding of outcome as- & Low risk \\
sessment (detection bias) & \\
All outcomes & \\
\hline
\end{tabular}

Incomplete outcome data Low risk ITT stated.

(attrition bias)

All outcomes

\section{Forrester 2014}

\begin{tabular}{ll}
\hline Methods & RCT \\
& Method of randomisation: not described \\
& Blinding of outcome assessors: stated as 'no' \\
& Adverse events: no \\
& Deaths: not mentioned \\
& Dropouts: 5 (3 in treatment group, 2 in control group)
\end{tabular}


Forrester 2014 (Continued)

$$
\text { ITT: no }
$$

Country: USA
Participants
Not ambulatory at start of study
Mean age: 63 years in experimental group and 60 years in control group
Inclusion criteria: first stroke; residual lower extremity hemiparesis involving the ankle $(1 / 5$ to $4 / 5 \mathrm{MRC}) ;$
capable of generating at least trace muscle activation in PF-DF; adequate language and neurocognitive
function; sit in the chair for 30 to 60 minutes per session of ankle training
Exclusion criteria: total plegia (0/5) at paretic ankle; fixed or painful contractures; dementia; or-
thopaedic, arthritic, or inflammatory condition limiting ankle movement; deep venous thrombosis or
pulmonary thromboembolism; vision impairment; severe receptive or global aphasia
2 arms:
- Experimental group: robot-assisted ankle training, daily for 60 minutes/day, 10 sessions until dis-
charge
- Control group: passive manual moving and stretching ankle, for the same time

Outcomes Outcomes were recorded at baseline and at discharge.

Outcome measures: walking ability (Functional Independence Measure walking), balance (Berg Balance Scale), walking velocity, active range of motion, muscle strength, spatiotemporal gait parameters (step time, step length, step symmetry), motor control variables (angular velocity, co-ordination)

Notes Unclear amount of therapy

\section{Risk of bias}

Bias Authors' judgement Support for judgement

Random sequence genera- Unclear risk Not clearly described; authors only state "blocked randomisation" tion (selection bias)

\begin{tabular}{lll}
\hline $\begin{array}{l}\text { Allocation concealment } \\
\text { (selection bias) }\end{array}$ & High risk & Not described \\
\hline
\end{tabular}

Blinding of outcome as- High risk Authors state "not blinded".

sessment (detection bias)

All outcomes

Incomplete outcome data High risk
(attrition bias)

(attrition bias)
All outcomes

$\begin{array}{ll} & \\ \text { Geroin } 2011 & \text { RCT } \\ \text { Methods } & \text { Method of randomisation: software-generated randomisation scheme } \\ & \text { Blinding of outcome assessors: no } \\ & \text { Adverse events: none } \\ & \text { Deaths: none } \\ & \text { Dropouts: none } \\ & \text { ITT:yes }\end{array}$


Geroin 2011 (Continued)
Participants
Country: Italy
30 participants ( 10 in treatment group 1, 10 in treatment group 2, and 10 in control group)
5 in both treatment groups and 7 in control group were ambulatory at start of study
Mean age: not stated
Inclusion criteria: at least 12 months from their first unilateral ischaemic stroke; age $<75$ years; Euro- pean Stroke Scale score between 75 and 85 ; MMSE score $\geqq 24$; ability to maintain standing position without aids for at least 5 minutes; ability to walk independently for at least 15 metres with the use of walking aids (cane and orthoses)
Exclusion criteria: preceding epileptic fits; an electroencephalography suspect of elevated cortical ex- citability; metallic implants within the brain and previous brain surgery; medications altering corti- cal excitability or with a presumed effect on brain plasticity; posterior circulation stroke; deficits of so- matic sensation involving the paretic lower limb; presence of vestibular disorders or paroxysmal ver- tigo; presence of severe cognitive or communicative disorders; presence of other neurological or or- thopaedic conditions involving the lower limbs; presence of cardiovascular comorbidity; performance of any type of rehabilitation treatment in the 3 months before start of study

- Robot-assisted gait training (Gait Trainer GT 1) combined with transcranial direct current stimulation

- Robot-assisted gait training (Gait Trainer GT 1) combined with sham transcranial direct current stimulation

- Walking overground

All participants received $10 \times$ 50-minute treatment sessions, 5 days a week, for 2 consecutive weeks

Outcomes were recorded at baseline and after 2 weeks:
- Primary outcomes were the 6-minute walk test and the 10-metre walking test
- Secondary outcomes were spatiotemporal gait parameters, FAC, Rivermead Mobility Index, Motricity
Index leg subscore, and Modified Ashworth Scale

Notes

We combined the results of both robotic-assisted groups (arms 1 and 2) into a single group, which we compared with the results of the control group (arm 3).

\section{Risk of bias}

\begin{tabular}{lll}
\hline Bias & Authors' judgement & Support for judgement \\
\hline $\begin{array}{l}\text { Random sequence genera- } \\
\text { tion (selection bias) }\end{array}$ & Low risk & Software-generated list \\
\hline $\begin{array}{l}\text { Allocation concealment } \\
\text { (selection bias) }\end{array}$ & Low risk & Central allocation \\
\hline $\begin{array}{l}\text { Blinding of outcome as- } \\
\text { sessment (detection bias) } \\
\text { All outcomes }\end{array}$ & High risk & Not done \\
\hline $\begin{array}{l}\text { Incomplete outcome data } \\
\text { (attrition bias) } \\
\text { All outcomes }\end{array}$ & Low risk & No missing outcome data \\
\hline
\end{tabular}

Han 2016

\begin{tabular}{ll}
\hline Methods & RCT \\
& Method of randomisation: not stated \\
& Blinding of outcome assessors: stated as 'yes'
\end{tabular}

Electromechanical-assisted training for walking after stroke (Review) 
Han 2016 (Continued)

\author{
Adverse events: none \\ Deaths: none \\ Dropouts: 4 in control group ( 2 refused and 2 dropped) \\ ITT: no
}

Country: Republic of Korea
60 participants ( 30 in treatment group, 30 in control group)
Non-ambulatory at start of study
Mean age: 68 years in experimental group and 63 years in control group
Inclusion criteria: clinical diagnosis of stroke $<3$ months after stroke onset, first-ever stroke, dependent
ambulation with severe gait impairment (FAC $<2$ ), and sufficient cognition to understand procedures
and provide informed consent
Exclusion criteria: contraindications for RAGT therapy; cerebellar or brainstem lesions that could af-
fect autonomic or balance function; musculoskeletal disease involving the lower limbs, such as severe
painful arthritis, osteoporosis, amputation, or joint contracture; and other concurrent neurological dis-
eases (e.g. Parkinson's disease, multiple sclerosis, etc.)

Interventions 2 arms:

- Experimental group: 30 minutes of exoskeletal robot-driven gait orthosis training (Lokomat) and 30 minutes conventional rehabilitation therapy 5 times per week for 4 weeks

- Control group: 60 minutes conventional rehabilitation therapy. Physical therapy conducted by physical therapists certified in neurodevelopmental techniques was provided for balance and mobility 5 times per week for 4 weeks

Outcomes

Outcomes were recorded at baseline and after the 4-week intervention; all outcome parameters were measured within 3 days before and after 20 sessions of training:

- Primary outcomes: brachial-ankle pulse wave velocity (baPWV, which evaluates arterial stiffness) and cardiopulmonary fitness

- Secondary outcomes: clinical functional outcomes, including basic ADL function, balance, gait functions, and motor functions of the paretic lower limb

Notes

\title{
Risk of bias
}

Bias Authors' judgement Support for judgement

Random sequence genera- Unclear risk Method of randomisation not described.

tion (selection bias)

Allocation concealment $\quad$ Unclear risk $\quad$ Allocation concealment not described.
(selection bias)

\begin{tabular}{|c|c|c|}
\hline $\begin{array}{l}\text { Blinding of outcome as- } \\
\text { sessment (detection bias) } \\
\text { All outcomes }\end{array}$ & Low risk & $\begin{array}{l}\text { A physiatrist (rehabilitation doctor) who remained blinded to participant } \\
\text { group and treatment throughout the entire study analysed outcome mea- } \\
\text { sures. }\end{array}$ \\
\hline
\end{tabular}

\begin{tabular}{l}
\hline Incomplete outcome data High risk No ITT \\
(attrition bias) \\
All outcomes
\end{tabular}


Hidler 2009

\begin{tabular}{ll}
\hline Methods & RCT \\
Method of randomisation: randomisation table \\
Blinding of outcome assessors: not described \\
Adverse events: control group 14; experimental group 11 \\
Deaths: 1 , which study arm not reported \\
Dropouts: 9 \\
ITT: no, described as analysis per protocol \\
Country: USA \\
72 participants ( 36 in treatment group, 36 in control group); 63 participants completed all training ses- \\
sions and were analysed as per protocol \\
All participants were ambulatory at start of study \\
Mean age: 60 years \\
Inclusion criteria: hemiparesis resulting from unilateral ischaemic or haemorrhagic stroke, time since \\
stroke less than 6 months, no prior stroke, age $>18$ years, ability to ambulate 5 metres without physical \\
assistance and a self selected walking speed between 0.1 and 0.6 m/s, not receiving any other physical \\
therapy targeting the lower limbs \\
Exclusion criteria: severe osteoporosis, contractures limiting range of motion in the lower extremities, \\
not ambulating before stroke, severe cardiac disease (NYHA classification of II-IV), uncontrolled hyper- \\
tension (systolic $>200$ mm Hg, diastolic $>110$ mm Hg), stroke of the brainstem or cerebellar lesions, un- \\
controlled seizures, presence of lower limb non-healing ulcers, lower limb amputation, uncontrolled \\
diabetes, cognitive deficits (<24 on the MMSE), symptoms of depression ( $\geq 16$ on the Center for Epi- \\
demiological Studies Depression Scale)
\end{tabular}

Interventions 2 arms:

- Control group received conventional gait training, 3 times a week for 8 to 10 weeks for 24 sessions, each session lasted $1 \frac{1}{2}$ hours

- Experimental group used the Lokomat for the same time and frequency

Outcomes

Outcomes were recorded at baseline and after 12 and 24 sessions, and at 3-month follow-up:

- Primary outcome measures: self selected walking speed over 5 metres, walking distance in 6 minutes

- Secondary outcome measures: Berg Balance Scale, FAC, NIHSS, Motor Assessment Scale, Rivermead Mobility Index, Frenchay Activities Index, SF-36, cadence

Notes

\section{Risk of bias}

\begin{tabular}{lll}
\hline Bias & Authors' judgement & Support for judgement \\
\hline $\begin{array}{l}\text { Random sequence genera- } \\
\text { tion (selection bias) }\end{array}$ & Low risk & Randomisation table \\
\hline $\begin{array}{l}\text { Allocation concealment } \\
\text { (selection bias) }\end{array}$ & Unclear risk & Not described in sufficient detail \\
\hline $\begin{array}{l}\text { Blinding of outcome as- } \\
\text { sessment (detection bias) } \\
\text { All outcomes }\end{array}$ & High risk & Not done \\
\hline $\begin{array}{l}\text { Incomplete outcome data } \\
\text { (attrition bias) } \\
\text { All outcomes }\end{array}$ & High risk & No ITT, analysis per protocol \\
\hline
\end{tabular}


Hornby 2008

\begin{tabular}{ll}
\hline Methods & RCT \\
Method of randomisation: opaque, sealed envelopes \\
Blinding of outcome assessors: not done \\
Adverse events: 8 events in control group and 3 events in experimental group \\
Deaths: none \\
Dropouts: 14 (10 in control group and 4 in experimental group) \\
ITT: no ITT; analysis per protocol
\end{tabular}

ITT: no ITT; analysis per protocol

\begin{tabular}{|c|c|}
\hline Participants & $\begin{array}{l}\text { Country: USA } \\
62 \text { participants ( } 31 \text { in treatment group, } 31 \text { in control group), } 48 \text { participants completed all training ses- } \\
\text { sions and were analysed as per protocol } \\
\text { All participants were ambulatory at start of study } \\
\text { Mean age: } 57 \text { years } \\
\text { Inclusion criteria: hemiparesis of longer than } 6 \text { months' duration after patients with unilateral, supra- } \\
\text { tentorial, ischaemic, or haemorrhage stroke were recruited; no evidence of bilateral or brainstem le- } \\
\text { sions; able to walk } 10 \text { metres overground without physical assistance at speeds of } 0.8 \mathrm{~m} / \mathrm{s} \text { at self select- } \\
\text { ed velocity, using assistive devices and bracing below the knee as needed } \\
\text { Exclusion criteria: significant cardiorespiratory/metabolic disease or other neurological or orthopaedic } \\
\text { injury that may limit exercise participation or impair locomotion, size limitations for the harness/coun- } \\
\text { terweight system or robotic orthosis, botulinum toxin therapy in the lower limbs within } 6 \text { months be- } \\
\text { fore enrolment, scores lower than } 23 \text { on the MMSE, patients could not receive concurrent physical ther- } \\
\text { apy }\end{array}$ \\
\hline Interventions & $\begin{array}{l}2 \text { arms: } \\
\text { - Control group received therapist-assisted gait training, } 12 \text { sessions, each session lasted } 30 \text { minutes } \\
\text { - Experimental group received robotic-assisted gait training using the Lokomat for the same time and } \\
\text { frequency }\end{array}$ \\
\hline Outcomes & $\begin{array}{l}\text { Outcomes were recorded at baseline and after } 12 \text { sessions and at 6-month follow-up: } \\
\text { - Primary outcome measures: self selected walking speed } \\
\text { - Secondary outcome measures: single-limb stance time, step length asymmetry, 6-minute walk test, } \\
\text { modified Emory Functional Ambulation Profile, Berg Balance Scale, Frenchay Activities Index, physi- } \\
\text { cal component summary score of the Medical Outcomes Questionnaire Short Form 36, strength, Mod- } \\
\text { ified Ashworth Scale, Center for Epidemiological Studies Depression Scale }\end{array}$ \\
\hline
\end{tabular}

Notes -

\section{Risk of bias}

\begin{tabular}{lll}
\hline Bias & Authors' judgement & Support for judgement \\
\hline $\begin{array}{l}\text { Random sequence genera- } \\
\text { tion (selection bias) }\end{array}$ & Low risk & (Probably) shuffling envelopes \\
\hline $\begin{array}{l}\text { Allocation concealment } \\
\text { (selection bias) }\end{array}$ & Low risk & Opaque, sealed envelopes \\
\hline $\begin{array}{l}\text { Blinding of outcome as- } \\
\text { sessment (detection bias) } \\
\text { All outcomes }\end{array}$ & High risk & No blinding \\
\hline $\begin{array}{l}\text { Incomplete outcome data } \\
\text { (attrition bias) } \\
\text { All outcomes }\end{array}$ & High risk & 'As-treated' analysis done \\
\hline
\end{tabular}


Husemann 2007

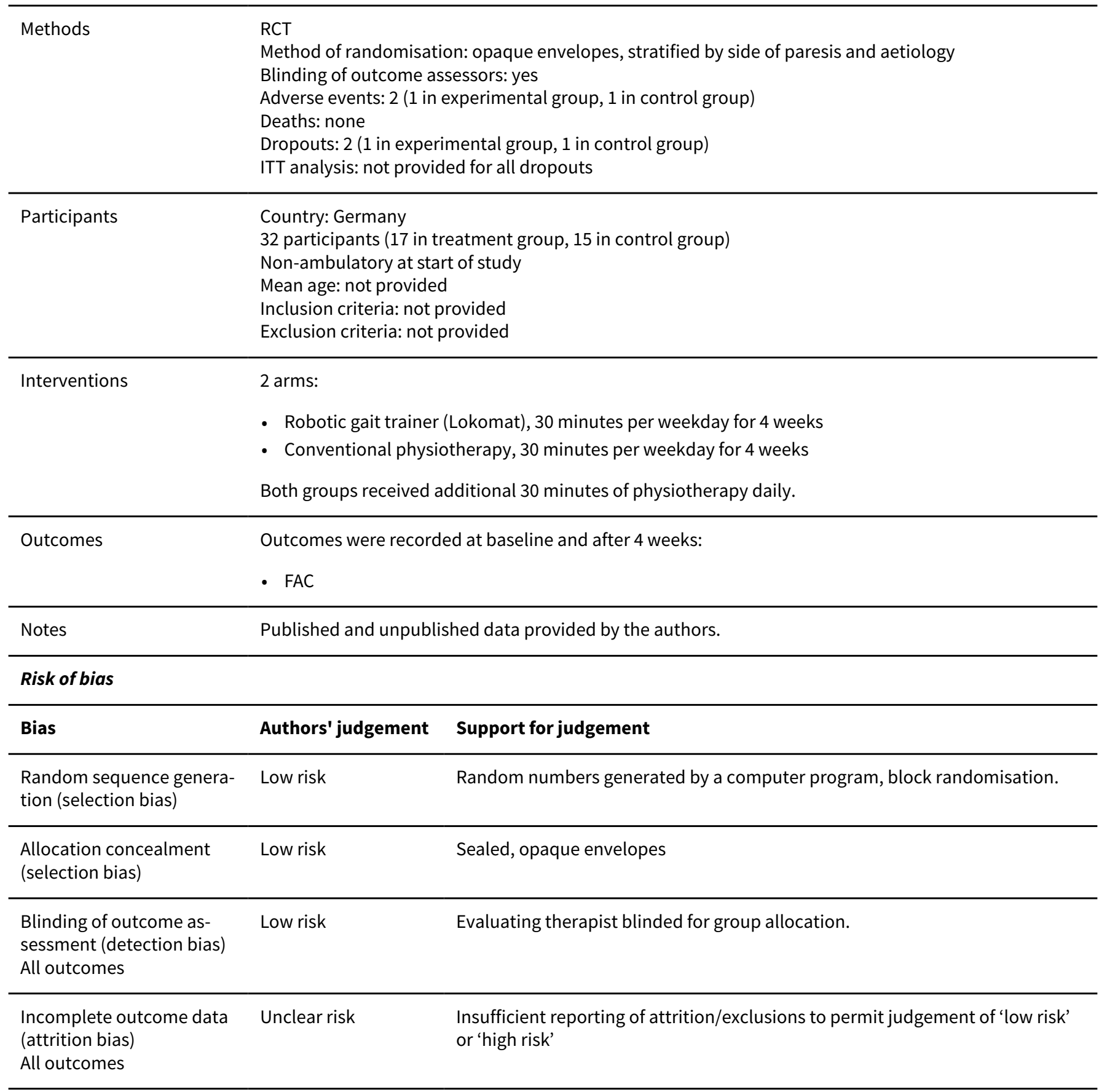

$\operatorname{Kim} 2015$

$\begin{array}{ll}\text { Methods } & \text { RCT } \\ \text { Method of randomisation: not described } \\ \text { Blinding of outcome assessors: not described } \\ \text { Adverse events: not mentioned } \\ \text { Deaths: none } \\ \text { Dropouts: } 4 \text { (2 in experimental group, } 2 \text { in control group) }\end{array}$


Kim 2015 (Continued)

$$
\text { ITT: no }
$$

Country: Korea
30 participants (15 in treatment group, 15 in control group)
Not ambulatory at start of study
Mean age: 54 years in experimental group and 50 years in control group
Inclusion criteria: first stroke $<1$ year, plateau in recovery of the locomotor functions after a 30 -day con-
ventional neurorehabilitation
Exclusion criteria: severe spasticity (Modified Ashworth Scale 2$)$, tremor, severe visual and cognitive im-
pairments, musculoskeletal diseases, cardiopulmonary diseases, body weight of $135 \mathrm{~kg}$; height of 150
$\mathrm{~cm}$
2 arms:
- Experimental group: robot-assisted training (Walkbot) ( $2 \times 20$ minutes/day) and conventional physical
therapy ( $2 \times 20$ minutes/day) 5 for 4 weeks
Control group: conventional physical therapy $(2 \times 40$ minutes/day) for the same time as experimental
group

Outcomes Outcomes were recorded at baseline and after 4 and 8 weeks.

Outcome measures: walking ability (FAC), balance (Berg Balance Scale), modified Barthel Index, spasticity (Modified Ashworth Scale), quality of life (EuroQol-5 dimension)

\begin{tabular}{lll}
\hline Notes & NCT02053233 & \\
\hline Risk of bias & & \\
\hline Bias & Authors' judgement & Support for judgement \\
\hline $\begin{array}{l}\text { Random sequence genera- } \\
\text { tion (selection bias) }\end{array}$ & Unclear risk & Method not described. \\
\hline $\begin{array}{l}\text { Allocation concealment } \\
\text { (selection bias) }\end{array}$ & Unclear risk & Unclear \\
\hline $\begin{array}{l}\text { Blinding of outcome as- } \\
\text { sessment (detection bias) } \\
\text { All outcomes }\end{array}$ & High risk & Not described \\
\hline $\begin{array}{l}\text { Incomplete outcome data } \\
\text { (attrition bias) } \\
\begin{array}{l}\text { All outcomes } \\
\hline\end{array}\end{array}$ & High risk & No ITT \\
\hline
\end{tabular}

\section{Kyung 2008}

$\begin{array}{ll}\text { Methods } & \text { RCT } \\ \text { Method of randomisation: unclear } \\ \text { Blinding of outcome assessors: unclear } \\ \text { Adverse events: unclear } \\ \text { Deaths: unclear } \\ \text { Dropouts: } 3 \text { ( } 2 \text { in experimental group, } 1 \text { in control group) } \\ \text { ITT analysis: unclear }\end{array}$

Participants Country: Republic of Korea


Kyung 2008 (Continued)

35 participants (18 in treatment group, 17 in control group)

10 participants in the experimental group and 7 participants in the control group were ambulatory at

start of study

Mean age: not stated

Inclusion criteria: not stated

Exclusion criteria: not stated

\begin{tabular}{ll}
\hline Interventions & arms: \\
& - Robotic training (Lokomat), 30 minutes, 3 times a week for 4 weeks \\
& - Conventional physiotherapy, received equal time and sessions of conventional gait training
\end{tabular}

\section{Outcomes}

Outcomes were recorded at baseline and after training

- FAC

- Modified Motor Assessment Scale

- Gait speed

- Isometric torque

- Fugl-Meyer Assessment

- Motricity Index

- Ashworth Scale

\section{Notes}

\section{Risk of bias}

\begin{tabular}{lll}
\hline Bias & Authors' judgement & Support for judgement \\
\hline $\begin{array}{l}\text { Random sequence genera- } \\
\text { tion (selection bias) }\end{array}$ & Unclear risk & Unclear \\
\hline $\begin{array}{l}\text { Allocation concealment } \\
\text { (selection bias) }\end{array}$ & Unclear risk & Method neither described nor stated. \\
\hline $\begin{array}{l}\text { Blinding of outcome as- } \\
\text { sessment (detection bias) } \\
\text { All outcomes }\end{array}$ & Unclear risk & Unclear \\
\hline $\begin{array}{l}\text { Incomplete outcome data } \\
\text { (attrition bias) }\end{array}$ & Unclear risk & Unclear \\
All outcomes & & \\
\hline
\end{tabular}

\section{Mayr 2008}

\begin{tabular}{ll}
\hline Methods & RCT \\
Method of randomisation: unclear \\
Blinding of outcome assessors: unclear \\
Adverse events: not stated \\
Deaths: unclear, probably none \\
Dropouts: 13 (4 in experimental group, 9 in control group) \\
ITT analysis: not stated
\end{tabular}

\begin{tabular}{ll}
\hline Participants & Country: Austria \\
& 74 participants ( 37 in treatment group, 37 in control group) \\
Most participants in both groups were non-ambulatory at start of study \\
Mean age: not stated
\end{tabular}


Mayr 2008 (Continued)

Inclusion criteria: primary ischaemic lesion of the medial cerebral artery, between 10 days and 6 weeks after stroke, stable cardiovascular system, ability to walk with assistance of 1 therapist

Exclusion criteria: brainstem lesions, thrombosis, severe contractures, good walking ability with stand-

ing only help by therapist

$\begin{array}{ll} & 2 \text { arms: } \\ \text { Interventions } & \text { Add-on robotic training (Lokomat), } 45 \text { minutes, } 5 \text { times a week for } 8 \text { weeks } \\ \text { - Add-on conventional physiotherapy, received equal time and sessions of conventional gait training }\end{array}$

\begin{tabular}{ll}
\hline Outcomes & Outcomes were recorded at baseline and after training phase: \\
- Modified Emory Functional Ambulatory Profile \\
- Hochzirl Walking Aids Profile \\
- Rivermead Motor Index \\
- Mobility milestones \\
- Gait analysis
\end{tabular}

Notes

Published as conference abstract and unpublished data

\section{Risk of bias}

\begin{tabular}{lll}
\hline Bias & Authors' judgement & Support for judgement \\
\hline $\begin{array}{l}\text { Random sequence genera- } \\
\text { tion (selection bias) }\end{array}$ & Low risk & Software-generated list \\
\hline $\begin{array}{l}\text { Allocation concealment } \\
\text { (selection bias) }\end{array}$ & Low risk & Described concealed allocation \\
\hline $\begin{array}{l}\text { Blinding of outcome as- } \\
\text { sessment (detection bias) } \\
\text { All outcomes }\end{array}$ & Low risk & Described as blinded evaluator \\
\hline $\begin{array}{l}\text { Incomplete outcome data } \\
\text { (attrition bias) }\end{array}$ & High risk & No ITT \\
$\begin{array}{l}\text { All outcomes } \\
\end{array}$ & \\
\hline
\end{tabular}

Morone 2011

\begin{tabular}{ll}
\hline Methods & RCT \\
Method of randomisation: by computer program \\
Blinding of outcome assessors: stated as 'yes' \\
Adverse events: control group 4, experimental group 3 \\
Deaths: none \\
Dropouts: (defined in this study as discontinued intervention) 12 in robotic groups and 9 in control \\
groups \\
ITT: yes \\
Country: Italy \\
48 participants (24 in treatment group, 24 in control group ) \\
All participants were non-ambulatory at start of study \\
Mean age: 62 years \\
Inclusion criteria: hemiplegia/hemiparesis in the subacute phase with significant gait deficits (FAC $<3$ ) \\
caused by a first-ever stroke, lesions that were confirmed by computed tomography or magnetic reso- \\
nance imaging, and age between 18 and 80 years
\end{tabular}


Morone 2011 (Continued)

Exclusion criteria: presence of subarachnoid haemorrhages, sequelae of prior cerebrovascular accidents or other chronic disabling pathologies, orthopaedic injuries that could impair locomotion, spasticity that limited lower extremity range of motion to less than $80 \%$, sacral skin lesions, MMSE score < 24 , and hemispatial neglect, as evaluated by a neuropsychologist

Interventions 2 arms (including strata for motor function):

- After first week post-admission, participants performed 20 robotic sessions (5 times per week for 4 weeks) instead of a second session of standard physiotherapy. These sessions lasted 40 minutes, 20 of which consisted of active gait-training therapy (the remaining 20 minutes were allocated for the participant's preparation, parameter setting, and rest breaks as needed)

- After first week of admission, participants performed 2 daily physiotherapy sessions. One session was dedicated to walking training, consisting of 20 sessions of 40-minute therapy ( 5 times per week), instead of a second session of standard physiotherapy. In light of the participant's ability, the walking therapy was focused on trunk stabilisation, weight transfer to the paretic leg, and walking between parallel bars or on the ground. If necessary, the participant was helped by 1 or 2 therapists and walking aids

The standard physiotherapy, shared by both groups, was focused on facilitation of movement on the paretic side and upper limb exercises, as well as improving balance, standing, sitting, and transferring.

Outcomes

Outcomes were recorded by a physician who was blinded to the treatment at baseline, after 4 weeks of the intervention, and at hospital discharge:

- Primary outcome: walking ability (as measured by FAC)

- Secondary outcomes: assessments of mobility function and ability level, evaluated by lower-leg Ashworth (sum of scores for hip, knee, and ankle), Rivermead Mobility Index, Motricity Index, Trunk Control Test, Canadian Neurological Scale, Barthel Index, Rankin Scale, 6-minute walk test on a 20-metre path and 10-metre walk test at a self selected speed

Notes

\section{Risk of bias}

\begin{tabular}{lll} 
Bias & Authors' judgement & Support for judgement \\
\hline $\begin{array}{l}\text { Random sequence genera- } \\
\text { tion (selection bias) }\end{array}$ & Low risk & Generated electronically by www.random.org \\
\hline $\begin{array}{l}\text { Allocation concealment } \\
\text { (selection bias) }\end{array}$ & Low risk & Central allocation \\
\hline $\begin{array}{l}\text { Blinding of outcome as- } \\
\text { sessment (detection bias) } \\
\text { All outcomes }\end{array}$ & Low risk & Yes \\
\hline
\end{tabular}

Incomplete outcome data Low risk

(attrition bias)

All outcomes
ITT done; missing outcome data balanced in numbers across intervention groups, with similar reasons for missing data across groups.

Noser 2012

Methods

RCT

Method of randomisation: unclear

Blinding of outcome assessors: stated as 'yes'

Adverse events: 4 ( 2 in experimental group and 2 in control group)

Deaths: none stated 
Noser 2012 (Continued)

Dropouts: 1 in the control group (protocol violation)

ITT: stated as 'yes'

\title{
Participants
}

\begin{abstract}
Country: USA
21 participants ( 11 in treatment group, 10 in control group); 20 participants completed all training sessions, and 11 in treatment group and 9 in control group completed the study and were analysed as per protocol

All participants were ambulatory at start of study

Mean age: unclear

Inclusion criteria: people with ischaemic or haemorrhagic stroke confirmed by cerebral CT or MRI scan; age > 18; at least 3 months' poststroke at time of enrolment into study; ability to walk at least 10 feet with maximum 1 person assist, but not to walk in the community independently; residual paresis in the lower extremity as defined by NIHSS lower extremity motor score 2 to 4 ; ability to perform Lokomat ambulation training with assistance of 1 therapist; ability to follow a 3-step command; physician approval for patient participation; ability to give informed consent, completed rehabilitation services (i.e. not receiving concurrent physical, occupational, or speech therapy)

Exclusion criteria: serious cardiac condition, uncontrolled blood pressure defined as $>200$ or diastolic $>100$ at rest, history of serious chronic obstructive pulmonary disease or oxygen dependence, severe weight-bearing pain, lower extremity amputation, claudication while walking, life expectancy $<1$ year, history of deep vein thrombosis or pulmonary embolism within 6 months, severe orthopaedic problem, any medical or psychiatric condition that the investigators believe would prevent participation in study
\end{abstract}

Interventions
$\begin{aligned} & \text { - Control group received therapist-assisted gait training (duration and frequency unclear) } \\ & \text { - Experimental group received robotic-assisted gait training using the Lokomat (duration and frequen- } \\ & \text { cy unclear) }\end{aligned}$

Outcomes Outcomes were recorded at baseline and at postintervention, 3 months' postintervention

- Primary outcome measures: 10-metre walk test

- Secondary outcome measures: 6-minute walk test

Notes NCT00975156; same study as Kelley 2013

\section{Risk of bias}

\begin{tabular}{lll}
\hline Bias & Authors' judgement & Support for judgement \\
\hline $\begin{array}{l}\text { Random sequence genera- } \\
\text { tion (selection bias) }\end{array}$ & Unclear risk & Unclear \\
\hline
\end{tabular}

\begin{tabular}{lll}
\hline $\begin{array}{l}\text { Allocation concealment } \\
\text { (selection bias) }\end{array}$ & Unclear risk & Unclear \\
\hline $\begin{array}{l}\text { Blinding of outcome as- } \\
\text { sessment (detection bias) } \\
\text { All outcomes }\end{array}$ & Low risk & $\begin{array}{l}\text { Authors state: "Blinded assessors tested the participants at baseline, post-in- } \\
\text { tervention, and 3-month follow-up." }\end{array}$ \\
\hline
\end{tabular}

Incomplete outcome data Unclear risk 1 participant in the control group was not analysed.

Methods RCT


Ochi 2015 (Continued)

Method of randomisation: random number table

Blinding of outcome assessors: stated as 'yes'

Adverse events: none

Deaths: none

Dropouts: none

Country: Japan
26 participants (13 in treatment group, 13 in control group)
Not ambulatory at start of study
Mean age: 62 years in experimental group and 65 years in control group
Inclusion criteria: first-ever stroke < 5 weeks; age between 40 and 85 years; lower extremities
Brunnstrom's recovery stage $\leq$ grade III; FAC $\leq 2$; independence in walking before stroke
Exclusion criteria: height between 145 and $180 \mathrm{~cm}$; body weight over $100 \mathrm{~kg}$; limitation in range of mo-
tion in the lower extremity; severe cardiovascular, respiratory, renal, or musculoskeletal disease; diffi-
culty in communicating

Interventions 2 arms:

- Experimental group: robot-assisted training (gait-assistance robot) 5 days/week for 4 weeks (20 minutes)

- Control group: overground conventional gait training for the same time as experimental group

Outcomes
Outcome measures: Fugl-Meyer Assessment lower extremity, muscle torque, walking ability (FAC), 10-
metre walk test, Functional Independence Measure

Notes Clinical group differences in FAC at baseline

\section{Risk of bias}

\begin{tabular}{|c|c|c|}
\hline Bias & Authors' judgement & Support for judgement \\
\hline $\begin{array}{l}\text { Random sequence genera- } \\
\text { tion (selection bias) }\end{array}$ & Unclear risk & Method of randomisation not described. \\
\hline $\begin{array}{l}\text { Allocation concealment } \\
\text { (selection bias) }\end{array}$ & Unclear risk & No allocation concealment described. \\
\hline $\begin{array}{l}\text { Blinding of outcome as- } \\
\text { sessment (detection bias) } \\
\text { All outcomes }\end{array}$ & Low risk & Described as blinded assessors \\
\hline $\begin{array}{l}\text { Incomplete outcome data } \\
\text { (attrition bias) } \\
\text { All outcomes }\end{array}$ & Low risk & No dropouts, no participants excluded from analysis. \\
\hline \multicolumn{3}{|l|}{ Peurala 2005} \\
\hline Methods & \multicolumn{2}{|c|}{$\begin{array}{l}\text { RCT } \\
\text { Method of randomisation: an investigator not involved in the study randomly assigned participants to } \\
\text { groups using concealed envelopes } \\
\text { Blinding of outcome assessors: no } \\
\text { Adverse events: none } \\
\text { Deaths: none }\end{array}$} \\
\hline
\end{tabular}


Peurala 2005 (Continued)

Dropouts: none

ITT analysis: not stated

\begin{tabular}{l} 
Participants \\
$\begin{array}{l}\text { Country: Finland } \\
\text { Ambarticipants (15 in treatment group A, } 15 \text { in treatment group B, } 15 \text { in control group) } \\
\text { Mean age: } 52 \text { years } \\
\text { Inclusion criteria: first supratentorial stroke with duration of illness longer than } 6 \text { months, younger than } \\
65 \text { years of age, slow or difficult walking, no unstable cardiovascular disease, no severe malposition of } \\
\text { joints, no severe cognitive or communicative disorders, written informed consent } \\
\text { Exclusion criteria: not stated }\end{array}$ \\
\hline 3 arms: \\
- Gait trainer exercise without functional electrical stimulation \\
- Gait trainer exercise with functional electrical stimulation \\
All participants practised gait for 15 sessions over 3 weeks (each session lasting 20 minutes) and re- \\
ceived an additional 55 minutes daily physiotherapy.
\end{tabular}

Outcomes

Outcomes were recorded at baseline and after 2 and 3 weeks and 6 months:

- 10-metre walk test

- 6-minute walk test

- Lower limb spasticity

- Muscle force

- Postural sway tests

- Modified Motor Assessment Scale

- Functional Independence Measure instrument scores

\section{Risk of bias}

\begin{tabular}{lll}
\hline Bias & Authors' judgement & Support for judgement \\
\hline $\begin{array}{l}\text { Random sequence genera- } \\
\text { tion (selection bias) }\end{array}$ & Low risk & $\begin{array}{l}\text { An investigator not involved in the study randomly assigned participants to } \\
\text { groups using concealed envelopes. }\end{array}$ \\
\hline $\begin{array}{l}\text { Allocation concealment } \\
\text { (selection bias) }\end{array}$ & Low risk & Concealed envelopes \\
\hline $\begin{array}{l}\text { Blinding of outcome as- } \\
\text { sessment (detection bias) } \\
\text { All outcomes }\end{array}$ & High risk & Not done \\
\hline $\begin{array}{l}\text { Incomplete outcome data } \\
\text { (attrition bias) } \\
\text { All outcomes }\end{array}$ & Unclear risk & $\begin{array}{l}\text { Unclear if reasons for missing outcome data are unlikely to be related to true } \\
\text { outcome }\end{array}$ \\
\hline
\end{tabular}

Peurala 2009

$\begin{array}{ll}\text { Methods } & \text { RCT } \\ & \text { Method of randomisation: sealed envelopes (stratified according to ability to walk) } \\ & \text { Blinding of outcome assessors: no }\end{array}$


Peurala 2009 (Continued)

Adverse events: 2 in treatment group A, 3 in control group

Deaths: 1 in control group

Dropouts: 5 in treatment group A, 1 in treatment group B, 3 in control group

ITT analysis: not stated

Country: Finland
56 participants (22 in treatment group A, 21 in treatment group B, 13 in control group)
Non-ambulatory at start of study
Mean age: 68 years
Inclusion criteria: first supratentorial stroke or no significant disturbance from an earlier stroke (Modi-
fied Rankin Scale 0 to 2 ), acute phase after stroke with a maximum duration of 10 days, FAC 0 to 3 , vol-
untary movement in the leg of the affected side, Barthel Index 25 to 75 points, age 18 to 85 years, no un-
stable cardiovascular disease, body mass index < 32, no severe malposition of joints, no severe cogni-
tive or communicative disorders
Exclusion criteria: not stated

Interventions Between June 2003 and December 2004, random allocation to 2 arms took place (2 walking exercise groups)

- Gait training with Gait Trainer device (GT-Group)

- Overground walking training (WALK-Group)

All participants received 55 minutes daily gait-oriented physiotherapy and additional gait training for 15 sessions over 3 weeks (each session lasting maximum of 20 minutes of walking).

Between January 2005 and February 2007, random allocation to 3 arms took place (3 walking exercise groups)

- Gait training with Gait Trainer device (GT-Group)

- Overground walking training (WALK-Group)

- Control group (CT-Group)

All participants received 55 minutes daily gait-oriented physiotherapy and additional gait training for 15 sessions over 3 weeks (each session lasting maximum of 20 minutes of walking). However, CT-Group received 1 or 2 physiotherapy sessions daily but not at the same intensity as in the other groups.

Outcomes Outcomes were recorded at baseline and after 3 weeks and 6 months:

- FAC

- 10-metre walk test

- 6-minute walk test

- Modified Motor Assessment Scale

- Rivermead Motor Assessment Scale

- Rivermead Mobility Index

Notes Because we were interested in the effects of automated electromechanical- and robotic-assisted gaittraining devices for improving walking after stroke, we combined the results of the CT-Group and the WALK-Group as one group, which we compared with the results from the GT-Group.

\section{Risk of bias}

\begin{tabular}{lll}
\hline Bias & Authors' judgement & Support for judgement \\
\hline $\begin{array}{l}\text { Random sequence genera- } \\
\text { tion (selection bias) }\end{array}$ & Low risk & $\begin{array}{l}\text { An investigator not involved in the study randomly assigned participants to } \\
\text { groups using concealed envelopes. }\end{array}$ \\
\hline $\begin{array}{l}\text { Allocation concealment } \\
\text { (selection bias) }\end{array}$ & Low risk & $\begin{array}{l}\text { Allocation was performed by an independent person not otherwise involved } \\
\text { with the participants. }\end{array}$ \\
\hline
\end{tabular}


Peurala 2009 (Continued)

$\begin{array}{lll}\text { Blinding of outcome as- } & \text { High risk } & \text { No } \\ \text { sessment (detection bias) } & & \end{array}$

All outcomes

\begin{tabular}{l}
$\begin{array}{l}\text { Incomplete outcome data Unclear risk } \\
\begin{array}{l}\text { (attrition bias) } \\
\text { All outcomes }\end{array}\end{array}$ \\
\hline
\end{tabular}

Picelli 2016

\begin{tabular}{|c|c|}
\hline Methods & $\begin{array}{l}\text { RCT } \\
\text { Method of randomisation: software generated } \\
\text { Blinding of outcome assessors: yes } \\
\text { Adverse events: none } \\
\text { Deaths: none } \\
\text { Dropouts: none } \\
\text { ITT analysis: no dropouts }\end{array}$ \\
\hline Participants & $\begin{array}{l}\text { Country: Italy } \\
22 \text { participants ( } 11 \text { in treatment group, } 11 \text { in control group) } \\
\text { Ambulatory at study onset } \\
\text { Mean age: } 63 \text { years } \\
\text { Inclusion criteria: age }>18 \text { years, leg spasticity, } F A C>4 \text {, duration of illness }>6 \text { months } \\
\text { Exclusion criteria: participation in other trials, deformities such as contractures, spasticity treatment } \\
\text { before the study }\end{array}$ \\
\hline Interventions & $\begin{array}{l}2 \text { arms: } \\
\text { - Botulinum toxin injections for spastic triceps surae and additional } 30 \text { minutes G-EO gait training for } \\
5 \text { days } \\
\text { - Botulinum toxin injections for spastic triceps surae without additional gait training }\end{array}$ \\
\hline Outcomes & $\begin{array}{l}\text { Outcomes were recorded at baseline, } 1 \text { month } \\
\text { Primary outcome: } \\
\text { - Modified Ashworth Scale } \\
\text { Secondary outcomes: } \\
\text { - Tardieu Scale } \\
\text { - 6-minute walk test }\end{array}$ \\
\hline
\end{tabular}

Notes 1 group received additional gait training (performance bias).

\section{Risk of bias}

\begin{tabular}{lll}
\hline Bias & Authors' judgement & Support for judgement \\
\hline $\begin{array}{l}\text { Random sequence genera- } \\
\text { tion (selection bias) }\end{array}$ & Low risk & Software-generated random order \\
\hline $\begin{array}{l}\text { Allocation concealment } \\
\text { (selection bias) }\end{array}$ & Low risk & Sealed, opaque envelopes \\
\hline $\begin{array}{l}\text { Blinding of outcome as- } \\
\text { sessment (detection bias) }\end{array}$ & Low risk & Blinded evaluator \\
\hline
\end{tabular}


Picelli 2016 (Continued)

All outcomes

Incomplete outcome data Low risk No dropouts
(attrition bias)

All outcomes

Pohl 2007

\begin{tabular}{|c|c|}
\hline Methods & $\begin{array}{l}\text { RCT } \\
\text { Method of randomisation: lots indicating A or B were prepared in sealed envelopes } \\
\text { Blinding of outcome assessors: primary outcomes were evaluated by blinded assessors } \\
\text { Adverse events: } 4 \text { ( } 3 \text { in experimental group, } 1 \text { in control group) } \\
\text { Deaths: } 2 \text { ( } 1 \text { in experimental group, } 1 \text { in control group) } \\
\text { Dropouts: } 11 \text { (5 in experimental group, } 6 \text { in control group) } \\
\text { ITT analysis: yes }\end{array}$ \\
\hline Participants & $\begin{array}{l}\text { Country: Germany } \\
155 \text { participants ( } 77 \text { in treatment group, } 78 \text { in control group) } \\
\text { Non-ambulatory at study onset } \\
\text { Mean age: } 63 \text { years } \\
\text { Inclusion criteria: first supratentorial stroke (ischaemic or haemorrhagic); age between } 18 \text { and } 79 \text { years; } \\
\text { interval between stroke and study onset less than } 60 \text { days; able to sit unsupported (i.e. without holding } \\
\text { onto supports such as the edge of the bed), with feet supported, could not walk at all, or required the } \\
\text { help of } 1 \text { or } 2 \text { therapists irrespective of the use of an ankle-foot orthosis or a walking aid (FAC } 3 \text { or less); } \\
\text { understanding the meaning of the study and following instructions, providing written informed con- } \\
\text { sent to participation in the study approved by the local ethical committee } \\
\text { Exclusion criteria: unstable cardiovascular condition after a } 12 \text {-lead electrocardiogram examined by a } \\
\text { cardiologist, restricted passive range of motion in the major lower limb joints (extension deficit }>20^{\circ} \\
\text { for the affected hip or knee joints, or a dorsiflexion deficit }>20^{\circ} \text { for the affected ankle, tested while lying } \\
\text { supine and on the non-affected side), prevalence of other neurological or orthopaedic diseases impair- } \\
\text { ing walking ability }\end{array}$ \\
\hline Interventions & $\begin{array}{l}2 \text { arms: } \\
\text { - } 20 \text { minutes locomotor training with Gait Trainer in combination with } 25 \text { minutes physiotherapy week- } \\
\text { days for } 4 \text { weeks } \\
\text { - } 45 \text { minutes physiotherapy weekdays for } 4 \text { weeks }\end{array}$ \\
\hline
\end{tabular}

Outcomes Outcomes were recorded at baseline and after 4 weeks and 6 months.

Primary outcomes:

- Gait ability (FAC 0 to 5)

- Barthel Index (0 to 100)

Participants who were ambulatory (FAC 4 or 5) or reaching a Barthel Index $>75$ were defined as responders to therapy.

Secondary outcomes:

- Walking velocity

- Walking endurance

- Mobility (Rivermead Mobility Index)

- Leg power (Motricity Index) 
Pohl 2007 (Continued)

Risk of bias

\begin{tabular}{|c|c|c|}
\hline Bias & Authors' judgement & Support for judgement \\
\hline $\begin{array}{l}\text { Random sequence genera- } \\
\text { tion (selection bias) }\end{array}$ & Low risk & $\begin{array}{l}\text { Lots indicating A or B were prepared in sealed envelopes; a person not in- } \\
\text { volved in the study allocated participants to groups using the concealed en- } \\
\text { velopes. }\end{array}$ \\
\hline $\begin{array}{l}\text { Allocation concealment } \\
\text { (selection bias) }\end{array}$ & Low risk & Concealed envelopes \\
\hline $\begin{array}{l}\text { Blinding of outcome as- } \\
\text { sessment (detection bias) } \\
\text { All outcomes }\end{array}$ & Low risk & $\begin{array}{l}\text { Blinded primary outcomes (a person not involved in the study rated video- } \\
\text { tapes of participants) }\end{array}$ \\
\hline $\begin{array}{l}\text { Incomplete outcome data } \\
\text { (attrition bias) } \\
\text { All outcomes }\end{array}$ & Low risk & $\begin{array}{l}\text { ITT analysis done; missing outcome data balanced in numbers across inter- } \\
\text { vention groups, with similar reasons for missing data across groups. }\end{array}$ \\
\hline
\end{tabular}

Saltuari 2004

\begin{tabular}{ll}
\hline Methods & Cross-over RCT \\
Method of randomisation: by random numbers \\
Blinding of outcome assessors: unclear \\
Adverse events: none \\
Deaths: none \\
Dropouts: none \\
ITT: yes
\end{tabular}

\begin{tabular}{ll}
\hline Participants & Country: Austria \\
& 16 participants (8 in treatment group, 8 in control group) \\
Ambulatory and non-ambulatory at study onset & Mean age: 61 years \\
Inclusion criteria: not provided \\
Exclusion criteria: not provided
\end{tabular}

\begin{tabular}{ll}
\hline Interventions & 2 arms (A: Lokomat, B: physiotherapy): \\
& - 3 weeks A, 3 weeks B, 3 weeks A \\
& - 3 weeks B, 3 weeks A, 3 weeks B
\end{tabular}

Outcomes

Outcomes were recorded at baseline and after 3 weeks (they were additionally recorded after 6 and 9 weeks, but only outcomes of the first phase were included in this review).

Notes Unpublished data provided by the authors.

\section{Risk of bias}

Bias Authors' judgement Support for judgement

Random sequence genera- Low risk By random numbers
tion (selection bias)

\begin{tabular}{ll}
\hline $\begin{array}{l}\text { Allocation concealment } \\
\text { (selection bias) }\end{array}$ & Unclear risk
\end{tabular}


Saltuari 2004 (Continued)

Blinding of outcome as- Unclear risk Unclear sessment (detection bias)

All outcomes

Incomplete outcome data Low risk No missing outcome data
(attrition bias)

(attrition bias)

All outcomes

\section{Schwartz 2006}

RCT
Methods
tal group and 2 control group)
Blinding of outcome assessors: no
Adverse events: 5 ( 3 in experimental group, 2 in control group)
Deaths: none
Dropouts: 11 (8 in experimental group, 3 in control group)
ITT: no (stated, but 2 participants from the control group were excluded from analysis)

Country: Israel
Participants
Non-ambulatory at study onset
Mean age: 60 years
Inclusion criteria: first stroke, until 3 months after stroke
Exclusion criteria: not provided

Interventions 2 arms:

- Physiotherapy with additional gait training using the Lokomat 3 times a week for 6 weeks

- Physiotherapy with additional gait training 3 times a week for 6 weeks

\begin{tabular}{ll}
\hline Outcomes & Outcomes were recorded at baseline and after 3, 6, and 9 weeks: \\
& - FAC \\
& - NIHSS \\
& - Stroke Activity Scale \\
& - Functional Independence Measure \\
& - 2-minute walk test \\
& - Timed Up and Go Test \\
& Stair-climbing test \\
\hline Notes & Published and unpublished data provided by the authors. \\
\hline Risk of bias & \\
\hline Bias & Authors' judgement Support for judgement \\
\hline $\begin{array}{l}\text { Random sequence genera- } \\
\text { tion (selection bias) }\end{array}$ & Unclear risk $\quad$ Block sampling \\
\hline $\begin{array}{l}\text { Allocation concealment } \\
\text { (selection bias) }\end{array}$ & Unclear risk Unclear \\
\hline
\end{tabular}


Schwartz 2006 (Continued)

Blinding of outcome assessment (detection bias)

High risk

Not done

All outcomes

$\begin{array}{ll}\begin{array}{l}\text { Incomplete outcome data } \\ \text { (attrition bias) }\end{array} & \text { High risk } \\ \text { All outcomes } & \begin{array}{l}\text { For dichotomous outcome data, the proportion of missing outcomes com- } \\ \text { pared with observed event risk was enough to induce clinically relevant bias } \\ \text { into intervention effect estimate. }\end{array}\end{array}$

Stein 2014

RCT
Methods
Blinding of outcome assessors: stated as 'yes'
Adverse events: none
Deaths: none
Dropouts: none immediately after study end (at 3-month follow-up: 2 in experimental group and 2 in
control group)
ITT: no

Country: USA
24 participants (12 in treatment group, 12 in control group)
Ambulatory at start of study
Mean age: 58 years in experimental group and 57 years in control group
Inclusion criteria: single stroke, significant leg weakness and gait alterations $<6$ months before study
entry, independent in household ambulation
Exclusion criteria: ongoing physical therapy for the leg and/or gait and mobility, botulinum toxin injec-
tions $<3$ months before study entry, no further planned injections, other neurologic disorders, exces-
sive spasticity of lower limb (Ashworth Scale $>3$ ), uncontrolled hypertension, unstable coronary artery
disease, contractures of lower limb, impaired cognition (MMSE score $<24$ )

2 arms:
Interventions
$\begin{aligned} & \text { Experimental group: robotic gait treatment (robotic leg brace), } 3 \text { days/week for } 6 \text { weeks (60 min- } \\ & \text { utes/day) }\end{aligned}$
$\begin{aligned} & \text { Control group: group exercises for relaxation/meditation, self stretching, and gentle upper and lower } \\ & \text { limb active range-of-motion exercises for the same time }\end{aligned}$

Outcomes Outcomes were recorded at baseline, after 6, 10, and 19 weeks

Outcome measures: Timed Up and Go Test, 10-metre walk test, 6-minute walk test, Five-Times-Sit-toStand Test, Berg Balance Scale, California Functional Evaluation, Emory Functional Ambulation Profile

\section{Notes}

\section{Risk of bias}

\begin{tabular}{lll}
\hline Bias & Authors' judgement & Support for judgement \\
\hline $\begin{array}{l}\text { Random sequence genera- } \\
\text { tion (selection bias) }\end{array}$ & Unclear risk & Method unclear \\
\hline $\begin{array}{l}\text { Allocation concealment } \\
\text { (selection bias) }\end{array}$ & Unclear risk & Unclear, not described \\
\hline
\end{tabular}


Stein 2014 (Continued)

Blinding of outcome as- Low risk Performed by 1 physical therapist blinded to group assignment sessment (detection bias)

All outcomes

Incomplete outcome data High risk $\quad$ No ITT
(attrition bias)

(attrition bias)

All outcomes

Tanaka 2012

\begin{tabular}{ll} 
Methods & Cross-over RCT \\
Method of randomisation: computer-generated randomisation \\
Blinding of outcome assessors: no \\
Adverse events: none described \\
Deaths: none \\
Dropouts: none \\
ITT: no \\
\hline Country: Japan \\
12 participants ( 7 in treatment group, 5 in control group) \\
All were ambulatory at study onset \\
Mean age: 62 years \\
Inclusion criteria: first stroke; more than 6 months since stroke onset; slight-to-moderate motor deficit \\
(Brunnstrom recovery stages III-VI); could walk with or without walking aids \\
Exclusion criteria: higher brain function disorder or cognitive deficit affecting ability to understand and \\
describe symptoms (<24 on the MMSE); severe heart disorder affecting gait movement intensity; severe \\
bone and joint disease affecting gait movement
\end{tabular}

Interventions 2 arms (only the first 12 weeks before cross-over are described here; A: no training, B: gait training with Gait Master 4, 1 session: 20 minutes):

- 4 weeks $A ; 2$ or 3 times a week, 12 gait training sessions $B ; 4$ weeks $A$

- 4 weeks $A ; 4$ weeks $A ; 4$ weeks follow-up

Outcomes Outcomes were recorded weekly over a 24-week period:

- Gait speed

- Timed Up and Go Test times

Notes

\section{Risk of bias}

\begin{tabular}{lll}
\hline Bias & Authors' judgement & Support for judgement \\
\hline $\begin{array}{l}\text { Random sequence genera- } \\
\text { tion (selection bias) }\end{array}$ & Low risk & Computer-generated randomisation \\
\hline $\begin{array}{l}\text { Allocation concealment } \\
\text { (selection bias) }\end{array}$ & Unclear risk & Unclear \\
\hline $\begin{array}{l}\text { Blinding of outcome as- } \\
\text { sessment (detection bias) } \\
\text { All outcomes }\end{array}$ & High risk & No \\
\hline
\end{tabular}


Tanaka 2012 (Continued)

Incomplete outcome data Unclear risk Unclear
(attrition bias)

All outcomes

Tong 2006

RCT
Randomisation was done by computer-generated random numbers
Blinding of outcome assessors: no (except for Barthel Index and Functional Independence Measure
scores, which were performed by nurses who were blinded)
Adverse events: 2 (none in experimental group, 2 in control group)
Deaths: none
Dropouts: 4 (none in experimental group, 4 in control group)
ITT: yes

Participants

Country: Hong Kong, China

50 participants (15 in treatment group A, 15 in treatment group B, 20 in control group)

Non-ambulatory at study onset

Mean age: 68 years

Inclusion criteria: diagnosis of first ischaemic brain injury or intracerebral haemorrhage shown by magnetic resonance imaging or computed tomography less than 6 weeks after onset of stroke; sufficient cognition to follow simple instructions and understand the content and purpose of the study (MMSE score > 21); ability to stand upright, supported or unsupported, for 1 minute; significant gait deficit (FAC score $<3$ ); no skin allergy to electrical stimulation

Exclusion criteria: recurrent stroke; other neurological, medical, or psychological deficit or condition that would affect ambulation ability or compliance with study protocol (such as Parkinson's disease, major depression, pain, cardiac arrhythmias); aphasia with an inability to follow 2 consecutive step commands or a cognitive deficit; severe hip, knee, or ankle contracture that would preclude passive range of motion of the leg

\begin{tabular}{ll}
\hline Interventions & 3 arms: \\
& - Gait trainer \\
& - Gait trainer + functional electrical stimulation \\
& - Conventional physiotherapy alone
\end{tabular}

The study consisted of 1 training session per weekday for 4 weeks.

Experimental groups 1 and 2 underwent gait training for 20 minutes, with body weight support by an electromechanical gait trainer; group 2 also received functional electrical stimulation to the paretic lower limb during gait training.

Participants in group 3 received physiotherapy overground gait training based on the principles of proprioceptive neuromuscular facilitation and Bobath concepts.

\begin{tabular}{ll}
\hline Outcomes & 5-metre walking speed test \\
- Elderly Mobility Scale \\
- Berg Balance Scale \\
- FAC \\
- Motricity Index leg subscale \\
- Functional Independence Measure instrument score \\
- Barthel Index score \\
\hline Notes \\
\hline
\end{tabular}

Risk of bias 
Tong 2006 (Continued)

\begin{tabular}{lll} 
Bias & Authors' judgement & Support for judgement \\
\hline $\begin{array}{l}\text { Random sequence genera- } \\
\text { tion (selection bias) }\end{array}$ & Low risk & Computer-generated random numbers \\
\hline $\begin{array}{l}\text { Allocation concealment } \\
\text { (selection bias) }\end{array}$ & Low risk & Concealed \\
\hline $\begin{array}{l}\text { Blinding of outcome as- } \\
\text { sessment (detection bias) } \\
\text { All outcomes }\end{array}$ & Low risk & Yes for primary outcome \\
\hline $\begin{array}{l}\text { Incomplete outcome data } \\
\text { (attrition bias) } \\
\text { All outcomes }\end{array}$ & Unclear risk & ITT unclear \\
\hline
\end{tabular}

Ucar 2014

Rethods
Method of randomisation: random number list
Blinding of outcome assessors: yes
Adverse events: not described
Deaths: not described
Dropouts: not described
ITT: unknown

Country: Turkey
22 participants (11 in treatment group, 11 in control group)
Ambulatory at start of study
Mean age: 56 years in experimental group and 62 years in control group
Inclusion criteria: adult male (> 18 years), ability to ambulate 10 metres without personal assistance,
and not receiving any other physical therapy
Exclusion criteria: body weight more than 300 pounds (135 $\mathrm{kg})$, FAC score $<3$ and not able to walk con-
sistently or independently within the community, cognitive deficits, cardiac disease, spasticity of the
lower limbs preventing robotic walking, traumatic stroke, intracranial space occupying lesion-induced
strokes, and seizures

Interventions 2 arms:

- Experimental group: robotic gait treatment (Lokomat), 30-minute sessions, 5 sessions per week for 2 weeks

- Control group: the conventional exercise group received the equivalent additional time of conventional physiotherapy at home as determined by rehabilitation unit physiotherapists. Home exercise procedure focused on gait in order to raise awareness about trunk stability-symmetry and body weight support on the paretic leg. Sessions taken 5 days per week for 2 weeks included active and passive range of motion, active-assistive exercises, strengthening of the paretic leg, and balance training

\section{Outcomes Outcomes were assessed at baseline and after 2 and 8 weeks:}

- Walking speed

- Timed Up and Go Test

Notes 
Ucar 2014 (Continued)

\section{Risk of bias}

\begin{tabular}{lll}
\hline Bias & Authors' judgement & Support for judgement \\
\hline $\begin{array}{l}\text { Random sequence genera- } \\
\text { tion (selection bias) }\end{array}$ & Low risk & Random number list \\
\hline $\begin{array}{l}\text { Allocation concealment } \\
\text { (selection bias) }\end{array}$ & Unclear risk & Not described \\
\hline $\begin{array}{l}\text { Blinding of outcome as- } \\
\text { sessment (detection bias) } \\
\text { All outcomes }\end{array}$ & Low risk & Stated as blinded \\
\hline $\begin{array}{l}\text { Incomplete outcome data } \\
\text { (attrition bias) } \\
\text { All outcomes }\end{array}$ & Unclear risk & Unclear \\
\hline
\end{tabular}

Van Nunen 2012

\begin{tabular}{ll}
\hline Methods & RCT \\
Method of randomisation: stated as block randomisation & Blinding of outcome assessors: no \\
Adverse events: none described & Deaths: none \\
Dropouts: none \\
ITT: unknown
\end{tabular}

Outcomes Outcomes were assessed at baseline and after 8 weeks:

- Walking speed

- FAC

- Berg Balance Scale

- Rivermead Mobility Index

- Fugl-Meyer Leg Score

Notes Published and unpublished data provided by the authors.

\section{Risk of bias}

Bias Authors' judgement Support for judgement


Van Nunen 2012 (Continued)

Random sequence genera- Unclear risk Unclear
tion (selection bias)

\begin{tabular}{|c|c|c|}
\hline $\begin{array}{l}\text { Allocation concealment } \\
\text { (selection bias) }\end{array}$ & Low risk & $\begin{array}{l}\text { A person not involved in the study was asked to draw } 1 \text { of the opaque en- } \\
\text { velopes inside which group assignment was established each time a new par- } \\
\text { ticipant entered the study. }\end{array}$ \\
\hline
\end{tabular}

\begin{tabular}{ll}
\hline Blinding of outcome as- & High risk \\
sessment (detection bias) & \\
All outcomes &
\end{tabular}

Incomplete outcome data Unclear risk Unclear
(attrition bias)
All outcomes

\section{Waldman 2013}

\begin{tabular}{ll}
\hline Methods & RCT \\
Method of randomisation: unclear \\
Blinding of outcome assessors: no \\
Adverse events: none described \\
Deaths: none \\
Dropouts: none \\
ITT: unknown \\
Country: USA \\
24 participants (12 in treatment group, 12 in control group) \\
Ambulatory at study onset \\
Mean age: 51 years \\
Inclusion criteria: people with stroke duration longer than 3 months, with reduced ankle range of mo- \\
tion and strength, and able to walk with or without assistant devices \\
Exclusion criteria: unknown \\
2 arms \\
- 18 sessions (1 hour, 3 times a week over 6 weeks) gait training with portable rehabilitation robot \\
- 18 sessions (1 hour, 3 times a week over 6 weeks) exercise training without device (instructed exercise \\
for the control group involved stretching the plantar flexors and active movement exercises for ankle \\
mobility and strength)
\end{tabular}

\begin{tabular}{ll}
\hline Outcomes & Outcomes were assessed at baseline and after 6 and 12 weeks : \\
- modified Ashworth scale \\
- Stroke Rehabilitation Assessment of Movement (STREAM) \\
- Berg Balance Scale \\
- 6 -minute walk test \\
- Passive range of motion \\
- Plantar flexor strength
\end{tabular}

Notes Published and unpublished data provided by the authors.

\section{Risk of bias}

Bias Authors' judgement Support for judgement


Waldman 2013 (Continued)

Random sequence genera- Unclear risk $\quad$ Method not described.
tion (selection bias)

$\begin{array}{lll}\text { Allocation concealment } & \text { High risk } & \text { Not described } \\ \text { (selection bias) }\end{array}$

(selection bias)

$\begin{array}{lll}\text { Blinding of outcome as- } & \text { High risk } & \text { Not described } \\ \text { sessment (detection bias) } & \end{array}$

All outcomes

Incomplete outcome data Unclear risk $\quad$ No ITT
(attrition bias)

(attrition bias)

All outcomes

\section{Watanabe 2014}

$\begin{array}{ll}\text { Methods } & \text { RCT } \\ \text { Method of randomisation: computer generated } \\ \text { Blinding of outcome assessors: stated as 'no' } \\ \text { Adverse events: none } \\ \text { Deaths: none } \\ \text { Dropouts: } 10 \text { (6 in experimental group and } 4 \text { in control group) } \\ \text { ITT: no }\end{array}$

Country: Japan
32 participants (17 in treatment group, 15 in control group)
Not ambulatory at start of study
Mean age: 67 years in experimental group and 76 years in control group
Inclusion criteria: stroke < 6 months
Exclusion criteria: not ambulating prior to stroke, FAC 4 or 5, severe cardiac disease, NYHA III or IV, se-
vere disturbance of consciousness (Japan Coma Scale II or III), size limitations for the robotic orthosis,
skin disease, pacemaker

Interventions 2 arms:

- Experimental group: robotic gait treatment (robot suit Hybrid Assistive Limb, single-leg version of the Hybrid Assistive Limb on the paretic side), 20 minutes daily for 12 sessions over 4 weeks

- Control group: conventional gait rehabilitation for the same amount of time

\section{Outcomes}

Outcomes were recorded at baseline, after 12 training sessions

Primary outcome:

- FAC

Secondary outcomes:

- Maximum walking speed

- Timed Up and Go Test

- 6-minute walk test

- Short Physical Performance Battery

- Fugl-Meyer Assessment of Lower Extremity

- Isometric muscle strength (hip flexion and extension, knee flexion and extension) 
Watanabe 2014 (Continued)

Notes

\section{Risk of bias}

\begin{tabular}{lll}
\hline Bias & Authors' judgement & Support for judgement \\
\hline $\begin{array}{l}\text { Random sequence genera- } \\
\text { tion (selection bias) }\end{array}$ & Low risk & Computer-generated sequence \\
\hline $\begin{array}{l}\text { Allocation concealment } \\
\text { (selection bias) }\end{array}$ & Unclear risk & $\begin{array}{l}\text { Odd-numbered participants underwent gait training using the Hybrid Assistive } \\
\text { Limb, and even-numbered participants underwent conventional gait training } \\
\text { (maybe even high risk of bias). }\end{array}$ \\
\hline $\begin{array}{l}\text { Blinding of outcome as- } \\
\text { sessment (detection bias) } \\
\begin{array}{l}\text { All outcomes } \\
\text { Incomplete outcome data }\end{array}\end{array}$ & High risk risk & Not done \\
$\begin{array}{l}\text { (attrition bias) } \\
\text { All outcomes }\end{array}$ & No ITT \\
\hline
\end{tabular}

\section{Werner 2002}

Cross-over RCT
Method of randomisation: participants randomly assigned to groups (group allocation in envelopes
that were drawn by an independent person)
Blinding of outcome assessors: yes
Adverse events: none
Deaths: none
Dropouts: none
ITT:yes

Country: Germany
Participants participants (15 in treatment group, 15 in control group)
Non-ambulatory at study onset
Mean age: 60 years
Inclusion criteria: first stroke, supratentorial lesion 4 to 12 weeks' poststroke, younger than 75 years of
age, not able to walk (FAC of 2 or less), able to sit unsupported on the edge of a bed, able to stand for at
least 10 seconds with help, able to provide and did provide written informed consent
Exclusion criteria: hip and knee extension deficit > 20 degrees; passive dorsiflexion of the affected an-
kle to less than a neutral position; severe impairment of cognition or communication; evidence of car-
diac ischaemia, arrhythmia, decompression, or heart failure; feeling of 'overexertion' or heart rate ex-
ceeding the age-predicted maximum (i.e. 190 beats/minute minus age) during training; resting systolic
blood pressure exceeding $200 \mathrm{~mm} \mathrm{Hg}$ at rest or dropping by more than 10 mm Hg with increasing work-
load

Interventions 2 arms:

- 2 weeks $A, 2$ weeks B, 2 weeks $A$

- 2 weeks B, 2 weeks A, 2 weeks B

Treated as inpatients for five 15- to 20-minute sessions per week for 2 weeks

A: treadmill training with body weight support: participants walked on a treadmill with partial body weight support provided by a harness

B: gait trainer with body weight support: participants walked on Gait Trainer with partial body weight support provided by a harness 
Werner 2002 (Continued)

Outcomes
Outcomes were recorded at baseline and after 2 weeks (additionally after 4 and 6 weeks, but only the first phase was included in this review):

- FAC

- Fast walking speed over 10 metres with personal assistance and gait aids if required

- Rivermead Motor Assessment Scale

- Ankle spasticity (Modified Ashworth Scale)

Notes

We used the first treatment phase only.

Published and unpublished data provided by the authors.

$0 \%$ dropouts at the end of first treatment phase (data were analysed as ITT)

\section{Risk of bias}

\section{Bias}

\section{Authors' judgement Support for judgement}

Random sequence genera- Low risk By envelopes

tion (selection bias)

\begin{tabular}{l} 
Allocation concealment $\begin{array}{l}\text { Low risk } \\
\text { (selection bias) }\end{array}$ \\
\hline
\end{tabular}

Blinding of outcome as- Low risk Yes

sessment (detection bias)

All outcomes

Incomplete outcome data Low risk No missing data
(attrition bias)

All outcomes

Westlake 2009

RCT
Methods of randomisation: computer-generated random order (stratified by fast or slow walking)
Blinding of outcome assessors: not described
Adverse events: 1 in control group
Deaths: none
Dropouts: none
ITT: yes

Participants Country: USA

16 participants (8 in treatment group, 8 in control group)

All were ambulatory at study onset

Mean age: 57 years

Inclusion criteria: hemiparesis resulting from a single cortical or subcortical stroke $>6$ months before the study, categorised as at least unlimited household ambulatory, written informed consent Exclusion criteria: unstable cardiovascular, orthopaedic, or neurological conditions; uncontrolled diabetes that would preclude exercise of moderate intensity; significant cognitive impairment affecting ability to follow directions
Interventions
2 arms:
- 12 physiotherapy sessions including gait training using the Lokomat ( 3 times a week over 4 weeks)
- 12 physiotherapy sessions including manual guided gait training ( 3 times a week over 4 weeks) 
Westlake 2009 (Continued)

- Self selected and fast walking speed

- 6-minute walk test

- Absolute step length ratio

- Lower extremity Fugl-Meyer

- Short Physical Performance Battery

- Berg Balance Scale

- Late-Life Function \& Disability Instrument

Notes -

\section{Risk of bias}

\begin{tabular}{lll}
\hline Bias & Authors' judgement & Support for judgement \\
\hline $\begin{array}{l}\text { Random sequence genera- } \\
\text { tion (selection bias) }\end{array}$ & Unclear risk & Unclear \\
\hline $\begin{array}{l}\text { Allocation concealment } \\
\text { (selection bias) }\end{array}$ & Low risk & $\begin{array}{l}\text { Randomisation list was overseen by } 1 \text { of the investigators who had no contact } \\
\text { with participants until group assignment was revealed. } \\
\text { Group assignment was not revealed to study personnel until the participant } \\
\text { consented and baseline testing was complete. }\end{array}$ \\
\hline $\begin{array}{l}\text { Blinding of outcome as- } \\
\text { sessment (detection bias) } \\
\text { All outcomes }\end{array}$ & High risk & No \\
\hline $\begin{array}{l}\text { Incomplete outcome data } \\
\text { (attrition bias) }\end{array}$ & Low risk & No missing data \\
$\begin{array}{l}\text { All outcomes } \\
\end{array}$ &
\end{tabular}

ABC: Activities-specific Balance Confidence

$A D L$ : activities of daily living

$\mathrm{CT}$ : computed tomography

FAC: Functional Ambulation Category

ITT: intention-to-treat

MMSE: Mini-Mental State Examination

MRC: Medical Research Council

MRI: magnetic resonance imaging

NIHSS: National Institutes of Health Stroke Scale

NYHA: New York Heart Association

PF-DF: plantar flexion and dorsiflexion

RAGT: robot-assisted gait training

$\mathrm{RCT}$ : randomised controlled trial

SF-36: 36-Item Short Form Health Survey

Characteristics of excluded studies [ordered by study ID]

\begin{tabular}{ll}
\hline Study & Reason for exclusion \\
\hline Bae 2014 & $\begin{array}{l}\text { Intervention: both groups received robot-assisted gait training (the experimental group also re- } \\
\text { ceived functional electrical stimulation on the ankle dorsiflexor of the affected side). }\end{array}$ \\
\hline Byun 2011 & Uses a sliding rehabilitation machine, not robotic training as experimental condition \\
\hline
\end{tabular}




\begin{tabular}{ll}
\hline Study & Reason for exclusion \\
\hline Caldwell 2000 & $\begin{array}{l}\text { Did not investigate electromechanical- and robotic-assisted gait-training devices as stated in the } \\
\text { protocol of this review: bicycle training versus treadmill walking versus variable surface training } \\
\text { were investigated }\end{array}$ \\
\hline
\end{tabular}

Danzl 2013 Investigates brain stimulation, and both groups participated in identical locomotor training with a
robotic gait orthosis

\begin{tabular}{ll}
\hline David 2006 & Did not meet inclusion criteria of this review: not an RCT \\
\hline Forrester 2016 & Compared different robotic applications \\
\hline Gong 2003 & $\begin{array}{l}\text { Did not investigate electromechanical- and robotic-assisted gait-training devices as stated in the } \\
\text { protocol of this review: no electromechanical-assisted devices were compared }\end{array}$
\end{tabular}

\begin{tabular}{ll}
\hline Goodman 2014 & Did not meet inclusion criteria of this review: not an RCT \\
\hline Hesse 2001 & Did not meet inclusion criteria of this review: not an RCT \\
\hline Hsieh 2014 & Investigated upper limbs \\
\hline Mirelman 2009 & $\begin{array}{l}\text { Did not meet inclusion criteria of this review: experimental and control groups received a kind of } \\
\text { assisted stepping therapy in a seated position. This study investigated the effects of virtual reali- } \\
\text { ty as an adjunct to stepping training. After discussion, we reached consensus to exclude this study } \\
\text { from our review. }\end{array}$ \\
\hline Morone 2016 & $\begin{array}{l}\text { Investigated the i-Walker, a rollator vehicle } \\
\text { NCT01337960 }\end{array}$ \\
\hline Compared different robotic approaches \\
\hline $\begin{array}{l}\text { Did not meet inclusion criteria of this review: the experimental group received a kind of assisted } \\
\text { stepping therapy in a seated position. This study investigated the effect of the NuStep apparatus. } \\
\text { After discussion, we reached consensus to exclude this study from our review. }\end{array}$
\end{tabular}

$\begin{array}{ll}\text { Park } 2015 & \text { Uses a treadmill training approach as experimental condition (Gait Trainer } 2 \text { analysis system, } \\ \text { Biodex Medical Systems, Inc., Shirley, NY, USA) }\end{array}$

\begin{tabular}{ll}
\hline Patten 2006 & $\begin{array}{l}\text { According to the information on ClinicalTrials.gov (NCT00125619), this is a 1-arm, non-randomised } \\
\text { trial. }\end{array}$ \\
\hline Pennati 2015 & Investigated upper limbs \\
\hline Picelli 2015 & Both groups received the same robotic treatment. \\
\hline Pitkanen 2002 & $\begin{array}{l}\text { Did not meet inclusion criteria of this review: the study describes preliminary findings of an initial } \\
\text { sample of } 9 \text { participants; the experimental group received treadmill training or gait training }\end{array}$ \\
\hline Richards 1993 & $\begin{array}{l}\text { Did not meet inclusion criteria of this review: the experimental group received a specialised loco- } \\
\text { motor training including early intensive physiotherapy with tilt table, limb load monitor, resistance } \\
\text { exercises, and treadmills to promote functional recovery. After discussion, we reached consensus } \\
\text { to exclude this study. }\end{array}$ \\
\hline Richards 2004 & $\begin{array}{l}\text { Did not meet inclusion criteria of this review: the experimental group received specialised locomo- } \\
\text { tor training including early intensive physiotherapy with tilt table, limb load monitor, resistance ex- } \\
\text { ercises and treadmills to promote functional recovery. After discussion, we reached consensus to } \\
\text { exclude this study. }\end{array}$ \\
\hline
\end{tabular}




\begin{tabular}{ll}
\hline Study & Reason for exclusion \\
\hline Shirakawa 2001 & Not an RCT \\
\hline Skvortsova 2008 & Not an RCT, control groups were age and sex matched \\
\hline Stoller 2015 & Compared 2 treadmill exercise options \\
\hline Wu 2014 & Compared different modes (resistance versus assistance training) of the same robotic device \\
\hline
\end{tabular}

$\mathrm{RCT}$ : randomised controlled trial

Characteristics of studies awaiting assessment [ordered by study ID]

Chernikova 2014

\begin{tabular}{ll}
\hline Methods & Probably an RCT \\
\hline Participants & Unclear \\
\hline Interventions & Unclear \\
\hline Outcomes & Unclear \\
\hline Notes & - \\
\hline
\end{tabular}

Globokar 2005

\begin{tabular}{ll}
\hline Methods & Probably an RCT \\
\hline Participants & People after stroke, number unclear \\
\hline Interventions & 2 arms: \\
& -25 minutes neurophysiotherapy plus 20 minutes of Gait Trainer \\
& Not described \\
\hline Outcomes & Unclear \\
\hline Notes & This study was presented at the 5th World Congress of Physical Medicine and Rehabilitation. \\
\hline
\end{tabular}

\section{Golyk 2006}

\begin{tabular}{ll}
\hline Methods & Probably an RCT \\
\hline Participants & Unclear \\
\hline Interventions & Unclear \\
\hline Outcomes & Unclear \\
\hline Notes & - \\
\hline
\end{tabular}


Jang 2005

\begin{tabular}{|c|c|}
\hline Methods & Probably an RCT \\
\hline Participants & 34 non-ambulatory stroke survivors \\
\hline Interventions & $\begin{array}{l}2 \text { arms: } \\
\text { - } 14 \text { participants: } 20 \text { minutes of physiotherapy } 2 \text { days per week and } 20 \text { minutes of Gait Trainer } 3 \\
\text { days per week } \\
\text { - } 20 \text { participants: } 20 \text { minutes of physiotherapy } 5 \text { days per week }\end{array}$ \\
\hline
\end{tabular}

\begin{tabular}{ll}
\hline Outcomes & Unclear \\
\hline Notes & This study was presented at the 5th World Congress of Physical Medicine and Rehabilitation. \\
\hline
\end{tabular}

Kim 2001

\begin{tabular}{ll}
\hline Methods & Probably an RCT \\
\hline Participants & Unclear \\
\hline Interventions & Unclear \\
\hline Outcomes & Unclear \\
\hline
\end{tabular}

Notes Study was found in the Proceedings of the 1st International Congress of International Society of Physical and Rehabilitation Medicine (ISPRM), 2001 July 7-13.

\section{Kim 2014}

\begin{tabular}{ll}
\hline Methods & Probably an RCT \\
\hline Participants & Unclear \\
\hline Interventions & Unclear \\
\hline Outcomes & Unclear \\
\hline Notes & - \\
\hline
\end{tabular}

Koeneman 2004

\begin{tabular}{ll}
\hline Methods & Probably an RCT \\
\hline Participants & Unclear \\
\hline Interventions & Unclear \\
\hline Outcomes & Unclear \\
\hline
\end{tabular}


Koeneman 2004 (Continued)

Notes

Mehrberg 2001

\begin{tabular}{ll}
\hline Methods & Probably an RCT \\
\hline Participants & Unclear \\
\hline Interventions & Unclear \\
\hline Outcomes & Unclear \\
\hline Notes & - \\
\hline
\end{tabular}

Ohata 2015

\begin{tabular}{ll}
\hline Methods & Probably a randomised cross-over trial \\
\hline Participants & 23 participants with stroke (stroke onset $<6$ months) \\
& Group $1(\mathrm{~N}=13$; mean: $60.9 \pm 9.6$ years $)$ \\
& Group $2(\mathrm{~N}=10$; mean: $61.1 \pm 14.6$ years $)$
\end{tabular}

Interventions

Gait training with the Stride Management Assist device (Honda R\&D Co., Ltd. Japan) (20 minutes/time, 5 times per week for 4 weeks)

Conventional rehabilitation (40 minutes/time) 4 weeks

\begin{tabular}{ll}
\hline Outcomes & Brunnstrom Recovery Stage \\
& - Sensory subscale of Fugl-Meyer Assessment \\
& - Bodified Ashworth Scale \\
& - Short-Form Berg Balance Scale \\
- Functional Reach & \\
- Activities-specific Balance Confidence Scale \\
- Functional Ambulation Category \\
- 10 -metre walk test \\
- Timed Up and Go Test \\
- Muscle strength measured by hand-held dynamometry \\
\hline Published as abstract \\
\hline
\end{tabular}

\section{Sale 2012}

\begin{tabular}{ll}
\hline Methods & Probably an RCT \\
\hline Participants & Unclear \\
\hline Interventions & Unclear \\
\hline
\end{tabular}


Sale 2012 (Continued)
Outcomes
Unclear

\section{Wu 2012}

\begin{tabular}{ll}
\hline Methods & Probably an RCT \\
\hline Participants & Unclear \\
\hline Interventions & Unclear \\
\hline Outcomes & Unclear \\
\hline Notes & - \\
\hline
\end{tabular}

Yoon 2015

\begin{tabular}{ll}
\hline Methods & Probably an RCT \\
\hline Participants & Unclear \\
\hline Interventions & $\mathrm{N}=10$ in gait training with active-assistive gait device group \\
& $\mathrm{N}=10$ in control group \\
\hline Outcomes & - 10 -metre walk test $(\mathrm{m} / \mathrm{s})$ \\
& - Step cycle $(\mathrm{cycle} / \mathrm{s})$ \\
& - Angle of ankle dorsiflexion in swing phase \\
& - Korean Modified Barthel Index \\
& Manual Muscle Test \\
\hline Notes & Modified Ashworth Scale of hemiplegic ankle \\
\hline
\end{tabular}

\section{Zhu 2016}

\begin{tabular}{ll}
\hline Methods & Probably an RCT \\
\hline Participants & Unclear \\
\hline Interventions & Unclear \\
\hline Outcomes & Unclear \\
\hline Notes & - \\
\hline
\end{tabular}

$\mathrm{RCT}$ : randomised controlled trial 
Characteristics of ongoing studies [ordered by study ID]

Louie 2015 $\begin{array}{ll}\text { Trial name or title } & \begin{array}{l}\text { Use of a powered robotic exoskeleton to promote walking recovery after stroke: study protocol for } \\ \text { a randomised controlled trial }\end{array}\end{array}$

Methods

Single-blind randomised controlled trial to evaluate the efficacy of a powered mobile exoskeleton (Ekso) on improving walking ability in people early after stroke

\section{Participants}

50 individuals admitted for stroke rehabilitation in Canada, within 4 weeks' poststroke and needing second person assist to walk, will be randomly assigned to either a usual care group or exoskeleton group for 5 days/week for 4 weeks.

Interventions
\[ \begin{array}{l}\text { arms: } \\ \text { ing-related activities including muscle strengthening and standing }\end{array} \]
- Exoskeleton group will receive the same care, except that the 45 minutes of walking-related ac-
tivities will initially take place with the participant wearing an exoskeleton to ensure early over-
ground walking; participants will transition to walking without the device when able

\begin{tabular}{ll}
\hline Outcomes & $\begin{array}{l}\text { Outcomes will be measured at baseline, } \\
\text { ends. }\end{array}$ \\
Primary outcome: \\
- Walking ability (FAC) \\
Secondary outcomes: \\
- Walking speed (10-metre walk test) \\
- Endurance (6-minute walk test) \\
- Quality of life
\end{tabular}

\begin{tabular}{ll}
\hline Starting date & Unknown \\
\hline Contact information & Louie DR ${ }^{1,2}$ \\
& University of British Columbia, Vancouver, Canada \\
& $\begin{array}{l}\text { 2Rehabilitation Research Program, Vancouver Coastal Health Research Institute, Vancouver, Cana- } \\
\text { da }\end{array}$ \\
\hline Notes & Presented at the Canadian Stroke Conference, Toronto, 2015 September 17 \\
\hline
\end{tabular}

\section{NCT00284115}

\begin{tabular}{ll}
\hline Trial name or title & $\begin{array}{l}\text { Efficacy of a mechanical gait repetitive training technique compared with a usual rehabilitation } \\
\text { program on gait recovery in hemiparetic stroke patients }\end{array}$ \\
\hline Methods & RCT with 2 arms \\
\hline Participants & $\begin{array}{l}\text { Country: France } \\
\text { Inclusion criteria: men or women aged } 18 \text { years or older; hemiplegia secondary to stroke; interval } \\
\text { between stroke and study inclusion of } 2 \text { months or less; first-time supratentorial stroke; non-ambu- }\end{array}$
\end{tabular}


NCT00284115 (Continued)

latory (FAC stage 0); able to sit unsupported at the edge of the bed; no severe impairment of cognition or communication; written informed consent provided

Exclusion criteria: orthopaedic or rheumatological disease impairing mobility, or both; other neurologically associated disease; history of myocardial infarction or deep venous embolism or pulmonary embolism within 3 months before study inclusion; chronic pulmonary disease; intolerance to standing up

\begin{tabular}{|c|c|}
\hline Interventions & $\begin{array}{l}\text { 4-week rehabilitation programme comparing physiotherapy and gait trainer therapy with physio- } \\
\text { therapy alone }\end{array}$ \\
\hline Outcomes & $\begin{array}{l}\text { Primary outcomes: walking speed (time needed to walk } 10 \text { metres) after the 4-week rehabilitation } \\
\text { programme } \\
\text { Secondary outcomes: FAC; walking endurance (6-minute walk test); time to self sufficient gait re- } \\
\text { covery; spasticity (Modified Ashworth Scale); Motricity Index; need for mobility and self assistance } \\
\text { (Barthel Index, PMSI-SSR scores, need for physical assistance); economic evaluation (healthcare re- } \\
\text { quirements, rehabilitation unit length of stay) }\end{array}$ \\
\hline
\end{tabular}

\begin{tabular}{ll}
\hline Starting date & March 2006 \\
\hline Contact information & Principal Investigator: \\
& Régine Brissot, MD, Service de Médecine Physique et Réadaptation, Hôpital Pontchaillou, Rennes, \\
& 35033, France \\
& Tel: +33 299284219 \\
& email: regine.brissot@chu-rennes.fr
\end{tabular}

Notes Expected total enrolment: 122 participants

Sponsored by: Rennes University Hospital

Information derived from: ClinicalTrials.gov identifier: NCT00284115

\section{NCT00530543}

Trial name or title Effects of gait training with assistance of a robot-driven gait orthosis in hemiparetic patients after stroke

\begin{tabular}{|c|c|}
\hline Methods & $\begin{array}{l}\text { Randomised } \\
2 \text { arms }\end{array}$ \\
\hline Participants & $\begin{array}{l}\text { Inclusion criteria } \\
\text { - first-ever stroke } \\
\text { - hemiplegic patient after stroke } \\
\text { - can stand independently, but cannot walk more than } 10 \text { meters independently } \\
\text { - muscle powers of hip and knee are more than poor on manual muscle test } \\
\text { Exclusion criteria } \\
\text { - previous gait difficulty before stroke onset } \\
\text { - arthralgia on lower extremity } \\
\text { - uncontrolled hypertension or hypotension } \\
\text { - severe medical illness }\end{array}$ \\
\hline Interventions & Robot-assisted gait training \\
\hline Outcomes & Not provided \\
\hline
\end{tabular}


NCT00530543 (Continued)

Starting date Unknown status

\begin{tabular}{ll}
\hline Contact information & Not provided \\
\hline Notes & $\begin{array}{l}\text { The recruitment status of this study is unknown. The completion date has passed, and the status } \\
\text { has not been verified in more than } 2 \text { years. }\end{array}$ \\
\hline
\end{tabular}

\section{NCT01146587}

\begin{tabular}{ll}
\hline Trial name or title & Comparative study of GangTrainer GT1, Lokomat and conventional physiotherapy (GALOP) \\
\hline Methods & RCT with 3 arms \\
\hline Participants & $\begin{array}{l}\text { Inclusion criteria: first supratentorial stroke (ischaemic, haemorrhagic, or intracerebral haemor- } \\
\text { rhage) resulting in hemiparesis; interval from stroke } 3 \text { to } 12 \text { weeks; non-ambulatory (FAC }<3 \text { ); free }\end{array}$ \\
& sitting on bedside for 1 minute, with both feet on the floor and holding onto bedside by hands; \\
& Barthel Index 25 to 65 \\
& Exclusion criteria: unstable cardiovascular system (in case of doubt, only after approval by an in- \\
& ternist); manifested heart diseases like labile compensated cardiac insufficiency (NYHA III), angi- \\
& na pectoris, myocardial infarction 120 days before study onset, cardiomyopathy, severe cardiac ar- \\
& rhythmia, severe joint misalignment (severe constriction of movement for hip, knee, or ankle, or \\
& any combination of the 3: more than $20^{\circ}$ fixed hip and knee extension deficit, or more than $20^{\circ}$ fixed \\
plantar flexion of the ankle); severe cognitive dysfunction that prevents comprehension of the aims \\
of study; severe neurological or orthopaedic diseases (e.g. polio, Parkinson's disease) that massive- \\
ly affect mobility; deep vein thrombosis; severe osteoporosis; or malignant tumour disease
\end{tabular}

Group A: 30 minutes of treatment on the GangTrainer GT1 and 30 minutes of conventional physio-
therapy every workday for 8 weeks
Group B: 30 minutes of treatment on the Lokomat and 30 minutes of conventional physiotherapy
every workday for 8 weeks
Group C: 60 minutes of conventional physiotherapy every workday for 8 weeks

$\begin{array}{ll}\text { Outcomes } & \text { Primary outcomes: FAC, modified Emory Functional Ambulation } \\ & \text { Secondary outcomes: Barthel Index, 10-metre walk test, 6-minute walk test on the floor, Medical } \\ & \text { Research Council, Rivermead Visual Gait Assessment, EuroQol-5 Dimensions (EQ-5D) }\end{array}$

\begin{tabular}{ll}
\hline Starting date & August 2010 \\
\hline Contact information & $\begin{array}{l}\text { Contact: Andreas Waldner, MD; +39 } 0471471471 ; \text { waldner.andreas@villamelitta.it } \\
\text { Contact: Christopher Tomelleri, MSc; +390471 471 471; christopher.tomelleri@villamelitta.it }\end{array}$ \\
\hline Notes & Estimated enrolment: 120 \\
& Estimated study completion date: August 2013 \\
& Estimated primary completion date: August 2013 (final data collection date for primary outcome \\
& measure)
\end{tabular}

\section{NCT01187277}

\section{Trial name or title}

A randomised controlled trial on hemiplegic gait rehabilitation: robotic locomotor training versus conventional training in subacute stroke

Methods RCT with 2 arms


NCT01187277 (Continued)

Participants
Country: Thailand

Inclusion criteria: subacute first-time stroke patients (haemorrhage and ischaemic), age 18 to 80 years, impaired FAC at initial score 0 to 2, cardiovascular stable, provided signed informed consent

Exclusion criteria: unstable general medical condition, severe malposition or fixed contracture of joint with an extension deficit $>30^{\circ}$, any functional impairment before stroke, cannot adequately co-operate in training, severe communication problems, severe cognitive-perceptual deficits
Group A: conventional therapy: 50 minutes individual physiotherapy and 60 minutes individual occupational therapy per workday ( 5 times per week) for 4 consecutive weeks

Group B: conventional therapy plus robot-assisted gait training: 30 minutes individual physiotherapy plus 20 minutes robotic-assisted gait training (with Gait Trainer GT1) and 60 minutes individual occupational therapy per workday ( 5 times per week) for 4 consecutive weeks

\begin{tabular}{ll}
\hline Outcomes & $\begin{array}{l}\text { Primary outcomes: FAC } 0 \text { to } 5 \text { and Barthel Index } 0 \text { to } 100 \\
\text { Secondary outcome: Berg Balance Scale } 0 \text { to 56, Resistance to Passive Movement Scale (REPAS)- } \\
\text { Muscle tone } 0 \text { to } 52\end{array}$ \\
\hline Starting date & January 2011 \\
\hline Contact information & $\begin{array}{l}\text { Principal Investigator: } \\
\text { Ratanapat Chanubol, MD, Rehabilitation Department, Prasat Neurological Institute, Mahidol Uni- } \\
\text { versity }\end{array}$ \\
\hline Notes & Study Completion Date: July 2012 \\
Enrolment: 60
\end{tabular}

\section{NCT01678547}

Trial name or title Robot walking rehabilitation in stroke patients

\begin{tabular}{|c|c|}
\hline Methods & RCT with 3 arms \\
\hline Participants & $\begin{array}{l}\text { Inclusion criteria: between the ages of } 18 \text { and } 95 \text { years, able to walk } 25 \text { feet unassisted or with as- } \\
\text { sistance, first acute event of cerebrovascular stroke, unilateral paresis, ability to understand and } \\
\text { follow simple instructions, ability to walk without assistance before stroke, endurance sufficient to } \\
\text { stand at least } 20 \text { minutes unassisted per participant report } \\
\text { Exclusion criteria: unable to understand instructions required by the study (Informed Consent Test } \\
\text { of Comprehension), medical or neurological comorbidities that could contribute to significant gait } \\
\text { dysfunction, uncontrolled hypertension }>190 / 110 \mathrm{~mm} \mathrm{Hg} \text {, significant symptoms of orthostasis } \\
\text { when standing up, circulatory problems, history of vascular claudication or significant (+ 3) pitting } \\
\text { oedema, lower extremity injuries or joint problems (hip or leg) that limit range of motion or func- } \\
\text { tion or cause pain with movement, bilateral impairment, severe sensory deficits in the paretic up- } \\
\text { per limb, cognitive impairment or behavioural dysfunction that would influence the ability to com- } \\
\text { prehend or participate in the study, women who are pregnant or lactating, or both }\end{array}$ \\
\hline
\end{tabular}
a week for 4 up to 5 weeks) consisting of a treatment cycle using the G-EO system device, according to individually tailored exercise scheduling Control group: Treadmill training: each participant will be asked to perform 15 sessions ( 3 to 5 days a week for 4 up to 5 weeks) consisting of a treatment cycle using the treadmill system device, according to individually tailored exercise scheduling Control group: Ground treatment: each participant will be asked to perform 15 sessions ( 3 to 5 days a week for 4 up to 5 weeks) of traditional lower limb physiotherapy 
NCT01678547 (Continued)

Outcomes

\begin{tabular}{ll}
\hline Starting date & September 2012 \\
\hline Contact information & $\begin{array}{l}\text { Contact: Patrizio Sale, MD; patrizio.sale@gmail.com } \\
\text { Contact: Marco Franceschini, MD; marco.franceschini@sanraffaele.it }\end{array}$ \\
\hline Notes & Estimated enrolment: 90 \\
& Estimated study completion date: September 2015 \\
& Estimated primary completion date: August 2014 (final data collection date for primary outcome \\
& measure) \\
\hline
\end{tabular}

\section{NCT01726998}

$\begin{array}{ll}\text { Trial name or title } & \begin{array}{l}\text { Effects of locomotion training with assistance of a robot-driven gait orthosis in hemiparetic pa- } \\ \text { tients after subacute stroke }\end{array}\end{array}$

\begin{tabular}{|c|c|}
\hline Methods & $\begin{array}{l}\text { Randomised trial } \\
2 \text { arms }\end{array}$ \\
\hline Participants & $\begin{array}{l}\text { Inclusion criteria } \\
\text { - Hemiparesis as result of first stroke } \\
\text { - No other neurologic or orthopaedic disorder } \\
\text { - Independent ambulation before the stroke } \\
\text { - No severe medical illnesses } \\
\text { - Hemiparesis: lower extremity strength graded } \leq 3 \text { in more than } 2 \text { muscle groups } \\
\text { - FAC } \leq 1 \text { : indicating a need for personal assistance in ambulation } \\
\text { - Time since stroke onset < } 6 \text { months } \\
\text { - Age } 20 \text { to } 80 \text { years old } \\
\text { Exclusion criteria } \\
\text { - Unstable fractures } \\
\text { - Severe osteoporosis } \\
\text { - Severe skin problems } \\
\text { - Severe joint problems } \\
\text { - Major difference in leg length } \\
\text { - Body weight over } 130 \text { kg } \\
\text { - Orthostatic circulatory problem } \\
\text { - Severe cognitive impairment } \\
72 \text { first-ever stroke patients who could not walk independently (FAC }<2 \text { ), and suffered stroke within } \\
6 \text { months were enrolled and randomly assigned into } 2 \text { groups. People with congestive heart failure, } \\
\text { malignancies, cardiopulmonary dysfunctions, and who could not walk independently before their } \\
\text { stroke were excluded. }\end{array}$ \\
\hline
\end{tabular}

Interventions

2 groups received 30 minutes of conventional gait training including neurodevelopmental treatment:

- the robotic-assisted locomotor training group received additional robotic-assisted gait therapy for 30 minutes with Lokomat (Hocoma, Zurich, Switzerland) daily for 4 weeks;

- the conventional gait-training group received additional daily conventional gait training with neurodevelopmental treatment for the same period. 
NCT01726998 (Continued)

Outcomes

Independent walking ability (FAC $\geq 3$ ), FAC, Motricity index, Fugl-Meyer Assessment, Modified Barthel Index, Medical Research Council were assessed for lower extremity muscles before, during ( 2 weeks), and after training. Independent walking ability was followed until 3 months.

\begin{tabular}{ll}
\hline Starting date & March 2012 \\
\hline Contact information & Yonsei University
\end{tabular}

Notes

\section{NCT02114450}

\section{Trial name or title}

\section{Methods}

Participants
Human-machine system for the $\mathrm{H} 2$ lower limb exoskeleton (H2-NeuroExo)

RCT with 2 arms

Inclusion criteria

- Subacute or chronic stroke, i.e. interval of at least 3 months or at least 6 months from stroke to time of enrolment, respectively

- Cognitive ability to assimilate and participate actively in the treatment protocol (Mini Mental State Examination score $>24$ points, out of a total 30 indicating normal cognitive ability)

- Modified Rankin Scale scores 2 to 4 (mild-moderate functional disability poststroke)

- Modified Ashworth Scale of Spasticity score $\leq 2$ (range 0 to 4, with 4 reflecting maximum spasticity)

- Have no skin integrity issues

- Sufficient passive range of motion at the hip (at least $90^{\circ}$ flexion, $15^{\circ}$ to $20^{\circ}$ extension), knee $\left(90^{\circ}\right.$ flexion, complete extension), and ankle ( $15^{\circ}$ dorsiflexion, $15^{\circ}$ plantar flexion)

- Have no contraindications to standing or walking; able to stand with assistive device for at least 5 minutes; and able to walk with assistive device for 10 metres

Exclusion criteria

- Severe cognitive or visual deficit, or both

- Hemineglect (determined based on medical record or initial clinical assessment)

- Severe sensory deficit

- Joint contractures of any extremity that limit normal range of motion during ambulation with assistive devices

- Skin lesions that may hinder or prevent the application of exoskeleton

- Uncontrolled angina

- Severe chronic obstructive pulmonary disease

- Other medical contraindications; any medical comorbidities that would prevent standard rehabilitation

Interventions

Experimental: robot-assisted rehabilitation participants will receive robot-assisted training with the $\mathrm{H} 2$ lower limb powered exoskeleton. They will perform walking and other lower limb exercises (as applicable) while wearing the $\mathrm{H} 2$ lower limb powered exoskeleton. Training will involve 3 sessions per week for 4 weeks, each lasting about 1.5 hours.

Control: supervised motor practice participants will perform walking and other lower limb exercises (as applicable) under the supervision of a research physical therapist. Training will involve 3 sessions per week for 4 weeks, each lasting about 1.5 hours.

Outcomes Primary outcome measures

- Change from baseline in Fugl-Meyer Assessment Lower Extremity 
NCT02114450 (Continued)

- Functional Gait Assessment

- Lower limb joint kinematics during walking

- Cortical dynamics measured by electroencephalography

Secondary outcome measures

- Robotic measure of performance measured by the $\mathrm{H} 2$

- Berg Balance Scale score

- Distance walked during the 6-minute walk test

- Timed Up and Go Test score

\begin{tabular}{ll}
\hline Starting date & March 2014 \\
\hline Contact information & clinicaltrials.gov/ct2/show/study/NCT02114450\#contacts \\
\hline
\end{tabular}

Notes

NCT02471248

\begin{tabular}{ll}
\hline Trial name or title & Interactive exoskeleton robot for walking - ankle joint \\
\hline Methods & Randomised \\
& 2 arms \\
\hline
\end{tabular}

Participants Inclusion criteria

- Ischaemic or haemorrhagic stroke with drop-foot problem

- Sufficient cognition to follow simple instructions and to understand the content and purpose of the study (Mini Mental State Examination > 21)

- Capable of standing and walking independently for an extended period of time (FAC $>3$, Berg Balance Scale > 40)

Exclusion criteria

- Any medical or psychological dysfunctions that would affect ability to comply with test study protocol, such as lower back pain, neuralgia, rotational vertigo, musculoskeletal disorders, injuries, and pregnancy

- Any severe contractures in hip, knee, or ankle joint that would preclude passive range of motion in the lower extremity

- Participation in any therapeutic treatment ("outside therapy") performed with the lower extremity during the planned study, including the baseline and the follow-up

Interventions

Outcomes
- Experimental: ankle robot with power assistance. The ankle robot assists the ankle dorsiflexion when the stroke patient voluntarily performs the swing phase gait movement.

- Placebo comparator: sham group. The ankle robot provides very low assistance to generate tactile feedback to the stroke patient indicating the patient is performing the swing phase gait movement, but no assistance will be given to support ankle dorsiflexion.

- Fugl-Meyer Assessment Lower Extremity

- Timed 10-metre walk test

- 6-minute walk test

- Berg Balance Scale

- Modified Ashworth Scale

- Kinematic and Kinetic Gait Motion Capture 
NCT02471248 (Continued)

- Subjective feedback questionnaire

\begin{tabular}{ll} 
Starting date & June 2015 \\
\hline Contact information & Raymond KY Tong, Professor, Chinese University of Hong Kong
\end{tabular}

Notes

NCT02483676

\begin{tabular}{ll}
\hline Trial name or title & Adaptive ankle robot control system to reduce foot-drop in chronic stroke \\
\hline Methods & Randomised \\
& 2 arms
\end{tabular}

\section{Participants}

Inclusion criteria

- Ischaemic or haemorrhagic stroke $>2$ months prior in men or women

- Residual hemiparesis of the lower extremity that includes symptoms of foot-drop

- Capable of ambulating on a treadmill with handrail support

- Have completed all conventional physical therapy

- Adequate language and cognitive function to provide informed consent and participate in testing and training

Exclusion criteria

- Cardiac history of: unstable angina, recent (<3 months) myocardial infarction, congestive heart failure (NYHA category II or higher), haemodynamic valvular dysfunction, hypertension that is a contraindication for a bout of treadmill training (> 160/100 on 2 assessments)

Interventions

- Device: treadmill plus Anklebot: this intervention employs the use of the adaptive Anklebot control system to complement treadmill exercise training over a 6 -week intervention period

- Behavioural: treadmill only: this intervention employs the use of a treadmill for gait exercise training over a 6-week intervention period

- Independent gait function indexed by gait velocity, swing-phase dorsiflexion, terminal stance push-off

- Balance function indexed by measures of postural sway (centre of pressure), asymmetric loading in quiet standing, peak paretic anteroposterior forces in non-paretic gait initiation, and standardised scales for balance and fall risk

- Long-term mobility outcomes, assessed by repeated measures of all key gait and balance outcomes at 6 weeks and 3 months after cessation of formal training

\begin{tabular}{ll}
\hline Starting date & September 2015 \\
\hline Contact information & clinicaltrials.gov/ct2/show/study/NCT02483676?term=NCT02483676\&rank=1\#contacts \\
\hline Notes & \\
\hline
\end{tabular}


NCT02545088 (Continued)

$\begin{array}{ll}\text { Methods } & \text { Randomised } \\ & 3 \text { arms }\end{array}$

3 arms

\section{Participants}

Inclusion criteria

- 1 to 10 years since stroke onset

- Able to walk but not independently, i.e. need for manual support or close supervision due to lower extremity paresis; FAC score 2 to 3 or FAC 4 combined with gait speed $<0.8 \mathrm{~m} / \mathrm{s}$ according to 10 metre walk test, which corresponds to limitations in community ambulation

- Ability to understand training instructions as well as written and oral study information and to express informed consent or by proxy

- Body size compatible with the Hybrid Assistive Limb (HAL) suit

Exclusion criteria

- Contracture restricting gait movements at any lower limb joint

- Cardiovascular or other somatic condition incompatible with intensive gait training

- Severe, contagious infections (e.g. methicillin-resistant Staphylococcus aureus or extended-spectrum beta-lactamase bacteria)

Interventions

- Device: Hybrid Assistive Limb (HAL) intensive gait training is performed 1 session/day, 3 days/ week for 6 weeks; each session will not exceed 60 minutes of effective walking time with HAL. In addition, each session will include conventional gait training that will not exceed 30 minutes effective training time.

- 1st control group: conventional gait training performed 1 session/day, 3 days/week for 6 weeks that will not exceed 90 minutes effective training time

- 2nd control group: no intervention

- FAC
- Fugl-Meyer Assessment Lower Extremity
- Modified Ashworth Scale
- Spasticity measured with NeuroFlexor foot module Spasticity
- 10 -metre walk test
- 2 -minute walk test
- 6 -minute walk test
- Borg Rating of Perceived Exertion Scale
- Montreal Cognitive Assessment
- Hospital Anxiety and Depression Scale
- Barthel Index
- Stroke Impact Scale
- Gait Deviation Index (Laboratory gait analysis)

Starting date October 2015


NCT02680691

\begin{tabular}{|c|c|}
\hline Trial name or title & Robot assisted gait training in patients with infratentorial stroke \\
\hline Methods & $\begin{array}{l}\text { Randomised } \\
2 \text { arms }\end{array}$ \\
\hline Participants & $\begin{array}{l}\text { Inclusion criteria } \\
\text { - Patients with infratentorial stroke } \\
\text { - Cognitively intact enough to understand and follow the instructions from the investigator } \\
\text { Exclusion criteria } \\
\text { - Chronic neurological pathology } \\
\text { - Orthopaedic injuries } \\
\text { - Femur lengths of less than } 34 \mathrm{~cm} \\
\text { - Severely limited range of lower extremity joint motion } \\
\text { - Medical instability }\end{array}$ \\
\hline Interventions & $\begin{array}{l}\text { - Experimental: robot, then conventional training: robot-assisted gait training } 4 \text { weeks after con- } \\
\text { ventional gait training } \\
\text { - Active comparator: conventional, then robot training: conventional gait training } 4 \text { weeks after } \\
\text { robot-assisted gait training }\end{array}$ \\
\hline
\end{tabular}

\begin{tabular}{ll}
\hline Outcomes & Primary outcome measures \\
- Berg Balance Scale \\
Secondary outcome measures \\
- Trunk Impairment Scale \\
- FAC \\
- 10 -metre walk test \\
- Fugl-Meyer Assessment \\
- Korean version of Falls Efficacy Scale (assesses fear of falling in the elderly population) (time \\
- nated as safety issue: no perception of balance and stability during activities of daily living \\
- Balance test using force plate \\
April 2015 \\
\hline Clinicaltrials.gov/ct2/show/study/NCT02680691?term=NCT02680691\&rank=1\#contacts
\end{tabular}

Notes

\begin{tabular}{ll}
\hline Trial name or title & Clinical trial of robot-assisted-gait-training (RAGT) in stroke patients (Walkbot) \\
\hline Methods & Randomised \\
& 2 arms \\
\hline
\end{tabular}

Participants Inclusion criteria


NCT02694302 (Continued)

- Age older than 19 years and younger than 80 years

- Weight under $100 \mathrm{~kg}$

- Height less than $200 \mathrm{~cm}$

- Able to walk independently before onset of stroke

- Ischaemic or haemorrhagic stroke patients

- Motor paralysis and gait disturbance after stroke and seeking rehabilitation treatment

- FAC under $3(0 \sim 2)$

- Subacute stroke patients, i.e. after 3 days and before 3 months of stroke onset

- Be informed of the nature of the study and agreed on written consent voluntarily

- Taking medications or scheduled medications due to stroke

Exclusion criteria

- Contraindications to weight bearing such as fractures, etc.

- Uncontrolled stage 2 hypertension (systolic over $160 \mathrm{~mm} \mathrm{Hg}$ or diastolic over $100 \mathrm{~mm} \mathrm{Hg}$ ) or with uncontrolled orthostatic hypotension

- Cardiopulmonary disease or other underlying diseases that cannot tolerate gait training

- Severe skin damage and bedsore on wearing part of the trial device

- Pregnant or breastfeeding

- Participationin other clinical trials within 30 days

- People whom the investigator considers inappropriate to participate in the study

Interventions

- Walkbot (robot-assisted gait training) 30 minutes and conventional physical therapy 30 minutes per day to be administered 5 times a week for 3 weeks

- Conventional physical therapy 30 minutes to be administered twice a day, 5 times a week for 3 weeks
Primary outcome measure

- $F A C$

Secondary outcome measures

- Motricity Index

- 10-metre walk test

- 6-minute walk test

- Medical Research Council

- Modified Ashworth Scale

- Fugl-Meyer Assessment

- Modified Barthel Index

- National Institutes of Health Stroke Scale

- Beck Depression Inventory

- Treatment Satisfaction Survey

Starting date March 2014


NCT02755415 (Continued)

\begin{tabular}{|c|c|}
\hline Methods & $\begin{array}{l}\text { Randomised } \\
2 \text { arms }\end{array}$ \\
\hline Participants & $\begin{array}{l}\text { Inclusion criteria } \\
\text { - Between the ages of } 20 \text { and } 80 \text { years } \\
\text { - Diagnosis of first single unilateral cortical-subcortical acute stroke verified by brain imaging } \\
\text { - Paresis of a lower limb } \\
\text { - Ability to walk only a few metres either with or without aid } \\
\text { Exclusion criteria } \\
\text { - Deemed by a physician to be medically unstable } \\
\text { - Other prior musculoskeletal conditions that affected gait capacity } \\
\text { - Coexistence of other neurological diseases } \\
\text { - Cognitive impairments that would impact on the safe participation in the study (Mini Mental State } \\
\text { Examination }<23 \text { ) }\end{array}$ \\
\hline Interventions & $\begin{array}{l}\text { Device: HIWIN Robotic Gait Training System }{ }^{\sim} \text { : the HIWIN Robotic Gait Training System is an auto- } \\
\text { matic training system that combines weight-bearing standing, repetitive stepping, and gait training }\end{array}$ \\
\hline Outcomes & $\begin{array}{l}\text { - Berg Balance Scale } \\
\text { - Pittsburgh Sleep Quality Index } \\
\text { - EuroQol-5 Dimensions (EQ-5D) } \\
\text { - 6-minute walk test } \\
\text { - Beck Depression Inventory }\end{array}$ \\
\hline
\end{tabular}

\begin{tabular}{ll}
\hline Starting date & May 2016 \\
\hline Contact information & China Medical University Hospital \\
\hline Notes & Other study ID: CMUH105-REC1-037 \\
\hline
\end{tabular}

\section{NCT02781831}

\begin{tabular}{ll}
\hline Trial name or title & Robot-assisted gait training for patients with stroke \\
\hline Methods & Randomised \\
& 2 arms \\
\hline
\end{tabular}

Participants

Inclusion criteria

1. Between the ages of 20 and 65 years

2. Diagnosis of first single unilateral cortical-subcortical stroke verified by brain imaging

3. Paresis of a lower limb

4. Inability to walk without aid or device

Exclusion criteria

1. Deemed by a physician to be medically unstable

2. Other prior musculoskeletal conditions that affected gait capacity

3. Coexistence of other neurological diseases 
NCT02781831 (Continued)

4. Cognitive impairments that would impact on the safe participation in the study (Mini Mental State Examination $<23$ )

\begin{tabular}{ll}
\hline Interventions & Standard hospital-based rehabilitation for people with stroke \\
\hline Outcomes & - Fugl-Meyer Assessment Lower Extremity \\
& - 10 -metre walk test \\
& Berg Balance Scale \\
\hline Starting date & May 2016 \\
\hline Contact information & HIWIN-CMU-C-105-1 \\
\hline Notes &
\end{tabular}

\section{NCT02843828}

$\begin{array}{ll}\text { Trial name or title } & \begin{array}{l}\text { Gait pattern analysis and feasibility of gait training with a walking assist robot in stroke patients } \\ \text { and elderly adults }\end{array}\end{array}$

\begin{tabular}{ll}
\hline Methods & Randomised \\
& 2 treatment groups
\end{tabular}

Purticipants
Inclusion criteria
- Elderly adults: age between 65 and 84 years; no neurological or musculoskeletal abnormalities
affecting gait; ability to walk at least 10 metres regardless of assist devices; high levels of physical
performance (Short Physical Performance Battery > 7); participant is willing to be randomised to
either the control group or the treatment group
- Stroke: age between 50 and 84 years; $\geq 3$ months' poststroke; ability to walk at least 10 metres re-
gardless of assist devices; adequate gait function (FAC > 3); physician approval for patient partic-
ipation; participant is willing to be randomised to either the control group or the treatment group
Exclusion criteria
- Elderly adults: history of any diseases (e.g. lower extremity orthopaedic diseases, neurologic dis-
orders, cardiovascular disease, heart failure, uncontrolled hypertension) that affect walking ca-
pacity, efficiency, and endurance; severe visual impairment or dizziness that increases the risk of
falls
Stroke: serious cardiac conditions (hospitalisation for myocardial infarction or heart surgery with-
in 3 months, history of congestive heart failure, documented serious and unstable cardiac arrhyth-
mias, hypertrophic cardiomyopathy, severe aortic stenosis, angina or dyspnoea at rest or during
activities of daily living); advanced liver, kidney, cardiac, or pulmonary disease; history of concus-
sion in last 6 months; history of unexplained, recurring headaches, epilepsy/seizures/skull frac-
tures, or skull deficits

Interventions

Group 1 : gait rehabilitation with hip assist robot (Samsung Hip Assist v1): 10 sessions ( 5 sessions: treadmill gait training/ 5 sessions: overground gait training), 30 minutes per session

Group 2 : gait rehabilitation without hip assist robot: 10 sessions (5 sessions: treadmill gait training/ 5 sessions: overground gait training), 30 minutes per session

$\begin{array}{ll}\text { - } & \text { Berg Balance Scale } \\ & \text { - Tinetti Performance-Oriented Mobility Assessment }\end{array}$


NCT02843828 (Continued)

- Modified Barthel Index

- $\mathrm{FAC}$

\begin{tabular}{ll}
\hline Starting date & September 2015 \\
\hline Contact information & Yun-Hee Kim, MD, PhD; 82-2-3410-2824 yunkim@skku.edu
\end{tabular}

Notes

FAC: Functional Ambulation Category

NYHA: New York Heart Association

$\mathrm{RCT}$ : randomised controlled trial

\section{DATA AND ANALYSES}

Comparison 1. Electromechanical- and robotic-assisted gait training plus physiotherapy versus physiotherapy (or usual care)

\begin{tabular}{|c|c|c|c|c|}
\hline Outcome or subgroup title & $\begin{array}{l}\text { No. of } \\
\text { studies }\end{array}$ & $\begin{array}{l}\text { No. of } \\
\text { partici- } \\
\text { pants }\end{array}$ & Statistical method & Effect size \\
\hline $\begin{array}{l}1 \text { Independent walking at the end of intervention } \\
\text { phase, all electromechanical devices used }\end{array}$ & 36 & 1472 & $\begin{array}{l}\text { Odds Ratio (M-H, Random, 95\% } \\
\mathrm{Cl} \text { ) }\end{array}$ & $1.94[1.39,2.71]$ \\
\hline $\begin{array}{l}2 \text { Recovery of independent walking at follow-up af- } \\
\text { ter study end }\end{array}$ & 6 & 496 & $\begin{array}{l}\text { Odds Ratio (M-H, Random, 95\% } \\
\mathrm{Cl} \text { ) }\end{array}$ & $1.93[0.72,5.13]$ \\
\hline $\begin{array}{l}3 \text { Walking velocity (metres per second) at the end } \\
\text { of intervention phase }\end{array}$ & 24 & 985 & $\begin{array}{l}\text { Mean Difference (IV, Random, } \\
95 \% \mathrm{CI})\end{array}$ & $\begin{array}{l}0.04[-0.00 \\
0.09]\end{array}$ \\
\hline 4 Walking velocity (metres per second) at follow-up & 9 & 578 & $\begin{array}{l}\text { Mean Difference (IV, Random, } \\
95 \% \mathrm{CI} \text { ) }\end{array}$ & $\begin{array}{l}0.07[-0.05 \\
0.19]\end{array}$ \\
\hline $\begin{array}{l}5 \text { Walking capacity (metres walked in } 6 \text { minutes) at } \\
\text { the end of intervention phase }\end{array}$ & 12 & 594 & $\begin{array}{l}\text { Mean Difference (IV, Random, } \\
95 \% \mathrm{CI} \text { ) }\end{array}$ & $\begin{array}{l}5.84[-16.73 \\
28.40]\end{array}$ \\
\hline $\begin{array}{l}6 \text { Walking capacity (metres walked in } 6 \text { minutes) at } \\
\text { follow-up }\end{array}$ & 7 & 463 & $\begin{array}{l}\text { Mean Difference (IV, Random, } \\
95 \% \mathrm{Cl} \text { ) }\end{array}$ & $\begin{array}{l}-0.82[-32.17 \\
30.53]\end{array}$ \\
\hline $\begin{array}{l}7 \text { Acceptability of electromechanical-assisted } \\
\text { gait training devices during intervention phase: } \\
\text { dropouts }\end{array}$ & 36 & 1472 & $\begin{array}{l}\text { Odds Ratio (M-H, Random, 95\% } \\
\mathrm{Cl} \text { ) }\end{array}$ & $0.67[0.43,1.05]$ \\
\hline $\begin{array}{l}8 \text { Death from all causes until the end of interven- } \\
\text { tion phase }\end{array}$ & 36 & 1472 & $\begin{array}{l}\text { Risk Difference (M-H, Random, } \\
95 \% \mathrm{Cl})\end{array}$ & $\begin{array}{l}0.00[-0.01 \\
0.02]\end{array}$ \\
\hline
\end{tabular}


Analysis 1.1. Comparison 1 Electromechanical- and robotic-assisted gait training plus physiotherapy versus physiotherapy (or usual care), Outcome 1 Independent walking at the end of intervention phase, all electromechanical devices used.

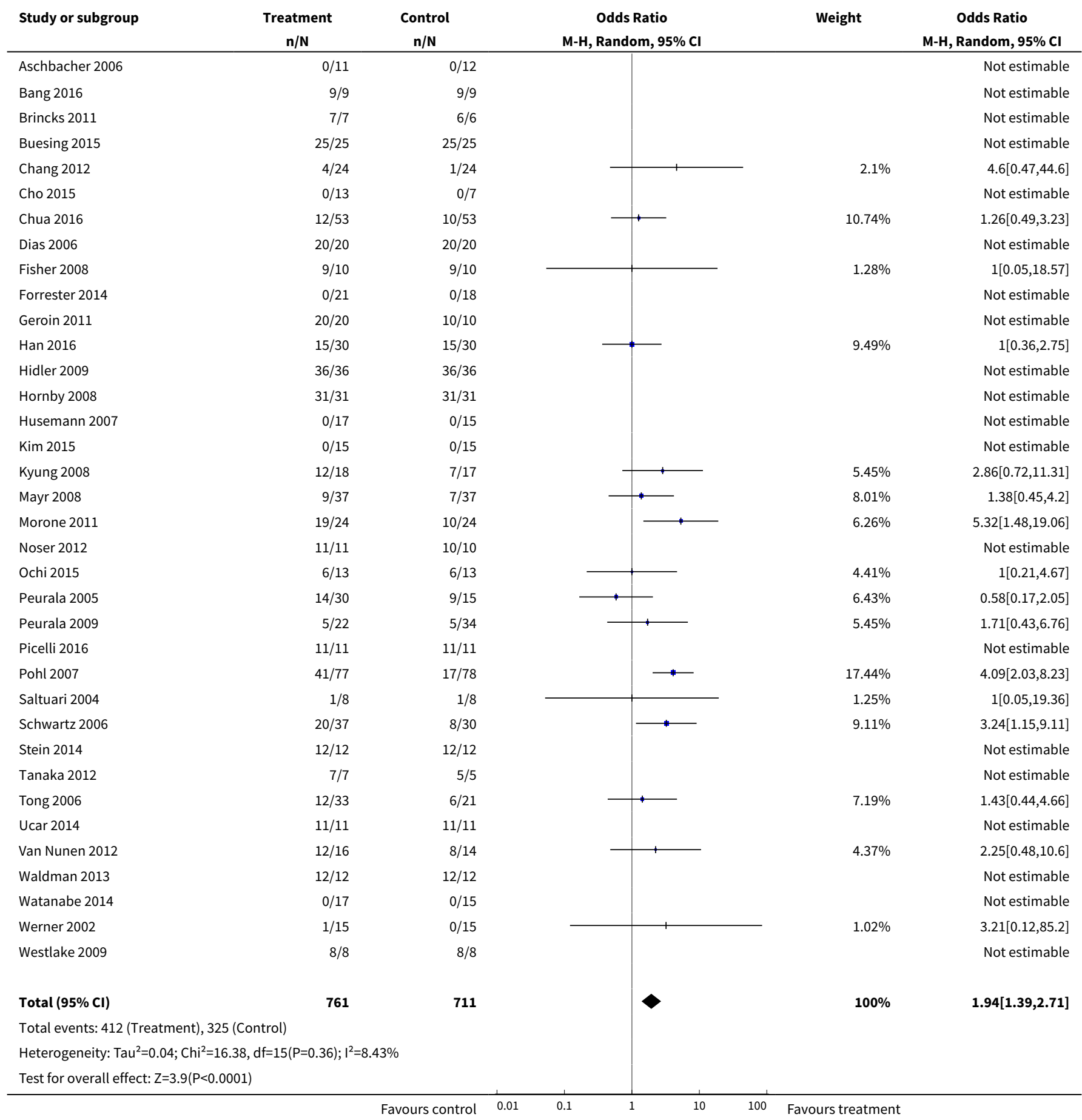


Analysis 1.2. Comparison 1 Electromechanical-and robotic-assisted gait training plus physiotherapy versus physiotherapy (or usual care), Outcome 2 Recovery of independent walking at follow-up after study end.

\begin{tabular}{|c|c|c|c|c|c|}
\hline Study or subgroup & $\begin{array}{c}\text { Treatment } \\
\mathrm{n} / \mathrm{N} \\
\end{array}$ & $\begin{array}{c}\text { Control } \\
\mathrm{n} / \mathrm{N}\end{array}$ & $\begin{array}{c}\text { Odds Ratio } \\
\text { M-H, Random, } 95 \% \text { Cl }\end{array}$ & Weight & $\begin{array}{c}\text { Odds Ratio } \\
\text { M-H, Random, } 95 \% \text { CI }\end{array}$ \\
\hline Chua 2016 & $20 / 53$ & $26 / 53$ & $\longrightarrow$ & $26.82 \%$ & $0.63[0.29,1.36]$ \\
\hline Hidler 2009 & $33 / 33$ & $30 / 30$ & & & Not estimable \\
\hline Hornby 2008 & $31 / 31$ & $31 / 31$ & & & Not estimable \\
\hline Peurala 2009 & $10 / 22$ & $12 / 34$ & - & $22.97 \%$ & $1.53[0.51,4.57]$ \\
\hline Pohl 2007 & $54 / 77$ & $28 / 78$ & $\longrightarrow$ & $27.96 \%$ & $4.19[2.14,8.21]$ \\
\hline Total $(95 \% \mathrm{Cl})$ & 249 & 247 & & $100 \%$ & $1.93[0.72,5.13]$ \\
\hline \multicolumn{6}{|c|}{ Total events: 172 (Treatment), 136 (Control) } \\
\hline \multicolumn{6}{|c|}{ Heterogeneity: $\mathrm{Tau}^{2}=0.78 ; \mathrm{Chi}^{2}=14.42, \mathrm{df}=3(\mathrm{P}=0) ; \mathrm{I}^{2}=79.19 \%$} \\
\hline Test for overall effec & & & & & \\
\hline
\end{tabular}

Analysis 1.3. Comparison 1 Electromechanical-and robotic-assisted gait training plus physiotherapy versus physiotherapy (or usual care), Outcome 3 Walking velocity (metres per second) at the end of intervention phase.

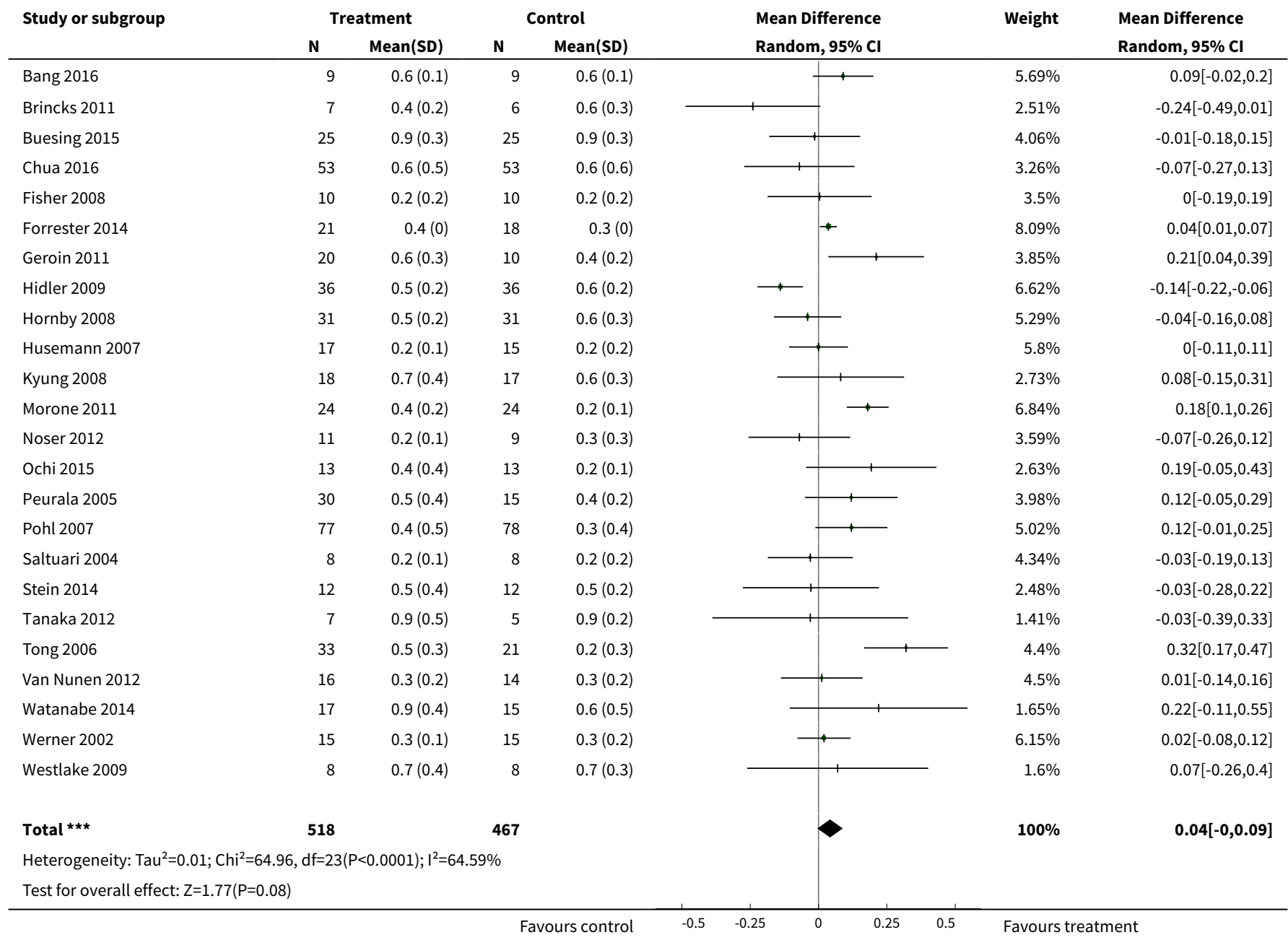


Analysis 1.4. Comparison 1 Electromechanical-and robotic-assisted gait training plus physiotherapy versus physiotherapy (or usual care), Outcome $\mathbf{4}$ Walking velocity (metres per second) at follow-up.

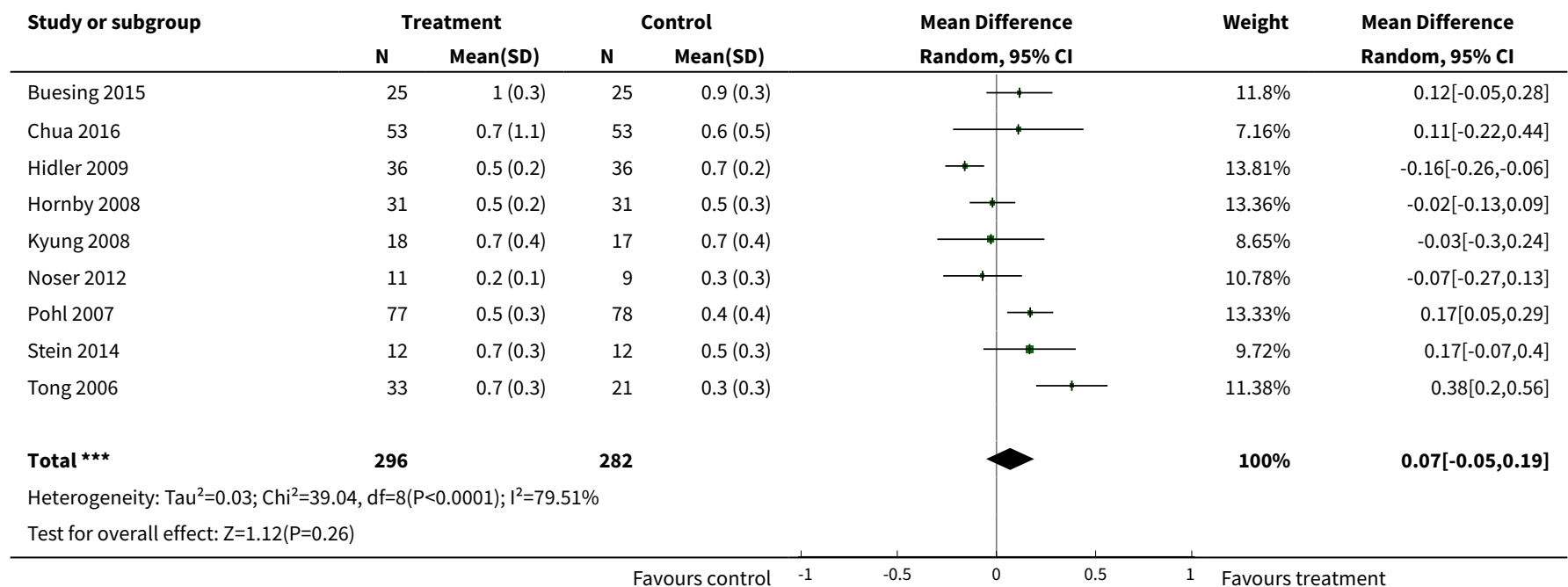

Analysis 1.5. Comparison 1 Electromechanical- and robotic-assisted gait training plus physiotherapy versus physiotherapy (or usual care), Outcome 5 Walking capacity (metres walked in 6 minutes) at the end of intervention phase.

\begin{tabular}{|c|c|c|c|c|c|c|c|}
\hline \multirow[t]{2}{*}{ Study or subgroup } & \multicolumn{2}{|c|}{ Treatment } & \multicolumn{2}{|c|}{ Control } & \multirow{2}{*}{$\begin{array}{l}\text { Mean Difference } \\
\text { Random, } 95 \% \mathrm{CI}\end{array}$} & \multirow[t]{2}{*}{ Weight } & \multirow{2}{*}{$\begin{array}{l}\text { Mean Difference } \\
\text { Random, } 95 \% \mathrm{Cl}\end{array}$} \\
\hline & $\mathbf{N}$ & Mean(SD) & $\mathbf{N}$ & Mean(SD) & & & \\
\hline Chua 2016 & 53 & $145.1(121)$ & 53 & $156.9(144)$ & $\longrightarrow$ & $9.34 \%$ & $-11.8[-62.44,38.84]$ \\
\hline Hidler 2009 & 36 & $168(59)$ & 36 & $218(64)$ & $\longrightarrow$ & $13.78 \%$ & $-50[-78.43,-21.57]$ \\
\hline Hornby 2008 & 31 & $186(88)$ & 31 & $204(96)$ & $\longrightarrow 1$ & $10.21 \%$ & $-18[-63.84,27.84]$ \\
\hline Noser 2012 & 11 & $57(25.5)$ & 9 & $70.3(60.4)$ & & $10.9 \%$ & $-13.24[-55.48,29]$ \\
\hline Peurala 2005 & 30 & $\begin{array}{r}164.1 \\
(103.4)\end{array}$ & 15 & $135.1(67.9)$ & & $9.37 \%$ & $29.07[-21.42,79.56]$ \\
\hline Picelli 2016 & 11 & $199.7(53.2)$ & 11 & $158.8(79.3)$ & & $8.39 \%$ & $40.9[-15.53,97.33]$ \\
\hline Pohl 2007 & 77 & $\begin{array}{r}134.4 \\
(125.5)\end{array}$ & 78 & $92.5(104.9)$ & $\longleftarrow$ & $12.09 \%$ & $41.9[5.46,78.34]$ \\
\hline Saltuari 2004 & 8 & $81.4(61.5)$ & 8 & $58.4(43.1)$ & & $9.1 \%$ & $23[-29.05,75.05]$ \\
\hline Stein 2014 & 12 & $\begin{array}{r}213.4 \\
(108.2)\end{array}$ & 12 & $194.8(83.2)$ & & $5.76 \%$ & $18.6[-58.62,95.82]$ \\
\hline Waldman 2013 & 12 & $\begin{array}{r}216.5 \\
(106.6)\end{array}$ & 12 & $\begin{array}{r}208.5 \\
(120.5)\end{array}$ & & $4.56 \%$ & $8[-83.03,99.03]$ \\
\hline Watanabe 2014 & 17 & $\begin{array}{r}156.7 \\
(137.9)\end{array}$ & 15 & $\begin{array}{r}134.5 \\
(132.1)\end{array}$ & & $4.37 \%$ & $22.2[-71.43,115.83]$ \\
\hline Westlake 2009 & 8 & $\begin{array}{r}278.1 \\
(176.5)\end{array}$ & 8 & $\begin{array}{r}212.4 \\
(113.5)\end{array}$ & & $2.12 \%$ & $65.7[-79.71,211.11]$ \\
\hline 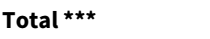 & 306 & & 288 & & & $100 \%$ & $5.84[-16.73,28.4]$ \\
\hline \multicolumn{8}{|c|}{ Heterogeneity: $\mathrm{Tau}^{2}=751.53 ; \mathrm{Chi}^{2}=23.38, \mathrm{df}=11(\mathrm{P}=0.02) ; \mathrm{I}^{2}=52.94 \%$} \\
\hline \multicolumn{8}{|c|}{ Test for overall effect: $Z=0.51(P=0.61)$} \\
\hline
\end{tabular}


Analysis 1.6. Comparison 1 Electromechanical-and robotic-assisted gait training plus physiotherapy versus physiotherapy (or usual care), Outcome 6 Walking capacity (metres walked in 6 minutes) at follow-up.

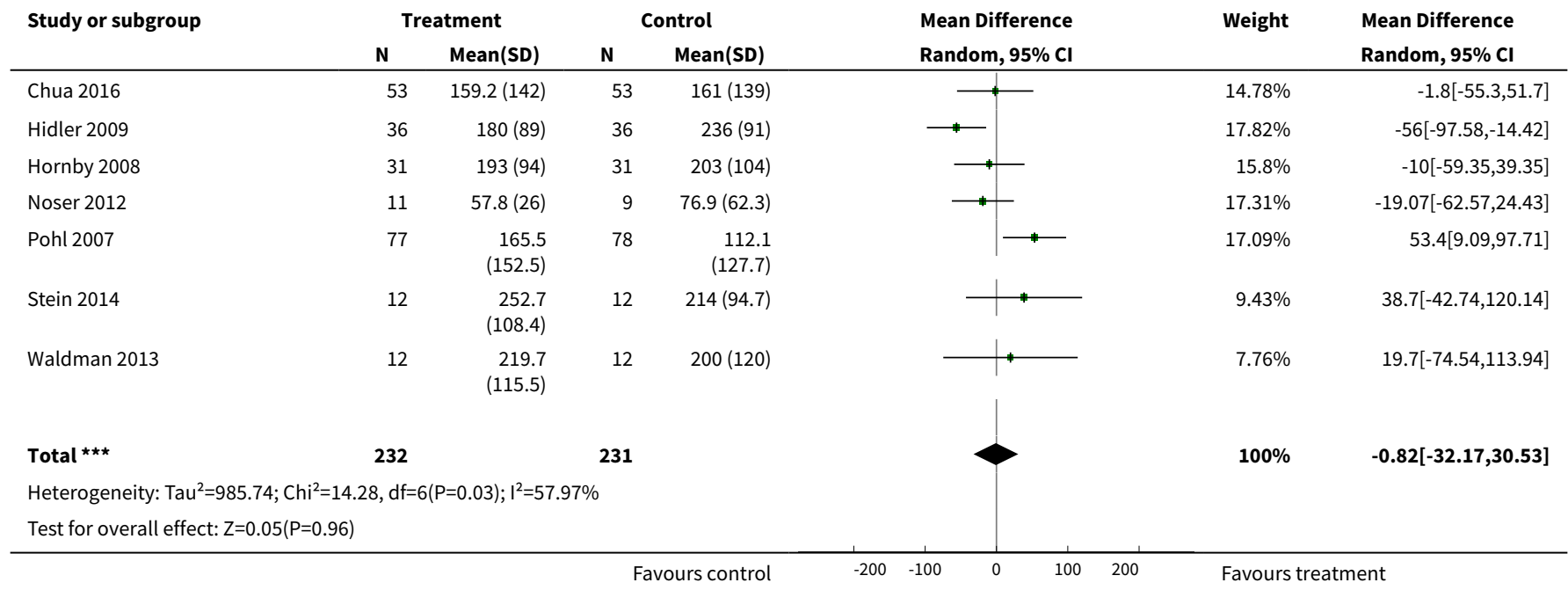

Analysis 1.7. Comparison 1 Electromechanical- and robotic-assisted gait training plus physiotherapy versus physiotherapy (or usual care), Outcome 7 Acceptability of electromechanical-assisted gait training devices during intervention phase: dropouts.

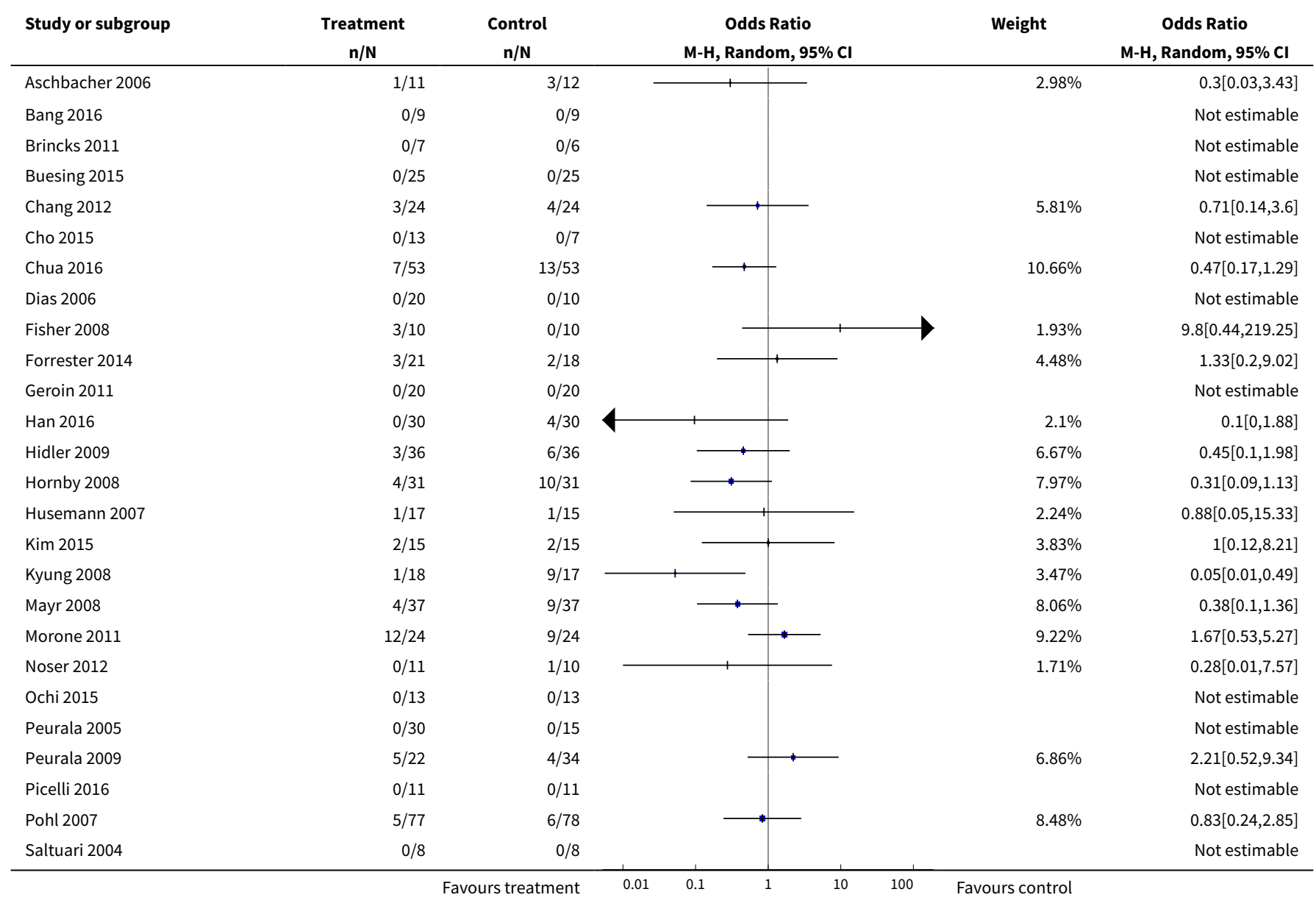




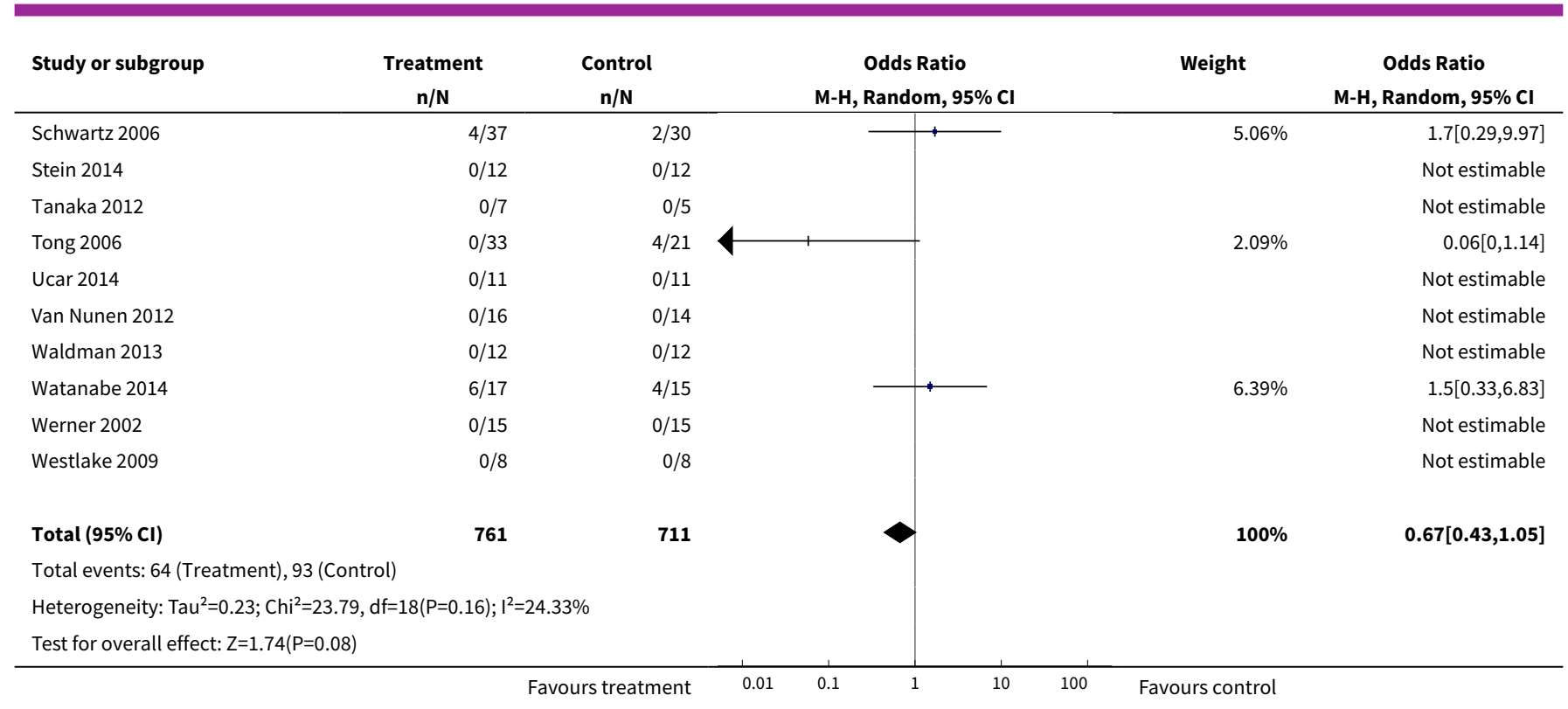

Analysis 1.8. Comparison 1 Electromechanical- and robotic-assisted gait training plus physiotherapy versus physiotherapy (or usual care), Outcome 8 Death from all causes until the end of intervention phase.

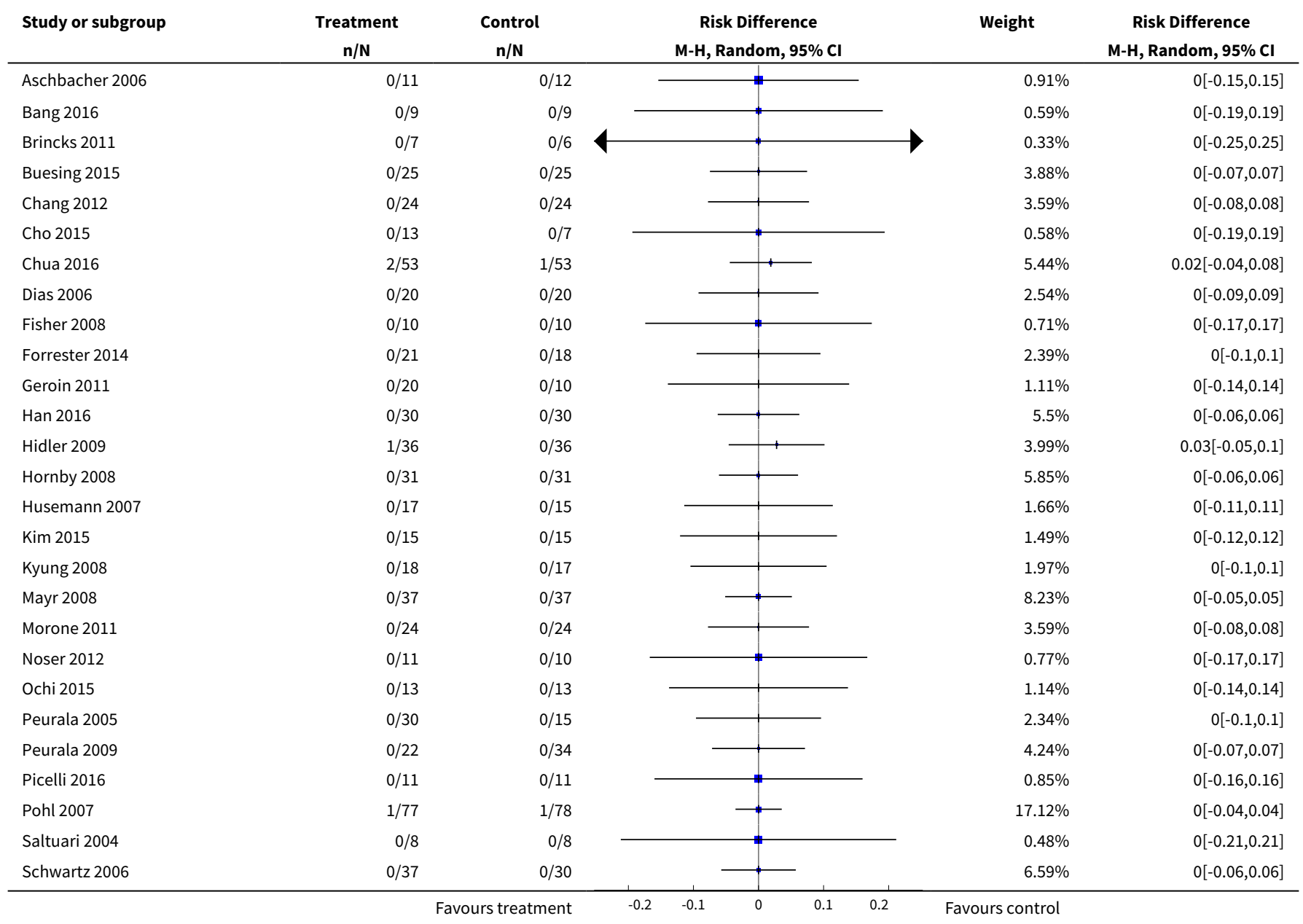




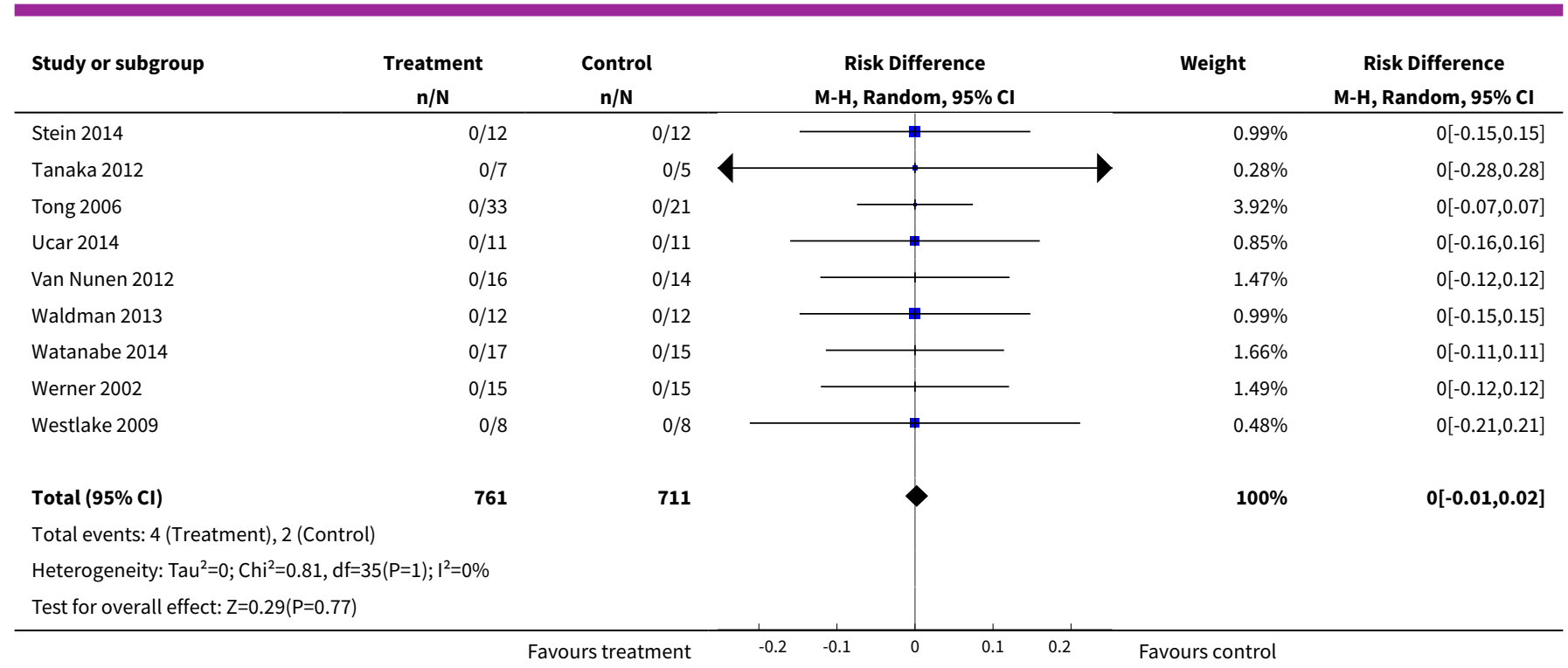

\section{Comparison 2. Planned sensitivity analysis by trial methodology}

\begin{tabular}{|c|c|c|c|c|}
\hline Outcome or subgroup title & $\begin{array}{l}\text { No. of } \\
\text { studies }\end{array}$ & $\begin{array}{l}\text { No. of } \\
\text { partici- } \\
\text { pants }\end{array}$ & Statistical method & Effect size \\
\hline 1 Regaining independent walking ability & 36 & & Odds Ratio (M-H, Random, 95\% Cl) & Subtotals only \\
\hline $\begin{array}{l}\text { 1.1 All studies with adequate sequence } \\
\text { generation process }\end{array}$ & 20 & 949 & Odds Ratio (M-H, Random, 95\% Cl) & $1.80[1.06,3.08]$ \\
\hline $\begin{array}{l}\text { 1.2 All studies with adequate concealed al- } \\
\text { location }\end{array}$ & 17 & 831 & Odds Ratio (M-H, Random, 95\% Cl) & $1.87[1.12,3.12]$ \\
\hline $\begin{array}{l}\text { 1.3 All studies with blinded assessors for } \\
\text { primary outcome }\end{array}$ & 16 & 762 & Odds Ratio (M-H, Random, 95\% Cl) & $1.81[1.10,2.98]$ \\
\hline $\begin{array}{l}\text { 1.4 All studies without incomplete out- } \\
\text { come data }\end{array}$ & 14 & 590 & Odds Ratio (M-H, Random, 95\% Cl) & $2.23[1.16,4.29]$ \\
\hline $\begin{array}{l}\text { 1.5 All studies excluding the largest study } \\
\text { Pohl } 2007\end{array}$ & 35 & 1317 & Odds Ratio (M-H, Random, 95\% Cl) & $1.65[1.17,2.34]$ \\
\hline
\end{tabular}

Analysis 2.1. Comparison 2 Planned sensitivity analysis by trial
methodology, Outcome 1 Regaining independent walking ability.

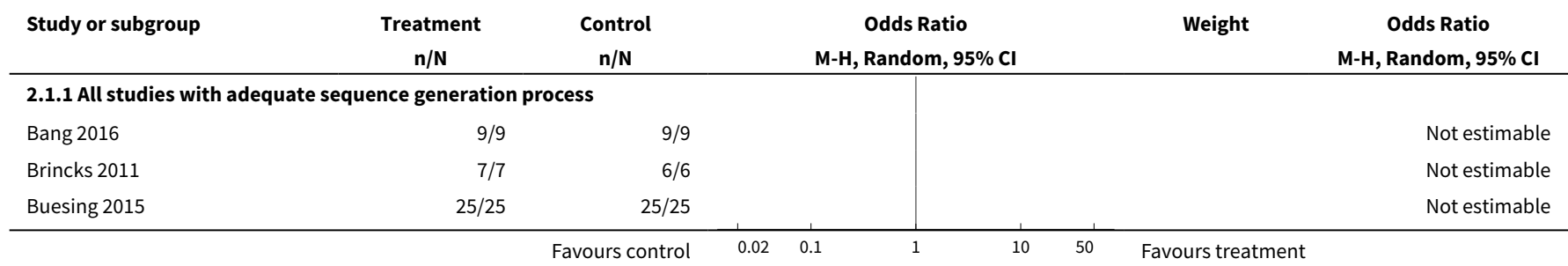




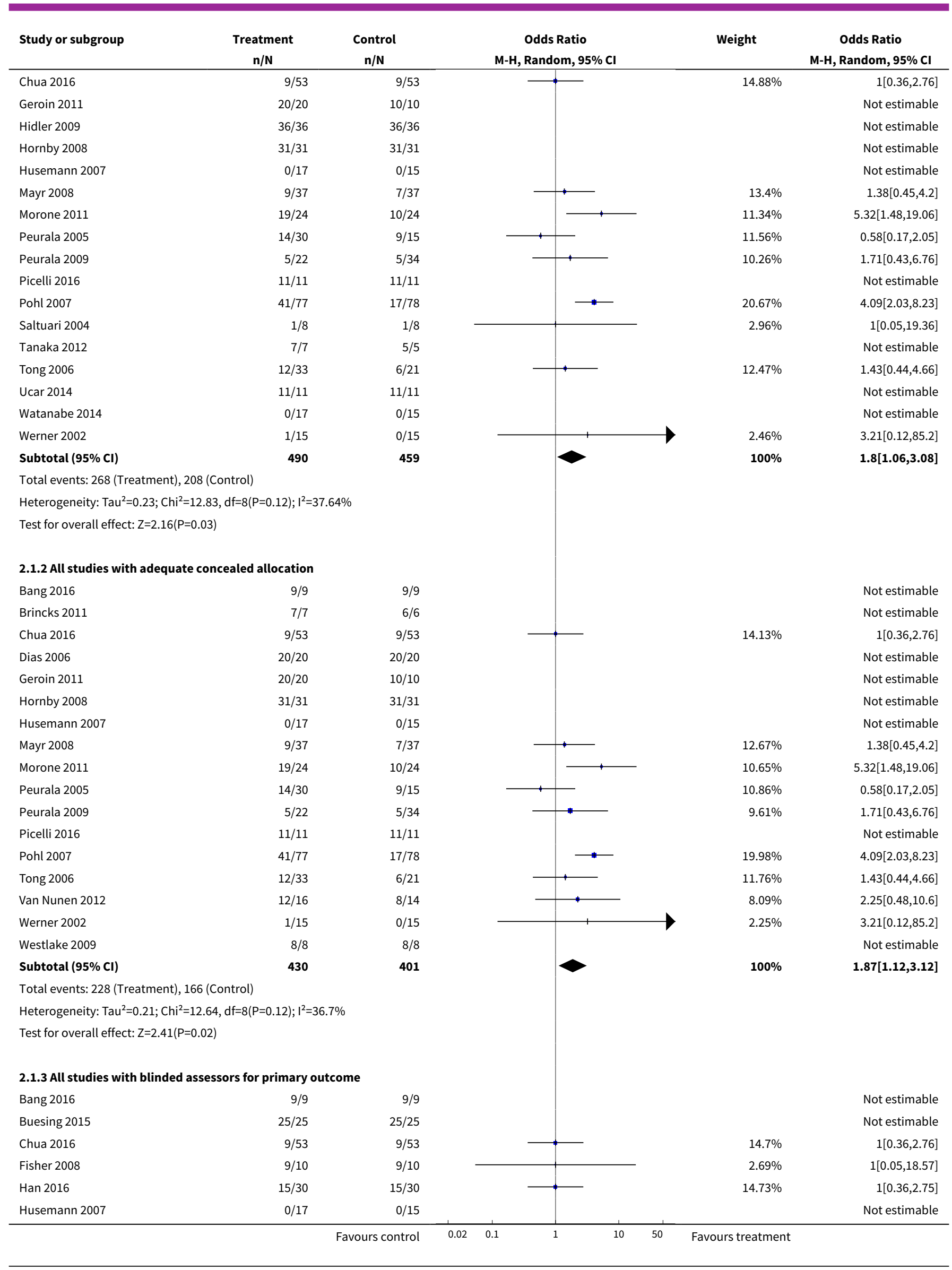




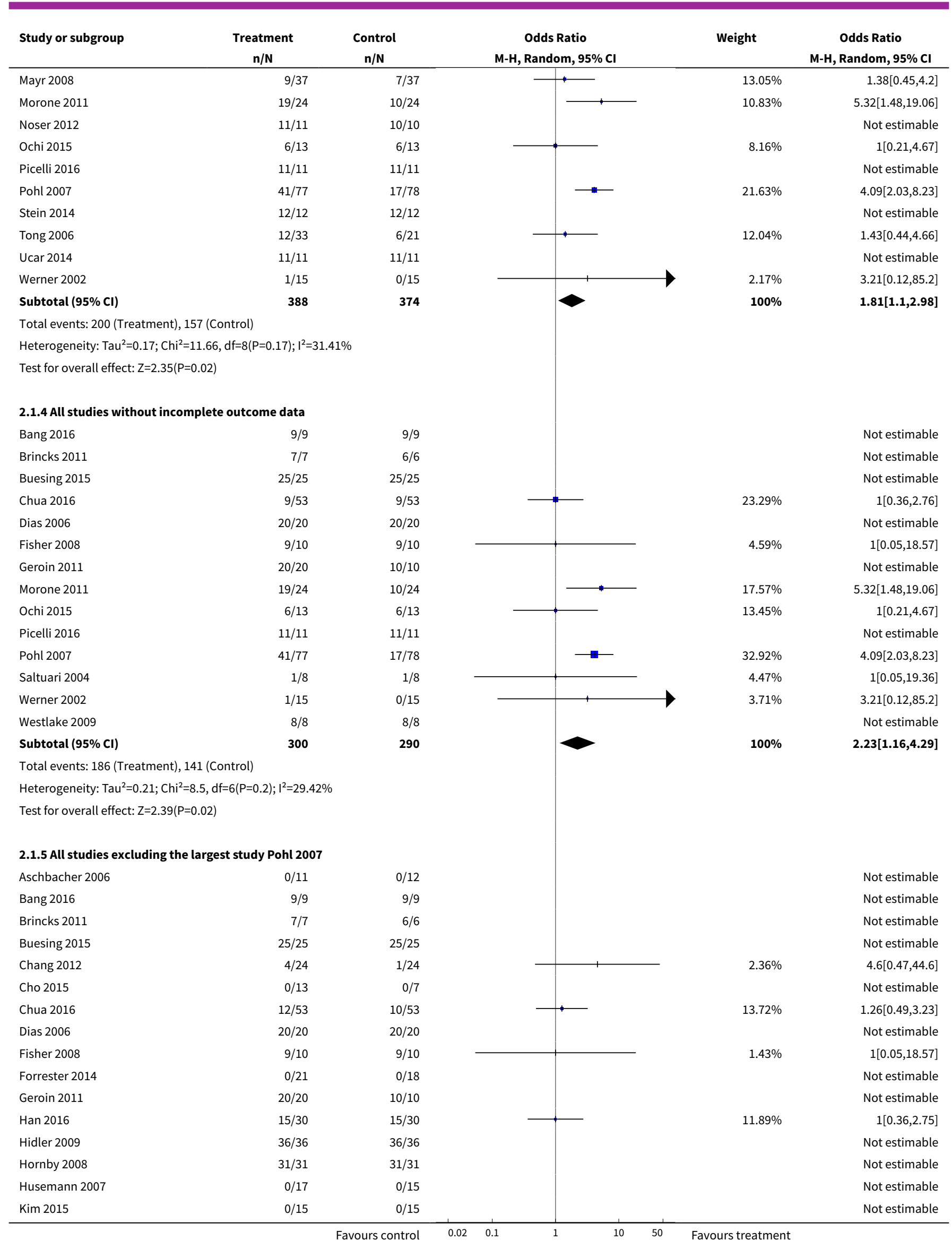




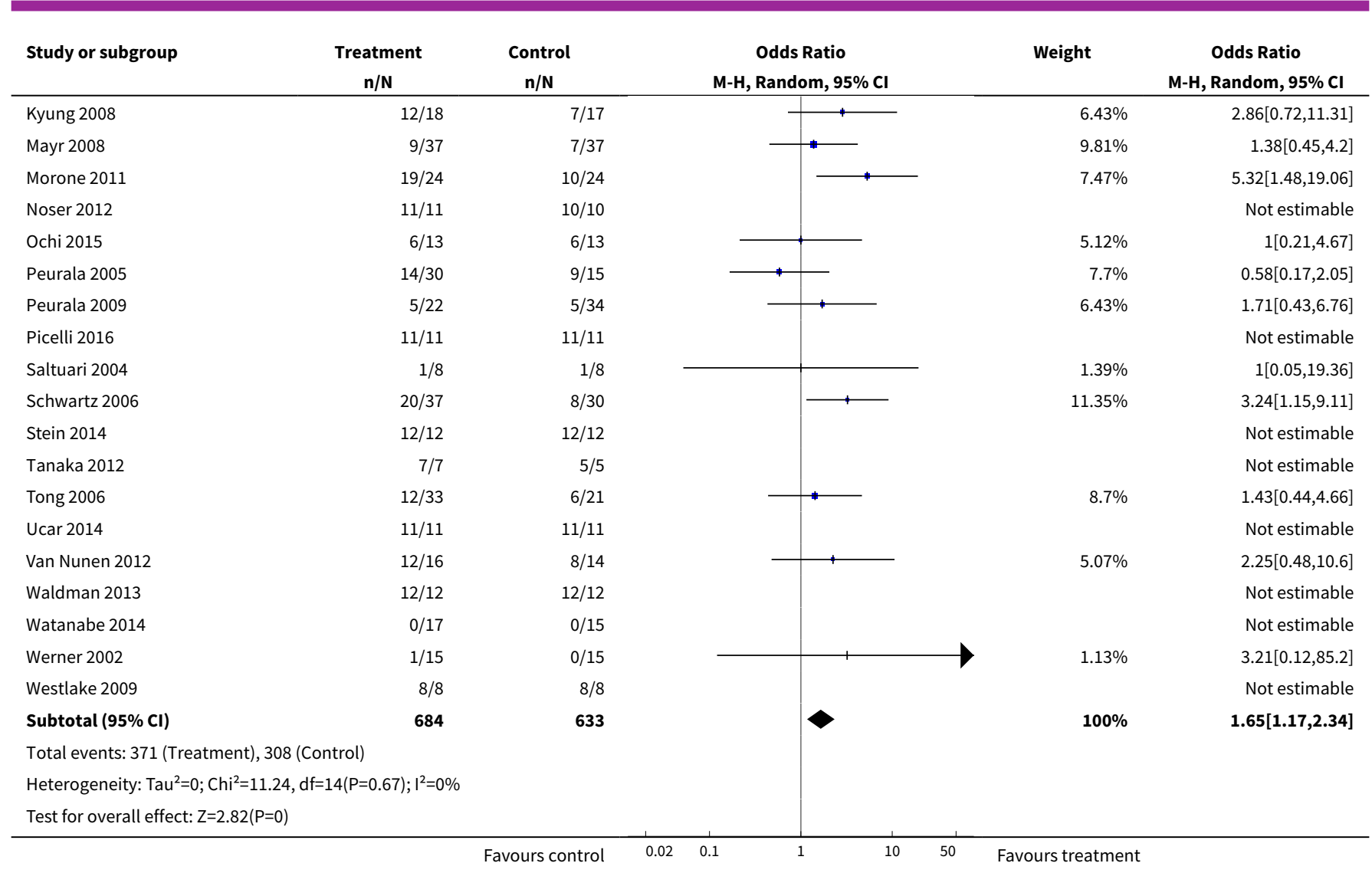

Comparison 3. Subgroup analysis comparing participants in acute and chronic phases of stroke

\begin{tabular}{|c|c|c|c|c|}
\hline Outcome or subgroup title & $\begin{array}{l}\text { No. of } \\
\text { studies }\end{array}$ & $\begin{array}{l}\text { No. of } \\
\text { partici- } \\
\text { pants }\end{array}$ & Statistical method & Effect size \\
\hline $\begin{array}{l}1 \text { Independent walking at the end of intervention } \\
\text { phase, all electromechanical devices used }\end{array}$ & 36 & & $\begin{array}{l}\text { Odds Ratio (IV, Random, 95\% } \\
\text { Cl) }\end{array}$ & Subtotals only \\
\hline $\begin{array}{l}1.1 \text { Acute phase: less than or equal to } 3 \text { months after } \\
\text { stroke }\end{array}$ & 20 & 1143 & $\begin{array}{l}\text { Odds Ratio (IV, Random, 95\% } \\
\text { Cl) }\end{array}$ & $\begin{array}{l}1.90[1.38 \\
2.63]\end{array}$ \\
\hline 1.2 Chronic phase: more than 3 months after stroke & 16 & 461 & $\begin{array}{l}\text { Odds Ratio (IV, Random, 95\% } \\
\text { Cl) }\end{array}$ & $\begin{array}{l}1.20[0.40 \\
3.65]\end{array}$ \\
\hline
\end{tabular}

Analysis 3.1. Comparison 3 Subgroup analysis comparing participants in acute and chronic phases of stroke, Outcome 1 Independent walking at the end of intervention phase, all electromechanical devices used.

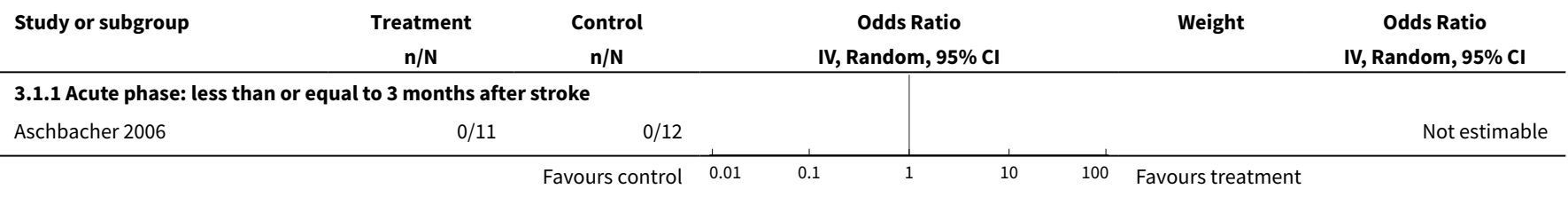




\begin{tabular}{|c|c|c|c|c|c|}
\hline Study or subgroup & $\begin{array}{l}\text { Treatment } \\
\mathrm{n} / \mathrm{N}\end{array}$ & $\begin{array}{c}\text { Control } \\
n / N\end{array}$ & $\begin{array}{c}\text { Odds Ratio } \\
\text { IV, Random, } 95 \% \mathrm{CI}\end{array}$ & Weight & $\begin{array}{c}\text { Odds Ratio } \\
\text { IV, Random, } 95 \% \mathrm{CI}\end{array}$ \\
\hline Brincks 2011 & $7 / 7$ & $6 / 6$ & & & Not estimable \\
\hline Chang 2012 & $4 / 24$ & $1 / 24$ & 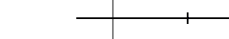 & $1.98 \%$ & $4.6[0.47,44.6]$ \\
\hline Chua 2016 & $12 / 53$ & $10 / 53$ & 1 & $10.77 \%$ & $1.26[0.49,3.23]$ \\
\hline Chua 2016 & $9 / 53$ & $9 / 53$ & | & $9.4 \%$ & $1[0.36,2.76]$ \\
\hline Forrester 2014 & $0 / 21$ & $0 / 18$ & & & Not estimable \\
\hline Han 2016 & $15 / 30$ & $15 / 30$ & $\longrightarrow$ & $9.43 \%$ & $1[0.36,2.75]$ \\
\hline Hidler 2009 & $36 / 36$ & $36 / 36$ & & & Not estimable \\
\hline Husemann 2007 & $0 / 17$ & $0 / 15$ & & & Not estimable \\
\hline Kim 2015 & $0 / 15$ & $0 / 15$ & & & Not estimable \\
\hline Mayr 2008 & $9 / 37$ & $7 / 37$ & 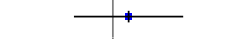 & $7.88 \%$ & $1.38[0.45,4.2]$ \\
\hline Morone 2011 & $19 / 24$ & $10 / 24$ & $\longrightarrow$ & $6.09 \%$ & $5.32[1.48,19.06]$ \\
\hline Ochi 2015 & $6 / 13$ & $6 / 13$ & & $4.23 \%$ & $1[0.21,4.67]$ \\
\hline Ochi 2015 & $6 / 13$ & $6 / 13$ & & $4.23 \%$ & $1[0.21,4.67]$ \\
\hline Peurala 2009 & $5 / 22$ & $5 / 34$ & & $5.27 \%$ & $1.71[0.43,6.76]$ \\
\hline Pohl 2007 & $41 / 77$ & $17 / 78$ & $\longrightarrow$ & $18.31 \%$ & $4.09[2.03,8.23]$ \\
\hline Saltuari 2004 & $1 / 8$ & $1 / 8$ & & $1.17 \%$ & $1[0.05,19.36]$ \\
\hline Schwartz 2006 & $20 / 37$ & $8 / 30$ & $\longrightarrow$ & $9.03 \%$ & $3.24[1.15,9.11]$ \\
\hline Tong 2006 & $12 / 33$ & $6 / 21$ & & $7.04 \%$ & $1.43[0.44,4.66]$ \\
\hline Van Nunen 2012 & $12 / 16$ & $8 / 14$ & & $4.19 \%$ & $2.25[0.48,10.6]$ \\
\hline Watanabe 2014 & $0 / 17$ & $0 / 15$ & & & Not estimable \\
\hline Werner 2002 & $1 / 15$ & $0 / 15$ & & $0.96 \%$ & $3.21[0.12,85.2]$ \\
\hline Subtotal $(95 \% \mathrm{Cl})$ & 579 & 564 & & $100 \%$ & $1.9[1.38,2.63]$ \\
\hline \multicolumn{6}{|c|}{ Total events: 215 (Treatment), 151 (Control) } \\
\hline \multicolumn{6}{|c|}{ Heterogeneity: $\mathrm{Tau}^{2}=0.02 ; \mathrm{Chi}^{2}=14.73, \mathrm{df}=14(\mathrm{P}=0.4) ; \mathrm{I}^{2}=4.98 \%$} \\
\hline \multicolumn{6}{|c|}{ Test for overall effect: $Z=3.92(P<0.0001)$} \\
\hline \multicolumn{6}{|c|}{ 3.1.2 Chronic phase: more than 3 months after stroke } \\
\hline Bang 2016 & $9 / 9$ & $9 / 9$ & & & Not estimable \\
\hline Buesing 2015 & $25 / 25$ & $25 / 25$ & & & Not estimable \\
\hline Cho 2015 & $0 / 13$ & $0 / 7$ & & & Not estimable \\
\hline Dias 2006 & $20 / 20$ & $20 / 20$ & & & Not estimable \\
\hline Fisher 2008 & $9 / 10$ & $9 / 10$ & & $12.78 \%$ & $1[0.05,18.57]$ \\
\hline Geroin 2011 & $20 / 20$ & $10 / 10$ & & & Not estimable \\
\hline Hornby 2008 & $31 / 31$ & $31 / 31$ & & & Not estimable \\
\hline Kyung 2008 & $12 / 18$ & $7 / 17$ & + & $41.21 \%$ & $2.86[0.72,11.31]$ \\
\hline Noser 2012 & $11 / 11$ & $10 / 10$ & & & Not estimable \\
\hline Peurala 2005 & $14 / 30$ & $9 / 15$ & 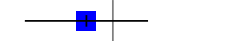 & $46.01 \%$ & $0.58[0.17,2.05]$ \\
\hline Picelli 2016 & $11 / 11$ & $11 / 11$ & & & Not estimable \\
\hline Stein 2014 & $12 / 12$ & $12 / 12$ & & & Not estimable \\
\hline Tanaka 2012 & $7 / 7$ & $5 / 5$ & & & Not estimable \\
\hline Ucar 2014 & $11 / 11$ & $11 / 11$ & & & Not estimable \\
\hline Waldman 2013 & $12 / 12$ & $12 / 12$ & & & Not estimable \\
\hline Westlake 2009 & $8 / 8$ & $8 / 8$ & & & Not estimable \\
\hline Subtotal $(95 \% \mathrm{Cl})$ & 248 & 213 & & $100 \%$ & $1.2[0.4,3.65]$ \\
\hline \multicolumn{6}{|c|}{ Total events: 212 (Treatment), 189 (Control) } \\
\hline \multicolumn{6}{|c|}{ Heterogeneity: $\mathrm{Tau}^{2}=0.28 ; \mathrm{Chi}^{2}=2.8, \mathrm{df}=2(\mathrm{P}=0.25) ; \mathrm{I}^{2}=28.69 \%$} \\
\hline \multicolumn{6}{|c|}{ Test for overall effect: $Z=0.33(P=0.74)$} \\
\hline Test for subgroup dif &, $\mathrm{df}=1(P=0.44)$, & & & & \\
\hline
\end{tabular}


Comparison 4. Post hoc sensitivity analysis: ambulatory status at study onset

\begin{tabular}{|c|c|c|c|c|}
\hline Outcome or subgroup title & $\begin{array}{l}\text { No. of } \\
\text { studies }\end{array}$ & $\begin{array}{l}\text { No. of } \\
\text { partici- } \\
\text { pants }\end{array}$ & Statistical method & Effect size \\
\hline $\begin{array}{l}1 \text { Recovery of independent walking: ambu- } \\
\text { latory status at study onset }\end{array}$ & 36 & & Odds Ratio (M-H, Random, 95\% Cl) & Subtotals only \\
\hline $\begin{array}{l}\text { 1.1 Studies that included independent } \\
\text { walkers }\end{array}$ & 15 & 500 & Odds Ratio (M-H, Random, 95\% Cl) & $1.38[0.45,4.20]$ \\
\hline $\begin{array}{l}\text { 1.2 Studies that included dependent and } \\
\text { independent walkers }\end{array}$ & 9 & 340 & Odds Ratio (M-H, Random, 95\% Cl) & $1.90[1.11,3.25]$ \\
\hline $\begin{array}{l}\text { 1.3 Studies that included dependent walk- } \\
\text { ers }\end{array}$ & 12 & 632 & Odds Ratio (M-H, Random, 95\% Cl) & $1.90[1.04,3.48]$ \\
\hline $\begin{array}{l}2 \text { Walking velocity: ambulatory status at } \\
\text { study onset }\end{array}$ & 24 & & Mean Difference (IV, Random, 95\% CI) & Subtotals only \\
\hline $\begin{array}{l}2.1 \text { Studies that included independent } \\
\text { walkers }\end{array}$ & 10 & 317 & Mean Difference (IV, Random, 95\% CI) & $-0.02[-0.10,0.06]$ \\
\hline $\begin{array}{l}\text { 2.2 Studies that included dependent and } \\
\text { independent walkers }\end{array}$ & 5 & 146 & Mean Difference (IV, Random, 95\% CI) & $0.03[-0.05,0.11]$ \\
\hline $\begin{array}{l}\text { 2.3 Studies that included dependent walk- } \\
\text { ers }\end{array}$ & 9 & 522 & Mean Difference (IV, Random, 95\% CI) & $0.10[0.03,0.17]$ \\
\hline
\end{tabular}

Analysis 4.1. Comparison 4 Post hoc sensitivity analysis: ambulatory status at study onset, Outcome 1 Recovery of independent walking: ambulatory status at study onset.

\begin{tabular}{|c|c|c|c|c|c|}
\hline Study or subgroup & $\begin{array}{c}\text { Experimental } \\
n / N\end{array}$ & $\begin{array}{c}\text { Control } \\
n / N\end{array}$ & $\begin{array}{c}\text { Odds Ratio } \\
\text { M-H, Random, } 95 \% \mathrm{Cl}\end{array}$ & Weight & $\begin{array}{c}\text { Odds Ratio } \\
\text { M-H, Random, } 95 \% \mathrm{Cl}\end{array}$ \\
\hline 4.1.1 Studies that ir & ident walkers & & & & \\
\hline Bang 2016 & $9 / 9$ & $9 / 9$ & & & Not estimable \\
\hline Brincks 2011 & $7 / 7$ & $6 / 6$ & & & Not estimable \\
\hline Buesing 2015 & $25 / 25$ & $25 / 25$ & & & Not estimable \\
\hline Dias 2006 & $20 / 20$ & $20 / 20$ & & & Not estimable \\
\hline Hidler 2009 & $36 / 36$ & $36 / 36$ & & & Not estimable \\
\hline Hornby 2008 & $31 / 31$ & $31 / 31$ & & & Not estimable \\
\hline Mayr 2008 & $9 / 37$ & $7 / 37$ & & $100 \%$ & $1.38[0.45,4.2]$ \\
\hline Noser 2012 & $11 / 11$ & $10 / 10$ & & & Not estimable \\
\hline Picelli 2016 & $11 / 11$ & $11 / 11$ & & & Not estimable \\
\hline Stein 2014 & $12 / 12$ & $12 / 12$ & & & Not estimable \\
\hline Ucar 2014 & $11 / 11$ & $11 / 11$ & & & Not estimable \\
\hline Waldman 2013 & $12 / 12$ & $12 / 12$ & & & Not estimable \\
\hline Westlake 2009 & $8 / 8$ & $8 / 8$ & & & Not estimable \\
\hline Subtotal $(95 \% \mathrm{CI})$ & 257 & 243 & & $100 \%$ & $1.38[0.45,4.2]$ \\
\hline Total events: 229 (Ex & (Control) & & & & \\
\hline
\end{tabular}




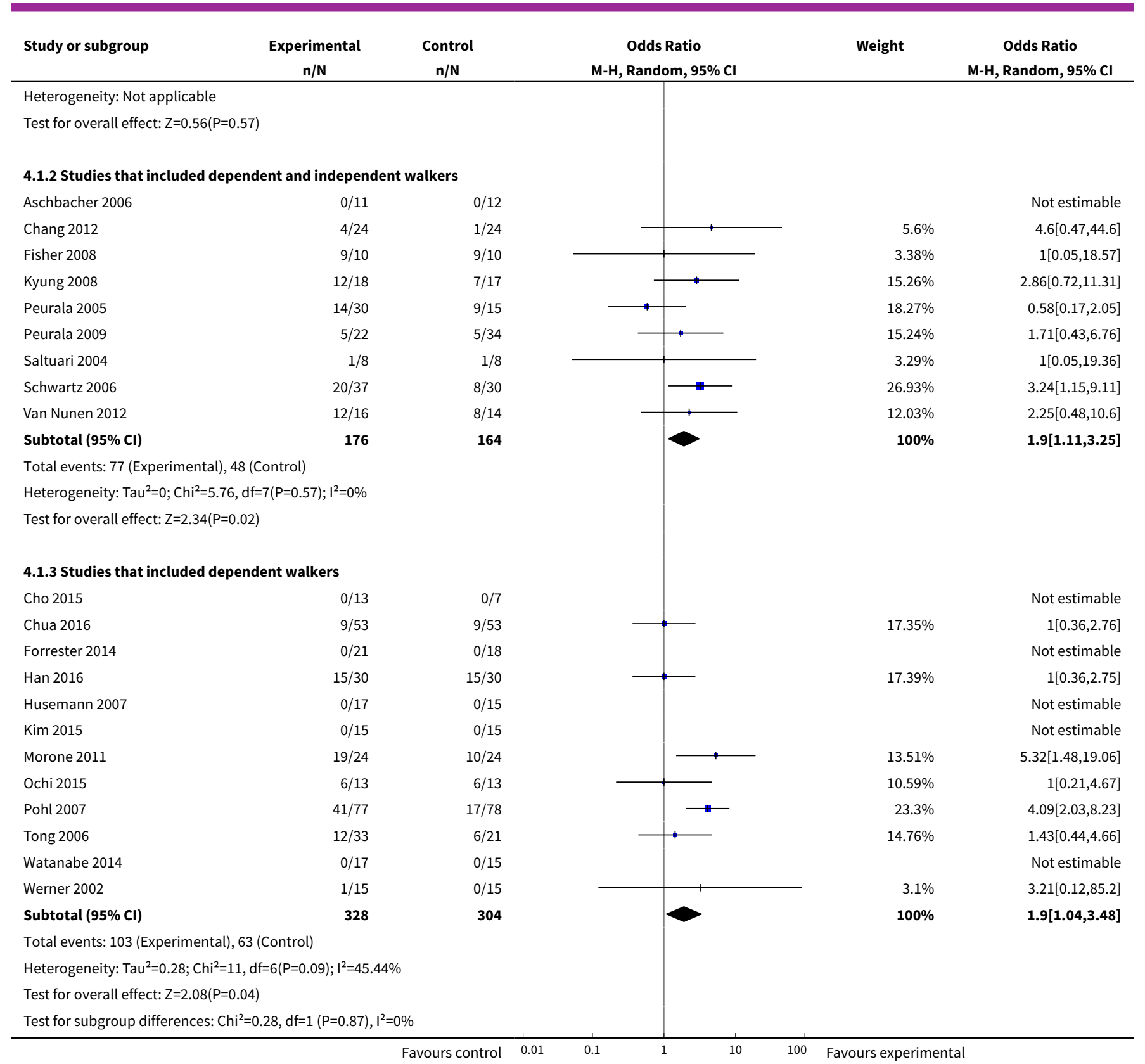

Analysis 4.2. Comparison 4 Post hoc sensitivity analysis: ambulatory status at study onset, Outcome 2 Walking velocity: ambulatory status at study onset.

\begin{tabular}{|c|c|c|c|c|c|c|c|c|}
\hline \multirow[t]{2}{*}{ Study or subgroup } & \multicolumn{2}{|c|}{ Experimental } & \multicolumn{2}{|c|}{ Control } & \multirow{2}{*}{\multicolumn{2}{|c|}{$\begin{array}{l}\text { Mean Difference } \\
\text { Random, } 95 \% \mathrm{Cl}\end{array}$}} & \multirow[t]{2}{*}{ Weight } & \multirow{2}{*}{$\begin{array}{l}\text { Mean Difference } \\
\text { Random, } 95 \% \mathrm{Cl}\end{array}$} \\
\hline & $\mathbf{N}$ & Mean(SD) & $\mathbf{N}$ & Mean(SD) & & & & \\
\hline \multicolumn{9}{|c|}{ 4.2.1 Studies that included independent walkers } \\
\hline Bang 2016 & 9 & $0.6(0.1)$ & 9 & $0.6(0.1)$ & & 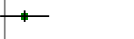 & $14.59 \%$ & $0.09[-0.02,0.2]$ \\
\hline Brincks 2011 & 7 & $0.4(0.2)$ & 6 & $0.6(0.3)$ & 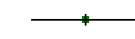 & & $7.28 \%$ & $-0.24[-0.49,0.01]$ \\
\hline Buesing 2015 & 25 & $0.9(0.3)$ & 25 & $0.9(0.3)$ & $\longrightarrow$ & - & $11.07 \%$ & $-0.01[-0.18,0.15]$ \\
\hline Geroin 2011 & 20 & $0.6(0.3)$ & 10 & $0.4(0.2)$ & & $\longrightarrow$ & $10.58 \%$ & $0.21[0.04,0.39]$ \\
\hline Hidler 2009 & 36 & $0.5(0.2)$ & 36 & $0.6(0.2)$ & $\rightarrow$ & & $16.43 \%$ & $-0.14[-0.22,-0.06]$ \\
\hline
\end{tabular}




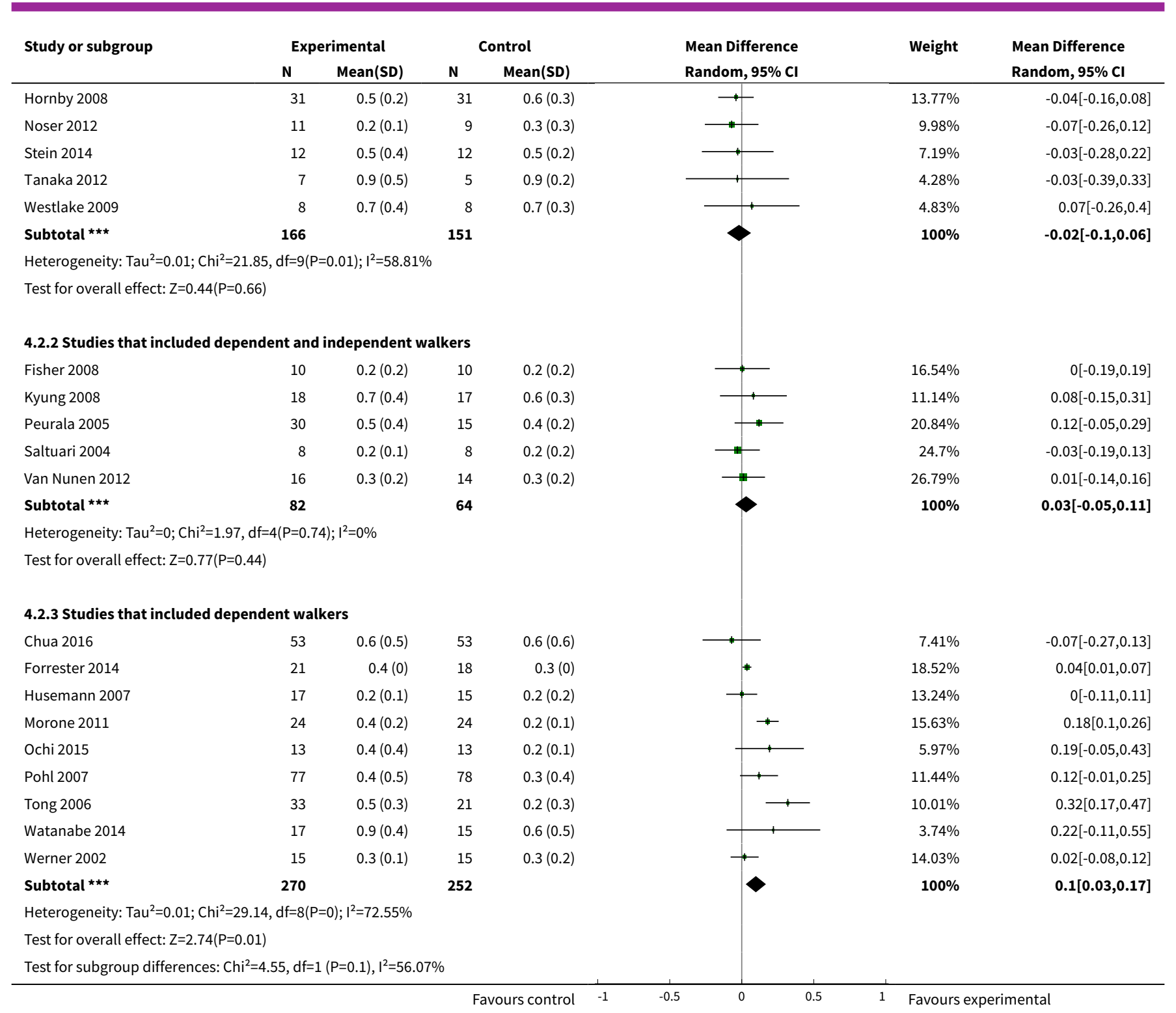

\section{Comparison 5. Post hoc sensitivity analysis: type of device}

\begin{tabular}{lllll}
\hline Outcome or subgroup title & $\begin{array}{l}\text { No. of } \\
\text { studies }\end{array}$ & $\begin{array}{l}\text { No. of } \\
\text { partici- } \\
\text { pants }\end{array}$ & Statistical method & Effect size \\
\hline $\begin{array}{l}1 \text { Different devices for regaining } \\
\text { walking ability }\end{array}$ & 32 & & Odds Ratio (M-H, Random, 95\% Cl) & Subtotals only \\
\hline $\begin{array}{l}1.1 \text { All studies using end-effector } \\
\text { devices }\end{array}$ & 11 & 598 & Odds Ratio (M-H, Random, 95\% Cl) & $1.90[0.99,3.63]$ \\
\hline $\begin{array}{l}1.2 \text { All studies using exoskeleton } \\
\text { devices }\end{array}$ & 16 & 585 & Odds Ratio (M-H, Random, 95\% Cl) & $2.05[1.21,3.50]$ \\
\hline
\end{tabular}




\begin{tabular}{|c|c|c|c|c|}
\hline Outcome or subgroup title & $\begin{array}{l}\text { No. of } \\
\text { studies }\end{array}$ & $\begin{array}{l}\text { No. of } \\
\text { partici- } \\
\text { pants }\end{array}$ & Statistical method & Effect size \\
\hline $\begin{array}{l}1.3 \text { All studies using mobile de- } \\
\text { vices }\end{array}$ & 3 & 106 & Odds Ratio (M-H, Random, 95\% Cl) & $0.0[0.0,0.0]$ \\
\hline 1.4 All studies using ankle devices & 2 & 63 & Odds Ratio (M-H, Random, 95\% Cl) & $0.0[0.0,0.0]$ \\
\hline $\begin{array}{l}2 \text { Different devices for regaining } \\
\text { walking speed }\end{array}$ & 24 & & Mean Difference (IV, Random, 95\% Cl) & Subtotals only \\
\hline $\begin{array}{l}\text { 2.1 All studies using end-effector } \\
\text { devices }\end{array}$ & 9 & 519 & Mean Difference (IV, Random, 95\% CI) & $0.11[0.04,0.18]$ \\
\hline $\begin{array}{l}\text { 2.2 All studies using exoskeleton } \\
\text { devices }\end{array}$ & 12 & 360 & Mean Difference (IV, Random, 95\% Cl) & $-0.02[-0.08,0.04]$ \\
\hline $\begin{array}{l}2.3 \text { All studies using mobile de- } \\
\text { vices }\end{array}$ & 3 & 106 & Mean Difference (IV, Random, 95\% CI) & $0.02[-0.11,0.15]$ \\
\hline 2.4 All studies using ankle devices & 1 & 39 & Mean Difference (IV, Random, 95\% Cl) & $0.04[0.01,0.07]$ \\
\hline $\begin{array}{l}3 \text { Different devices for regaining } \\
\text { walking capacity }\end{array}$ & 12 & 594 & Mean Difference (IV, Random, 95\% Cl) & $5.84[-16.73,28.40]$ \\
\hline $\begin{array}{l}\text { 3.1 All studies using end-effector } \\
\text { devices }\end{array}$ & 4 & 328 & Mean Difference (IV, Random, 95\% Cl) & $27.50[3.64,51.36]$ \\
\hline $\begin{array}{l}\text { 3.2 All studies using exoskeleton } \\
\text { devices }\end{array}$ & 5 & 186 & Mean Difference (IV, Random, 95\% Cl) & $-15.64[-46.34,15.05]$ \\
\hline $\begin{array}{l}3.3 \text { All studies using mobile de- } \\
\text { vices }\end{array}$ & 2 & 56 & Mean Difference (IV, Random, 95\% Cl) & $20.06[-39.52,79.63]$ \\
\hline 3.4 All studies using ankle devices & 1 & 24 & Mean Difference (IV, Random, 95\% Cl) & $8.0[-83.03,99.03]$ \\
\hline
\end{tabular}

Analysis 5.1. Comparison 5 Post hoc sensitivity analysis: type of device, Outcome 1 Different devices for regaining walking ability.

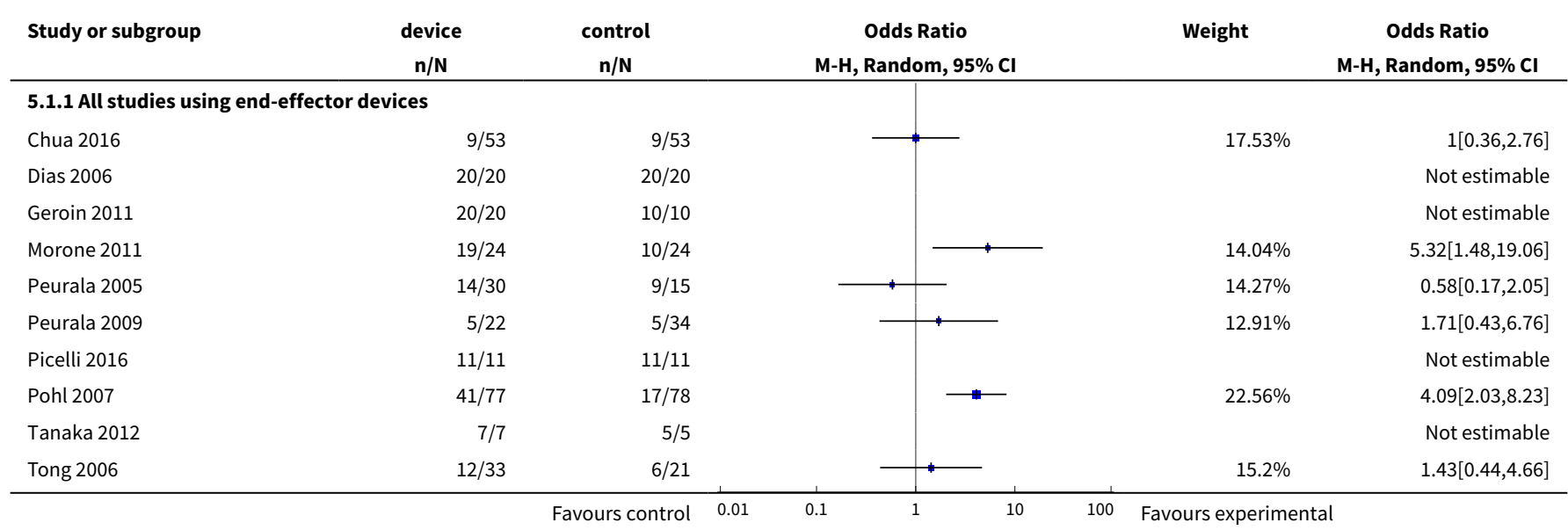




\begin{tabular}{|c|c|c|c|c|c|}
\hline Study or subgroup & $\begin{array}{c}\text { device } \\
\mathrm{n} / \mathrm{N}\end{array}$ & $\begin{array}{c}\text { control } \\
n / N\end{array}$ & $\begin{array}{c}\text { Odds Ratio } \\
\text { M-H, Random, } 95 \% \mathrm{CI}\end{array}$ & Weight & $\begin{array}{c}\text { Odds Ratio } \\
\text { M-H, Random, } 95 \% \mathrm{Cl}\end{array}$ \\
\hline Werner 2002 & $1 / 15$ & $0 / 15$ & 1 & $3.49 \%$ & $3.21[0.12,85.2]$ \\
\hline Subtotal $(95 \% \mathrm{Cl})$ & 312 & 286 & & $100 \%$ & $1.9[0.99,3.63]$ \\
\hline \multicolumn{6}{|c|}{ Total events: 159 (device), 102 (control) } \\
\hline \multicolumn{6}{|c|}{ Heterogeneity: $\mathrm{Tau}^{2}=0.36 ; \mathrm{Chi}^{2}=12.12, \mathrm{df}=6(\mathrm{P}=0.06) ; \mathrm{I}^{2}=50.48 \%$} \\
\hline \multicolumn{6}{|c|}{ Test for overall effect: $Z=1.92(P=0.05)$} \\
\hline \multicolumn{6}{|c|}{ 5.1.2 All studies using exoskeleton devices } \\
\hline Aschbacher 2006 & $0 / 11$ & $0 / 12$ & & & Not estimable \\
\hline Brincks 2011 & $7 / 7$ & $6 / 6$ & & & Not estimable \\
\hline Chang 2012 & $4 / 24$ & $1 / 24$ & & $5.49 \%$ & $4.6[0.47,44.6]$ \\
\hline Fisher 2008 & $9 / 10$ & $9 / 10$ & & $3.32 \%$ & $1[0.05,18.57]$ \\
\hline Hidler 2009 & $36 / 36$ & $36 / 36$ & & & Not estimable \\
\hline Hornby 2008 & $31 / 31$ & $31 / 31$ & & & Not estimable \\
\hline Husemann 2007 & $0 / 17$ & $0 / 15$ & & & Not estimable \\
\hline Kim 2015 & $0 / 15$ & $0 / 15$ & & & Not estimable \\
\hline Kyung 2008 & $12 / 18$ & $7 / 17$ & $\rightarrow$ & $14.97 \%$ & $2.86[0.72,11.31]$ \\
\hline Mayr 2008 & $9 / 37$ & $7 / 37$ & & $22.84 \%$ & $1.38[0.45,4.2]$ \\
\hline Noser 2012 & $11 / 11$ & $10 / 10$ & & & Not estimable \\
\hline Ochi 2015 & $6 / 13$ & $6 / 13$ & & $11.92 \%$ & $1[0.21,4.67]$ \\
\hline Saltuari 2004 & $1 / 8$ & $1 / 8$ & & $3.23 \%$ & $1[0.05,19.36]$ \\
\hline Schwartz 2006 & $20 / 37$ & $8 / 30$ & $\longrightarrow$ & $26.42 \%$ & $3.24[1.15,9.11]$ \\
\hline Van Nunen 2012 & $12 / 16$ & $8 / 14$ & \begin{tabular}{l|l} 
& $\longrightarrow$
\end{tabular} & $11.81 \%$ & $2.25[0.48,10.6]$ \\
\hline Westlake 2009 & $8 / 8$ & $8 / 8$ & & & Not estimable \\
\hline Subtotal $(95 \% \mathrm{Cl})$ & 299 & 286 & & $100 \%$ & $2.05[1.21,3.5]$ \\
\hline \multicolumn{6}{|c|}{ Total events: 166 (device), 138 (control) } \\
\hline \multicolumn{6}{|c|}{ Heterogeneity: $\operatorname{Tau}^{2}=0 ; \mathrm{Chi}^{2}=3.25, \mathrm{df}=7(\mathrm{P}=0.86) ; \mathrm{I}^{2}=0 \%$} \\
\hline \multicolumn{6}{|c|}{ Test for overall effect: $Z=2.65(P=0.01)$} \\
\hline \multicolumn{6}{|c|}{ 5.1.3 All studies using mobile devices } \\
\hline Buesing 2015 & $25 / 25$ & $25 / 25$ & & & Not estimable \\
\hline Stein 2014 & $12 / 12$ & $12 / 12$ & & & Not estimable \\
\hline Watanabe 2014 & $0 / 17$ & $0 / 15$ & & & Not estimable \\
\hline Subtotal $(95 \% \mathrm{Cl})$ & 54 & 52 & & & Not estimable \\
\hline \multicolumn{6}{|c|}{ Total events: 37 (device), 37 (control) } \\
\hline \multicolumn{6}{|c|}{ Heterogeneity: Not applicable } \\
\hline \multicolumn{6}{|c|}{ Test for overall effect: Not applicable } \\
\hline \multicolumn{6}{|c|}{ 5.1.4 All studies using ankle devices } \\
\hline Forrester 2014 & $0 / 21$ & $0 / 18$ & & & Not estimable \\
\hline Waldman 2013 & $12 / 12$ & $12 / 12$ & & & Not estimable \\
\hline Subtotal $(95 \% \mathrm{Cl})$ & 33 & 30 & & & Not estimable \\
\hline \multicolumn{6}{|c|}{ Total events: 12 (device), 12 (control) } \\
\hline \multicolumn{6}{|c|}{ Heterogeneity: Not applicable } \\
\hline \multicolumn{6}{|c|}{ Test for overall effect: Not applicable } \\
\hline Test for subgroup di & $f=1(P=0.85)$, & & & & \\
\hline
\end{tabular}


Analysis 5.2. Comparison 5 Post hoc sensitivity analysis: type of device, Outcome 2 Different devices for regaining walking speed.

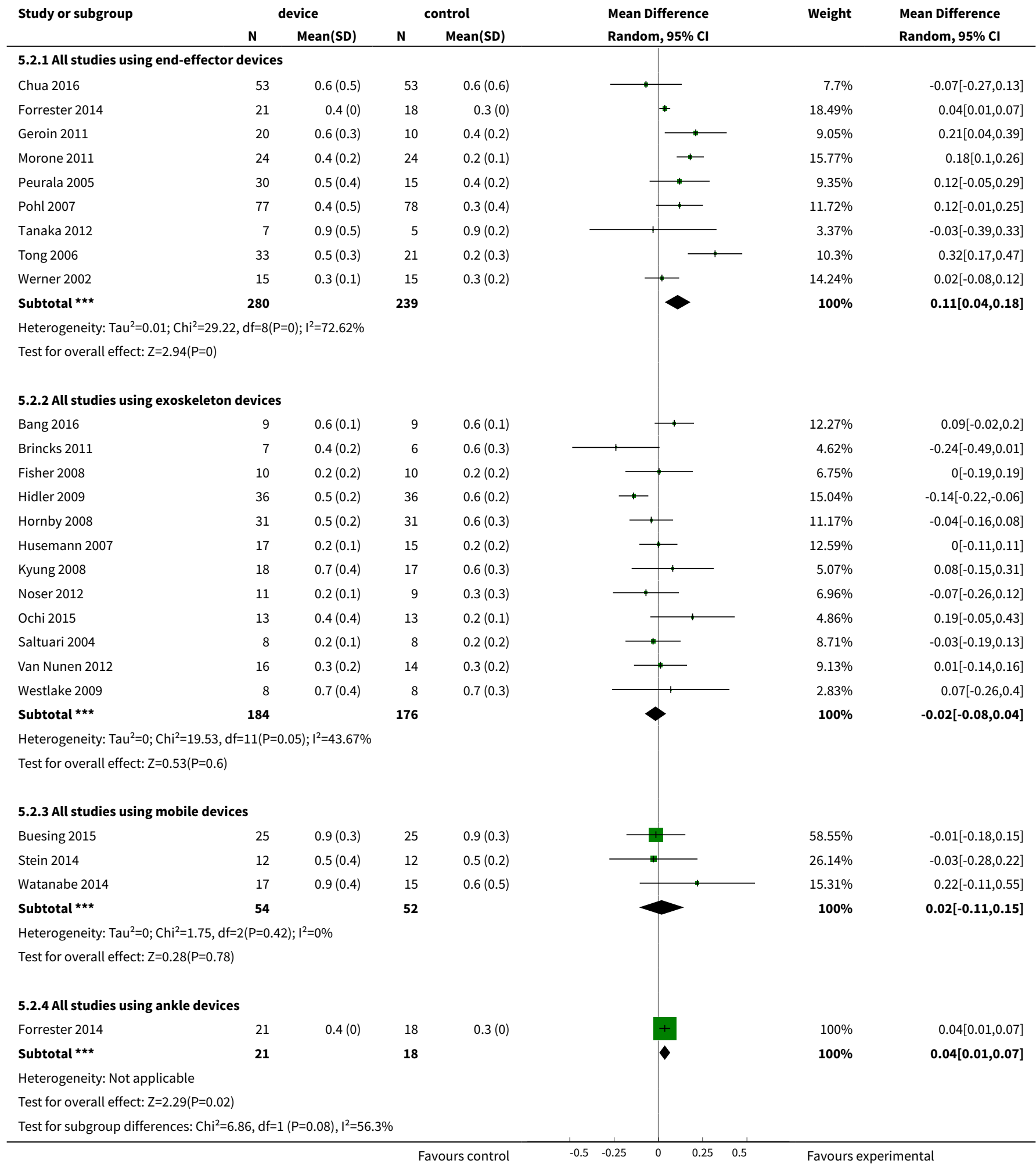


Analysis 5.3. Comparison 5 Post hoc sensitivity analysis: type of device, Outcome 3 Different devices for regaining walking capacity.

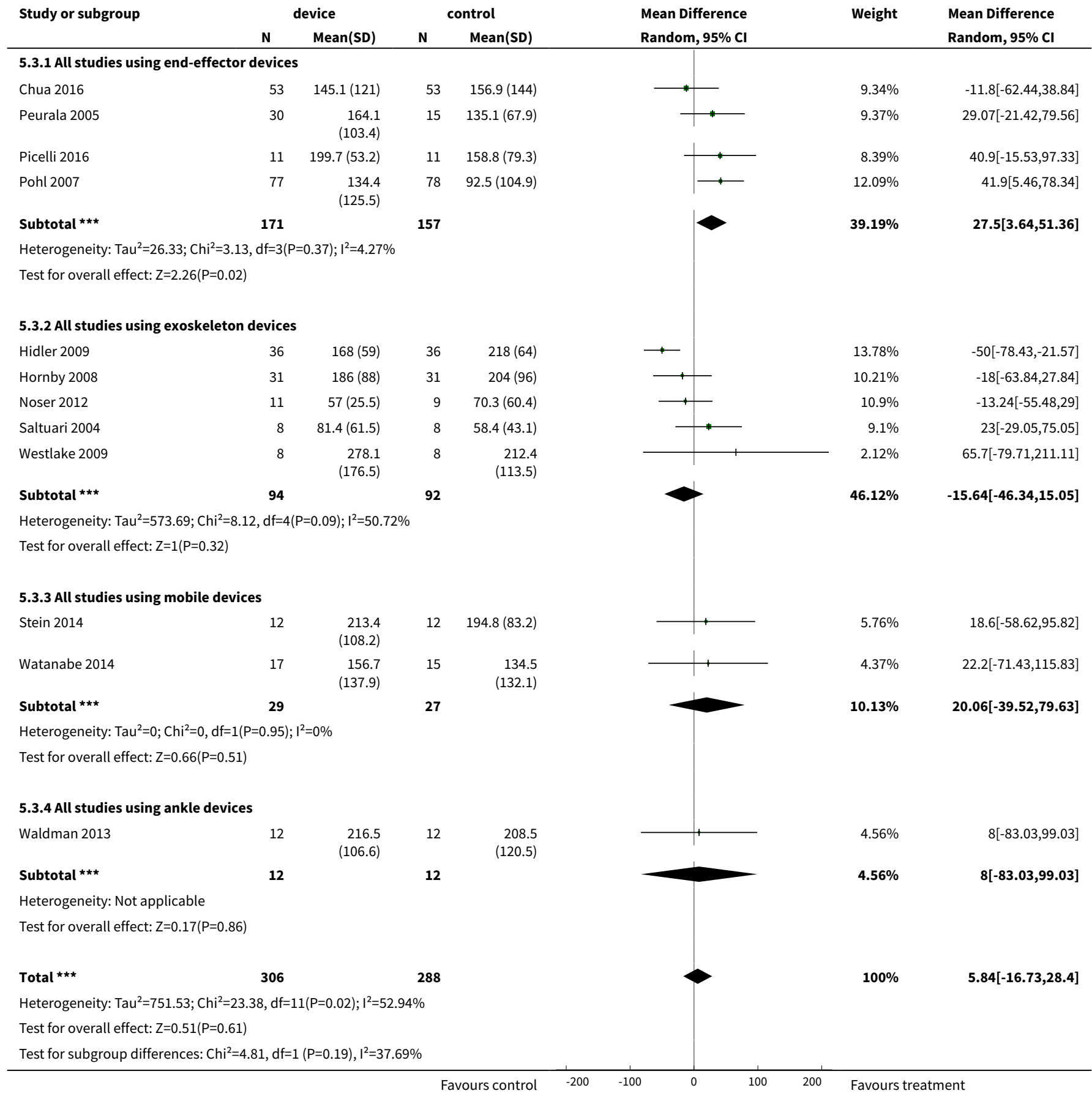

\section{ADDITIONAL TABLES}




\begin{tabular}{|c|c|c|c|c|c|c|c|c|}
\hline Study ID & $\begin{array}{l}\text { Experimen- } \\
\text { tal: } \\
\text { age, mean } \\
\text { (SD) }\end{array}$ & $\begin{array}{l}\text { Control: } \\
\text { age, mean } \\
\text { (SD) }\end{array}$ & $\begin{array}{l}\text { Experimental: } \\
\text { time post- } \\
\text { stroke }\end{array}$ & $\begin{array}{l}\text { Control: } \\
\text { time post- } \\
\text { stroke }\end{array}$ & $\begin{array}{l}\text { Experimental: } \\
\text { sex }\end{array}$ & $\begin{array}{l}\text { Control: } \\
\text { sex }\end{array}$ & $\begin{array}{l}\text { Experimental: } \\
\text { side paresis }\end{array}$ & $\begin{array}{l}\text { Control: } \\
\text { side paresis }\end{array}$ \\
\hline $\begin{array}{l}\text { Aschbacher } \\
2006\end{array}$ & 57 years & 65 years & $\leq 3$ months & $\leq 3$ months & 2 female & 4 female & Not stated & Not stated \\
\hline Bang 2016 & 54 years & 54 years & 12 months & 13 months & 5 male, 4 female & 4 male, 5 female & 4 right, 5 left & 4 right, 5 left \\
\hline Brincks 2011 & $\begin{array}{l}61 \text { (median) } \\
\text { years }\end{array}$ & $\begin{array}{l}59 \text { (median) } \\
\text { years }\end{array}$ & $\begin{array}{l}56 \text { (median) } \\
\text { days }\end{array}$ & $\begin{array}{l}21 \text { (median) } \\
\text { days }\end{array}$ & 5 male, 2 female & 4 male, 2 female & 5 right, 2 left & 1 right, 5 left \\
\hline $\begin{array}{l}\text { Buesing } \\
2015\end{array}$ & 60 years & 62 years & 7 years & 5 years & 17 male, 8 female & 16 male, 9 female & 13 right, 12 left & 12 right, 13 left \\
\hline Chang 2012 & 56 (12) years & 60 (12) years & 16 (5) days & 18 (5) days & 13 male, 7 female & 10 male, 7 female & 6 right, 14 left & 6 right, 11 left \\
\hline Cho 2015 & 55 (12) years & 55 (15) years & 15 months & 13 months & Not stated & Not stated & $\begin{array}{l}6 \text { right, } 4 \text { left (4 } \\
\text { both) }\end{array}$ & $\begin{array}{l}3 \text { right, } 1 \text { left ( } 3 \\
\text { both) }\end{array}$ \\
\hline Chua 2016 & 62 (10) years & 61 (11) years & 27 (11) days & 30 (14) days & $\begin{array}{l}35 \text { male, } 18 \mathrm{fe}- \\
\text { male }\end{array}$ & $\begin{array}{l}40 \text { male, } 13 \mathrm{fe}- \\
\text { male }\end{array}$ & 24 right, 29 left & 21 right, 32 left \\
\hline Dias 2006 & 70 (7) years & 68 (11) years & 47 (64) months & 48 (30) months & 16 male, 4 female & 14 male, 6 female & Not stated & Not stated \\
\hline Fisher 2008 & Not stated & Not stated & $\begin{array}{l}\text { Less than } 12 \\
\text { months }\end{array}$ & $\begin{array}{l}\text { Less than } 12 \\
\text { months }\end{array}$ & Not stated & Not stated & Not stated & Not stated \\
\hline $\begin{array}{l}\text { Forrester } \\
2014\end{array}$ & 63 years & 60 years & 12 days & 11 days & Not stated & Not stated & 9 right, 9 left & 7 right, 9 left \\
\hline Geroin 2011 & 63 (7) years & $61(6)$ years & 26 (6) months & 27 (6) months & 14 male, 6 female & 9 male, 1 female & Not stated & Not stated \\
\hline Han 2016 & $68(15)$ years & 63 (11) years & 22 (8) days & 18 (10) days & Not stated & Not stated & 20 right, 10 left & 14 right, 12 left \\
\hline Hidler 2009 & $60(11)$ years & 55 (9) years & 111 (63) days & 139 (61) days & $\begin{array}{l}21 \text { male, } 12 \mathrm{fe}- \\
\text { male }\end{array}$ & $\begin{array}{l}18 \text { male, } 12 \mathrm{fe}- \\
\text { male }\end{array}$ & 22 right, 11 left & 13 right, 17 left \\
\hline $\begin{array}{l}\text { Hornby } \\
2008\end{array}$ & 57 (10) years & 57 (11) years & 50 (51) months & 73 (87) months & 15 male, 9 female & 15 male, 9 female & 16 right, 8 left & 16 right, 8 left \\
\hline
\end{tabular}




\begin{tabular}{|c|c|c|c|c|c|c|c|c|}
\hline $\begin{array}{l}\text { Husemann } \\
2007\end{array}$ & $60(13)$ years & 57 (11) years & 79 (56) days & 89 (61) days & 11 male, 5 female & 10 male, 4 female & 12 right, 4 left & 11 right, 3 left \\
\hline Kim 2015 & 54 (13) years & 50 (16) years & 80 (60) days & 120 (84) days & 9 male, 4 female & 10 male, 3 female & 8 right, 5 left & 10 right, 3 left \\
\hline Kyung 2008 & 48 (8) years & 55 (16) years & 22 (23) months & 29 (12) months & 9 male, 8 female & 4 male, 4 female & 9 right, 8 left & 4 right, 4 left \\
\hline Mayr 2008 & Not stated & Not stated & $\begin{array}{l}\text { Between } 10 \\
\text { days and } 6 \\
\text { months }\end{array}$ & $\begin{array}{l}\text { Between } 10 \\
\text { days and } 6 \\
\text { months }\end{array}$ & Not stated & Not stated & Not stated & Not stated \\
\hline $\begin{array}{l}\text { Morone } \\
2011\end{array}$ & 62 (11) years & 62 (14) years & 19 (11) days & 20 (14) days & 15 male, 9 female & $\begin{array}{l}13 \text { male, } 11 \mathrm{fe}- \\
\text { male }\end{array}$ & 13 right, 11 left & 15 right, 9 left \\
\hline Noser 2012 & 67 (9) years & 64 (11) years & 1354 days & 525 days & 7 male, 4 female & 6 male, 4 female & Not stated & Not stated \\
\hline Ochi 2015 & $62(8)$ years & 66 (12) years & 23 (7) days & 26 (8) days & 11 male, 2 female & 9 male, 4 female & 6 right, 7 left & 5 right, 8 left \\
\hline $\begin{array}{l}\text { Peurala } \\
2005\end{array}$ & 52 (8) years & $52(7)$ years & 2.5 (2.5) years & $4.0(5.8)$ years & 26 male, 4 female & 11 male, 4 female & 13 right, 17 left & 10 right, 5 left \\
\hline $\begin{array}{l}\text { Peurala } \\
2009\end{array}$ & 67 (9) years & $68(10)$ years & 8 (3) days & 8 (3) days & $\begin{array}{l}11 \text { male, } 11 \mathrm{fe}- \\
\text { male }\end{array}$ & $\begin{array}{l}18 \text { male, } 16 \mathrm{fe}- \\
\text { male }\end{array}$ & 11 right, 11 left & 14 right, 20 left \\
\hline Picelli 2016 & $62(10)$ years & 65 (3) years & $6(4)$ years & $6(4)$ years & 7 male, 4 female & 9 male, 2 female & Not stated & Not stated \\
\hline Pohl 2007 & $62(12)$ years & 64 (11) years & $4.2(1.8)$ weeks & 4.5 (1.9) weeks & $\begin{array}{l}50 \text { male, } 27 \mathrm{fe}- \\
\text { male }\end{array}$ & $\begin{array}{l}54 \text { male, } 24 \mathrm{fe}- \\
\text { male }\end{array}$ & 36 right, 41 left & 33 right, 45 left \\
\hline $\begin{array}{l}\text { Saltuari } \\
2004\end{array}$ & $62(13)$ years & 60 (19) years & 3.6 (4.6) months & 1.9 (0.8) months & 4 male, 4 female & 2 male, 6 female & Not stated & Not stated \\
\hline $\begin{array}{l}\text { Schwartz } \\
2006\end{array}$ & 62 (9) years & 65 (8) years & 22 (9) days & 24 (10) days & $\begin{array}{l}21 \text { male, } 16 \mathrm{fe}- \\
\text { male }\end{array}$ & $\begin{array}{l}20 \text { male, } 10 \mathrm{fe}- \\
\text { male }\end{array}$ & 17 right, 20 left & 8 right, 22 left \\
\hline Stein 2014 & 58 (11) years & 57 (15) years & 49 (39) months & 89 (153) months & Not stated & Not stated & Not stated & Not stated \\
\hline Tanaka 2012 & $63(10)$ years & 60 (9) years & 55 (37) months & 65 (67) months & 10 male, 2 female & & 9 right, 3 left & \\
\hline Tong 2006 & 71 (14) years & $64(10)$ years & 2.5 (1.2) weeks & 2.7 (1.2) weeks & $\begin{array}{l}19 \text { male, } 11 \mathrm{fe}- \\
\text { male }\end{array}$ & 12 male, 8 female & 13 right, 17 left & 7 right, 13 left \\
\hline
\end{tabular}




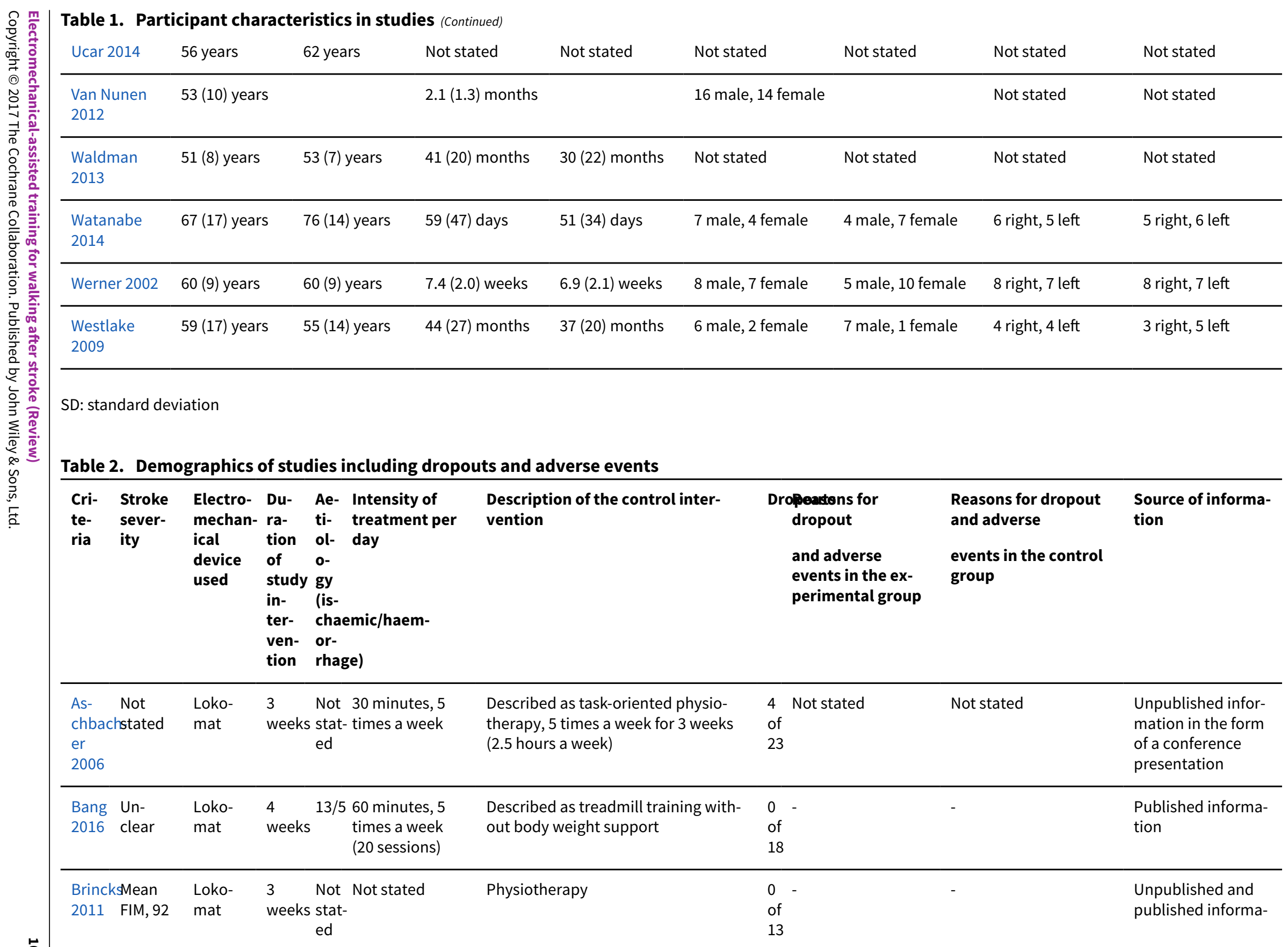




\begin{tabular}{|c|c|c|c|c|c|c|c|c|c|}
\hline & $\begin{array}{l}\text { of } 126 \\
\text { points }\end{array}$ & & & & & & & & $\begin{array}{l}\text { tion provided by } \\
\text { the authors. }\end{array}$ \\
\hline $\begin{array}{l}\text { Buesi } \\
2015\end{array}$ & $\begin{array}{l}\text { En- } \\
\text { clear }\end{array}$ & $\begin{array}{l}\text { Wear- } \\
\text { able } \\
\text { ex- } \\
\text { oskele- } \\
\text { ton } \\
\text { Stride } \\
\text { Man- } \\
\text { age- } \\
\text { ment } \\
\text { Assist } \\
\text { system } \\
\text { (SMA) }\end{array}$ & $\begin{array}{l}6 \text { to } \\
8 \\
\text { weeks }\end{array}$ & $\begin{array}{l}\text { Un- } 3 \text { times per } \\
\text { clear week for a max- } \\
\text { imum of } 18 \text { ses- } \\
\text { sions }\end{array}$ & $\begin{array}{l}\text { Functional task-specific training (in- } \\
\text { tensive overground training and mo- } \\
\text { bility training) }\end{array}$ & $\begin{array}{l}0 \\
\text { of } \\
50\end{array}$ & & - & $\begin{array}{l}\text { Published informa- } \\
\text { tion }\end{array}$ \\
\hline $\begin{array}{l}\text { Chang } \\
2012\end{array}$ & $\begin{array}{l}\text { Not } \\
\text { stated }\end{array}$ & $\begin{array}{l}\text { Loko- } \\
\text { mat }\end{array}$ & $\begin{array}{l}10 \\
\text { days }\end{array}$ & $\begin{array}{l}\text { Not } 30 \text { minutes dai- } \\
\text { stat- ly for } 10 \text { days } \\
\text { ed }\end{array}$ & $\begin{array}{l}\text { Conventional gait training by phys- } \\
\text { ical therapists (with equal therapy } \\
\text { time and same amount of sessions } \\
\text { as experimental group) }\end{array}$ & $\begin{array}{l}3 \\
\text { of } \\
40\end{array}$ & $\begin{array}{l}\text { Not described by gro } \\
\text { (3 participants drop } \\
1 \text { due to aspiration } \\
\text { unable to co-operat } \\
\text { mental procedure) }\end{array}$ & $\begin{array}{l}\text { ed out: } \\
\text { eumonia, and } 2 \text { were } \\
\text { fully with the experi- }\end{array}$ & $\begin{array}{l}\text { Unpublished and } \\
\text { published informa- } \\
\text { tion provided by } \\
\text { the authors. }\end{array}$ \\
\hline $\begin{array}{l}\text { Cho } \\
2015\end{array}$ & $\begin{array}{l}\text { Mean } \\
\text { Mod- } \\
\text { ified } \\
\text { Barthel } \\
\text { In- } \\
\text { dex, } 36 \\
\text { points }\end{array}$ & $\begin{array}{l}\text { Loko- } \\
\text { mat }\end{array}$ & $\begin{array}{l}8 \\
\text { weeks } \\
\text { (2 } \\
\text { phas- } \\
\text { es, } \\
\text { cross- } \\
\text { over } \\
\text { af- } \\
\text { ter } \\
4 \\
\text { weeks }\end{array}$ & $\begin{array}{l}4 / 1430 \text { minutes, } 3 \\
\text { both)for } 4 \text { weeks } \\
\text { ) }\end{array}$ & $\begin{array}{l}\text { Bobath (neurophysiological exercis- } \\
\text { es, inhibition of spasticity and syner- } \\
\text { gy pattern) }\end{array}$ & $\begin{array}{l}0 \\
\text { of } \\
20\end{array}$ & - & - & $\begin{array}{l}\text { Published informa- } \\
\text { tion }\end{array}$ \\
\hline $\begin{array}{l}\text { Chua } \\
2016\end{array}$ & $\begin{array}{l}\text { Mean } \\
\text { Barthel } \\
\text { In- } \\
\text { dex, } 49 \\
\text { points }\end{array}$ & $\begin{array}{l}\text { Gait } \\
\text { Trainer }\end{array}$ & $\begin{array}{l}8 \\
\text { weeks }\end{array}$ & $\begin{array}{l}\text { Not Not stated } \\
\text { stat- } \\
\text { ed }\end{array}$ & $\begin{array}{l}\text { Physiotherapy including } 25 \text { minutes } \\
\text { of stance/gait, } 10 \text { minutes cycling, } 10 \\
\text { minutes tilt table standing }\end{array}$ & $\begin{array}{l}20 \\
\text { of } \\
106\end{array}$ & $\begin{array}{l}2 \text { death, } 3 \text { refusal, } 1 \\
\text { medical problem, } 1 \\
6 \text { transport problem } \\
\text { (1 pain as adverse } \\
\text { event) }\end{array}$ & $\begin{array}{l}1 \text { death, } 6 \text { refusal, } 3 \\
\text { medical problem, } 1 \text { ad- } \\
\text { ministrative problem } \\
\text { (no adverse events) }\end{array}$ & $\begin{array}{l}\text { Published informa- } \\
\text { tion }\end{array}$ \\
\hline $\begin{array}{l}\text { Dias } \\
2006\end{array}$ & $\begin{array}{l}\text { Mean } \\
\text { Barthel } \\
\text { In- }\end{array}$ & $\begin{array}{l}\text { Gait } \\
\text { Trainer }\end{array}$ & $\begin{array}{l}4 \\
\text { weeks }\end{array}$ & $\begin{array}{l}\text { Not } 40 \text { minutes, } 5 \\
\text { stat- times a week } \\
\text { ed }\end{array}$ & $\begin{array}{l}\text { Bobath method, } 5 \text { times a week for } 5 \\
\text { weeks }\end{array}$ & $\begin{array}{l}0 \\
\text { of } \\
40\end{array}$ & & - & $\begin{array}{l}\text { Unpublished and } \\
\text { published informa- }\end{array}$ \\
\hline
\end{tabular}




\begin{tabular}{|c|c|c|c|c|c|c|c|c|c|c|}
\hline & $\begin{array}{l}\text { dex, } 75 \\
\text { points }\end{array}$ & & & & & & & & $\begin{array}{l}\text { tion provided by } \\
\text { the authors. }\end{array}$ & $=$ \\
\hline $\begin{array}{l}\text { Fish- } \\
\text { er } \\
2008\end{array}$ & $\begin{array}{l}\text { Not } \\
\text { stated }\end{array}$ & $\begin{array}{l}\text { Au- } \\
\text { toAm- } \\
\text { bulator }\end{array}$ & $\begin{array}{l}24 \\
\text { ses- } \\
\text { sions }\end{array}$ & 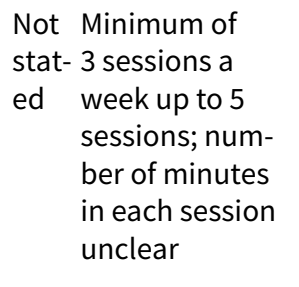 & $\begin{array}{l}\text { "Standard" physical therapy, } 3 \text { to } 5 \\
\text { times a week for } 24 \text { consecutive ses- } \\
\text { sions }\end{array}$ & $\begin{array}{l}0 \\
\text { of } \\
20\end{array}$ & $\begin{array}{l}14 \text { adverse events, } \\
\text { no details provided }\end{array}$ & $\begin{array}{l}11 \text { adverse events, } \\
\text { no details provided }\end{array}$ & $\begin{array}{l}\text { Unpublished and } \\
\text { published informa- } \\
\text { tion provided by } \\
\text { the authors. }\end{array}$ & 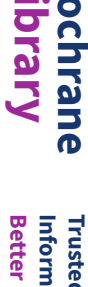 \\
\hline $\begin{array}{l}\text { For- } \\
\text { rester } \\
2014\end{array}$ & $\begin{array}{l}\text { Mean } \\
\text { FIM } \\
\text { walk } 1 \\
\text { point }\end{array}$ & $\begin{array}{l}\text { Ankle- } \\
\text { bot }\end{array}$ & $\begin{array}{l}8 \text { to } \\
10 \\
\text { ses- } \\
\text { sions } \\
\text { (with } \\
\text { ca. } \\
200 \\
\text { rep- } \\
\text { eti- } \\
\text { tions) }\end{array}$ & $\begin{array}{l}\text { Not } 60 \text { minutes, } 8 \text { to } \\
\text { stat- } 10 \text { sessions } \\
\text { ed }\end{array}$ & Stretching of the paretic ankle & & $\begin{array}{l}\text { Total of } 5 \text { dropouts it } \\
\text { complication, } 1 \text { discl } \\
\text { time poststroke }>49\end{array}$ & $\begin{array}{l}\text { both groups ( } 1 \text { medical } \\
\text { arge prior study end, } 2 \\
\text { days, } 1 \text { non-compliance) }\end{array}$ & $\begin{array}{l}\text { Published informa- } \\
\text { tion provided by } \\
\text { the authors. }\end{array}$ & 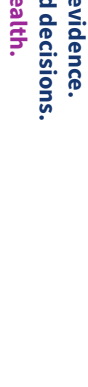 \\
\hline $\begin{array}{l}\text { Geroir } \\
2011\end{array}$ & $\begin{array}{l}\text { Mean } \\
\text { Euro- } \\
\text { pean } \\
\text { Stroke } \\
\text { Scale, } \\
80 \\
\text { points }\end{array}$ & $\begin{array}{l}\text { Gait } \\
\text { Trainer }\end{array}$ & $\begin{array}{l}2 \\
\text { weeks }\end{array}$ & $\begin{array}{l}\text { Not } 50 \text { minutes, } 5 \\
\text { stat- times a week } \\
\text { ed }\end{array}$ & $\begin{array}{l}\text { Walking exercises according to the } \\
\text { Bobath approach }\end{array}$ & $\begin{array}{l}0 \\
\text { of } \\
30\end{array}$ & & - & $\begin{array}{l}\text { Unpublished and } \\
\text { published informa- } \\
\text { tion provided by } \\
\text { the authors. }\end{array}$ & \\
\hline $\begin{array}{l}\text { Han } \\
2016\end{array}$ & $\begin{array}{l}\text { Not } \\
\text { stated }\end{array}$ & $\begin{array}{l}\text { Loko- } \\
\text { mat }\end{array}$ & $\begin{array}{l}4 \\
\text { weeks }\end{array}$ & $\begin{array}{r}33 / 2330 \text { minutes, } 5 \\
\text { times a week }\end{array}$ & $\begin{array}{l}\text { Neurodevelopmental techniques for } \\
\text { balance and mobility }\end{array}$ & $\begin{array}{l}4 \\
\text { of } \\
60\end{array}$ & & 4 unclear reasons & $\begin{array}{l}\text { Published informa- } \\
\text { tion provided by } \\
\text { the authors. }\end{array}$ & \\
\hline $\begin{array}{l}\text { Hi- } \\
\text { dler } \\
2009\end{array}$ & $\begin{array}{l}\text { Not } \\
\text { stated }\end{array}$ & $\begin{array}{l}\text { Loko- } \\
\text { mat }\end{array}$ & $\begin{array}{l}8 \text { to } \\
10 \\
\text { weeks } \\
\text { (24 } \\
\text { ses- } \\
\text { sions) }\end{array}$ & $\begin{array}{l}\text { 47/1645 minutes, } 3 \\
\text { days a week }\end{array}$ & $\begin{array}{l}\text { Conventional gait training, } 3 \text { times a } \\
\text { week for } 8 \text { to } 10 \text { weeks ( } 24 \text { sessions), } \\
\text { each session lasted } 1.5 \text { hours }\end{array}$ & $\begin{array}{l}9 \\
\text { of } \\
72\end{array}$ & $\begin{array}{l}\text { Not described by gro } \\
\text { (9 withdrew or were } \\
\text { poor attendance or } \\
\text { cluding } 1 \text { death, whi } \\
\text { thors was unrelated }\end{array}$ & $\begin{array}{l}\text { emoved because of } \\
\text { decline in health, in- } \\
\text { haccording to the au- } \\
\text { o study) }\end{array}$ & $\begin{array}{l}\text { Unpublished and } \\
\text { published informa- } \\
\text { tion provided by } \\
\text { the authors. }\end{array}$ & 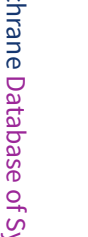 \\
\hline $\begin{array}{l}\text { Horn- } \\
\text { by } \\
2008\end{array}$ & $\begin{array}{l}\text { Not } \\
\text { stated }\end{array}$ & $\begin{array}{l}\text { Loko- } \\
\text { mat }\end{array}$ & $\begin{array}{l}12 \\
\text { ses- } \\
\text { sions }\end{array}$ & $\begin{array}{l}\text { 22/2630 minutes, } 12 \\
\text { sessions }\end{array}$ & $\begin{array}{l}\text { Therapist-assisted gait training, } 12 \\
\text { sessions, each session lasted } 30 \mathrm{~min} \text { - } \\
\text { utes }\end{array}$ & $\begin{array}{l}14 \\
\text { of } \\
62\end{array}$ & $\begin{array}{l}4 \text { participants } \\
\text { dropped out }(2 \\
\text { discontinued sec- } \\
\text { ondary }\end{array}$ & $\begin{array}{l}10 \text { participants } \\
\text { dropped out }\end{array}$ & $\begin{array}{l}\text { Published informa- } \\
\text { tion provided by } \\
\text { the authors. }\end{array}$ & 被. \\
\hline
\end{tabular}




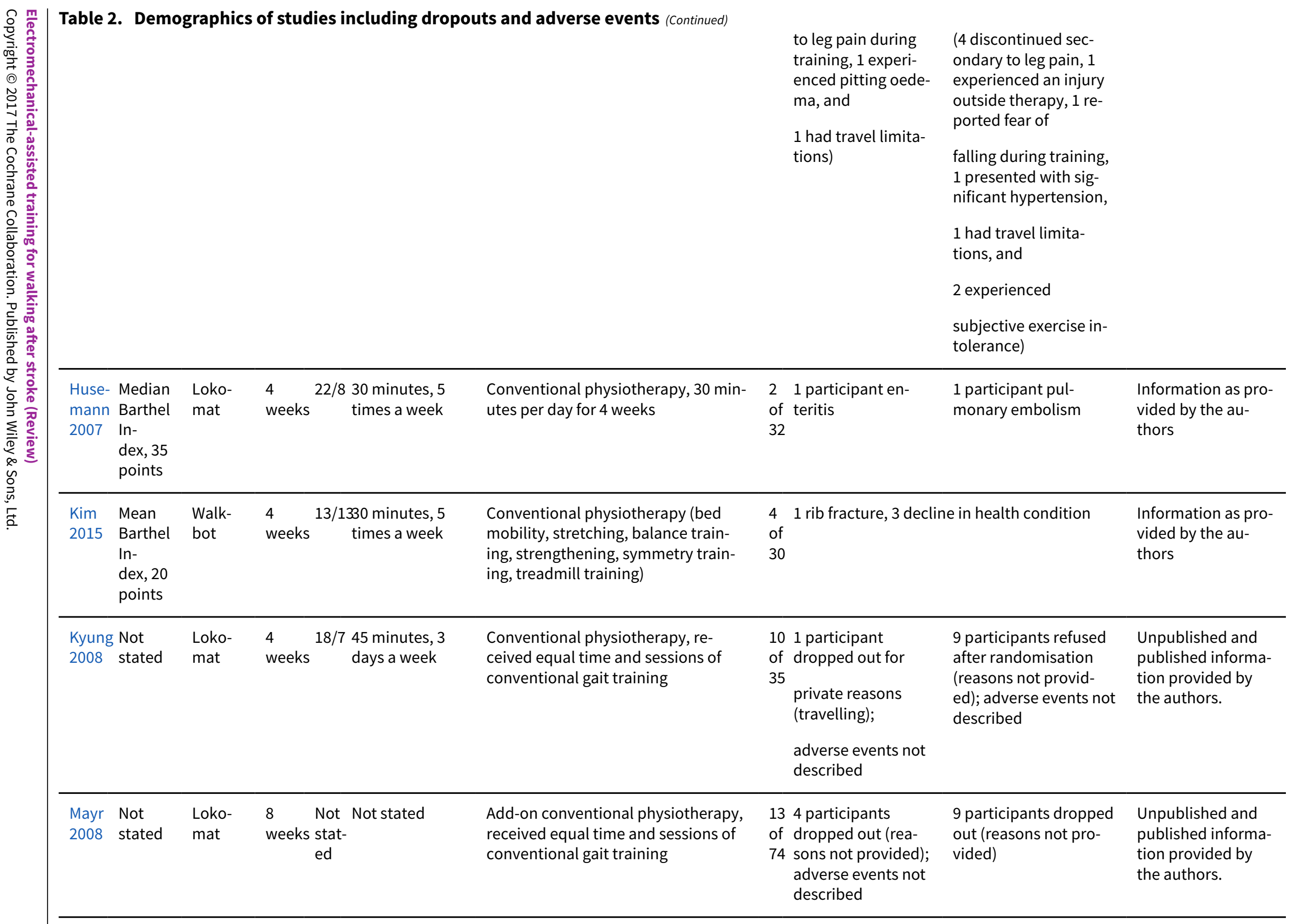




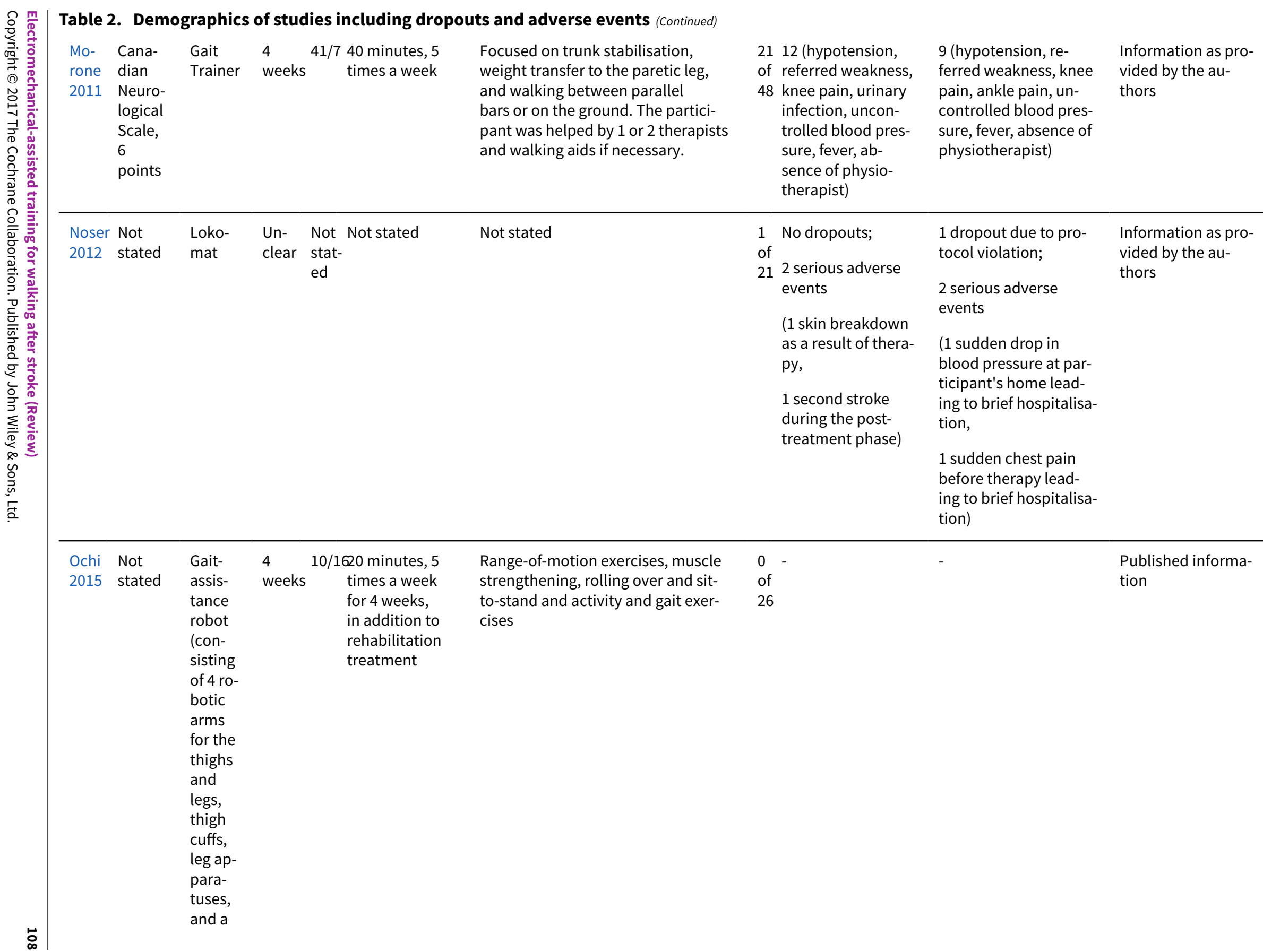




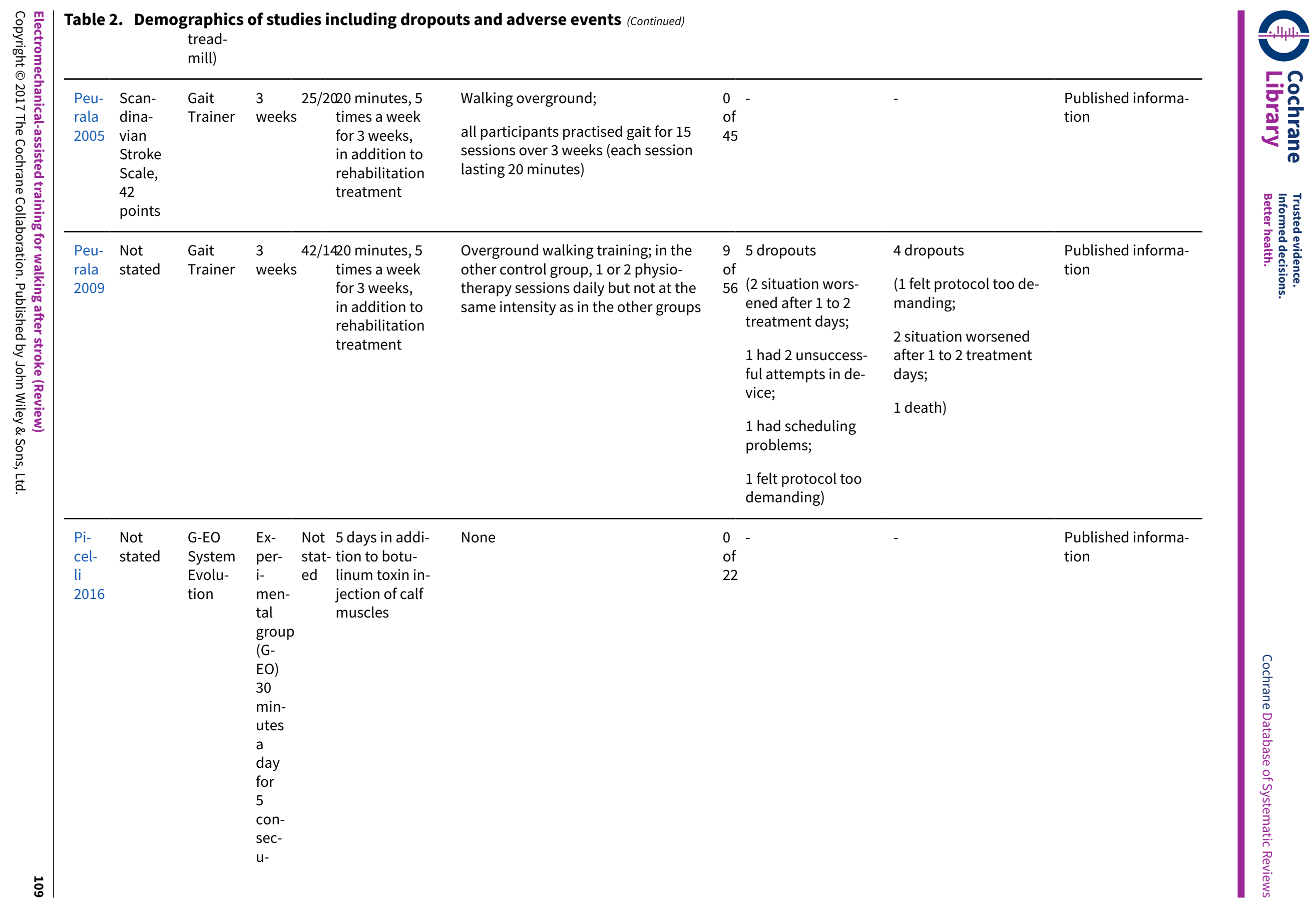




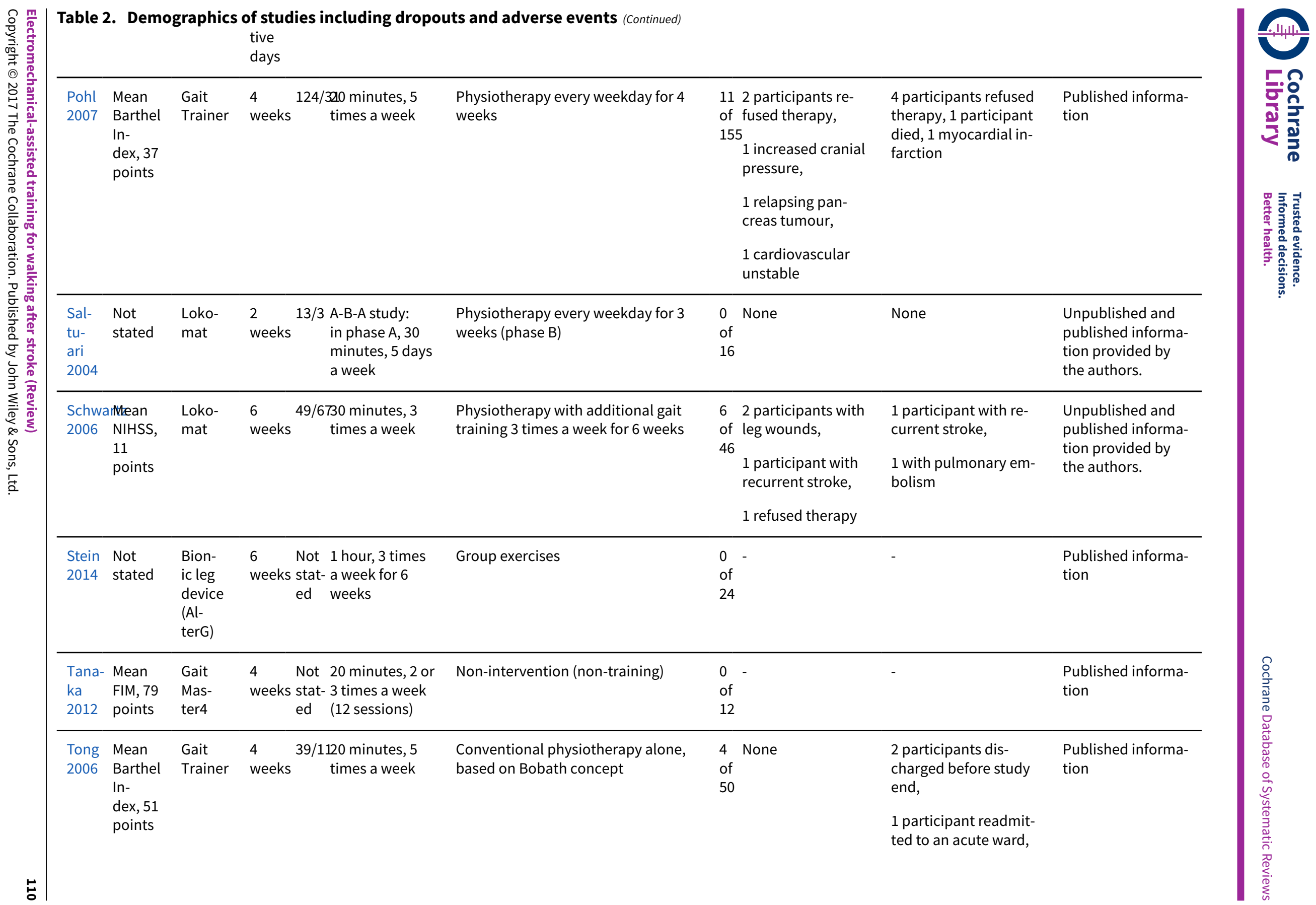




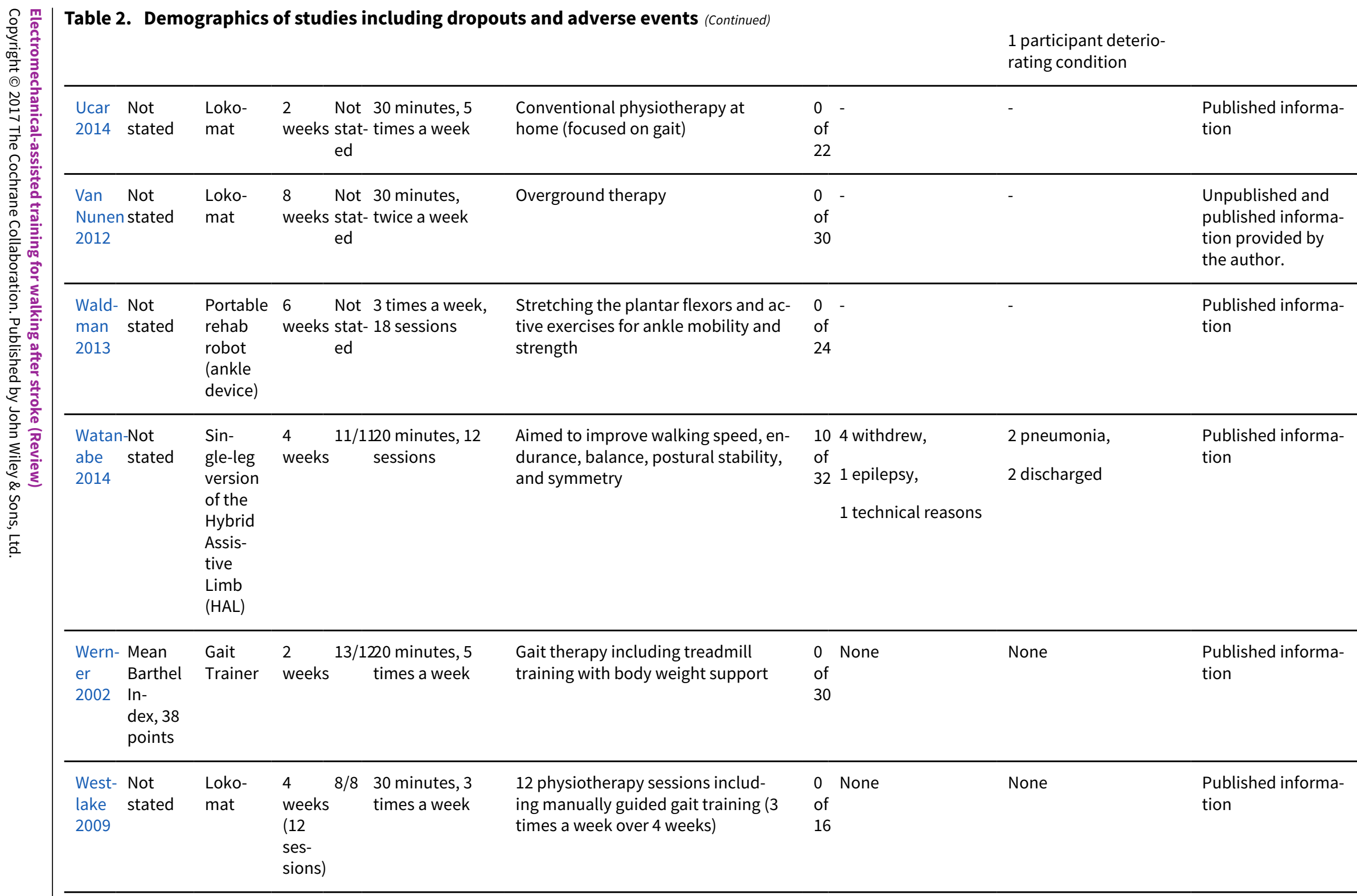

FIM: Functional Independence Measure

NIHSS: National Institutes of Health Stroke Scale 


\section{AP PEN DICES}

\section{Appendix 1. CENTRAL search strategy}

\#1MeSH descriptor: [Cerebrovascular Disorders] explode all trees \#2MeSH descriptor: [Brain Injuries] this term only \#3MeSH descriptor: [Brain Injury, Chronic] this term only \#4stroke* or cva or poststroke or post-stroke \#5cerebrovasc* or cerebral vascular \#6cerebral or cerebellar or brain* or vertebrobasilar \#7infarct* or isch?emi* or thrombo* or emboli* or apoplexy \#8\#6 and \#7 \#9cerebral or brain or subarachnoid \#10haemorrhage or hemorrhage or haematoma or hematoma or bleed ${ }^{\star}$ $\# 11 \# 9$ and \#10 \#12MeSH descriptor: [Hemiplegia] this term only \#13MeSH descriptor: [Paresis] explode all trees \#14hempar* or hemipleg* or brain injur ${ }^{\star}$ \#15MeSH descriptor: [Gait Disorders, Neurologic] this term only $\# 16 \# 1$ or \#2 or \#3 or \#4 or \#5 or \#8 or \#11 or \#12 or \#13 or \#14 or \#15 $\# 17 \mathrm{MeSH}$ descriptor: [Physical Therapy Modalities] this term only \#18MeSH descriptor: [Exercise Therapy] this term only \#19MeSH descriptor: [Motion Therapy, Continuous Passive] this term only \#20MeSH descriptor: [Musculoskeletal Manipulations] this term only \#21MeSH descriptor: [Exercise] this term only \#22MeSH descriptor: [Exercise Test] this term only \#23MeSH descriptor: [Robotics] this term only \#24MeSH descriptor: [Automation] this term only \#25MeSH descriptor: [Orthotic Devices] this term only \#26MeSH descriptor: [Man-Machine Systems] this term only \#27MeSH descriptor: [Self-Help Devices] this term only \#28MeSH descriptor: [Therapy, Computer-Assisted] this term only \#29MeSH descriptor: [Body Weight] this term only \#30MeSH descriptor: [Weight-Bearing] this term only \#31((gait or locomot ${ }^{\star}$ ) near/5 (train ${ }^{\star}$ or therapy or rehabilitat ${ }^{\star}$ or re-educat ${ }^{\star}$ or machine* or powered or device $\left.{ }^{\star}\right)$ ) \#32(electromechanical or electro-mechanical or mechanical or mechanised or mechanized or driven or assistive device ${ }^{\star}$ ) \#33((body-weight or body weight) near/3 (support* or relief))

\#34(robot ${ }^{\star}$ or orthos $^{\star}$ or orthotic or automat ${ }^{\star}$ or computer aided or computer assisted or power-assist ${ }^{\star}$ )

\#35 (bws or harness or treadmill or exercise* or fitness train* or Lokomat or Locomat or GaiTrainer or GT1 or Kinetron or Haptic Walker or Anklebot or LOPES or AutoAmbulator) \#36(continuous passive or $\mathrm{cpm}$ ) near/3 therap* $\# 37 \# 17$ or \#18 or \#19 or \#20 or \#21 or \#22 or \#23 or \#24 or \#25 or \#26 or \#27 or \#28 or \#29 or\#30 or \#31 or \#32 or \#33 or\#34 or \#35 or \#36 \#38MeSH descriptor: [Gait] this term only \#39MeSH descriptor: [Walking] explode all trees \#40MeSH descriptor: [Locomotion] this term only \#41MeSH descriptor: [Range of Motion, Articular] this term only \#42MeSH descriptor: [Recovery of Function] this term only \#43walk* or gait* or ambulat* or mobil ${ }^{\star}$ or locomot ${ }^{\star}$ or balanc ${ }^{*}$ or stride $\# 44 \# 38$ or \#39 or \#40 or \#41 or \#42 or \#43

$\# 45 \# 16$ and \#37 and \#44

\#46MeSH descriptor: [Animals] explode all trees

\#47\#45 not \#46

\#48\#47 in Trials

\#49\#48 Publication Year from 2012 to 2016

Number of records retrieved until 2012: 1140

Number of records retrieved until 2016: 861

\section{Appendix 2. MEDLINE search strategy (OvidSP)}

1. exp cerebrovascular disorders/ or brain injury, chronic/ 
2. (stroke\$ or cva or poststroke or post-stroke).tw.

3. (cerebrovasc $\$$ or cerebral vascular).tw.

4. (cerebral or cerebellar or brain\$ or vertebrobasilar).tw.

5. (infarct\$ or isch?emi\$ or thrombo or emboli\$ or apoplexy).tw.

6. 4 and 5

7. (cerebral or brain or subarachnoid).tw.

8. (haemorrhage or hemorrhage or haematoma or hematoma or bleed\$).tw.

9. 7 and 8

10. hemiplegia/ or exp paresis/

11. (hempar\$ or hemipleg\$ or brain injur\$).tw.

12. Gait Disorders, Neurologic/

13. 1 or 2 or 3 or 6 or 9 or 10 or 11 or 12

14. physical therapy modalities/ or exercise therapy/ or motion therapy, continuous passive/ or musculoskeletal manipulations/

15. *exercise/ or *exercise test/

16. robotics/ or automation/ or orthotic devices/ or man-machine systems/ or self-help devices/ or therapy, computer-assisted/

17. body weight/ or weight-bearing/

18. ((gait or locomot\$) adj5 (train\$ or therapy or rehabilitat\$ or re-educat\$ or machine\$ or powered or device\$)).tw.

19. (electromechanical or electro-mechanical or mechanical or mechanised or mechanized or driven or assistive device\$).tw.

20. ((body-weight or body weight) adj3 (support\$ or relief)).tw.

21. (robot\$ or orthos\$ or orthotic or automat\$ or computer aided or computer assisted or power-assist\$).tw.

22. (bws or harness or treadmill or exercise\$ or fitness train\$ or Lokomat or Locomat or GaiTrainer or GT1 or Kinetron or Haptic Walker or Anklebot or LOPES or AutoAmbulator).tw.

23. ((continuous passive or $\mathrm{cpm})$ adj3 therap\$).tw.

24. or/14-23

25. gait/ or exp walking/ or locomotion/

26. "Range of Motion, Articular"/

27. recovery of function/

28. (walk\$ or gait\$ or ambulat\$ or mobil\$ or locomot\$ or balanc\$ or stride).tw.

29. or/25-28

30. 13 and 24 and 29

31. Randomized Controlled Trials as Topic/

32. random allocation/

33. Controlled Clinical Trials as Topic/

34. control groups/

35. clinical trials as topic/ or clinical trials, phase i as topic/ or clinical trials, phase ii as topic/ or clinical trials, phase iii as topic/ or clinical trials, phase iv as topic/ 
36. double-blind method/

37. single-blind method/

38. Placebos/

39. placebo effect/

40. cross-over studies/

41. Therapies, Investigational/

42. Research Design/

43. evaluation studies as topic/

44. randomized controlled trial.pt.

45. controlled clinical trial.pt.

46. (clinical trial or clinical trial phase i or clinical trial phase ii or clinical trial phase iii or clinical trial phase iv).pt.

47. (evaluation studies or comparative study).pt.

48. random\$.tw.

49. (controlled adj5 (trial\$ or stud\$)).tw.

50. (clinical\$ adj5 trial\$).tw.

51. ((control or treatment or experiment\$ or intervention) adj5 (group\$ or subject\$ or patient\$)).tw.

52. (quasi-random $\$$ or quasi random\$ or pseudo-random $\$$ or pseudo random\$).tw.

53. ((multicenter or multicentre or therapeutic) adj5 (trial\$ or stud\$)).tw.

54. ((control or experiment\$ or conservative) adj5 (treatment or therapy or procedure or manage\$)).tw.

55. ((singl\$ or doubl\$ or tripl\$ or trebl\$) adj5 (blind\$ or mask\$)).tw.

56. (coin adj5 (flip or flipped or toss\$)).tw.

57. versus.tw.

58. (cross-over or cross over or crossover).tw.

59. placebo\$.tw.

60. sham.tw.

61. (assign\$ or alternate or allocat\$ or counterbalance\$ or multiple baseline).tw.

62. or/31-61

63. 30 and 62

64. exp animals/ not humans.sh.

65.63 not 64

66. limit 65 to ed=20120719-20160815

Number of records retrieved until 2012: 1928

Number of records retrieved until 2016: 1094 


\section{Appendix 3. Embase search strategy (OvidSP)}

1. cerebrovascular disease/ or exp basal ganglion hemorrhage/ or exp brain hematoma/ or exp brain hemorrhage/or exp brain infarction/or exp brain ischemia/ or exp carotid artery disease/ or cerebral artery disease/ or exp cerebrovascular accident/ or exp intracranial aneurysm/ or exp occlusive cerebrovascular disease/ or stroke patient/

2. (stroke or poststroke or post-stroke or cerebrovasc\$ or brain vasc\$ or cerebral vasc\$ or cva\$ or apoplex\$ or SAH).tw.

3. ((brain\$ or cerebr\$ or cerebell\$ or intracran\$ or intracerebral) adj5 (isch?emi\$ or infarct\$ or thrombo or emboli\$ or occlus\$)).tw.

4. ((brain\$ or cerebr\$ or cerebell\$ or intracerebral or intracranial or subarachnoid) adj5 (haemorrhage\$ or hemorrhage\$ or haematoma\$ or hematoma\$ or bleed\$)).tw.

5. hemiparesis/ or hemiplegia/ or paresis/

6. (hemipleg\$ or hemipar\$ or paresis or paretic or hemineglect or hemi-neglect or ((unilateral or spatial or hemi?spatial or visual) adj5 neglect)).tw.

7. Gait Disorders, Neurologic/

8. or/1-7

9. physical therapy modalities/ or exercise therapy/ or motion therapy, continuous passive/ or musculoskeletal manipulations/

10. *exercise/ or *exercise test/

11. robotics/or automation/ or orthotic devices/or man-machine systems/ or self-help devices/ or therapy, computer-assisted/

12. body weight/ or weight-bearing/

13. ((gait or locomot\$) adj5 (train\$ or therapy or rehabilitat\$ or re-educat\$ or machine\$ or powered or device\$)).tw.

14. (electromechanical or electro-mechanical or mechanical or mechanised or mechanized or driven or assistive device\$).tw.

15. ((body-weight or body weight) adj3 (support\$ or relief)).tw.

16. (robot\$ or orthos\$ or orthotic or automat\$ or computer aided or computer assisted or power-assist\$).tw.

17. (bws or harness or treadmill or exercise\$ or fitness train\$ or Lokomat or Locomat or GaiTrainer or GT1 or Kinetron or Haptic Walker or Anklebot or LOPES or AutoAmbulator).tw.

18. ((continuous passive or $\mathrm{cpm})$ adj3 therap\$).tw.

19. or/9-18

20. gait/ or exp walking/ or locomotion/

21. "Range of Motion, Articular"/

22. recovery of function/

23. (walk\$ or gait\$ or ambulat\$ or mobil\$ or locomot\$ or balanc\$ or stride).tw.

24. $\mathrm{or} / 20-23$

25. 19 and 24

26. Randomized Controlled Trial/ or "randomized controlled trial (topic)"/

27. Randomization/

28. Controlled clinical trial/ or "controlled clinical trial (topic)"/

29. control group/ or controlled study/

30. clinical trial/ or "clinical trial (topic)"/ or phase 1 clinical trial/ or phase 2 clinical trial/ or phase 3 clinical trial/ or phase 4 clinical trial/

31. Crossover Procedure/ 
32. Double Blind Procedure/

33. Single Blind Procedure/ or triple blind procedure/

34. placebo/ or placebo effect/

35. (random\$ or RCT or RCTs).tw.

36. (controlled adj5 (trial\$ or stud\$)).tw.

37. (clinical\$ adj5 trial\$).tw.

38. ((control or treatment or experiment\$ or intervention) adj5 (group $\$$ or subject\$ or patient\$)).tw.

39. (quasi-random $\$$ or quasi random\$ or pseudo-random $\$$ or pseudo random\$).tw.

40. ((control or experiment\$ or conservative) adj5 (treatment or therapy or procedure or manage\$)).tw.

41. ((singl\$ or doubl\$ or tripl\$ or trebl\$) adj5 (blind\$ or mask\$)).tw.

42. (cross-over or cross over or crossover).tw.

43. (placebo\$ or sham).tw.

44. trial.ti.

45. (assign\$ or allocat\$).tw.

46. controls.tw.

47. or/26-46

48. 8 and 25 and 47

49. (exp animals/ or exp invertebrate/ or animal experiment/ or animal model/ or animal tissue/ or animal cell/ or nonhuman/) not (human/ or normal human/ or human cell/)

50.48 not 49

51. limit 50 to $d d=20120719-20160815$

Number of records retrieved until 2012: 2315

Number of records retrieved until 2016: 1601

\section{Appendix 4. CINAHL search strategy (via EBSCOHost)}

S1 .(MH "Cerebrovascular Disorders") OR (MH "Basal Ganglia Cerebrovascular Disease+") OR (MH "Carotid Artery Diseases+") OR (MH "Cerebral Ischemia+") OR (MH "Cerebral Vasospasm") OR (MH "Intracranial Arterial Diseases+") OR (MH "Intracranial Embolism and Thrombosis") OR (MH "Intracranial Hemorrhage+") OR (MH "Stroke") OR (MH "Vertebral Artery Dissections")

S2.(MH "Stroke Patients") OR (MH "Stroke Units")

S3 . TI ( stroke or poststroke or post-stroke or cerebrovasc* or brain vasc* or cerebral vasc or cva or apoplex or SAH ) or AB ( stroke or poststroke or post-stroke or cerebrovasc* or brain vasc* or cerebral vasc or cva or apoplex or SAH )

S4 .TI ( brain* or cerebr* or cerebell* or intracran* or intracerebral ) or AB ( brain* or cerebr* or cerebell* or intracran ${ }^{\star}$ or intracerebral )

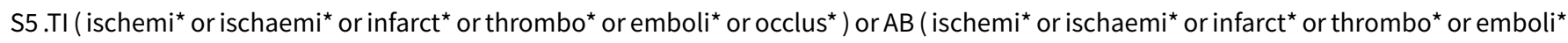
or occlus ${ }^{\star}$ )

S6.S4 and S5

S7 .TI ( brain* or cerebr ${ }^{\star}$ or cerebell* or intracerebral or intracranial or subarachnoid ) or AB ( brain ${ }^{\star}$ or cerebr ${ }^{\star}$ or cerebell ${ }^{\star}$ or intracerebral or intracranial or subarachnoid)

S8 .TI ( haemorrhage* or hemorrhage* or haematoma* or hematoma* or bleed ${ }^{\star}$ ) or AB ( haemorrhage* or hemorrhage* or haematoma* or hematoma* or bleed*) 
S9.S7 and S8

\section{S10.(MH "Hemiplegia")}

S11 .TI ( hemipleg* or hemipar* or paresis or paretic ) or AB ( hemipleg* or hemipar* or paresis or paretic )

\section{S12 .S1 OR S2 OR S3 OR S6 OR S9 OR S10 OR S11}

S13.(MM "PhysicalTherapy") OR (MM "TherapeuticExercise") OR (MM "Motion Therapy, Continuous Passive") OR (MM "Robotics") OR (MM "Automation") OR (MM "Orthoses") OR (MM "Assistive Technology Devices") OR (MM "Therapy, Computer Assisted") OR (MM "Body Weight") OR (MM "Weight-Bearing")

S14 *exercise or ( ${ }^{*}$ exercise test)

S15 "man-machine systems"

S16 ((gait or locomot $\left.{ }^{\star}\right)$ N5 (train* or therapy or rehabilitat* or re-educat* or machine* or powered or device $\left.{ }^{\star}\right)$ )

S17 electromechanical or electro-mechanical or mechanical or mechanised or mechanized or driven or assistive device*

S18 ((body-weight or body weight) N3 (support* or relief))

S19 robot* $^{\star}$ or orthos ${ }^{\star}$ or orthotic or automat* or computer aided or computer assisted or power-assist*

S20 bws or harness or treadmill or exercise* or fitness train* or Lokomat or Locomat or GaiTrainer or GT1 or Kinetron or Haptic Walker or Anklebot or LOPES or AutoAmbulator

S21 (continuous passive or cpm) N3 therap*

S22 S13 OR S14 OR S15 OR S16 OR S17 OR S18 OR S19 OR S20 OR S21

S23 (MM "Gait")

S24 (MH "Walking+")

S25 (MM "Locomotion")

S26 (MM "Range of Motion")

S27 (MM "Recovery")

S28 walk $^{\star}$ or gait* or ambulat* or mobil ${ }^{\star}$ or locomot* or balanc $^{\star}$ or stride

S29 S23 OR S24 OR S25 OR S26 OR S27 OR S28

S30 S22 AND S29

S31 .(MH "Randomized Controlled Trials") or (MH "Random Assignment") or (MH "Random Sample+")

S32.(MH "Clinical Trials") or (MH "Intervention Trials") or (MH "Therapeutic Trials")

S33.(MH "Double-Blind Studies") or (MH "Single-Blind Studies") or (MH "Triple-Blind Studies")

S34 .(MH "Control (Research)") or (MH "Control Group") or (MH "Placebos") or (MH "Placebo Effect")

S35.(MH "Crossover Design") OR (MH "Quasi-Experimental Studies")

S36 .PT (clinical trial or randomized controlled trial)

S37 .TI (random* or RCT or RCTs) or AB (random* or RCT or RCTs)

S38 .TI (controlled N5 (trial ${ }^{\star}$ or stud $\left.\left.{ }^{\star}\right)\right)$ or AB (controlled N5 (trial ${ }^{\star}$ or stud $\left.\left.{ }^{\star}\right)\right)$

S39.TI (clinical* N5 trial*) or AB (clinical ${ }^{\star}$ N5 trial $\left.{ }^{\star}\right)$

S40 .TI ((control or treatment or experiment ${ }^{\star}$ or intervention) N5 (group* or subject* or patient $\left.{ }^{\star}\right)$ ) or AB ((control or treatment or experiment ${ }^{\star}$ or intervention) N5 (group ${ }^{\star}$ or subject ${ }^{\star}$ or patient $\left.^{\star}\right)$ ) 
S41.TI ((control or experiment* or conservative) N5 (treatment or therapy or procedure or manage $\left.{ }^{\star}\right)$ ) or AB ((control or experiment ${ }^{\star}$ or conservative) N5 (treatment or therapy or procedure or manage $\left.{ }^{\star}\right)$ )

S42 .TI ((singl* or doubl* or tripl ${ }^{\star}$ or trebl*) N5 (blind ${ }^{\star}$ or mask $\left.\left.{ }^{\star}\right)\right)$ or AB ((singl* or doubl* or tripl* or trebl*) N5 (blind ${ }^{\star}$ or mask $\left.\left.{ }^{\star}\right)\right)$

S43 .TI (cross-over or cross over or crossover) or AB (cross-over or cross over or crossover)

S44 .TI (placebo* or sham) or AB (placebo* or sham)

S45.TI trial

S46.TI (assign^ or allocat*) or AB (assign* or allocat*)

S47 .TI controls or AB controls

S48 .TI (quasi-random* or quasi random* or pseudo-random* or pseudo random ${ }^{\star}$ ) or AB (quasi-random* or quasi random* or pseudorandom* or pseudo random*)

S49.S31 OR S32 OR S33 OR S34 OR S35 OR S36 OR S37 OR S38 OR S39 OR S40 OR S41 OR S42 OR S43 OR S44 OR S45 OR S46 OR S47 OR S48

S50 .S12 AND S30 AND S49

S51 .EM 201207-

S52.S50 AND S51

Number of records retrieved until 2012: 787

Number of records retrieved until 2016: 382

\section{Appendix 5. AMED search strategy (OvidSP)}

1. cerebrovascular disorders/ or cerebral hemorrhage/ or cerebral infarction/ or cerebral ischemia/ or cerebrovascular accident/ or stroke/

2. (stroke or poststroke or post-stroke or cerebrovasc\$ or brain vasc\$ or cerebral vasc\$ or cva $\$$ or apoplex\$ or SAH).af.

3. ((brain\$ or cerebr\$ or cerebell\$ or intracran\$ or intracerebral) adj5 (isch?emi\$ or infarct\$ or thrombo\$ or emboli\$ or occlus\$)).af.

4. ((brain\$ or cerebr\$ or cerebell\$ or intracerebral or intracranial or subarachnoid) adj5 (haemorrhage\$ or hemorrhage\$ or haematoma\$ or hematoma\$ or bleed\$)).af.

5. hemiplegia/

6. (hemipleg\$ or hemipar\$ or paresis or paretic or hemineglect or hemi-neglect or ((unilateral or spatial or hemi?spatial or visual) adj5 neglect)).af.

7. or/1-6

8. physical therapy modalities/ or exercise therapy/ or motion therapy, continuous passive.mp or musculoskeletal manipulations/

9. exercise/ or exercise test/

10. robotics/ or orthotic devices/ or myoelectric prosthesis/ or therapy, computer-assisted/

11. body weight/ or weight-bearing/

12. ((gait or locomot\$) adj5 (train\$ or therapy or rehabilitat\$ or re-educat\$ or machine\$ or powered or device\$)).af.

13. (electromechanical or electro-mechanical or mechanical or mechanised or mechanized or driven or assistive device\$).af.

14. ((body-weight or body weight) adj3 (support\$ or relief)).af.

15. (robot\$ or orthos\$ or orthotic or automat\$ or computer aided or computer assisted or power-assist\$).af.

16. (bws or harness or treadmill or exercise\$ or fitness train\$ or Lokomat or Locomat or GaiTrainer or GT1 or Kinetron or Haptic Walker or Anklebot or LOPES or AutoAmbulator).af.

17. ((continuous passive or $\mathrm{cpm})$ adj3 therap\$).af. 
18. or/8-17

19. gait/ or exp walking/ or locomotion/

20. "Range of Motion"/

21. recovery of function/

22. (walk\$ or gait\$ or ambulat\$ or mobil\$ or locomot\$ or balanc\$ or stride).af.

23. or $/ 19-22$

24. 7 and 18 and 23

25. exp animals/ not humans.sh.

26. 24 not 25

27. limit 26 to $u p=201207-201609$

Number of records retrieved until 2012: 383

Number of records retrieved until 2016: 392

\section{Appendix 6. Web of Science search strategy}

\#1.TS=(stroke or poststroke or post-stroke or cerebrovasc ${ }^{*}$ or brain vasc* or cerebral vasc* or cva* or apoplex* or SAH)

\#2.TS=((brain ${ }^{\star}$ or cerebr ${ }^{\star}$ or cerebell ${ }^{\star}$ or intracran ${ }^{\star}$ or intracerebral) NEAR/5 (isch\$emi ${ }^{\star}$ or infarct ${ }^{\star}$ or thrombo* or emboli $^{\star}$ or occlus $\left.{ }^{\star}\right)$ )

\#3.TS=((brain* or cerebr ${ }^{\star}$ or cerebell* or intracran* or intracerebral) NEAR/5 (h\$emorrhage* or h\$ematoma* or bleed $\left.\left.{ }^{\star}\right)\right)$

\#4.TS=(hemipleg* ${ }^{\star}$ or hemipar* or paresis or paretic)

\#5.\#4 OR \#3 OR \#2 OR \#1

\#6.TS=(Neurologic NEAR/5 Gait NEAR/5 Disorders)

\#7.TS= (robotics or automation or orthotic devices or man-machine system or self-help devices or (computer-assisted NEAR/5 therapy)) \#8.TS=((gait or locomot $\left.{ }^{\star}\right)$ NEAR/5 (train* or therapy or rehabilitat ${ }^{\star}$ or re-educat ${ }^{\star}$ or machine* or powered or device\$))

\#9.TS=(electromechanical or electro-mechanical or mechanical or mechanised or mechanized or driven or assistive device\$)

$\# 10 . T S=(($ body-weight or (body NEAR/3 weight)) NEAR/3 (support\$ or relief))

\#11.TS=(robot* or $^{*}$ orthos ${ }^{\star}$ or orthotic or automat ${ }^{\star}$ or computer aided or computer assisted or power-assist ${ }^{\star}$ )

\#12.TS=(bws or harness or treadmill or exercise\$ or fitness train* or Lokomat or Locomat or GaiTrainer or GT1 or Kinetron or Haptic Walker or Anklebot or LOPES or AutoAmbulator)

\#13.TS=(((continuous NEAR/3 passive) or cpm) NEAR/3 therap $\left.{ }^{\star}\right)$

\#14. \#6 or \#7 or \#8 or \#9 or \#10 or \#11 or \#12 or \#13

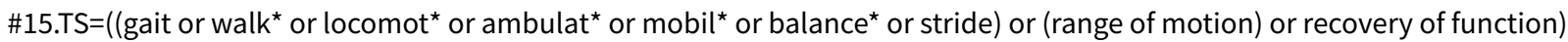

\#16.\#14 and \#15

\#17.TS=(random* or RCT or RCTs)

\#18.TS=(controlled NEAR/5 (trial\$ or stud*))

\#19.TS=(clinical ${ }^{\star}$ NEAR/5 trial $\left.^{\star}\right)$

\#20.TS=((control or treatment or experiment* or intervention) NEAR/5 (group\$ or subject\$ or patient\$))

\#21.TS=(quasi-random* or quasi random* or pseudo-random* or pseudo random*) 
\#22.TS=((control\$ or experiment ${ }^{\star}$ or conservative) NEAR/5 (treatment or therapy or manage ${ }^{\star}$ or procedure))

\#23.TS=((singl\$ or doubl ${ }^{\star}$ or tripl* or trebl $\left.{ }^{\star}\right)$ NEAR/5 $\left(\right.$ blind $^{\star}$ or mask $\left.\left.{ }^{\star}\right)\right)$

\#24.TS=(cross-over or cross over or crossover)

\#25.TS=(placebo* or sham)

\#26.TI=trial

\#27.TS=(assign* or allocat $\left.{ }^{\star}\right)$

\#28.TS=controls

$\# 29 . \# 17$ or \#18 or \#19 or \#20 or \#21 or \#22 or \#23 or \#24 or \#25 or \#26 or \#27 or \#28

\#30.\#5 and \#16 and \#29

Number of records retrieved until 2016: 3806

\section{Appendix 7. PEDro search strategy}

Abstract\&Title: Stroke AND gait

Method: Clinical Trial

Published since: 2012

All other fields not mentioned here have been left blank.

Number of records retrieved until 2012: 165

Number of records retrieved until 2016: 166

\section{Appendix 8. COMPENDEX search strategy (via DIALOG)}

1. CEREBROVASCULAR (W) DISORDER? ?/TI,AB,DE

2. BRAIN (W) INJUR???/TI,AB,DE

3. CHRONIC (W) BRAIN (W) INJUR???/TI,AB,DE

4. (STROKE? OR CVA OR POSTSTROKE? OR CEREBROVASC?)/TI,AB,DE

5. CEREBRAL (W) VASCULAR/TI,AB,DE

6. (CEREBRAL OR CEREBELLAR OR BRAIN? OR

7. (INFARCT? OR ISCHAEMI? OR ISCHEMI? OR THROMBO? OR

8. S6 AND S7

9. (CEREBRAL OR BRAIN OR SUBARACHNOID)/TI,AB,DE

10. (HAEMORRHAGE OR HEMORRHAGE OR HAEMATOMA OR HEMATOMA OR

11. S9 AND S10

12. (HEMIPLEG? OR HEMIPAR? OR PARESIS)/TI,AB,DE

13. BRAIN (W) INJUR???/TI,AB,DE

14. GAIT (W) DISORDER? ?/TI,AB,DE

15. NEUROLOGIC??/TI,AB,DE

16. S14 AND S15

17. S1 OR S2 OR S3 OR S4 OR S5 OR S 8 OR S 16 OR S11-S13

18. PHYSICAL (W) THERAPY (W) MODALIT???/TI,AB,DE

19. EXERCISE (W) THERAP?/TI,AB,DE

20. MOTION (W) THERAP? /TI,AB,DE

21. CONTINUOUS (3W) PASSIVE (3W) MOTION (3W) THERAP?

22. EXERCISE?/TI,AB,DE

23. (ROBOTICS OR AUTOMATION) /TI,AB,DE

24. ORTHOTIC (W) DEVICE? ?/TI,AB,DE

25. BODY (W) WEIGHT/TI,AB,DE

26. WEIGHT (W) BEARING/TI,AB,DE

27. GAIT (5N) TRAIN???/TI,AB,DE

28. GAIT (5N) THERAP?/TI,AB,DE

29. GAIT (5N) REHABILITAT?/TI,AB,DE

30. GAIT (5N) EDUCAT?/TI,AB,DE

31. LOCOMOT? (5N) TRAIN?/TI,AB,DE 
32. LOCOMOT? (5N) THERAP?/TI,AB,DE

33. LOCOMOT? (5N) REHABILITAT?/TI,AB,DE

34. LOCOMOT? (5N) EDUCAT?/TI,AB,DE

35. (ELECTROMECHANICAL OR MECHANICAL OR MECHANI?ED OR

36. ((BODY (W) WEIGHT (3N) SUPPORT?))/TI,AB,DE

37. ((BODY (W) WEIGHT (3N) RELIEF))/TI,AB,DE

38. (ROBOT? OR ORTHOS? OR ORTHOTIC OR AUTOMAT?)/TI,AB,DE

39. COMPUTER (W) AIDED/TI,AB,DE

40. (COMPUTER (W) ASSISTED)/TI,AB,DE

41. (BWS OR HARNESS OR TREADMILL OR LO?OMAT OR GAITRAINER

42. FITNESS (W) TRAIN?/TI,AB,DE

43. CONTINUOUS (W) PASSIVE/TI,AB,DE

44. THERAP?/TI,AB,DE

45. S43 AND S44

46. CPM (3N) THERAP?/TI,AB,DE

47. $\mathrm{S} 18-\mathrm{S} 42$

48. S48 OR S45 OR S46

49. (GAIT OR WALKING OR LOCOMOTION)/TI,AB,DE

50. RANGE (1W) MOTION/TI,AB,DE

51. ARTICULAR/TI,AB,DE

52. S51 AND S52

53. RECOVERY (3N) FUNCTION/TI,AB,DE

54. (WALK? OR GAIT? ? OR AMBULAT? OR MOBIL? OR LOCOMOT? OR

55. S50 OR S53 OR S54 OR S55

56. S17 AND S49 AND S56

57. S57 AND HUMAN

Number of records retrieved until 2012: 701

\section{Appendix 9. SPORTDiscus search strategy (via EBSCOHost)}

S1 .DE "CEREBROVASCULAR disease" OR DE "BRAIN -- Hemorrhage" OR DE "CEREBRAL embolism \& thrombosis"

S2 .DE "CEREBROVASCULAR disease -- Patients"

S3 .DE "HEMIPLEGIA" OR DE "HEMIPLEGICS"

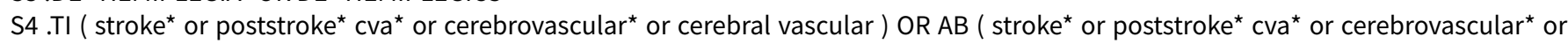
cerebral vascular)

S5 .TI ( cerebral or cerebellar or brain* or vertebrobasilar) OR AB ( cerebral or cerebellar or brain* or vertebrobasilar)

S6 .TI ( infarct ${ }^{\star}$ or ischemi ${ }^{\star}$ or ischaemi ${ }^{\star}$ or thrombo* or emboli* or apoplexy ) OR AB ( infarct ${ }^{\star}$ or ischemi ${ }^{\star}$ or ischaemi ${ }^{\star}$ or thrombo ${ }^{\star}$ or emboli* or apoplexy)

S7.S5 and S6

S8 .TI ( cerebral or brain or subarachnoid) OR AB ( cerebral or brain or subarachnoid)

S9 .TI ( haemorrhage or hemorrhage or haematoma or hematoma or bleed ${ }^{*}$ ) OR AB ( haemorrhage or hemorrhage or haematoma or hematoma or bleed ${ }^{*}$ )

S10.S8 and S9

S11 .TI ( hempar\$ or hemipleg* or brain injur ${ }^{\star}$ OR AB ( hempar\$ or hemipleg* or brain injur ${ }^{\star}$ )

S12.DE "GAIT disorders"

$\mathrm{S} 13 . \mathrm{S} 1$ or $\mathrm{S} 2$ or S3 or S4 or S7 or S10 or S11 or S12

S14 .DE "PHYSICAL therapy"

S15.DE "EXERCISE" OR DE "LEG exercises" OR DE "STRENGTH training" OR DE "TREADMILL exercise"

S16.DE "EXERCISE therapy"

S17.DE "MANIPULATION (Therapeutics)"

S18.TI ( gait or locomot* ) OR AB ( gait or locomot ${ }^{\star}$ )

S19 .TI ( train $^{\star}$ or therapy or rehabilitat ${ }^{\star}$ or re-educat* or machine* or powered or device* ) OR AB ( train $^{\star}$ or therapy or rehabilitat* or reeducat $^{\star}$ or machine ${ }^{\star}$ or powered or device* ${ }^{\star}$ )

S20 .S18 and S19

S21 .TI ( electromechanical or electro-mechanical or mechanical or mechanised or mechanized or driven or assistive device* ) OR AB ( electromechanical or electro-mechanical or mechanical or mechanised or mechanized or driven or assistive device ${ }^{\star}$ )

S22.TI ( body-weight or body weight) OR AB ( body-weight or body weight)

S23.TI ( support* or relief) OR AB ( support* or relief)

S24.S22 and S23

S25 .TI ( robot $^{\star}$ or orthos ${ }^{\star}$ or orthotic or automat* or computer aided or computer assisted or power-assist ${ }^{\star}$ ) OR AB ( robot $^{\star}$ or orthos $^{\star}$ or $^{\circ}$ orthotic or automat ${ }^{\star}$ or computer aided or computer assisted or power-assist ${ }^{\star}$ ) 
S26.TI ( bws or harness or treadmill or exercise* or fitness train* or Lokomat or Locomat or GaiTrainer or GT1 or Kinetron or Haptic Walker or Anklebot or LOPES or AutoAmbulator ) OR AB ( bws or harness or treadmill or exercise* or fitness train* or Lokomat or Locomat or GaiTrainer or GT1 or Kinetron or Haptic Walker or Anklebot or LOPES or AutoAmbulator )

S27 TI ( continuous passive or cpm ) OR AB ( continuous passive or cpm )

S28.TI Therapy OR AB therapy

S29.S27 and S28

S30.S14 or S15 or S16 or S17 or S20 or S21 or S24 or S25 or S26 or S29

S31.DE "WALKING" OR DE "FITNESS walking" OR DE "GAIT in humans"

S32.DE "LOCOMOTION" OR DE "HUMAN locomotion"

S33.DE "JOINTS -- Range of motion"

S34 .TI ( walk ${ }^{\star}$ or gait or ambulat* or mobil ${ }^{\star}$ or locomot ${ }^{\star}$ or balanc ${ }^{\star}$ or stride ) OR AB ( walk* or gait ${\text { or ambulat } \text { or mobil }^{\star} \text { or locomot }}^{\star}$ or balanc* or stride )

$\mathrm{S} 35 . \mathrm{S} 31$ or S32 or S33 or S34

$\mathrm{S} 36 . \mathrm{S} 13$ and S30 and S35

S37 .TI ( random* or RCT or trial* or placebo* or sham or double-blind* or single-blind or control or controls or assign* or allocat* ) OR AB ( random* or RCT or trial* or placebo* or sham or double-blind* or single-blind or control or controls or assign* or allocat* ${ }^{\star}$ )

S38.S36 and S37

Number of records retrieved until 2012: 461

\section{Appendix 10. Inspec search strategy (TecFinder)}

Robot AND gait AND stroke

publication year: 2012 - 2016

Number of records retrieved until 2012: 81

Number of records retrieved until 2016: 20

\section{Appendix 11. World Health Organization International Clinical Trials Registry Platform (WHO ICTRP)}

Robot AND gait AND stroke

Robot AND Walking AND stroke

publication year: 2012 - 2016

Number of records retrieved until 2016: 10

\section{FEE D B A C K}

\section{Feedback, 30 June 2010}

\section{Summary}

It appears that the $\mathrm{P}$ value for the walking capacity outcome is incorrect in your abstract. The $\mathrm{P}$ value is reported as $\mathrm{P}=0.073$ in the abstract but is reported as $\mathrm{P}=0.73$ in the results section and in the forest plot.

\section{Reply}

The feedback from Meghan Malone-Moses, above, is accurate. I am sorry for this error which occurred in the abstract. The printed $\mathrm{P}$ value in the abstract $(P=0.073)$ was not correct and has now been changed to $P=0.73$ as reported correctly in the Results section and in the forest plot. There is no change to the conclusions because the $P$ value for the walking capacity outcome remains non-significant.

\section{Contributors}

Commenter: Meghan Malone-Moses, MPH, Medical Writer, DynaMed Responder: Jan Mehrholz

\section{WHAT'S NEW}




\begin{tabular}{lll}
\hline Date & Event & Description \\
\hline 6 December 2016 & New search has been performed & $\begin{array}{l}\text { We have updated the searches to September 2016 and revised } \\
\text { the text as appropriate. We have included } 36 \text { studies with } 1472 \\
\text { participants in this update, compared with } 23 \text { trials with } 999 \text { par- } \\
\text { ticipants in the previous version of this review from } 2013 .\end{array}$ \\
\hline 6 December 2016 & $\begin{array}{l}\text { New citation required and conclusions } \\
\text { have changed }\end{array}$ & $\begin{array}{l}\text { The conclusions of the review have changed. The previous ver- } \\
\text { sion of this review concluded that, for the primary outcome } \\
\text { (walking), the number needed to treat was five patients to pre- } \\
\text { vent one dependency; this updated version of our review con- } \\
\text { cludes that seven patients need to be treated to prevent one de- } \\
\text { pendency in walking. }\end{array}$
\end{tabular}

\section{H I S T O RY}

Protocol first published: Issue 4, 2006

Review first published: Issue 3, 2007

\begin{tabular}{lll}
\hline Date & Event & Description \\
\hline 23 January 2013 & $\begin{array}{l}\text { New citation required and conclusions } \\
\text { have changed }\end{array}$ & $\begin{array}{l}\text { The conclusions of the review have changed. The previous ver- } \\
\text { sion of this review concluded that, for the primary outcome } \\
\text { (walking), the number needed to treat was six patients to pre- } \\
\text { vent one dependency; this updated version of our review con- } \\
\text { cludes that five patients need to be treated to prevent one de- } \\
\text { pendency in walking. }\end{array}$ \\
\end{tabular}

14 January $2013 \quad$ New search has been performed We have updated the searches to December 2012 and revised the
text as appropriate.

We have included 23 trials with 999 participants in this update, compared with 17 trials with 837 participants in the previous version of this review from 2009.

\begin{tabular}{lll}
\hline 28 July 2010 & Feedback has been incorporated & $\begin{array}{l}\text { Feedback and author response included in the Feedback section, } \\
\text { and error corrected in the Abstract. }\end{array}$ \\
\hline 16 October $2009 \quad$ New search has been performed & $\begin{array}{l}\text { We have updated the searches to April } 2009 \text { and revised the text } \\
\text { as appropriate. The conclusions of the review have not changed. }\end{array}$ \\
& $\begin{array}{l}\text { We have included } 17 \text { trials with } 837 \text { participants in this update, } \\
\text { as compared with eight trials with } 414 \text { participants in the previ- } \\
\text { ous version of this review from } 2007 .\end{array}$ \\
& $\begin{array}{l}\text { The previous version of this review concluded that, for the pri- } \\
\text { mary outcome (walking), the number needed to treat was four } \\
\text { patients to prevent one dependency; this updated version of our } \\
\text { review concludes that six patients need to be treated to prevent } \\
\text { one dependency in walking. }\end{array}$
\end{tabular}

6 August 2008 Amended Converted to new review format.




\section{CONTRIBUTIONS OF AUTHORS}

Jan Mehrholz (JM) contributed to the conception and the design of the protocol and drafted the protocol. He searched electronic databases and conference proceedings, screened titles and abstracts of references identified by the search, selected and assessed trials, extracted trial and outcome data, guided the analysis and interpretation of data, and contributed to and approved the final manuscript of the review.

Simone Thomas (ST) evaluated and extracted trial data, assessed the methodological quality of selected trials, contributed to the interpretation of data, and contributed to and approved the final manuscript of the review.

Cordula Werner (CW) screened the titles and abstracts of references identified by the search; located, selected, and assessed trials; extracted trial and outcome data; assessed the methodological quality of selected trials; contributed to the interpretation of data; and contributed to and approved the final manuscript of the review.

Joachim Kugler (JK) evaluated and extracted trial and outcome data, assessed the methodological quality of selected trials, contributed to the interpretation of data, and contributed to and approved the final manuscript of the review.

Marcus Pohl (MP) contributed to the conception and design of the review, drafted the protocol, and assessed the methodological quality of selected trials. Together with JM, he contacted trialists about unpublished data and entered the data, carried out statistical analysis, helped with the interpretation of the data, drafted the review, and approved the final manuscript of the review.

Bernhard Elsner (BE) searched electronic databases and conference proceedings, screened titles and abstracts of references identified by the search, selected and assessed trials, guided analysis and the interpretation of the data, and contributed to and approved the final manuscript of the review.

\section{DECLARATIONS OF INTEREST}

Bernhard Elsner: none known.

Simone Thomas: none known.

Joachim Kugler: none known.

Marcus Pohl was author of one included trial (Pohl 2007).

Jan Mehrholz was co-author of one included trial (Pohl 2007).

Cordula Werner was an author of two included trials (Pohl 2007; Werner 2002), and of one excluded trial (Hesse 2001).

These review authors (MP, JM, CW) did not participate in quality assessment and data extraction of these studies.

\section{SOURCES OFSUPPORT}

\section{Internal sources}

- Klinik Bavaria Kreischa, Wissenschaftliches Institut, Germany.

- Technical University Dresden, Lehrstuhl Public Health, Germany.

- SRH Fachhochschule Gera, Lehrstuhl Therapiewissenschaften, Germany.

\section{External sources}

- No sources of support supplied

\section{DIFFERENCES BETWEEN PROTOCOLANDREVIEW}

In our protocol we stated that we would use the PEDro Scale to assess the methodological quality of the included trials. However, Chapter 8 of the latest edition of the Cochrane Handbook for Systematic Reviews of Interventions suggests that scales that yield a summary score should be avoided (Higgins 2011a). In accordance with this suggestion, we no longer used the PEDro Scale to assess the methodological quality of the included trials, instead using the Cochrane 'Risk of bias' tool to analyse trial methodology.

In our protocol we planned to quantify heterogeneity with the $\mathrm{I}^{2}$ statistic and to use a cutoff of $\mathrm{I}^{2}=50 \%$ for all comparisons. Additonally, we planned to calculate the overall effects using a random-effects model instead of a fixed-effect model when we found substantial heterogeneity. However, in this update we calculated the overall effects using a random-effects model, irrespective of the level of heterogeneity. 
In this review update we expanded our post-hoc sensitivity analysis: type of device (Analysis 5.1; Analysis 5.2; Analysis 5.3) by introducing a new subgroup of studies using mobile and ankle devices and adding a new comparison in Analysis 5 (Analysis 5.3 Different devices for regaining walking capacity).

\section{INDEX TERMS}

\section{Medical Subject Headings (MeSH)}

${ }^{\star}$ Orthotic Devices; *Stroke Rehabilitation; *Walking; Combined Modality Therapy [instrumentation] [methods]; Electric Stimulation Therapy; Equipment Design; Exercise Therapy [methods]; Gait; Randomized Controlled Trials as Topic; Robotics [ ${ }^{\star}$ instrumentation]; Walking Speed

\section{MeSH check words}

Aged; Humans; Middle Aged 